NERGY

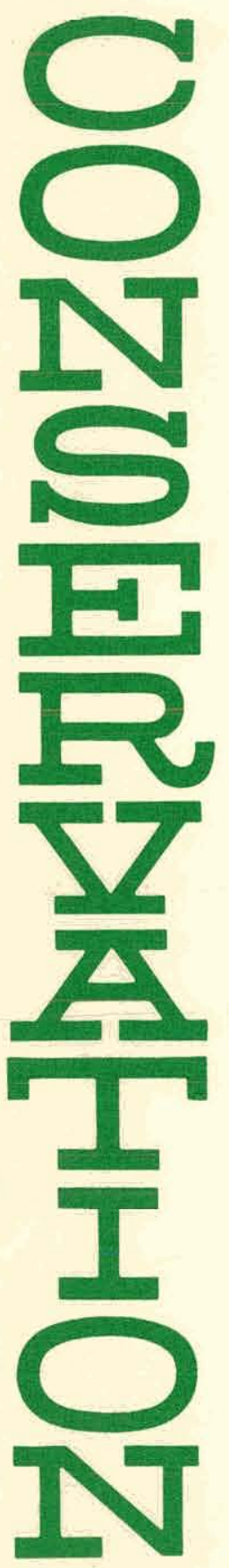

$$
\begin{aligned}
& \text { Bins - 112 } \\
& \text { NTIS - 25 MASTER }
\end{aligned}
$$

DOE/ET/15208-T1(Vol.1)

\title{
DESIGN AND DEVELOPMENT OF STIRLING ENGINES FOR STATIONARY POWER GENERATION APPLICATIONS IN THE 500 TO 3000 HP RANGE
}

Phase I. Final Report (Volume 1)

\section{October 1980}

Work Performed Under Contract Nos. AC02-79ET15208

W-31-109-ENG-38

Foster-Miller Associates, Incorporated

Waltham, Massachusetts

\section{U. S. DEPARTMENT OF ENERGY}




\section{DISCLAIMER}

This report was prepared as an account of work sponsored by an agency of the United States Government. Neither the United States Government nor any agency Thereof, nor any of their employees, makes any warranty, express or implied, or assumes any legal liability or responsibility for the accuracy, completeness, or usefulness of any information, apparatus, product, or process disclosed, or represents that its use would not infringe privately owned rights. Reference herein to any specific commercial product, process, or service by trade name, trademark, manufacturer, or otherwise does not necessarily constitute or imply its endorsement, recommendation, or favoring by the United States Government or any agency thereof. The views and opinions of authors expressed herein do not necessarily state or reflect those of the United States Government or any agency thereof. 


\section{DISCLAIMER}

Portions of this document may be illegible in electronic image products. Images are produced from the best available original document. 


\section{DISCLAIMER}

"This book was prepared as an account of work sponsored by an agency of the United States Government. Neither the United States Government nor any agency thereof, nor any of their employees, makes any warranty, express or implied, or assumes any legal liability or responsibility for the accuracy, completeness, or usefulness of any information, apparatus, product, or process disclosed, or represents that its use would not infringe privately owned rights. Reference herein to any specific commercial product, process, or service by trade name, trademark, manufacturer, or otherwise, does not necessarily constitute or imply its endorsement, recommendation, or favoring by the United States Government or any agency thereof. The views and opinions of authors expressed herein do not necessarily state or reflect those of the United States Government or any agency thereof."

This report has been reproduced directly from the best available copy.

Available from the National Technical Information Service, U:S. Department of Commerce, Springfield, Virginia 22161.

Price: Printed Copy A11

Microfiche A01 
PHASE I FINAL REPORT

(VOLUME 1)

DESIGN AND DEVELOPMENT OF STIRLING

ENGINES FOR STATIONARY POWER

GENERATION APPLICATIONS IN THE

500 TO 3000 hP RANGE

Contract NO. DE-ACO2-79ET15208

\author{
Submitted to: \\ Argonne National Laboratory \\ Components Technology Division \\ Argonne, IL 60439
}

Sponsored by :

U.S. Department of Energy

Assistant Secretary for Fossil Energy

office of Coal Utilization

Submitted by:

Foster-Miller Associates, Inc. 350 Second Avenue

Wal tham, MA.02154

October 1980 
THIS PAGE

\section{WAS INTENTIONALLY LEFT BLANK}




\section{ACKNOWLEDGEMENTS}

The development team consisted of Foster-Miller Associates, Inc. (FMA), Teledyne Continental Motor's (TCM), SUNPOWER, Inc. and independent Stirling Engine Consultants: The participants of the program included:

Foster-Miller Associates, Inc.

William Toscano - Program Manager

Ram Chandrasekhar

Roger Demler

Andy Harvey

Scott Hynek

Ira Krepchin

Kangpil Lee

Charles Mariano

David McFadden

Teledyne Continental Motors

Ted Schwallie - Principal Investigator

Alex Brouwers

Steve Berenyi

SUNPOWER, InC.

William Beale - Principal Investigator

David Gedeon

\section{Stirling Engine Consultants}

Stig carlquist

Joseph Smith, Jr.

Uonald Ernst 
The program was funded by the Department of. Energy (DOE) under Contract No. DE-AC02-79ET15208 and was monitored by the Argonne National Laboratory (ANL). Mr. Kenneth Uherka of ANL was the Technical Monitor and Warren Bunker of DOE was overall Program Manager. 


\section{1.. Introduction}

With the rising costs of energy and the expected depletion of the conventional fuels of oil and gas the U.S. Department of Energy (DOE) has expressed concern for the absence in the commercial marketplace of a multifuel engine for stationary power generation. In response to the potential long-term energy dependence on imported oil and gas, DOE has initiated the development of a multifuel (including solid coal) stirling cycle engine for stationary power generation applications in the residential and commercial energy market segments. The present report presents the analysis and results of a conceptual design study and a proposed program plan performed by the development team consisting of Foster-Miller Associates, Inc. (FMA), Teledyne Continental Motors (TCM), SUNPOWER, InC., and Stirling engine consultants.

It is planned that the large stationary stirling engine development program will consist of five phases as follows:

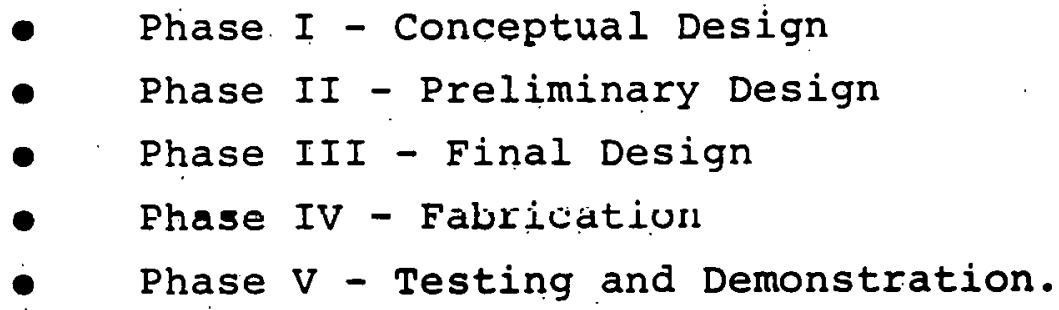

The objective of Phase I was to provide conceptual designs and associated manufacturing assessments/production cost estimates of stirling cycle engine systems for stationary power applications in the $373(500)$ to $2237 \mathrm{~kW}(3000 \mathrm{hp})$ range. 


\section{Conceptual Design Methodology}

The design methodology consists of the review of design and performance objectives, compilation of previous engine data, elucidation of parametric or "scaling" relationships, preparation of decision trees for configurational choices, preparation of preliminary designs, conceptual designs selection and refinement, and description of recommended conceptual designs. A flow diagram of the design synthesis is shown in Figure ES-1. The design process is not straightforward, but requires iterations of several steps. In general for this stirling engine application, thermodynamic efficiency, engine configuration, and engine cost are approximately in descending.order of importance.

The possible configuration's for stirling cycle engine systems were described segmentally in a decision tree having three major branches: the fuel combustion system, the engine heat transfer system arrangement, and the engine machine configuration. The fuel combustion system branch includes gas, oil, residual fuel, and coal. The engine heat transfer arrangement includes direct heat transfer and indirect heat transfer. Finally, the third branch includes the vast number of design alternatives for the stirling engine.

For the third branch, design studies were conducted to evalwate the different engine configurations. The engine configuration is dependent on both the heat exchanger configuration and engine configuration. There are three possible ways to arrange the heat exchanger: axial, manifold, and concentric. "The axial heat exchanger configuration has minimum dead volume; however, it is inconvenient for mechanical adaptation and it is not advantageous for coupling with normal heater systems. The manifolded configuration has large dead volumes and high temperature swings. The concentric heat exchanger arrangement is nearly compatible with all heater systems. There are two possible methods for arranging the engine: single acting and double acting. 


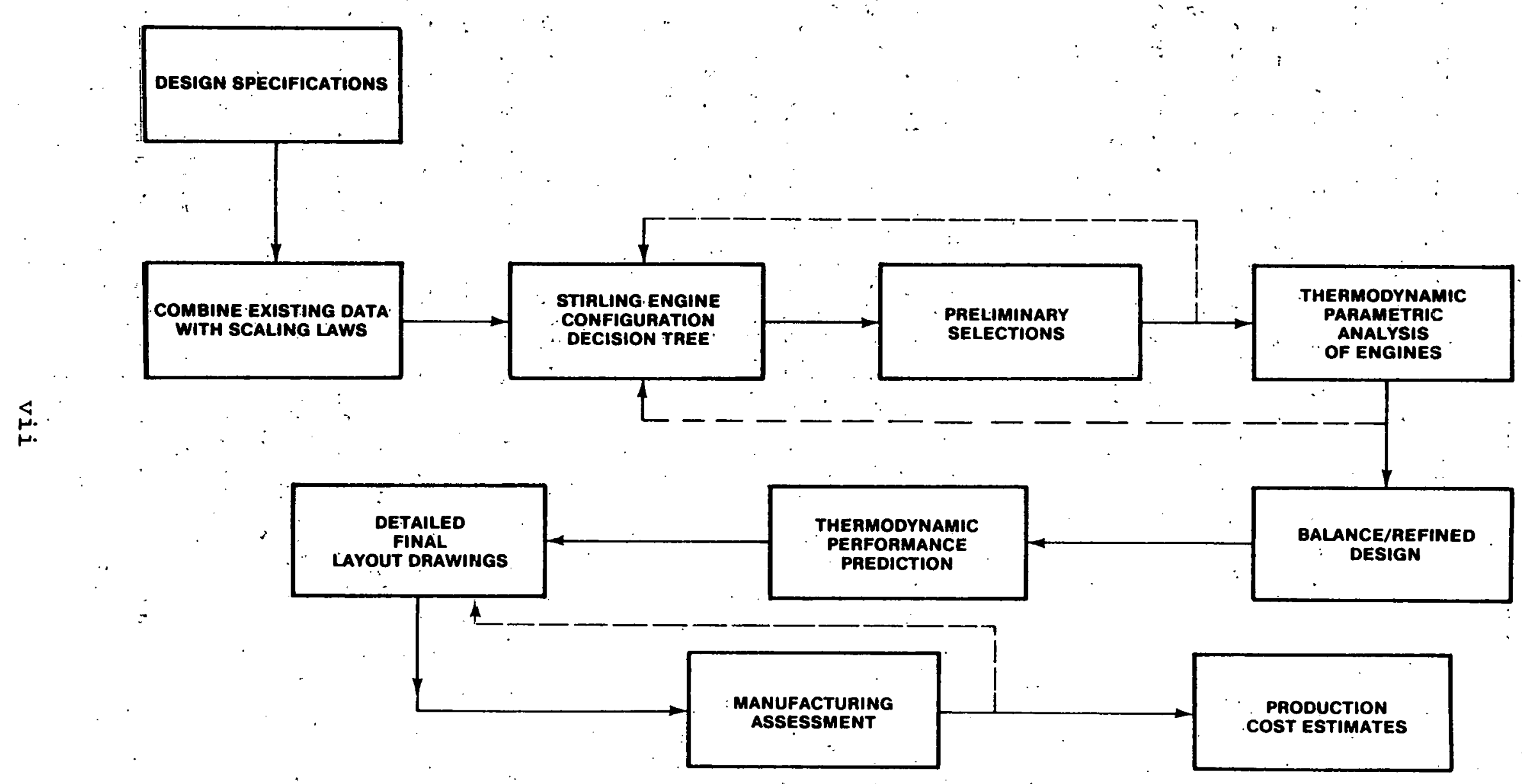

Figure ES-1. Flow Diagram of the Design Synthesis 
Four different heater head designs which are compatible for both direct and indirect heat transfer and five different machine designs were prepared in sufficient detail to select a design recommended for development in the near future. The conceptual designs investigated included:

- Axial flow, single-acting opposed piston engine

- Manifolded flow, single-acting U engine

- Single-acting displacer $\mathrm{V}$ engine with pressure control

- Double-acting Rhinia in-line engine

- Double-acting Rhinia barrel engine with variable stroke control.

In addition to the above designs, a concentric module design was prepared, in, which the heat exchangers are concentric with the hot cylinders, and the heater consists of multiple hairpins with both ends of each hairpin attached near the same place on the common pressure dome for the cylinder and regenerator. The concentric module design can be applied in several engine machine designs of single-acting, displacer and double-acting: The significant advantages of the concentric module design are:

- Efficient internal and external flow distribution

- Simplicity of construction of the hot end

- Adaptability to direct or indirect heat exchange

- Modular assembly and maintenance of engine

- Adaptability to various engine lower-end designs. 


\section{Engine Thermodynamic Performance Evaluation}

The next step in the design syuthesis was to evaluate the preliminary engine designs. The engine design characteristic criteria include:

\footnotetext{
- Thermodynamic performance

- Fuel flexibility

- Manufacturing assessment

- Production costs.
}

The first step in analyzing the engine is to predict the engine thermodynamic performance. The thermodynamic evaluation included development of a second order model computer program, thermodynamic parametric analysis, and prediction of engine performance by means of both the FMA second order model computer program and the SUNPOWER third order model computer program.

FMA has prepared a second order model for examining the various loss mechanisms in the stirling engine as outlined in Table ES-1. The original version of the second order analysis was developed by Professor Smith and Dr. Rios of MIT: The most salient feature of the FMA second order analysis is the cyclic heat transfer loss mechanism. This loss mechanism is similar to gas spring loss due to cyclic heating and cooling at the gas wall interface. Up to now, this loss mechanism has not been recognized by stirling engine analysts as a significant loss mechanism for stirling engines. FMA has identified the significance of this loss mechanism and included it in its second order analysis. In some cases the cyclic heat transfer loss can be as high as 9 percent of the basic adiabatic power. 
Table ES-1. Governing Factors Influencing Stirling. Engine Thermodynamic Performance

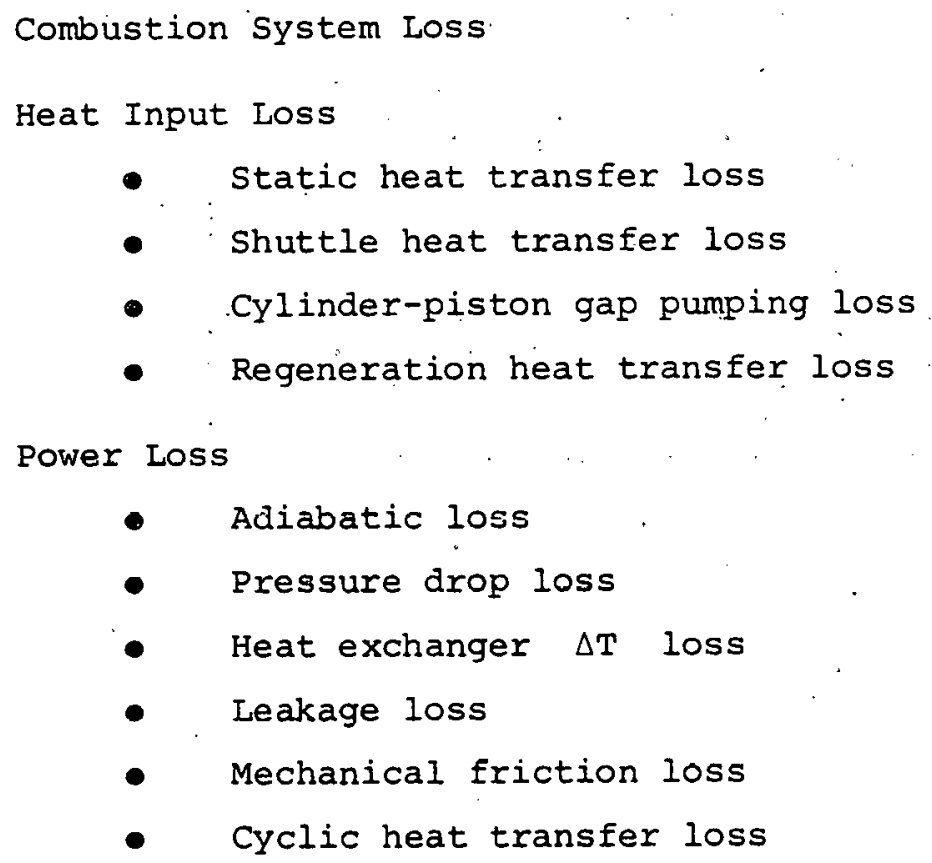

In order to validate the second order model computer program, the performance of actual GPU-3 stirling engines was predicted and compared with actual data as shown in Table ES-2. Also, proprietary data from two modern stirling engines designated as 4-D1 and 4-D2 were obtained to be compared with FMA predictions. The FMA second order analysis predicts the brake power with maximum 15 percent error and the brake efficiency with maximum 12 percent error. Considering the uncertainties in the experimental data involved, the prediction errors are very reasonable, particularly since the second order model is based solely on the fundamental principles and requires no empirical calibration with stirling engine data.

With the aid of the second order analysis and third order analysis computer programs, a sensitivity analysis of various engine design parameters was performed in order to determine the 
Table ES-2. Comparison of Predicted Performance with Actual Performance

\begin{tabular}{|c|c|c|c|c|c|c|c|c|c|}
\hline \multirow[b]{2}{*}{$\begin{array}{l}\text { Engine } \\
\text { Name }\end{array}$} & \multicolumn{3}{|c|}{ Operating Condition } & \multicolumn{3}{|c|}{ Brake Power/Cylinder } & \multicolumn{3}{|c|}{ Brake Thermal Efficiency* } \\
\hline & $\begin{array}{c}\text { Temperature } \\
\left({ }^{\circ} \mathrm{C}\right)\end{array}$ & $\begin{array}{c}\text { Mean } \\
\text { Pressure } \\
\text { (atmosphere) }\end{array}$ & $\begin{array}{l}\text { Speed } \\
\text { (rpm) }\end{array}$ & $\begin{array}{l}\text { Predicted } \\
\quad(\mathrm{kW})\end{array}$ & $\begin{array}{l}\text { Actual } \\
(\mathrm{kW})\end{array}$ & $\begin{array}{l}\text { Error } \\
(8)\end{array}$ & $\begin{array}{c}\text { Predicted } \\
(8)\end{array}$ & $\begin{array}{l}\text { Actual } \\
\text { (z) }\end{array}$ & $\begin{array}{c}\text { Error } \\
(8)\end{array}$ \\
\hline \multirow[t]{5}{*}{ GPU-3 } & $\begin{array}{l}\text { Heater: } 704 \\
\text { Cooler: } 15\end{array}$ & $\begin{array}{l}27.2 \\
\left(400 \quad 1 b / \text { in. }{ }^{2}\right)\end{array}$ & & & & & & & \\
\hline & & & 1500 & 1.725 & 1.50 & 15.0 & 28.4 & 25.5 & 11.4 \\
\hline & & & 2000 & 2.25 & 1.98 & 13.6 & 29.3 & 27.1 & B.1 \\
\hline & & & 2500 & 2.58 & 2.39 & 7.9 & 28.0 & 26.8 & 4.5 \\
\hline & & & 3000 & 2.75 & 2.61 & 5.4 & 25.9 & 25.5 & 1.6 \\
\hline $4-D 1$ & $\begin{array}{l}\text { Heater: } 650 \\
\text { Cooler: } 75\end{array}$ & $\begin{array}{c}148.1 \\
\left(2177 \mathrm{lb} / \text { in. }^{2}\right.\end{array}$ & 1400 & 5.0 & 5.0 & 0.0 & 33.1 & 32.0 & 3.5 \\
\hline $4-\mathrm{D} 2$ & $\begin{array}{l}\text { Heater: } 720 \\
\text { Cooler: } 50\end{array}$ & $\begin{array}{c}148.1 \\
(2177 \mathrm{lb} / \mathrm{in.2})\end{array}$ & & & & & & 34.0 & 3.5 \\
\hline & & & 1250 & 11.95 & 11.0 & 9.0 & 35.4 & 36.0 & -1.7 \\
\hline & & & 1500 & 14.0 & 12.5 & 12.0 & 34.5 & 33.0 & 4.5 \\
\hline
\end{tabular}


significance of these parameters on the design of the high efficiency stirling engine. The sensitivity analysis included the investigation of engine phase angle, heater temperature, pressure, working fluid, dead volume, engine speed, heater effectiveness, cooler effectiveness, and power control. Significant results of * the sensitivity analysis are:

- Stroke control appears more favorable as in terms of engine performance compared to other power control methods.

- A $100^{\circ} \mathrm{C}$ increase in heater temperature will cause à 10 percent increase in engine efficiency and power.

- An engine optimized for helium will have the same efficiency as an engine optimized for hydrogen.

The basic concentric module engine design thermodynamic performance was predicted with both the FMA second order analysis and the SUNPOWER third order analysis computer programs. Since the same basic engine design which includes the concentric module design and seal module was employed, the predicted performance applies to all engine candidate designs, although slight differences in performance may result due to different mechanical design configurations at the bottom end of the engines. The predicted brake thermal efficiency excluding combustion efficiency is approximately 42 percent which exceeds the design objective of 40 percent.

\section{Combustion Systems Analysis and Design}

The combustion system designs were prepared for both a clean fuel combustion system and a two-stage atmospheric fluidized bed combustion system. Based on current engine developments, there 
appear to be no major obstacles to burning conventional liquid and gaseous fuels. The clean fuel combustion system is designed for direct coupling to the heater head of the engine. Because of the unique method of fuel preparation used in the burner design, any fuel oil. "cut" up to and including No. 2 fuel may be considered as a clean fuel. For the proposed clean fuel combustion process, liquid fuel is vaporized by atomization into a carrier stream of hot gasses, either exhaust gas recirculation (EGR) or combustion gas recirculation (CGR) mixed with air. The vaporized fuel and air mixture then burn with a sootless, quiet, blue flame. Figure ES-2 shows how fuel vaporization has been applied to the proposed clean fuel combustion system. This method of combustion has been applied successfully many times at FMA for natural gas, gasoline, and No. 2 fuel oil burners, ranging in size from 2.9 to $5.86 \mathrm{~kW}$, and for turndown ratios of 20 to 1 .

The proposed clean fuel combustion system is shown in Figure ES-3. The recuperator is located outside the EGR Ioop. The calculated clean fuel combustion system efficiency is approximately 90 percent. The combustion head of the burner is the only unique component in the proposed system; all other components and fabrication techniques are standard.

Because the stirling engine is an external combustion engine, fuels which produce high levels of abrasive particulars and relatively. large amount of corrosive byproducts can be used without adversely affecting the engine's operating parts. For the use of coal as a fuel for stirling engines, four options were investigated: on-site gasification, on-site liquefaction, coal/oil mixtures, and solid-coal combustion. 


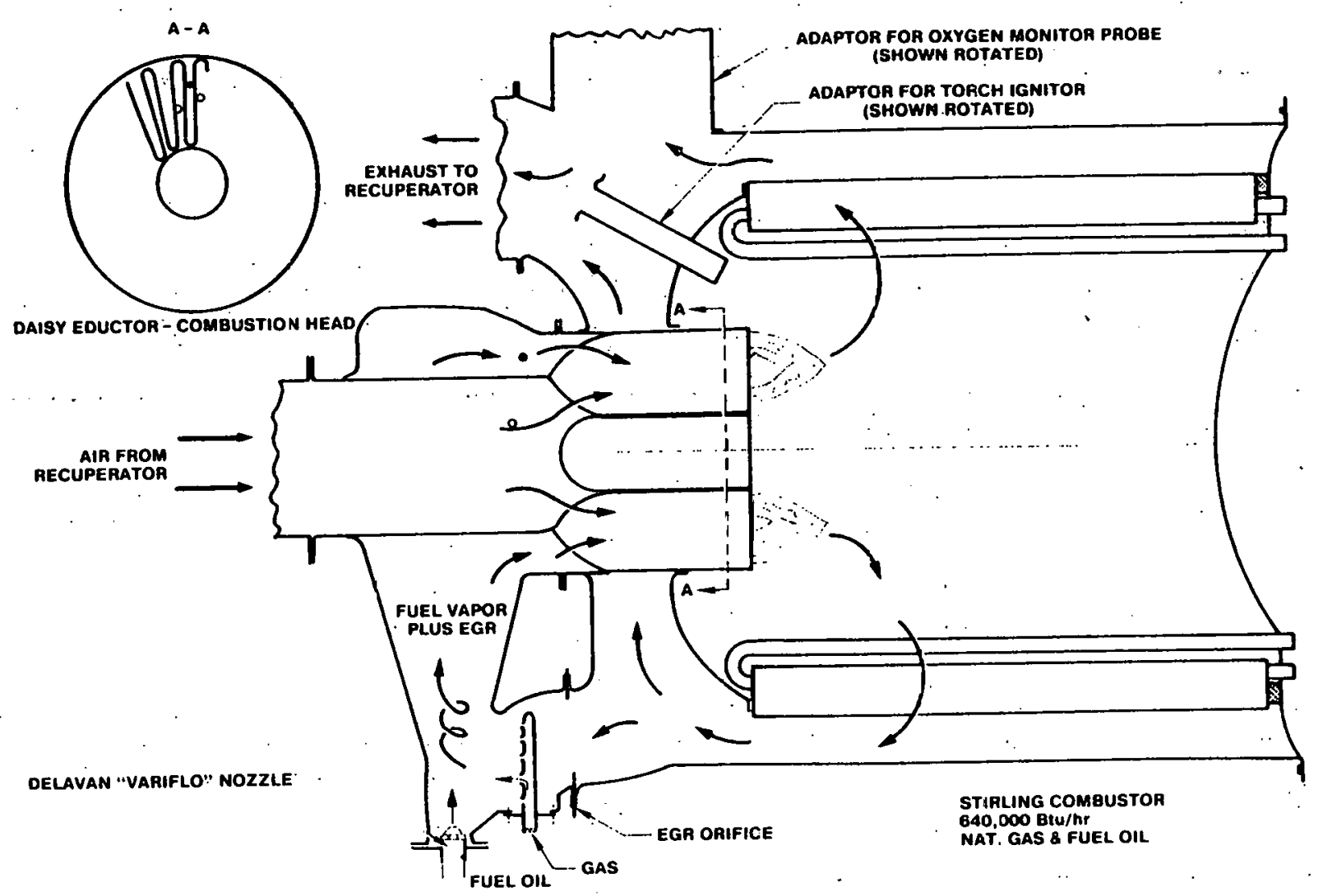

Figure ES-2. Clean Multifuel Burner for Stirling Engine 


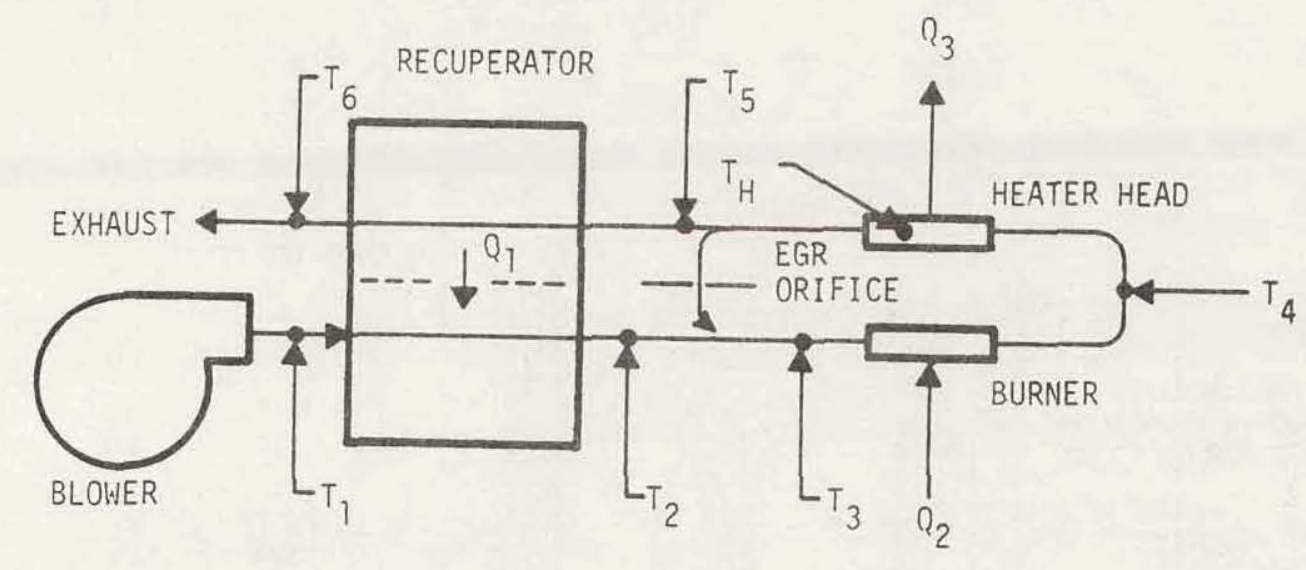

Figure ES-3. Clean Fuel Combustion system, Fuel Design Schematic

For on-site coal gasification, on-site coal liquefaction, and coal/oil mixtures it was concluded that the small power requirements of the stirling engine system do not justify the initial capital costs.

For coal combustion it was concluded that atmospheric fluidized bed combustion is the only presently viable option. A twostage atmospheric fluidized bed combustion system was designed for the stirling cycle engine system. A preliminary schematic of the coal combustion system is shown in Figure ES-4. The proposed design is an extension of the Wormser Grate (47), a twostage fluidized bed combustion system, which is suitable for small-scale applications and is readily adaptable to the stirling cycle engine. The coal combustion system consists of two combustors and a holding bed. The primary combustor stage consists of a shallow combustion bed made up of inert sand into which coal is injected. Approximately 90 percent of the stoichiometric air is injected into this combustor stage. An indirect heat exchanger is introduced into this stage to maintain the bed temperature at any level independent of the sulfur retention requirements. This 


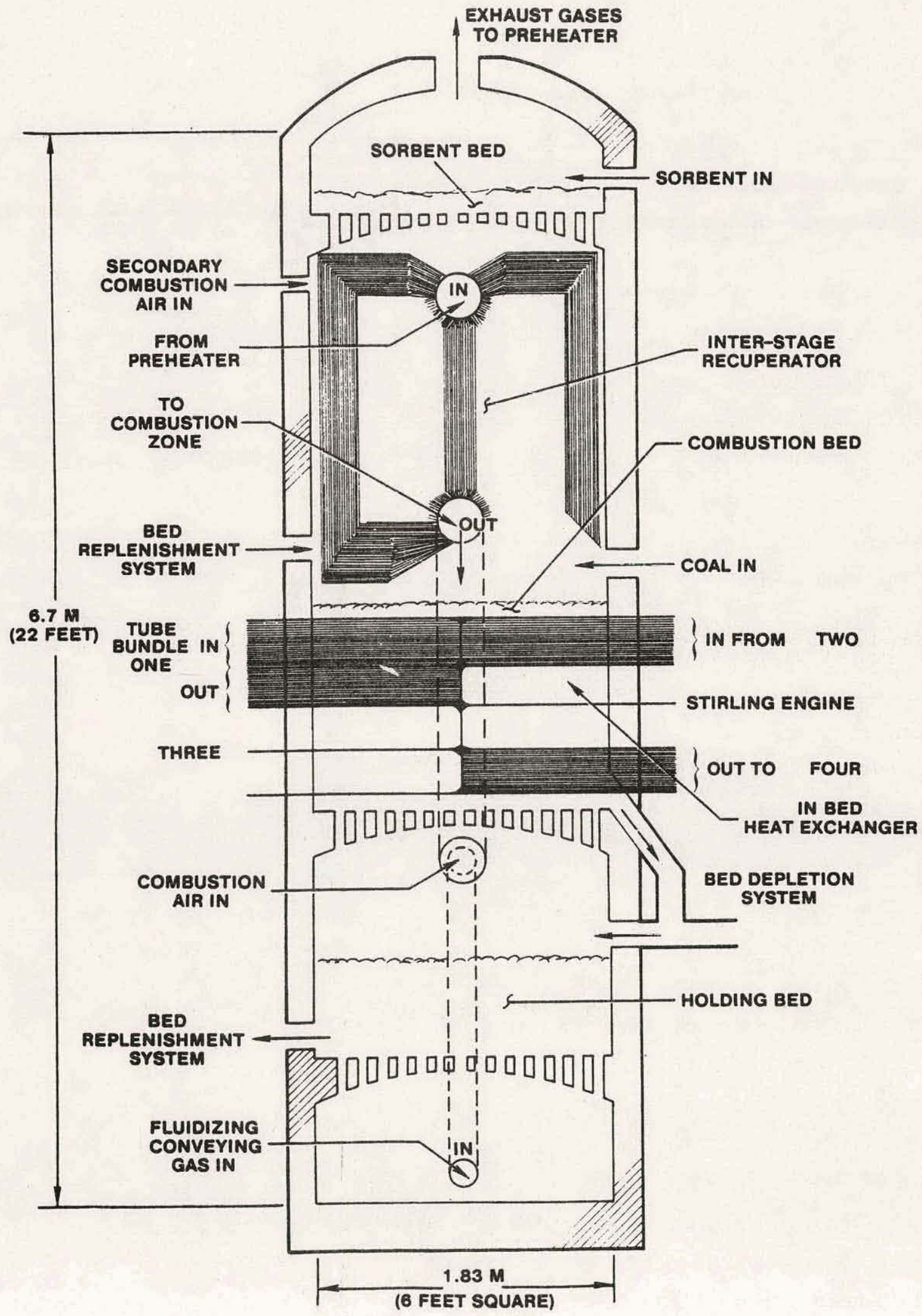

Figure ES-4. Atmospheric Fluidized Bed Coal Combustor for Stirling Engine Application

Preliminary Schematic 
fuel-rich stage is essentially aimed at reducing conditions easing the materials selection problem for the heat exchanger. The possibility of operating the bed at temperatures above that for sulfur fixation will permit the increase of the Stirling engine efficiency. Also the higher operating temperatures increase the heat flux which reduce the heat exchanger surface area requirements.

The secondary combustor stage contains the sorbent for sulfur removal. The operating temperature of the bed can be adjusted to the optimum with in-bed heat exchangers or interstage recuperators for heat recovery. The remainder of the combustion air is introduced just below or above the upper stage distributor thus making the upper bed atmosphere essentially oxidizing; this eases the materials selection. Also the secondary combustor stage helps burn all the entrained fine coal; this eliminates the need for carbon burn-up cell or fly ash recirculation and improves the combustion system efficiency.

The holding bed is located below the primary combustor stage. Bed material from the primary stage can be transferred to the holding bed exposing the upper heat transfer tubes. The transfer is accomplished by bed overflow and gravity transport method. The purpose of the holding bed is to permit large turndown ratios of 30 to 1 .

The advantages of the Wormser Grate two-stage atmospheric fluidized bed combustion system are:

- Combustion bed temperature is independent of sorbent bed temperature.

- Combustion temperature only limited by materials of construction. 
- Sorbent bed can be operated at the optimum temperature band of $810^{\circ}$ to $850^{\circ} \mathrm{C}$ for maximum sulfur retention.

- $\quad \mathrm{NO}_{\mathrm{X}}$ emissions are lower than those for conventional atmospheric fluidized bed combustion systems.

- Less sulfidation corrosion as compared to a conventional atmospheric fluidized bed combustion system.

- Turndown ratios of 30 to 1 are possible.

- Less liquid fossil fuel is required to start the proposed combustion system as compared to a conventional atmospheric fluidized bed combustion system.

- Combustion efficiency of 80 percent is achievable.

\section{Heater System Analysis and Design}

For an externally heated engine such as a stirling cycle engine a heat transport system is required to transfer the heat from the energy source to the engine working fluid. The heat transfer may either be accomplished directly or indirectly. Presently all Stirling cycle engines employ direct heating. For the heater head assembly it is desirable to minimize the internal heater tube volume and surface area in order to obtain better engine performance. However, for the case of coal and heavy oil combustion products which have high particulate concentrations, fouling would occur on the external surfaces of the tubes and since the combustion side heat transfer coefficient dictates the overall heat transfer coefficient, there is a desire to increase the tube heat transfer surface area or to provide blower power for forced convection. There is a tradeoff of heat transfer surface area and blower power to reduce heater tube volume. 
Because of the presence of the heavy fouling for solid fuels, residual oils and other heavy fuels, it is desirable to employ indirect heating techniques. Three heat transport systems were studied for indirectly transporting heat from the combustion system to the heater tubes: liquid metal heat pipes, liquid metal circulation loop, and gas circulation loop.

For the burning of clean fuels, a direct-fired stirling cycle engine heater head design was prepared. The heater head is a small, efficient heat exchanger with 48 tube hairpins with external fins; the fin density is $3.9 \mathrm{fins} / \mathrm{cm}$ (10 fins/in.); the projected heat exchanger effectiveness of the heater head is 0.90 . The materials specifications and fabrication techniques are compatible with current state-of-the-art technology.

For the burning of coal and other nonclean fuels, designs for both a liquid metal heat pipe system and a gas circulation loop to accommodate indirect heat transfer were prepared. The proposed liquid metal heat pipe design concept consists of two separate heat pipe systems thermally communicating with each other via liquid metal joints which connect to a single manifold. A schematic of the proposed liquid metal heat pipe system for a large stationary stirling cycle engine coupled to an atmospheric fluidized bed combustion system is presented in Figure ES-5. The 1320 small primary heat pipes are located in the fluidized bed coal combustor and the secondary heat pipes are attached to the hot ends of the stirling engine cylinders. The heat transfer working fluid is liquid sodium.

The proposed gas circulation loop consists of 800 tubes embedded in the atmospheric fluidized bed combustion system and connected by a manifold to the stirling engine head heat exchangers. A blower is used to circulate the heat transfer working gas of either hydrogen or helium. 


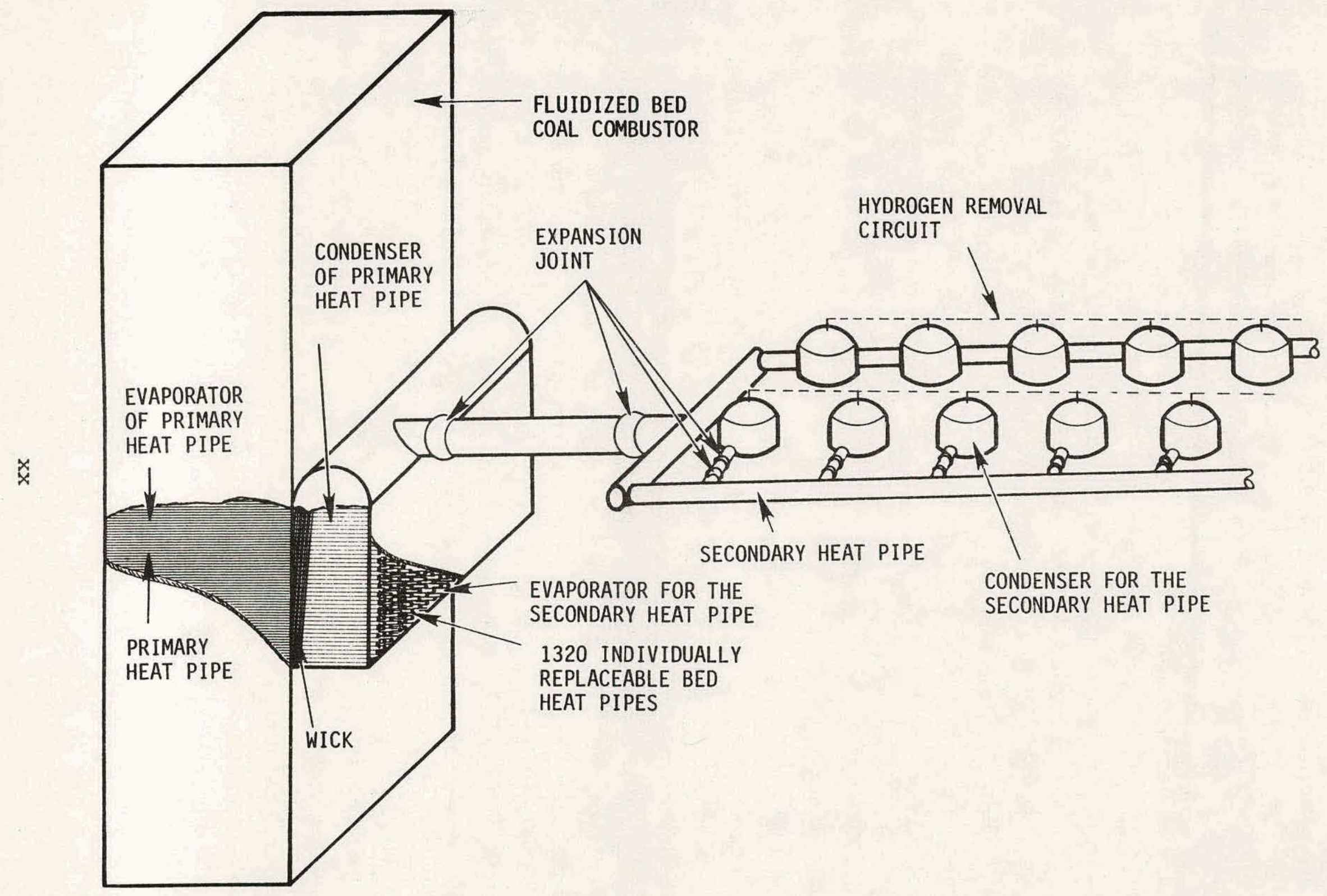

Figure ES-5. Schematic of Heat Pipe System for a Large Stationary Stirling Engine/Fluidized Coal Combustion 


\section{Recommended Conceptual System Designs}

The recommended conceptual system is modular, consisting of a basic stirling engine cylinder that is easily adaptable to any type of heat input or machine output. The nominal power is determined by the number of cylinders and design conditions and the cylinder has been designed to accommodate the several options for fuel combustion.

The cylinder module is axisymmetric around the piston with a single hot head and hairpin arranged heater flow passages. A schematic of the conceptual design of the Stirling engine cylinder module is presented in Figure ES-6. The cylinder module consists of a monolithic pressure dome, penetrating heater tube passages, regenerator, cooler, piston, piston seal assembly, and cylinder liner.

The engine output configuration selected is the single crank, narrow $v$, multicylinder arrangement in which any number of cylinders, in groups of four or five, provide the desired power rating. This is the simplest and most common configuration currently manufactured for large stationary diesel engines. The conceptual design of the narrow $\mathrm{V}$ engine is illustrated in Figures ES- 6 and ES-7. The engine uses one crank throw per cylinder, so that the $\mathrm{V}$-angle and the cycle phase angle are optional.

An important feature of the design is that complete servicing of the piston, cylinder liner, seal assembly, and all lubricated machine parts can be accomplished from below, crank-side, without disturbing any parts on the upper side.

It is recommended that the engine be developed initially with mean pressure control. To simplify the design and to improve load following, it is suggested that dead volume control be developed later. 


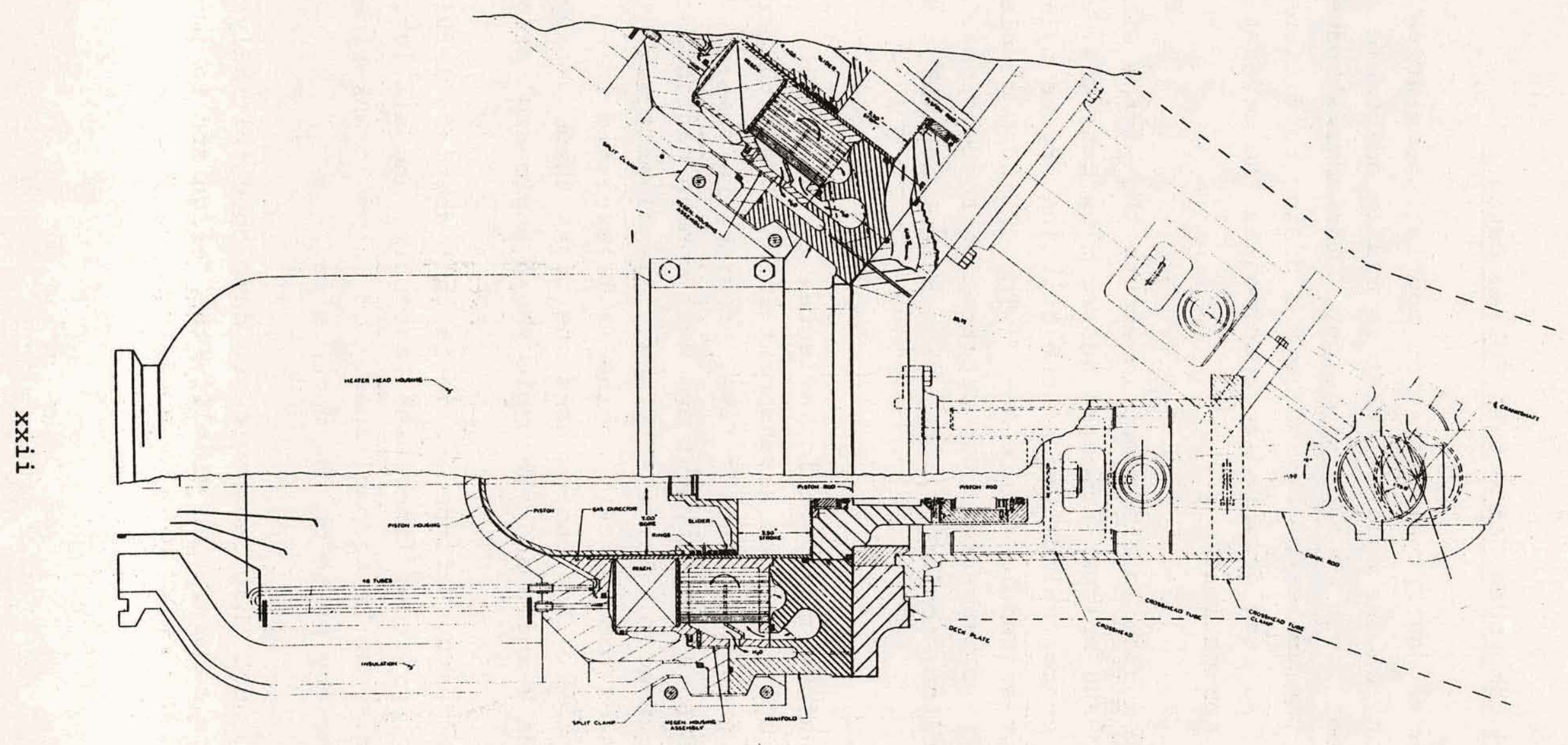

Figure ES-6. Cross-Sectional View of the Double-Acting Narrow.V Stirling Engine 


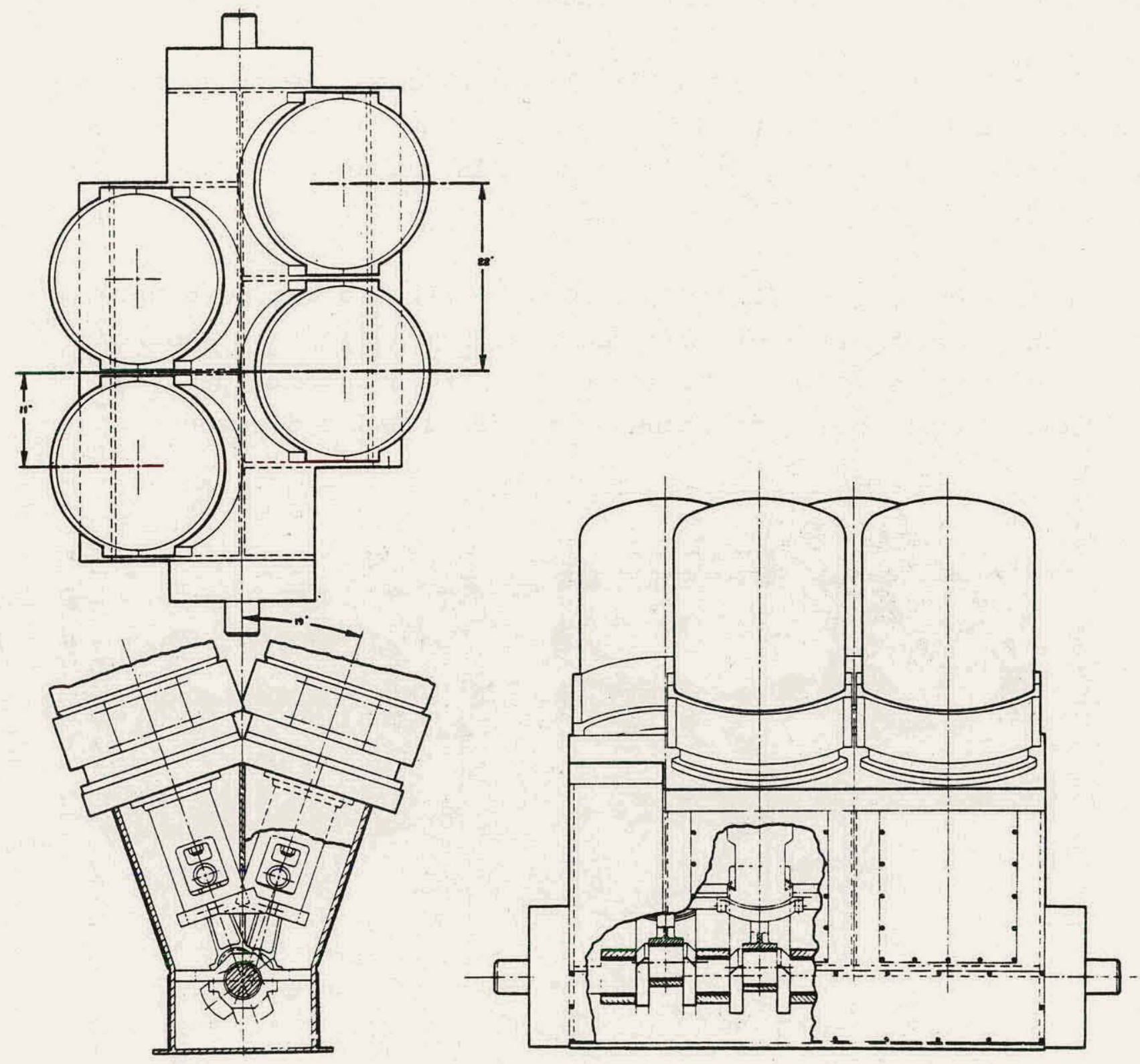

Figure ES-7. Configuration Layout of the $373 \mathrm{~kW}$ (500 hp) Double-Acting, Narrow $V$ Stirling Fingine (4 Cylinders) Without Combustion System 
The basic engine design is suitable for speeds up to approximately $30 \mathrm{~Hz}$ without severe penalties in thermal efficiency or machine reliability except for piston rings, which are the critical limiting reliability components.

An artist's conception of a $373 \mathrm{~kW}$ (500 hp) Stirling engine/ generator set which is fueled by clean fuels is shown in Figure ES-8. The prevaporized, premixed EGR combustion method is employed.

A schematic of a $2237 \mathrm{~kW}(3000 \mathrm{hp})$ Stirling engine/generator set with atmospheric fluidized bed coal combustion and indirect heat transfer is shown in Figure ES-9. It is recommended that a Wormser Grate two-stage atmospheric fluidized bed combustion

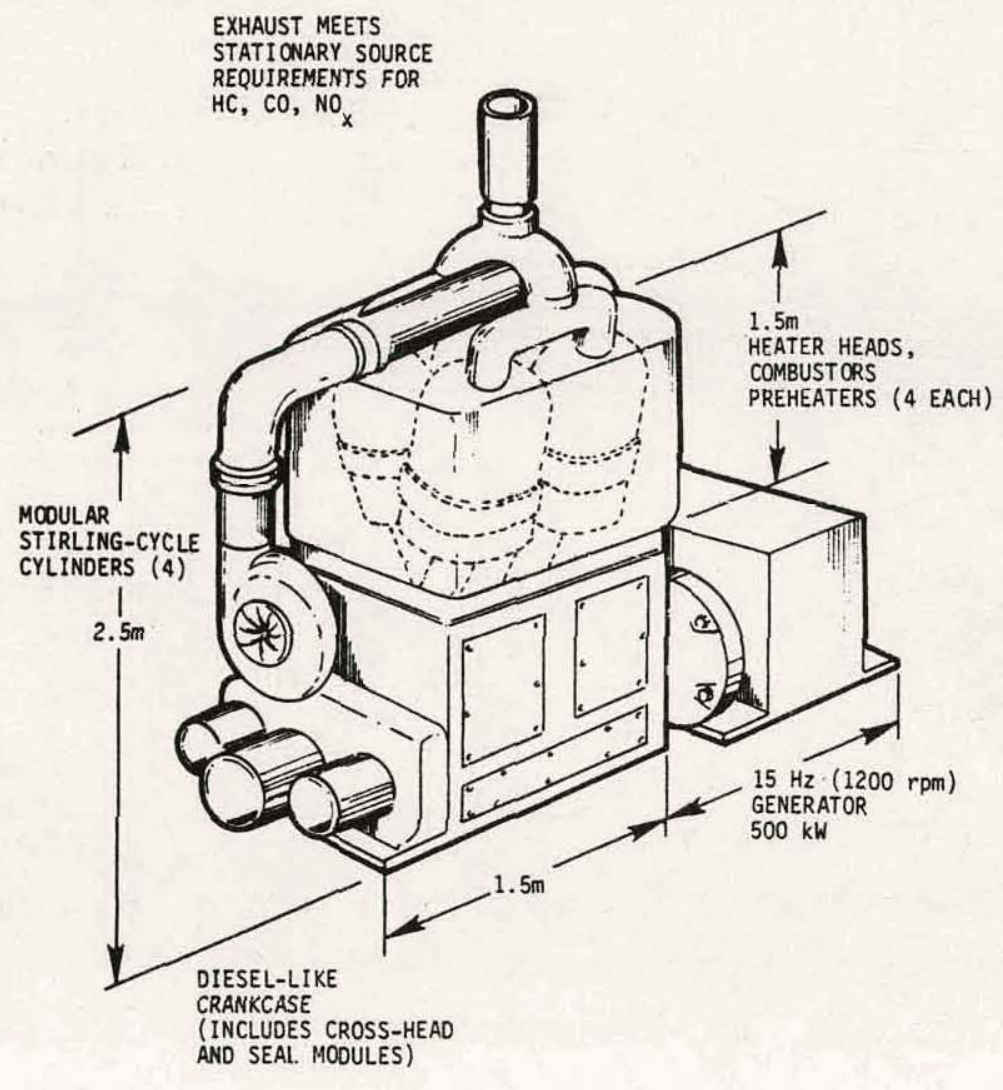

Figure ES-8. $373 \mathrm{~kW}(500 \mathrm{hp})$ Stirling Cycle Engine with Clean Fuel Combustion System 


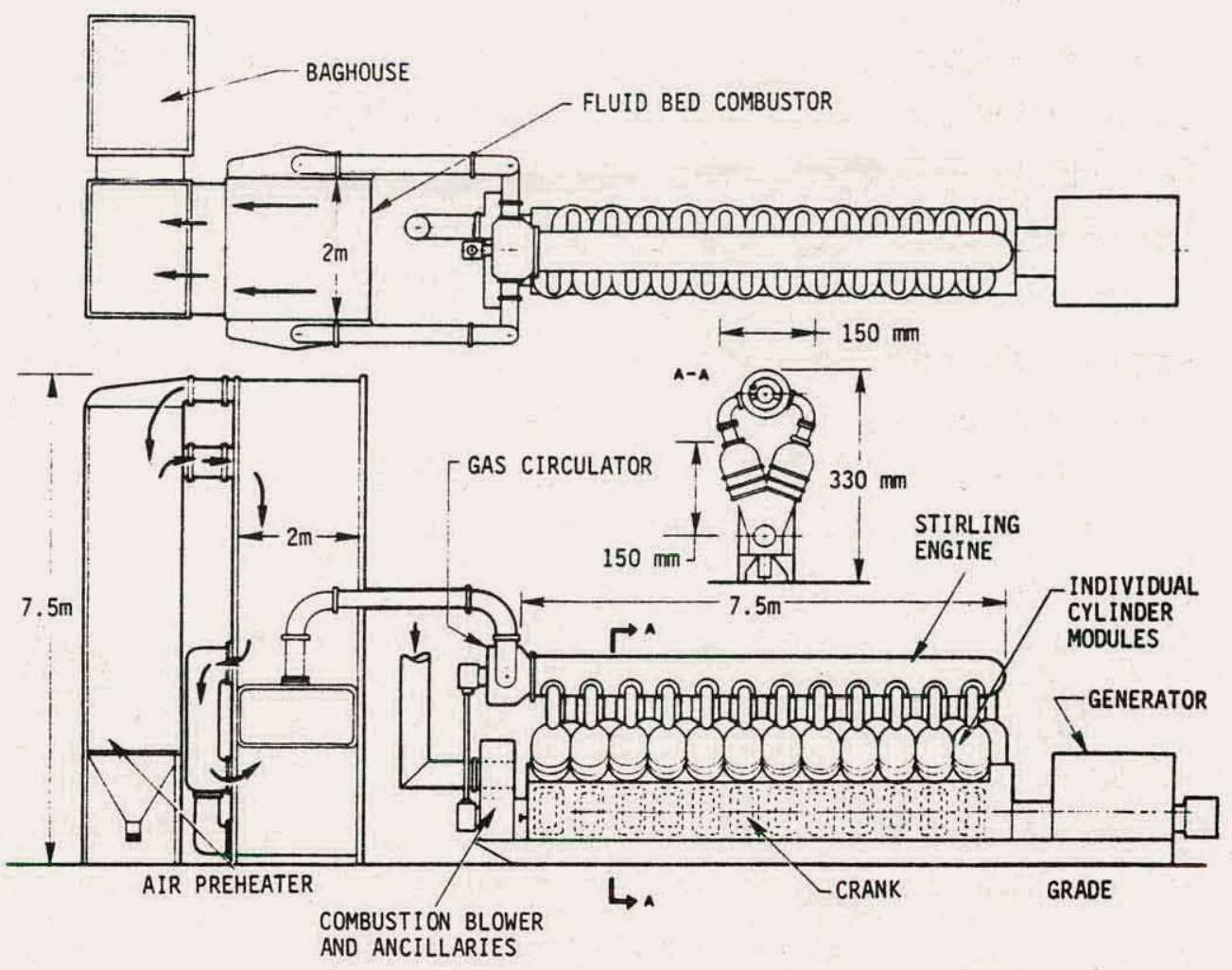

Figure ES-9. $2237 \mathrm{~kW} \mathrm{(3000} \mathrm{hp)} \mathrm{Stirling} \mathrm{Cycle} \mathrm{Engine} \mathrm{with}$ a Two-Stage Atmospheric Fluidized Bed Combustion System and a Gas Circulation Loop

system be employed because of compactness, low $\mathrm{NO}_{\mathrm{X}}$ emissions and potential low cost. For the first demonstration of a stirling cycle engine/FBC system, it is recommended that a pressurized gas circulation loop be employed for the indirect heat transfer method. The advanced liquid metal heat pipe system should be developed independently.

For the advanced system designs, it is recommended that liquid metal heat pipes be used for indirect heat transfer from a fluidized bed combustion system to the stirling cycle engine be considered for future development. 


\section{Production Cost Estimates for the Proposed Stirling Cycle Engine Systems}

Production cost estimates for quantities of 1000 units/year were prepared for the four proposed Stirling cycle engine systems :

- $\quad 373 \mathrm{~kW}(500 \mathrm{hp})$ Stirling cycle engine with clean fuel direct combustion system

- $\quad 2237 \mathrm{~kW}(3000 \mathrm{hp})$ Stirling cycle engine with clean fuel direct combustion system

- $\quad 2237 \mathrm{kw}(3000 \mathrm{hp})$ Stirling cycle engine with a twostage atmospheric fluidized bed combustion system and a liquid metal heat pipe system

- $\quad 2237 \mathrm{kw}(3000 \mathrm{hp})$ Stirling cycle engine with a twostage atmospheric fluidized bed combustion system and a gas circulation loop.

A summary of the production cost estimates is presented in Table ES-3. For clean fuels combustion the proposed $2237 \mathrm{~kW}$ ( $3000 \mathrm{hp}$ ) system (does not include generator) production cost is $\$ 478,242$ or $\$ 214 / \mathrm{kW}(\$ 159 / \mathrm{hp})$. A comparable size diesel engine cost is between approximately $\$ 40 \quad(\$ 30)$ and $\$ 100 / \mathrm{kW}$ $(\$ 75 / \mathrm{hp})$ for a cost ratio of stirling to diesel ranging from 2.9 to 5.4. It is apparent that Stirling engines employing clean fossil fuels cannot compete with diesel engines.

For solid coal combustion the proposed $2237 \mathrm{~kW}$ ( $3000 \mathrm{hp}$ ) system production cost is approximately $\$ 2,246,242$ which corresponds to a cost to power capacity ratio of $\$ 1004 / \mathrm{kW}(\$ 749 / \mathrm{hp})$. 
Table ES-3. Summary of Production Cost. Estimates for the Proposed Stirling Cycle Engine Systems

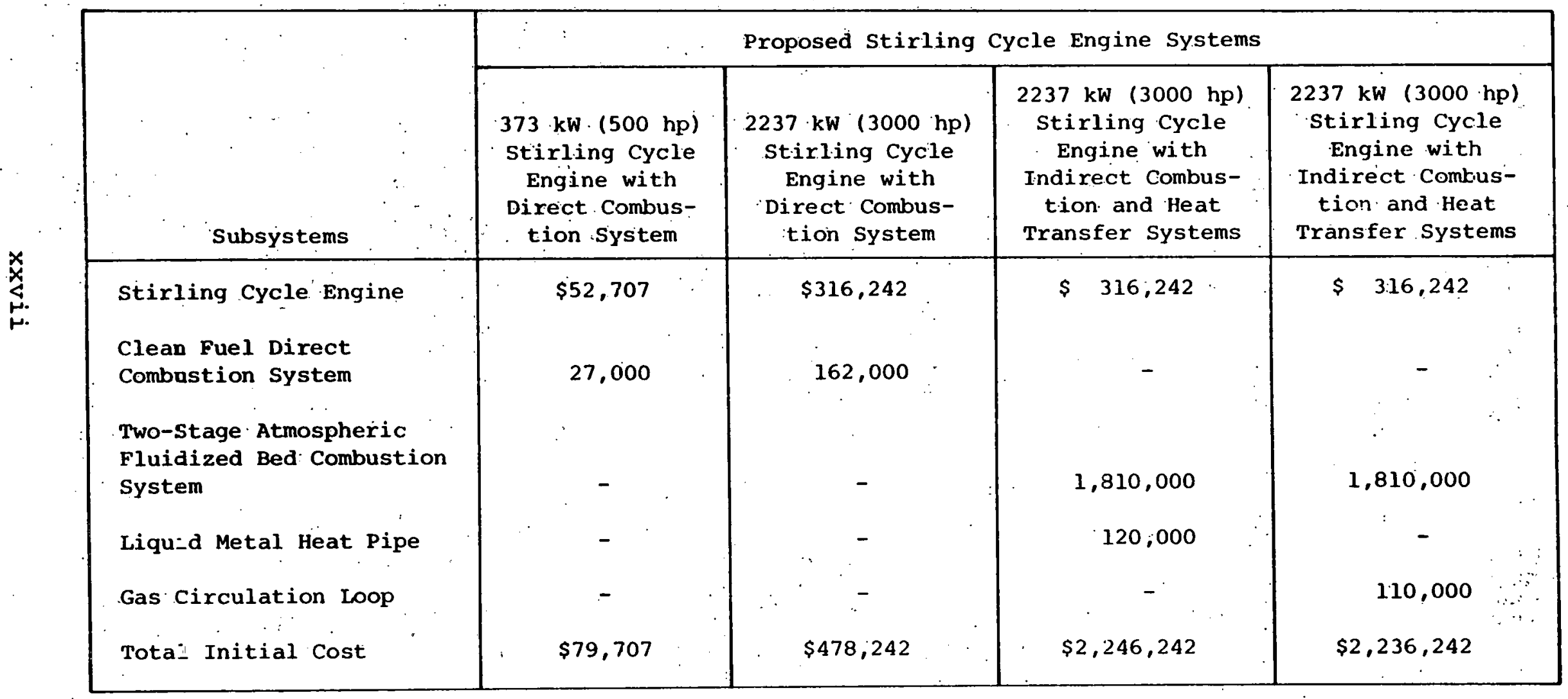


The dominant cost contribution for the proposed system is the two-stage atmospheric fluidized bed combustion system which represents 81 percent of the total cost; the engine represents only 14 percent of the total cost.

Depending on the future price differential between coal and conventional clean fuels, a short payback period of the proposed stirling cycle engine/FBC system may justify the initial cost. For example, if the present price differentials are employed, the payback period is approximately 3.3 years and the recurring annual energy cost savings is approximately $\$ 656,000$.

xxviii 
ACKNOWLEDGEMENTS

EXECUTIVE SUMMARY

1. INTRODUCTION

1.1

Market. Assessment

i.i.1

Present and Future Markets

1.1 .2

Prime Mover Options

1.1 .3

Design Specifications

1.2

Development Program Description

1.3

Team Description and Qualifications

1.4

Contents of Volume 1

2.

DESIGN METHODOLOGY

20

2.1

Review of objectives.

20

2.2

Parametric Analysis

2.2 .1

Internal Thermodynamic Parametric Similarity

External Constraining Factors

2.2 .3

Deviation from Parametric Similarity

2.2 .4

Summary of Parametric Analysis

Preliminary Engine Design Candidates

2.4 .1

Axial. Flow Opposed Piston Design

2.4 .2

Manifolded Single-Acting U-Design

2.4 .3

Concentric Module Design

2.4 .4

Alternate Machines with Modular.

Head Design

2.4 .5

Engine Design Selection

3. ENGINE THERMODYNAMIC PERFORMANCE

EVALUATION 
$3.1: 1$

3.1 .2

3.1 .3

3.2

3.3

3.4

3.5

3.6

4.

4.1

4.1.1

4.1 .2

4.1 .3

4.1 .4

4.1 .5

4.1 .6

4.1 .7

4.1 .8

4.2

4.2 .1

4.2 .1 .1

4.2 .1 .2

4.2 .2

4.2 .3

4.2 .4

4.2 .4 .1
Combustion System Loss

Heat Input Loss

52

Power Loss

54

Third Order Computer Analysis

63

Comparison of Predicted Performance

With Actual Performance

68

Sensitivity Analysis

74

Thermodynamic Performance Prediction

of FMA Engine Design

86

Conclusions and Recommendations

89

COMBUSTION SYSTEMS ANALYSIS AND DESIGN

92

Clean Fuel Combustion System

93

Proposed Clean Fuel Combustion System

Analysis and Design

95

Efficiency

104

${ }^{N O} X$ Minimization

Burner Description

104

106

Controls

107

Safety Controls

109

Start-Up

110

Design Summary

110

Onsite Coal Utilization Systems

110

Coal Gasification

111

113

113

114

114

115

Coal Combustion

(COM)

120 
Section No.

Page No.

4.2.4.2 Conventional Atmospheric Fluidized Beds Versus Two Stage Beds

4.2.4.3 A Two-Stage Fluidized Bed Combustor

$5 .$.

HEATER SYSTEM ANALYSIS AND DESIGN

130

5.1

Direct Heat Transfer

5.1 .1

Heater Head Design Goals and

Specifications

132

5.1 .2

Heater Head Theory and Design

134

5.1 .3

Materials and Construction

5.1 .4

Design Summary

5.2 .

Indirect Heat Transfer.

5.2 .1

Liquid Metal Heat Pipes

5.2 .2

Liquid Metal Circulation Loop

5.2 .3

Gas Circulation Loop

6.

RECOMMENDED CONCEPTUAL SYSTEM DESIGNS

154

6.1

Initial Design and Development

6.1 .1

Stirling Engine Design

6.1 .2

Direct Combustion Systems

6.1 .3

Indirect Combustion Systems

166

6.1 .4

Predicted Engine System Performance

171

6.2

Advanced Systems Designs

173

7.

MANUFACTURING ASSESSMENT/PRODUCTION

COST ESTIMATES

7.1

Engine Manufacturing Assessment

176

7.2

Engine Production Cost Estimates

7.3

Conventional Direct Combustion System

Production Cost Estimates -.

183

7.4

Production Cost and Operating Cost Estimates for a Two-Stage Fluidized Bed Combustion System 
TABLE OF CONTENTS (Continued)

Section No:

Pagéno.

7.5 Indirect Heat Transfer Systems Production Cost Estimates

7.6

Summary of the Production Cost Estimates for the Proposed Stirling Cycle Engine Systems

8.

REFERENCES 


\begin{tabular}{|c|c|c|}
\hline ES-1 & Flow Diagram of the Design Synthesis & vii \\
\hline$E S-2$ & Clean Multifuel Burner for Stirling Engine & xiv \\
\hline$E S-3$ & $\begin{array}{l}\text { Clean Fuei Combustion System; Fuel } \\
\text { Design Schematic }\end{array}$ & $x V$ \\
\hline ES-4 & $\begin{array}{l}\text { Atmospheric Fluidized Bed Coal Combustor } \\
\text { for stirling Engine Application Preliminary } \\
\text { Schematic }\end{array}$ & $x v i$ \\
\hline ES-5 & $\begin{array}{l}\text { Schematic of Heat Pipe System for a Large } \\
\text { Stationary Stirling Engine/Fluidized Coal } \\
\text { Combustion }\end{array}$ & $x x$ \\
\hline ES -6 & $\begin{array}{l}\text { Cross-Sectional View of the Double-Acting } \\
\text { Narrow V Stirling Engine }\end{array}$ & $x x i i$ \\
\hline ES-7 & $\begin{array}{l}\text { Configuration Layout of the } 373 \mathrm{~kW}(500 \mathrm{hp}) \\
\text { Double-Acting, Narrow V Stiriing Engine } \\
\text { (4.Cylinders)' Without Combustion System }\end{array}$ & xxiii \\
\hline ES-8 & $\begin{array}{l}373 \mathrm{~kW}(500 \mathrm{hp}) \text { Stirling Cycle Engine with } \\
\text { Fuel Combustion System }\end{array}$ & xxiv \\
\hline ES -9 & $\begin{array}{l}2237 \mathrm{~kW}(3000 \mathrm{hp}) \text { Stirling Cycle Engine with } \\
\text { a Two-stage Atmospheric Fluidized Bed Com- } \\
\text { bustion System and a Gas Circulation Loop }\end{array}$ & $x x v$ \\
\hline 1. & Program Organization & 17 \\
\hline 2 . & Flow Diagram of the Design Synthesis & 21 \\
\hline 3. & Stirling Engine Configuration Decision Tree & 29 \\
\hline 4. & $\begin{array}{l}\text { Fuel/Combustion system Configuration } \\
\text { Decision Tree }\end{array}$ & 30 \\
\hline 5 . & $\begin{array}{l}\text { Fuel/Combustion System Configuration } \\
\text { Decision Tree: Onsite Coal Utilization }\end{array}$ & 31 \\
\hline 6 . & Heater System Configuration Decision Tree & 33 \\
\hline 7. & Máchine Configuration Decision Tree. & 34 \\
\hline
\end{tabular}




\section{LIST OF ILLUSTRATIONS (Continued)}

Figure No.

Page No.

8

Single-Acting Manifolded Engine

38

9. Single-Acting Displacer V-Engine With

Pressure Control

41

10.

Double Acting Rhinia In-Line Engine

43

11. Double Acting Rhinla Barrel Engine with Variable Stroke Control

12.

Relative Magnitudes of Various Power and Heat Input Losses in the Viking-1 Engine

13.

Control Volumes of a Stirling Engine for the Cyclic Heat Transfer Analysis

Effect of Manifold Geometry on Cyclic Heat Transfer and Stirling Engine Performance

15. Comparison of Power Predictions with Experimental Data for GPU-3

16. Comparisons of Heat Input Predictions with Experimental Data for GPU-3

17. Comparison of Brake Efficiency Predictions with Experimental Data for. GPU-3

18. Effect of Piston Phase Angle Variation on Stirling Engine Performance

19. Effect of Hot Temperature Variation on Stirling Engine Performance

FMA Viking-1 Performance Versus Engine Speed

21. Effect of Heater NTU Variation on Stirling Engine Performance

22. Effect of Cooler NTU Variation on Stirling Enginé Performance

23.

Effect of Regenerator Matrix Specific Heat Variation on Stiriing Engine Performance. 
Figure No.

Page No.

24. Comparison of Power Control Methods For a Stirling Engine

25. Energy Flow Diagram of the Viking-1 Engine

87

26 .

Effect of Scaling-Up on Stirling Engine

Performance

27.

Clean Multifuel Burner for Stirling Engine

94

28.

Conventional Direct Fired Heating system

99

29.

Split Flow Air Preheater, Direct Fired Heating System. Provides Cooler Air For Vaporizing or Staged Combustion

30.

Remotely Fired Heating System with Heat Pipe or Gas Couple. EGR and Split Flow Air Preheater Are Options

Clean Fuel Combustion System, Final Design Schematic and Equations

32.

Stirling Clean Fuel Combustor Flow Diagram

Fuel/Combustion System Configuration

Decision Tree: Onsite Coal Utilization

Effect of Capacity on Cost of Heat (34)

for Coal Combustion Systems

35.

Effect of Bed Temperature on sulfur

Retention"

36.

Effect of Bed Tempërature on Sulfidation Corrosion

37.

Atmospheric Fluidized Bed Coal Combustor for Stirling Engine Applications: Preliminarÿ Schematic

38

Effect of Staging Fluidized. Bed

Combustion (43) 


\section{LIST OF ILLUSTRATIONS (Continued)}

Figure No.

Page No.

40 .

Heater Head Tube and: Fin Arrangement

136

41 .

Schematic of Heat Pipe System for a Large Stationary Stirling Engine/Fluidized Coal

Combustion

42. Cross-Sectional View of the Compact, Integrated Heater Design for an Advanced Engine - Schematic

43. Cross-Sectional View of the Double-Acting Narrow $V$ stirling Engine

44. Configuration Layout of the $373 \mathrm{~kW}$ (500 hp) Double-Acting, Narrow $V$ Stirling Engine (4. Cylinders)

45. $\quad 373 \mathrm{~kW}(500 \mathrm{hp})$ Stirling Cycle Engine with Clean Fuel Combustion System

46 . $2237 \mathrm{~kW}$ ( $3000 \mathrm{hp})$ Stirling Cycle Engine with a Two-Stage Atmospheric Fluidized Bed Combustion System and a Gas Circulation Loop

47. Process Flow Diagram of the Atmospheric Fluidized. Bed Combustion System Coupled to the Stirling Cycle Engine 


\begin{tabular}{|c|c|c|}
\hline ES-1 & $\begin{array}{l}\text { Governing Factors Influencing stirling } \\
\text { Engine Thermodynamic Performance }\end{array}$ & $\mathbf{x}$ \\
\hline ES-2 & $\begin{array}{l}\text { Comparison of Predicted Performance with } \\
\text { Actual Performance }\end{array}$ & $\mathbf{x} \dot{i}$ \\
\hline ES-3 & $\begin{array}{l}\text { Summary of Production Cost Estimates for } \\
\text { the Proposed Stirling Cycle Engine Systems }\end{array}$ & \\
\hline 1 & Comparison of Prime Mover Options (I) & 14 \\
\hline 2. & $\begin{array}{l}\text { Design Specifications for the stirling } \\
\text { Engine for Stationary Power Generation }\end{array}$ & 15 \\
\hline 3. & Comparison of Engine Design Concepts & 47 \\
\hline 4. & $\begin{array}{l}\text { Governing Factors Influencing stirling } \\
\text { Engine Thermodynamic Performance }\end{array}$ & 50 \\
\hline 5. & $\begin{array}{l}\text { Summary of the Performance Analysis for } \\
\text { Viking-1 vs. 4-D2 per Cylinder }\end{array}$ & 57 \\
\hline 6 . & $\begin{array}{l}\text { Comparison of Predicted Performance with } \\
\text { Actual Performance }\end{array}$ & 70 \\
\hline$\therefore$ & $\begin{array}{l}\text { Typical FMA Experience in Conventional } \\
\text { Fuel Combustion }\end{array}$ & 96 \\
\hline 8. & Clean Combustion System Design Goals & 97 \\
\hline 9 . & Burner Specifirations & 97 \\
\hline 10. & $\begin{array}{l}\text { Calculated Combustion system Temperatures. } \\
\text { for No. } 2 \text { Fuel Oil }\end{array}$ & 103 \\
\hline 11. & Combustor Safety Controls & 109 \\
\hline 12. & Direct-Fired Heater Head Specifications & 133 \\
\hline 13. & $\begin{array}{l}\text { Stirling Engine System Predicted Design } \\
\text { Point Efficiency. }\end{array}$ & 172 \\
\hline 14. & $\begin{array}{l}\text { Estimated Weight of a Four Gylinder } \\
373 \mathrm{~kW}(500 \mathrm{hp}) \text { stirling Engine Module }\end{array}$ & $1: 80$ \\
\hline
\end{tabular}


Table No.

Page No.

!

15. Comparison of Weight to Power Capacity

Ratios for Stirling Cycle Engines

181

16.

Detailed Production Cost Estimates for the

Manufacture of the Double-Acting $\mathrm{V}$

Configuration $373 \mathrm{~kW}(500 \mathrm{hp})$ Stirling

Cycle Engine for Quantity of 1000 Units/Year 182

17. Summary of Production Cost Estimates for

the Manufacture of the Double-Acting $V$

Configuration Stirling Cycle $373 \mathrm{kw}$

(500 hp) Engine

18. Estimated Manufacturing and operating

Costs for a (Demonstration) First Two-stage Atmospheric Fluidized Bed Combustion

System (56)

19. Estimated Production and Operating Costs

for Developed Two-stage Atmospheric

Fluidized Bed Combustion System

20.

Summary of Production Cost Estimates for

the Proposed Stirling Cycle Engine Systems 


\section{INTRODUCTION}

With the rising costs of energy and the expected depletion of the conventional fuels of oil and gas, the U.S. Department of Energy. (DOE) has expressed concern for the lack in the commercial marketplace of a multifuel engine for stationary power generation. In response to the potential long-term energy dependence on imported oil and gas; DOE has initiated the development of a multifuel (including solid coal) stirling cycle engine for stationary power generation applications in the residential and commercial energy market segments. The present report presents the analysis and results of a conceptual design study undertaken by the development team consisting of Foster-Miller Associates, Inc. (FMA), Teledyne Continental Motors (TCM), SUNPOWER, Inc., and Stirling. engine consultants.

\section{I Market Assessment}

A market assessment of a stirling engine for total and integrated energy systems was performed by Argonne National Laboratory (ANL) (I). The market assessment revealed that there was a need for a stationary power engine in total energy and cogeneration systems. The engine must offer both high thermal efficiency and fuel flexibility, particularly the use of coal and coal-derived fuels. A summary of the results of that assessment which include present and future markets for stationary power generation is presented in this section. Also; the three viable prime mover options, Stirling, Diesel, and Brayton are examined and the final design specifications are presented.

\subsubsection{Present and Future Markets}

Prior to examining the engine options, it is worthwhile to examine both the present and future markets for integrated energy 
systems. The characteristics of the present market for stationary. engines in the 500 to $4000 \mathrm{~kW}$ range for total energy systems are the following:

- As of 1974 there were only 232 installations in the United States

- Diesels comprised 85.percent, gas turbines comprised 13 percent, and steam turbines comprised 2 percent of the present market

- There are only two market segments, industrial and residential/commercial; the latter segment dominates

- Most of the total energy systems have capacities less than $10,000 \mathrm{kw}$.

The future market is expected to be different from the present market. Six energy market segments for total energy systems or integrated energy systems have been identified and are summarized as follows:

Market Segment

Capacity Range

Total energy systems

0.1 to $60 \mathrm{MW}$

- Selective energy systems

0.1 to $60 \mathrm{MW}$

- Grid-connected systems

6 to $200 \mathrm{MW}$

Coal using systems

6 to $20.0 \mathrm{MW}$

District Heating and Cooling Systems

20 to $100 \mathrm{MW}$

Thermal Transport Systems

20 to $1000 \mathrm{kw}$ 
From the results of the market assessment it is anticipated that the typical integrated energy'system will have an average size of $25 \mathrm{MW}$ and there will be a cumulative number of 12,000 systems by the year 2000 .

\subsubsection{Prime Mover Options}

From the results of the market assessment it was discovered that there is a need for a prime mover for stationary power generation applications. Three prime mover candidates were examined: Stirling, diesel, and gas turbine. The results of the comparison are shown in Table 1. For the near term the Stirling is competitive with the diesel and gas turbine. However, with respect to fuel flexibility, coal fuel, and life cycle costs, the Stirling is superior to the diesel and gas turbine. For these three important reasons the stirling was selected as the candidate prime mover.

The primary advantages of a Stirling engine may be summarized:

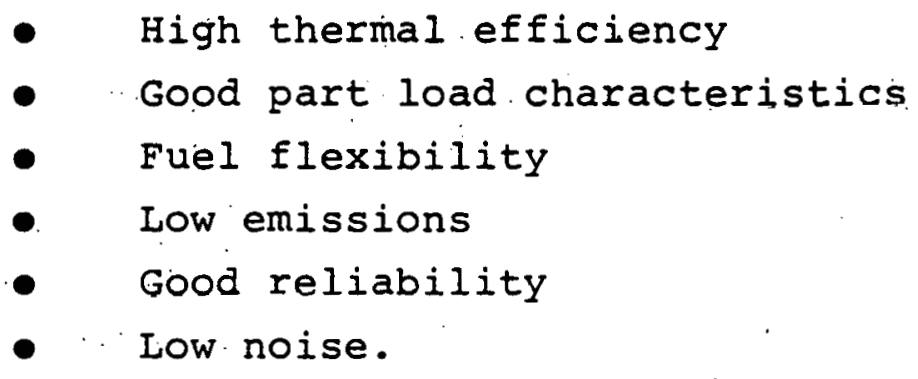

\subsubsection{Design Specifications}

From the results of the market assessment and prime mover options comparison, the design specifications were established. A summary of the design specifications for the stirling engine for stationary power generation is presented in Table 2. The 
Table 1. Comparison of Prime Mover Options (1)

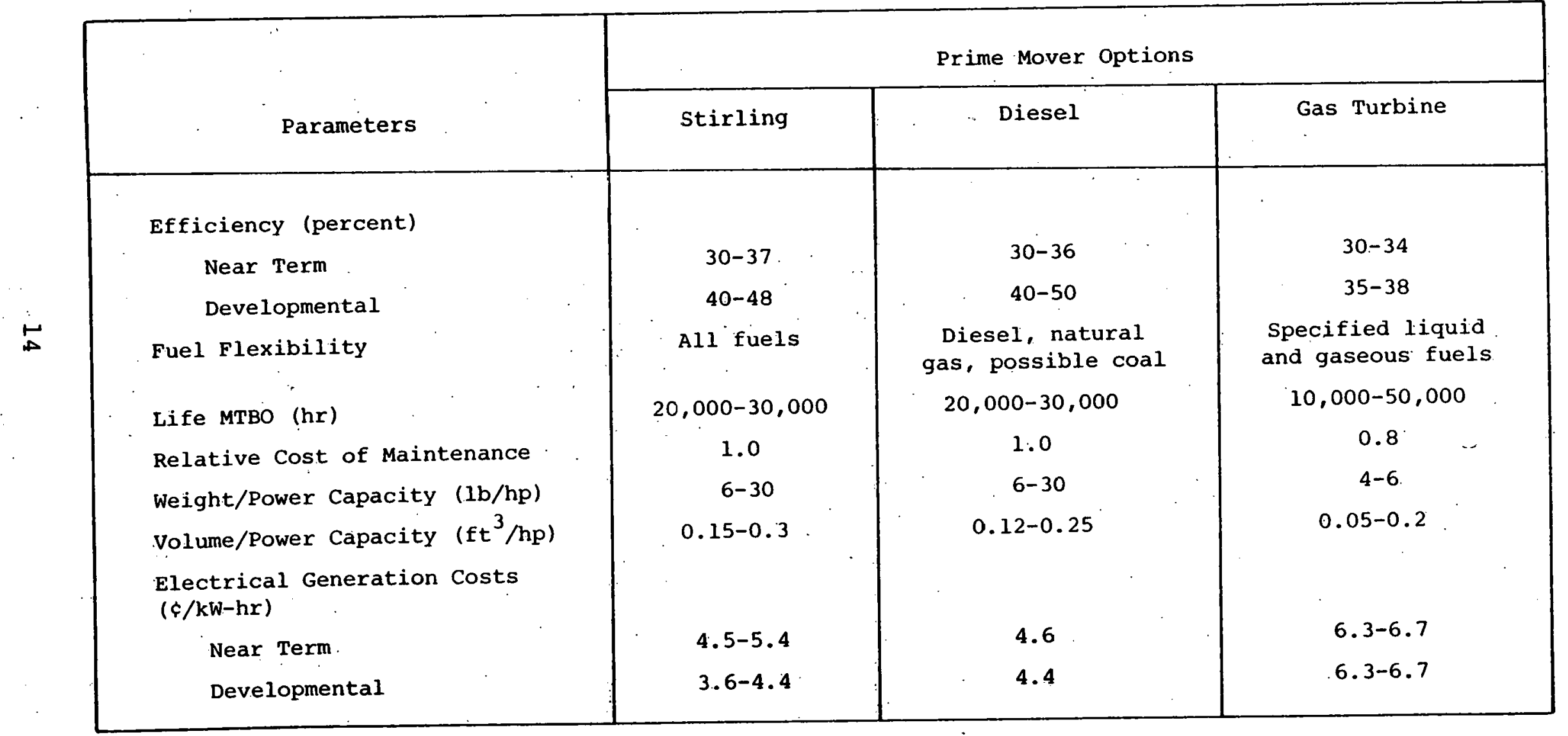


Table 2. Design Specifications for the Stirling Engine for Stationary Power Generation

\begin{tabular}{|c|c|}
\hline & Design Specifications \\
\hline$\bullet$ & $\begin{array}{l}\text { Power Range of } 373 \text { to } 2237 \mathrm{~kW}(500 \text { to } 3000 \mathrm{hp}) \\
\text { Engine design speed compatible with a } 60 \mathrm{~Hz} \\
\text { electric generator }\end{array}$ \\
\hline$\bullet$ & $\begin{array}{l}\text { Shaft power output efficiency of } 40 \text { percent or } \\
\text { greater (excluding combustion efficiency) }\end{array}$ \\
\hline$\bullet$ & $\begin{array}{l}\text { Fuel flexibility - use of low cost fuels such } \\
\text { as coal and coal-derived liquids }\end{array}$ \\
\hline$\bullet$ & $\begin{array}{l}\text { Costs less than } 150 \text { percent of a comparable } \\
\text { diesel engine and } 180 \text { percent of a solid fuel. } \\
\text { engine }\end{array}$ \\
\hline$\bullet$ & MTBO of $10,000 \mathrm{hr}$ or greater \\
\hline
\end{tabular}

power range is between 500 to $3000 \mathrm{hp}$. The engine efficiency (excluding combustion system efficiency) is to be 40 percent or greater. The engine design should be compatible for both coal combustion and conventional fuels combustion.

\subsection{Development Program Description}

It is planned that the large stationary Stirling engine development program will consist of five phases as follows:

Phase I - Conceptual Design
Phase II - Preliminary Design
Phase III - Final Design
Phase IV - Fabrication
Phase V - Testing and Demonstration.

The present report addresses the first phase, conceptual design; the remaining phases are described in detail in. Volume II. 
The objective of. Phase I was to provide conceptual designs and associated manufacturing assessment production cost estimates of stirling cycle engine systems for stationary power applications in the $373(500)$ to $2237 \mathrm{~kW} "(3000 \mathrm{hp})$ range. Phase I was divided into two major tasks:

Task 1 - Conceptual designs of large Stirling cycle stationary engines

Task 2 - Program plan for implementing Phases II through V.

The Task 1 effort was divided into two major subtasks:

- Subtask IA - State-of-the-art conceptual designs of large Stirling cycle stationary engines

- Subtask 1B - Advanced conceptual designs of large Stirling cycle stationary engines.

Subtask $1 \mathrm{~A}$ culminated in the generation of state-of-the-art conceptual designs having the greatest potential for prototype testing and demonstration by 1985 and subtask $1 B$ resulted in the preparation of advanced conceptual designs which require significant research and development prior to commercialization.

\subsection{Team Description and Qualifications}

FMA has assembled a team of engine companies and consultants to accomplish successfully, the first phase of the aforementioned program. As shown in Figure 1, FMA was responsible for program management, mechanical design, thermodynamic analysis, and the coordination of the subcontractor's efforts. TCM, a diesel engine manufacturer, was responsible for the manufacturing assessment and production cost assessment of the Stirling engine conceptual 


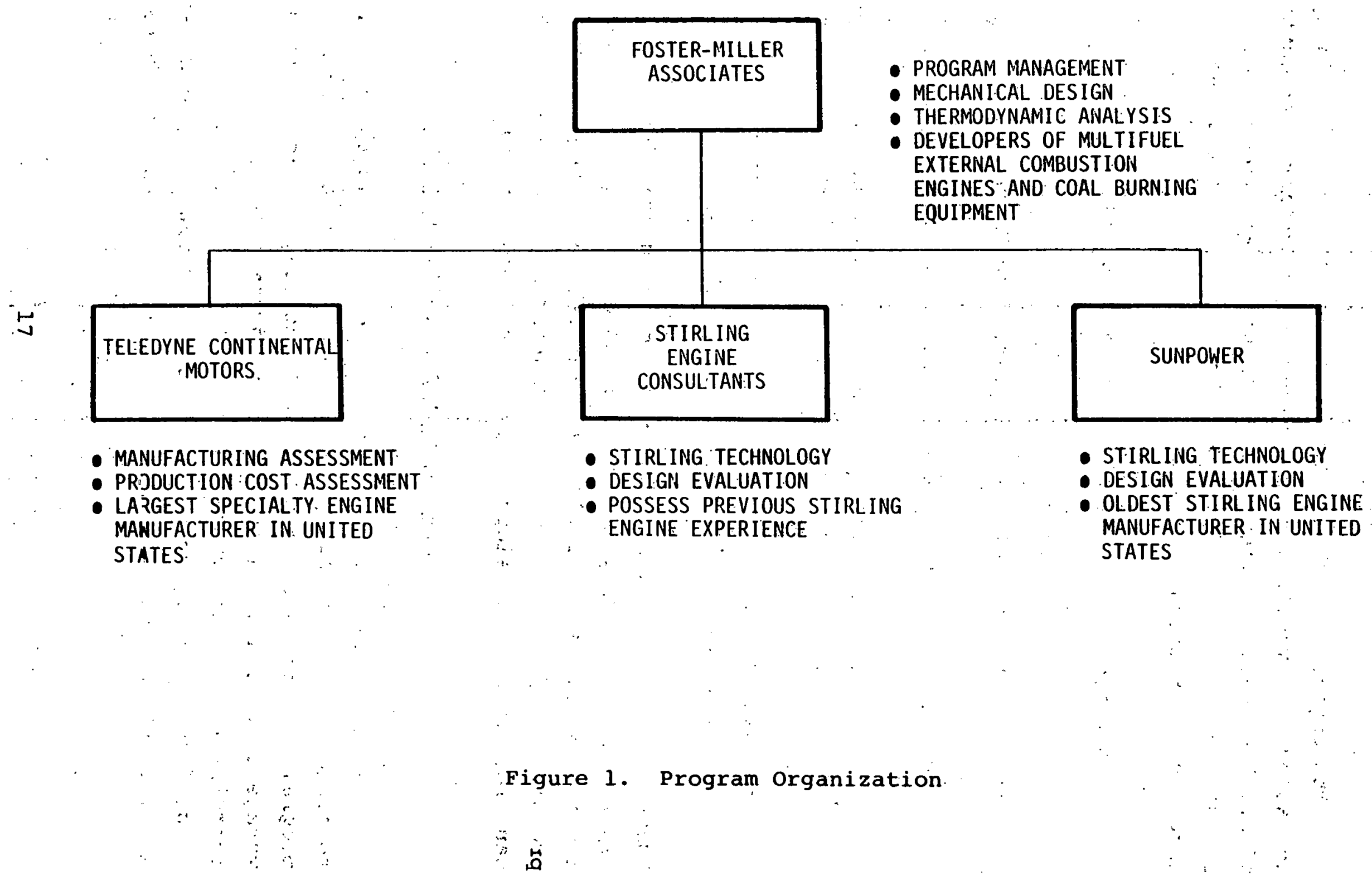


desigris. The Stirling engine consultants, who are Mr. Stig Carlquist, former managing director of United Stirling of Sweden, and Professor Joseph L. Smith, Jr. of the Massachusetts Institute of Technology, were responsible for providing previous stirling engine technology and design evaluation. Also participating in the program is SUNPOWER., Inc. which is presided over by Mr. William Beale, developer of the free piston stirling engine. SUNPOWER is also responsible for providing previous stirling engine technology and design evaluation. Part of the design evaluation was the prediction of the engine performance with the suNPOWER third order computer program. Finally, FMA secured the corisulting services of Thermacore, Inc. which was responsible for evaluating heat pipe concepts for stirling engines.

The FMA/TCM/SUNPOWER/Stirling Engine consultants project team was ideally suited to meet the objectives of the program; that is, the design, development, demonstration, and eventual commercialization of a fuel-flexible stirling cycle stationary engine. FMA brought to the program substantial expertise in combustion technology, heat transport systems, and heat engine development. TCM is a large engine manufacturer and has extensive experience in manufacturing small lots of custom designed engines; in fact, TCM is the largest speciality engine manufacturer in the United States. SUNPOWER is the oldest stirling engine manufacturer in the United States.

\subsection{Contents of Volume 1}

Volume 1 is divided into eight sections. Section 1 (Introduction) includes a summary of the market assessment performed by ANL, a description of the development program team and summary of the Phase I results and conclusions. Section 2 (Design Methodology) presents the design objectives, review of the thermodynamic 
parametric analysis, discussion of the Stirling engine configuration choices, and description of the preliminary engine design candidates.

Section 3 (Engine Thermodynamic Performance Evaluation) presents descriptions of the FMA second order analysis and the SUNPOWER third order analysis, comparison of predicted and actual stirling engines performances, sensitivity analysis, and proposed engine design performance prediction.

Section 4 (Combustion System Analysis and Design) presents the design of a clean multifuel combustion system, discussion of: on-site coal utilization systems, and a preliminary design of a: two-stage atmospheric fluidized bed combustion system. Section 5 (Heater System Analysis and Design) presents a discussion of direct heat transfer methods including a heater head design and a discussion of indirect heat transfer methods including a liquid metal heat pipe design and a gas circulation loop preliminary design.

Section 6 (Recommended Conceptual System Designs) presents a state-of-the-art system design including stirling engine, direct combustion system, and indirect combustion system and an . advanced system design. Section 7 (Manufacturing Assessment/ Production Cost Estimates) includes production costs for the engine, heat transfer systems both direct and indirect, and combustion systems both the clean multifuel combustor and the two-stage atmospheric fluidized bed combustion system. Finally, Section 8 (Summary and Recommendations) presents Phase I conclusions and recommendations for further analysis, design and. development work. 


\section{DESIGN METHODOLOGY}

The design methodology consists of a review of design and performance objectives, compilation of previous engine data, elucidation of parametric or "scaling" relationships, preparation of "decision trees" for configurational choices, preliminary designs, then selection, refinement, and description of recommended conceptual designs. A flow diagram of this synthesis is shown in Figure 2. Note that the process cannot be straightforward, but requires iteration of several steps. In general for this stirling engine application, thermodynamic efficiency, engine configuration, and engine cost are approximately in descending order of importance, and these subjects can be treated sequentially.

\subsection{Review of Objectives}

Program goals for engine performance were specified in Section 1 and are summarized again.

- Power capacity - 373 to $2237 \mathrm{~kW}(500$ to $3000 \mathrm{hp})$.

- Efficiency - Over 40 percent exclusive of combustion system

- Multifuel capabilitý

Cost - Below 180 percent of comparable diesel engine powered with solid fuel.

An overview of alternative engines for this range of stationary power generation indicates that the highest possible thermal efficiency and the ability to burn sulfurous coal or oil are of overriding importance for this stirling engine development... : 


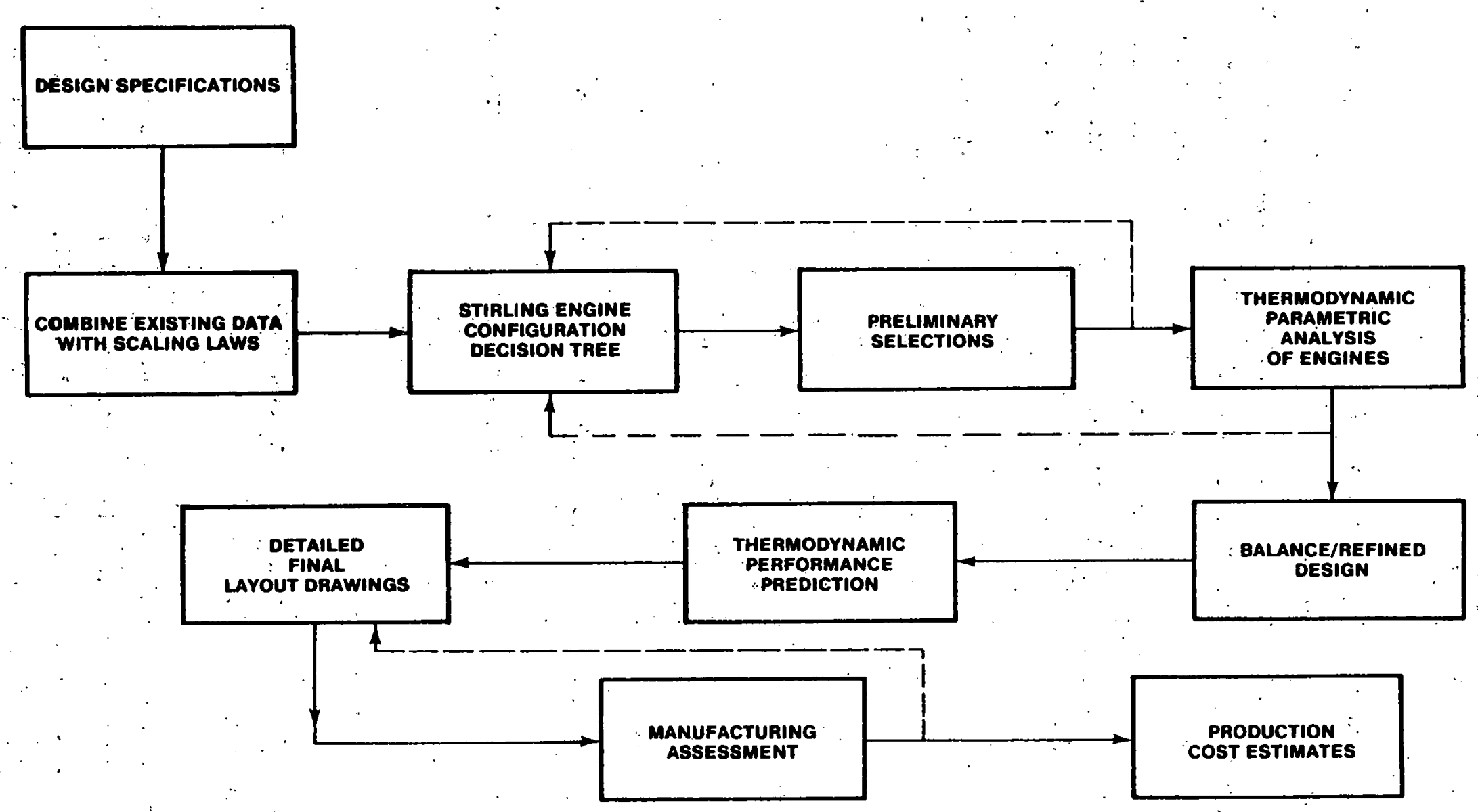

Figure 2. Flow Diagram of the Design Synthesis 
Other engines (Diesel, Rankine, Brayton) have demonstrated either. item, but not both simultaneously. A corollary appears that the total costs of this stirling combustion-heating system must be competitive with the costs of using converted fuels in current or advanced high-efficiency internal combustion engines.

The question then simple becomes what is the best configuration for burning coal acceptably with high efficiency using the stirling cycle. It is not necessary for this power plant to resemble previous stirling engines for smaller sizes or very different applications.

\subsection{Parametric Analysis}

The purpose of parametric analysis is twofold: to provide preliminary conceptual designs of large engines (internal flow spaces) that should have performance similar to existing small engines, and to identify the effect of various parameters on performance. In short, the question is if and why big engines are different from small engines. Previous studies have discussed basic scaling rules, but any limitations and desirable trends were not obvious (2) .

\subsubsection{Internal Thermodynamic Parametric Similarity}

A more fundamental parametric analysis of the Stirling engine can be accomplished by first reviewing the differential equations used to analyze internal performance, and then studying what parametric changes do or do not produce similar results. (Solution of these equations, amounting to "third order analysis," is not necessary for conclusions to be made.) The usual assumptions are that the engine cycle can be described as two nearly adiabatic volumes varying with time, connected by fixed volumes having substantial heat transfer and ali filled with a nearly perfect gas. In addition, the flow is usually assumed to be one-dimensional, 
with position identified only along the flow path, and the fluid dynamics are predicted according to known relationships for heat transfer and friction in nearly steady flow. These assumptions result in cycle performance determined by three flow variables, velocity, temperature, and pressure that are functions of flow position or length, and time; all for geometry prescribed by cylinder volume, and flow area, which are functions of only time or flow position, respectively. (Mathematically, $\mathbf{v}, \mathbf{T}, \mathbf{p}=$ $\left.\phi_{1}, 2,3(x, t) ; V=\phi_{4}(t) ; A_{C}=\phi_{5}(x).\right)$ All the variables may be normalized with respect to some choice of nominal dimensions, for example, swept displacement, maximum flow area (usually the regenerator), rotational speed, and extremes of pressure and temperature.

Analysis indicates that the internal thermodynamic cycles of different engines are the same when the following criteria are met:

1. Similar distributions of flow area versus flow length

2. Same nominal temperature ratio as well as gas composition or gas constants.

3. Same nominal flow velocity; implying that power $\mathbf{P}$, speed. $\omega$, displacement $v$, pressure $p$, and nominal flow cross-sectional area $A_{C}$ are related by $P \sim V \omega p \sim A_{C} P$

4. Fiow length inversely proportional to speed

5. Hydraulic radii $r_{h}$ in the similar heat exchangers simultaneously satisfy conditions for pressure loss and heat transfer; specifically. Nst $\sim r_{h} \omega \sim f$, where $\omega$ is engine speed, $N_{s t}$ is stanton number, and $f$ is friction factor. 
Items 1 through 3 indicate that engines do not have to be geometrically similar in order to have similar performance such as efficiency and specific power as measured by flow area (or Beale number, in effect, where the Beale number is the nondimensional mean effective pressure. Theoretically, then bore and stroke can have any ratio, and any speed can be employed if the stroke is chosen to maintain constant piston speed.

Item 5 can be accomplished to sufficient accuracy with reference to typical dimensionless correlations of friction and heat transfer; for example: friction factor $f$ and stanton number' $\mathrm{N}_{\text {st }}$ versus Reynolds' number $\mathrm{N}_{\mathrm{Re}}$. It appears that both criteria for similar engines can be met simultaneously over the widest range of parameters and flow geometries. This may be explained by the nearly constant ratio of $\mathrm{N}_{s t} / \mathrm{f}$ versus $\mathrm{N}_{\mathrm{Re}}$ and geometry (3). For example, with similar engine designs at various design speeds, in the typical regenerator mesh where flow is at very low $\mathrm{N}_{\mathrm{Re}}$, wire diameter $4 r_{\mathrm{h}}$ should be related to speed $\omega$, as $r_{h} \sim \omega^{-0.7}$; while in the typical tubular heaters and coolers where flow is at very high. $\mathrm{N}_{\mathrm{Re}}$, tube diameter should be related to speed as $r_{h} \sim \omega^{-0.85}$.

In short, it would appear that basically "good" stirling engines can be made any size and speed, but that engines of similar performance need not "look like" each other, proportionately. However, the previous analysis is for internal thermodynamics and ignores major factors such as external heat and fiuid flow, parasitic heat flow, and mechanical factors. These may limit the range of choices for the big stationary stirling engine:

\subsubsection{External Constraining Factors}

External heat transfer must be arranged in crossflow with the internal stirling cycle (necessarily in the ducting and usually most conveniently in the heat exchanger core). This. 
makes external flow area $A_{C}^{\prime}$ vary in relation to the design parameters, speed $\omega$, and pressure $p$; for similar engines of equal power, $A_{c}^{\prime} \sim \omega^{-1} p^{-1 / 2}$. This implies that as more power is desired from bigger single cylinders it becomes more difficult to arrange for adequate or efficient heat transfer to and from the heaters and coolers, respectively, unless speed or pressure is reduced. Of course this reduces the specific volumetric power of the engine. If the type of heat exchange is changed, this difficulty may be avoided. The heater is typically more critical than the cooler.

Parasitic heat flow losses in similar engine designs are not a strong. function of engine size. In fact, theory shows that the fractional power and efficiency losses due to direct conductive heat flow in similar engines are solely in proportion to. speed if the sectional areas of the conductive paths are sized for constant stress. Higher power per. cylinder usually offers less fractional parasitic heat loss, even at the same speed, because of structural refinement and reduced conduction losses that are not dependent on structural strength.

A significant parasitic thermal loss that is not structurally dependent is the cyclical heat transfer (this phenomenon is described in subsection 1.3) in the hot and cold cylinders of var-. iable volumes. Parametric relations that describe this internal surface heat transfer have not been confirmed yet, and in addition it occurs that surface-to-volume, or bore-stroke ratio is independently variable within the scope of basic similarity for Stirling cycles. Preliminary analysis indicates that the effect of cyclic heat transfer will reduce rather gradually as engine size or power density increase.

There are two mechanical factors that may constrain the design of similar stirling engines: dynamic loads and friction. Parametric variation or similitude of dynamic loads and stresses 
in the Stirling engine piston-crank section is the same as for other typical reciprocating machinery, which is well known. There is somewhat more freedom for variation of bore-stroke ratio in the stirling engine because the bore or head does not have to accommodate valved flow and reasonable combustion chamber proportions. Quantitatively, it appears that practical designs of large Stirling engines for the present application will not be limited by dynamic stresses. Likewise it appears from a consideration of the machine elements that the frictional losses in terms of the mechanical efficiency at an optimized design point will not vary with engine size or any other parameter, fundamentally.

Frictional wear may be a constraining factor in the design of big stirling engines, but the parameters are not well-defined, as usual in the realm of wear. The limiting component currently appears to be the piston rings, and perhaps the rod seals. Some experience suggests that the sliding velocity be limited (for example, to $2 \mathrm{~m} / \mathrm{sec}^{-1}$ ) in order to achieve long life. This puts an obvious limit on stroke-speed product and favors high pressure engines having high power per unit volume. However, if piston ring life is developed to be dependent on the pressure-velocity product, which is typical of many other sliding seal applications, then low pressure, high speed engines may be attractive.

\subsubsection{Deviation from Parametric Similarity}

Stirling engine output performance depends on the design of several specific components, so it seems probable that engines having quite dissimilar designs still may be equal in efficiency and power. This occurs for two reasons: a change in one component or parameter can be offset by changes in others, and components that contribute little loss can be modified without affecting overall performance. 
For example, a heater unit may be made bigger to accommodate better external heat transfer while the cooler is reduced in volume without penalty in net performance. Or, if a heat exchanger is approximately adequate, its design can be changed, offering more heat transfer (NTU) and more pressure loss, yielding no significant change in net performance. Also, apparently equivalent engines may be similar with respect to heat exchangers, but dissimilar with respect to speed and volume ratios: an increase in speed and decrease in swept volume can result in little change in efficiency or power in an otherwise specified engine design.

A review of fractional. losses for nearly optimized designs is discussed in section 3, but it is worthwhile to present the conclusions with respect to parametric design scaling.

The largest discrepancy between ideal and actual stirling cycles is due to adiabatic (net) expansion and compression. Consequently, dissimilar engines can approach ideal efficiency limity only if they have low pressure ratio. A corollary of this is that high specific power is not possible in conjunction with present goals of minimum fuel consumption. The second largest deviation from the ideal involves cyclic heat transfer. This also favors low pressure ratio for high efficiency. The third largest debit usually is due to pressure loss and incomplete heat exchange in the regenerator. This implies that engines cannot greatly exceed the power scaling rule based on flow area $\left(P \sim A_{C} P\right.$ ) without suffering in net efficiency.

\subsubsection{Summary of Parametric Analysis}

The parametric analysis offers rules by which large engines can be scaled from small ones. No basic limits in size or deviations in performance appear for such scaled engines. 
Practical difficulties with achieving good external heat transfer and seal life may result from high speed. Otherwise, basic performance is not very dependent on design speed. Many deviations from "exact" scaling rules are possible while projecting design methods for small engines to large engines without much change in basic performance. Maximum fuel efficiency requires low pressure ratio and efficient regeneration, which preclude maximum specific power.

\subsection{System Configuration Choices}

Several references $(\underline{2}, \underline{4}, \underline{5})$ discuss the myriad historical and possible variations in Stirling engines. Possible configurations will be discussed only in relation to particular factors for large, stationary, efficient, multifuel, utility engine systems.

The possible choices for systems can be described generally sequentially in a decision tree having three main branches: the fuel combustion system, the engine, heat transfer arrangement, and the engine machine configuration, as shown in Figure 3. Each of these branches may have more than one desired option to be accommodated in system development, near and far term. The fuel/ combustion branch has the most options and the highest level of unknowns, notably fuel availability and price. Figures 4 and 5 show this branch divided essentially into clean fuels and coal; and it is discussed in section 4. An obvious conclusion is that for the foreseeable future the engine design should accommodate both compact combustion of clean fuel as well as large complex coal combustion methods.

The second main branch of systems' choices involves the transfer of heat from combustion to the Stirling heater external surfaces; using either direct convection from combustion gases 


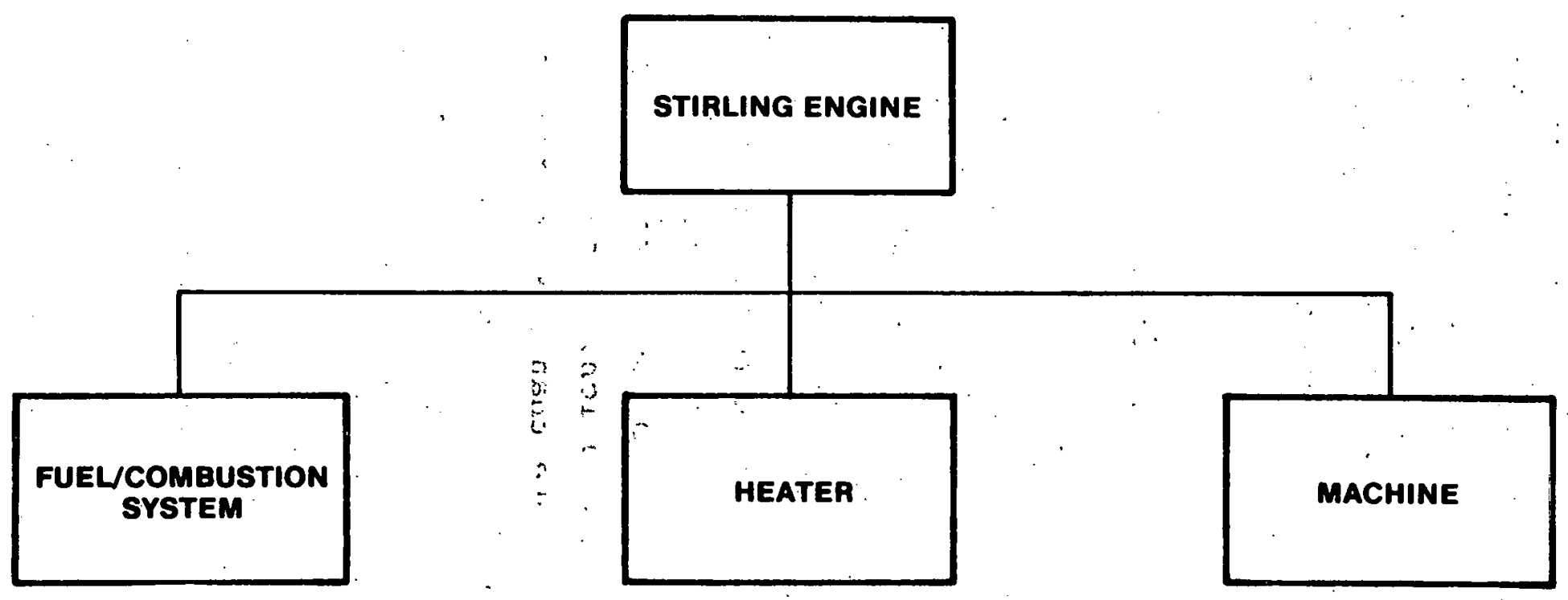

ENGINE DEBIGN MAY BE 8EPARATED INTO THREE 8UBSY8TEMS

Figure 3. Stirling Engine Configuration Decision Tree 


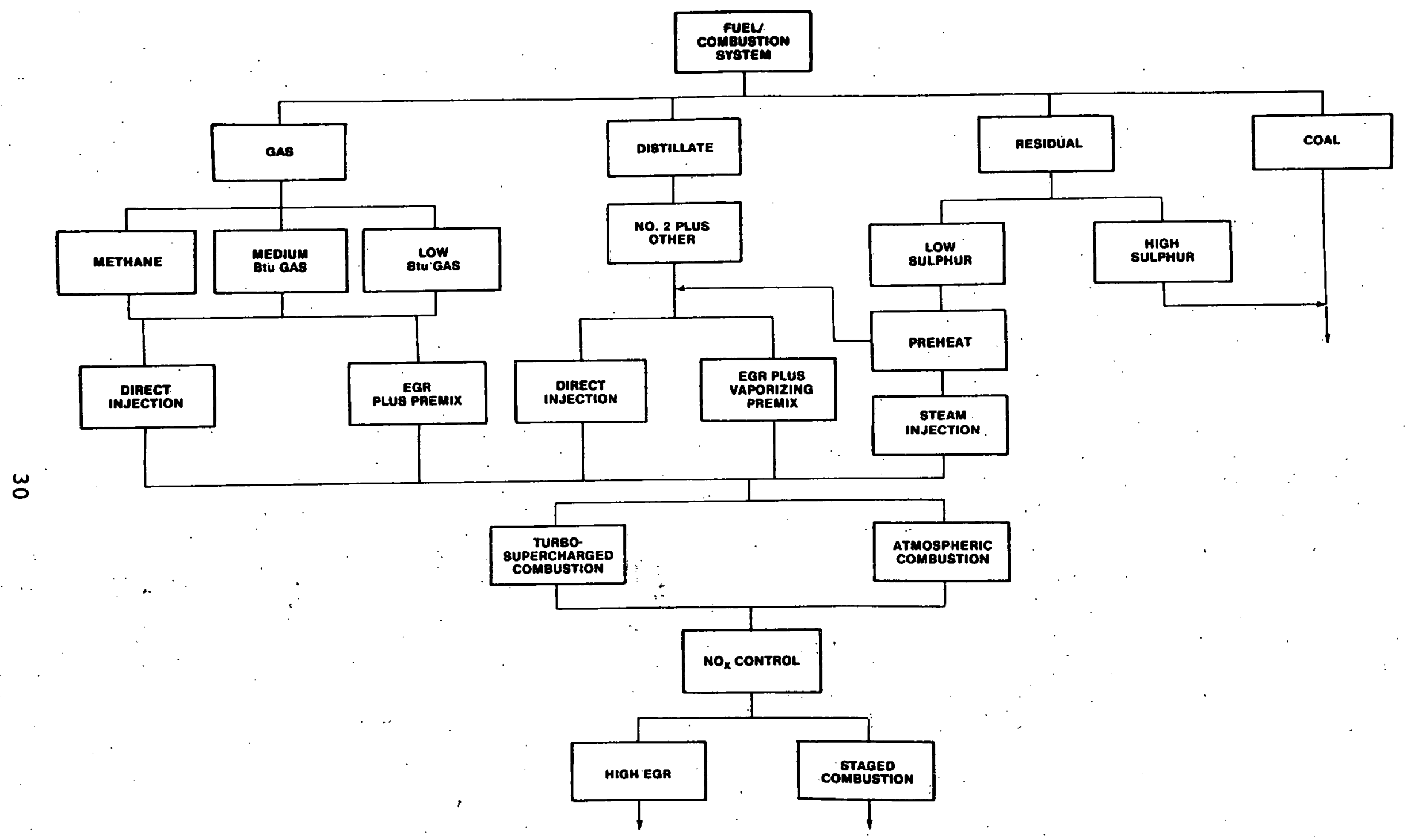

Figure 4. Fuel/Combustion System Configuration Decision Tree 


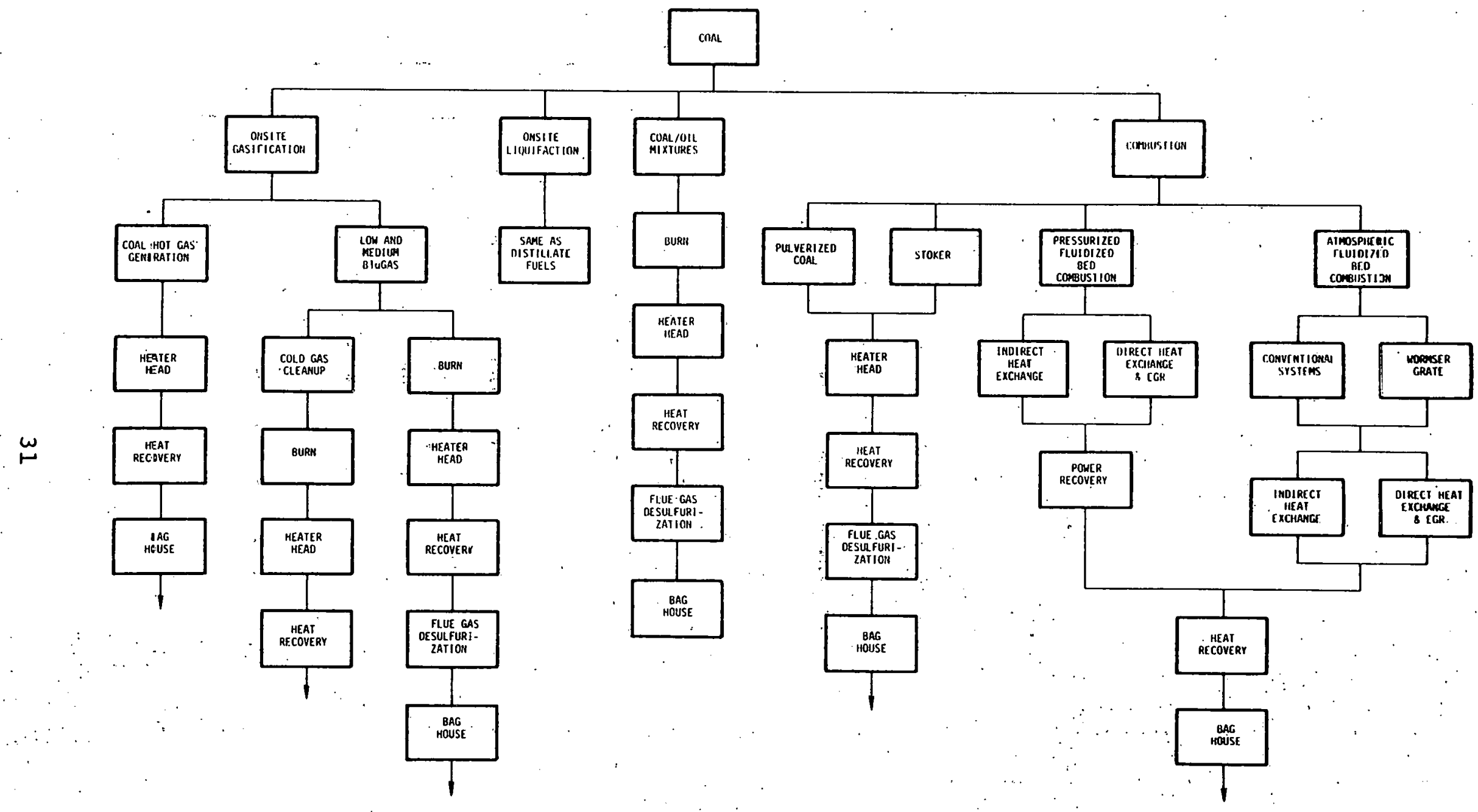

Figure 5. Fuel/Combustion System Configuration Decision Tree: Onsite Coal Utilization 
or indirect heat transfer with an intermediate media. Options are shown in Figure 6 and discussed in Section. 4. Obvious conclusions are that direct heat transfer with clean fuel is the simplest;" and indirect heat transfer is convenient for coal combustion, but there are also possibly attractive systems using the reverse combinations. Again, engine design should accommodate development of both direct and indirect methods:

The third branch of choices includes the vast number of design alternatives for the stirling engine proper. One reasonable delineation of options is shown in Figure 7 . Here the most important choice is in the general arrangement of engine heat exchangers. Many engine mecharical configurations can be adapted to work well with a given heat exchanger design layout. It is usually considered that the heater is the most critical part of the heat exchangers, the regenerator must be highly effective, and the cooler is fairly easy to arrange.

Generally speaking, there are three ways of arranging the heat exchangers, relative to the cylinder-heater-regenerator. flowpath. Most current multicylinder engines have opposite ends of the heater tubes inserted in manifolds that are part of the cylinder and regenerator housings, respectively. Heater tubes for all cylinders are formed in groups for common heat supply. Single cylinder engines are often made with concentric cylinder and regenerator(s) with heater tubes folded (hairpin) to connect the two spaces. Research (and cryogenic) engines have been made in which the heater, regenerator, cooler, and opposite cylinders have been connected along the axis of the flowpath with no apparent manifolding. Critical features of these three arrangements for the present application are discussed in subsection 2.4. The concentric design is chosen on the basis of adaptability to all hëating and engine subsystem approaches without compromising ultimate performance. 


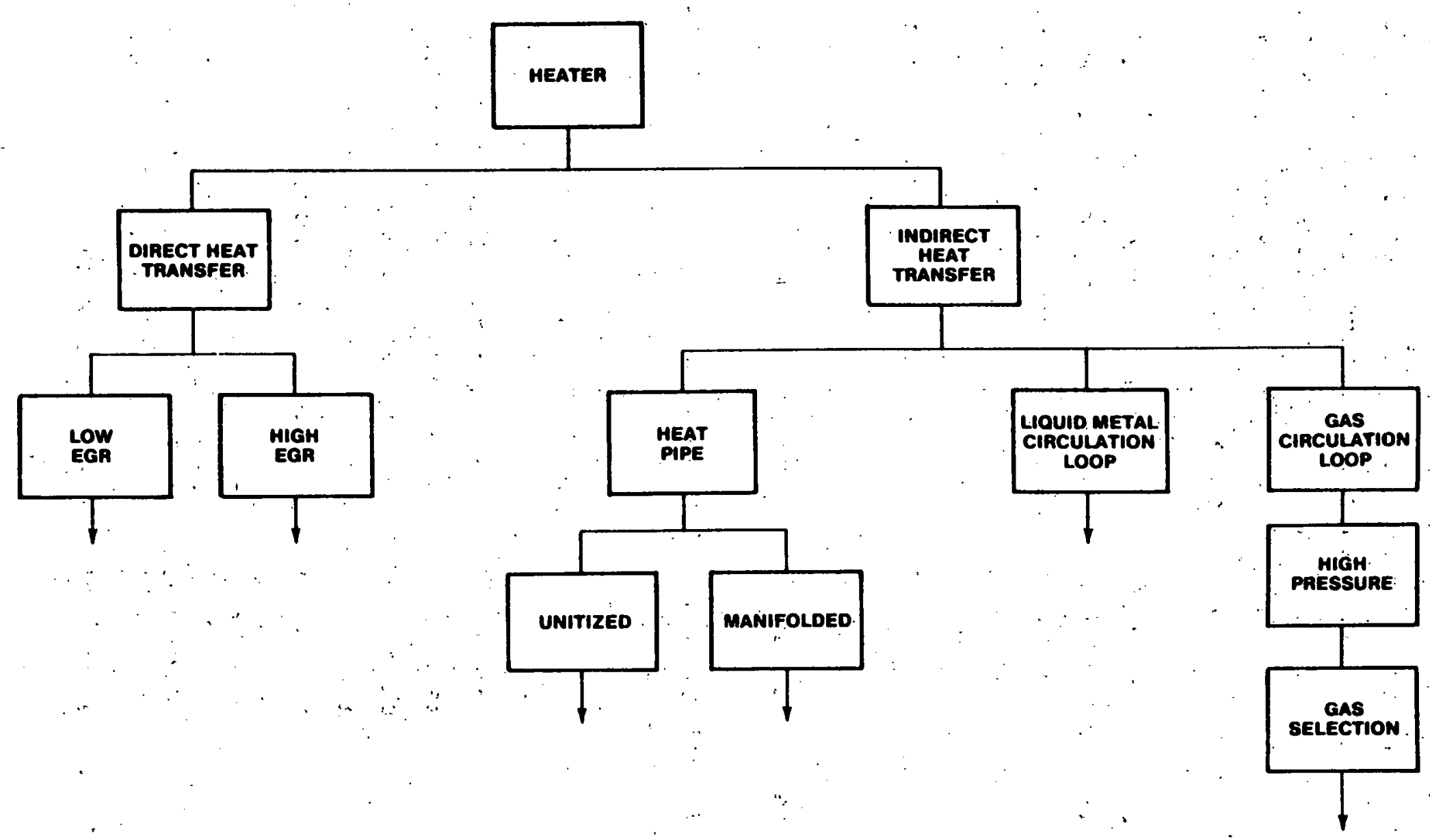

Figure 6. Heater System Configuration Decision Tree 


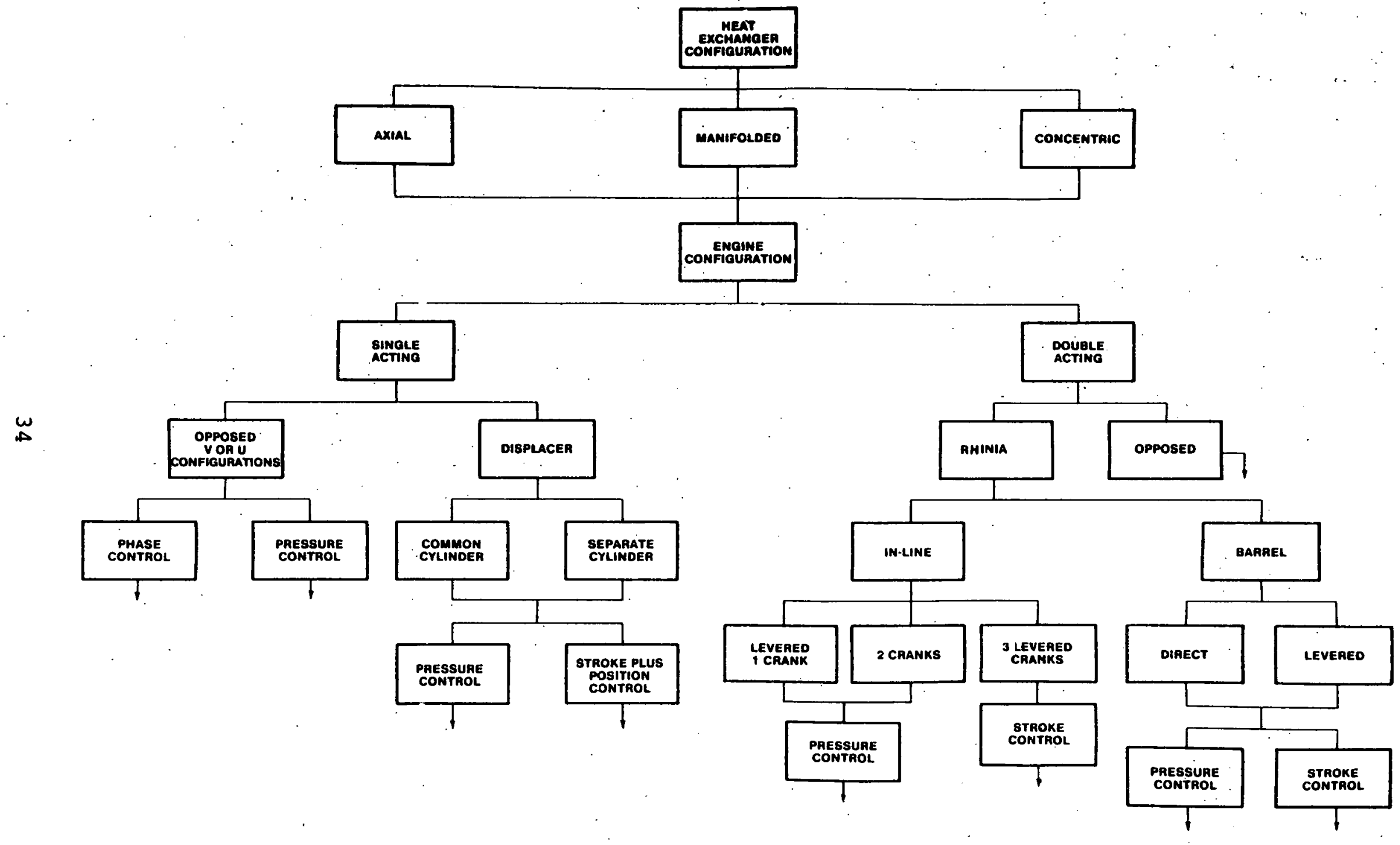

Figure 7. Machine Configuration Decision Tree 
The engine configuration itself (pistons, cranks, seals, etc.) submits to great variety without making very much difference to the ultimate viability of the present application. This is because the several machine layouts can all be designed to offer the same system efficiency and the cost of the machine components will be a small fraction of the entire system. Other factors are not so important, such as size and response that dominate the automotive application. Opposed piston, displacer, and double acting preliminary designs are discussed in subsection 2.4, and novelties that are particularly attractive for the present application are offered, but the conclusion is that there is no reason to extend beyond the simplest Rhinia-crank layout at this time.

\subsection{Preliminary Engine Design Candidates}

Design studies were conducted to evaluate the difference between classifications of engine configuration just introduced. In all, four different heater head designs and five different machine designs were prepared in sufficient detail to select a design recommended for development in the near term. In addition, a low-pressure engine was sized, not prepared in detail, but considered worthy of further study in connection with direct coal combustion. Obviously, features from the various designs can be mixed conceptually to describe other candidate configurations.

\subsubsection{Axial Flow Opposed Piston Design}

An early design attempt included axial-flow heat exchangers and opposed pistons on separate cranks at either end of the exchanger stack. This layout offers the following advantages:

Minimum losses and no manifold volume in the heat exchangers 
- Independent cylinders suitable for any number or size of engine as well. as for power modulation by phase control of the opposed cranks

Resolution of the flow-axial pressure force in opposing "cold" structure with minimal, cylindrical hot cortainment structure.

This heat exchanger layout necessitates a single-acting piston action with one hot-end piston, one cold-end piston, and mean gas pressure on the rod side of both.

Note here that a single-acting engine is not simply twice as complex as a double-acting or Rhinia design. A (373 kW or $500 \mathrm{hp}$ ) minimum sized engine having four pistons and crank throws can be nearly the same mechanically. whether there are two or four distinct gas spaces. The former single-acting design has larger displacement but less pressure differential load on each rod. It also has larger but half the number of heat exchange units. Therein lies the difficulty.

Heat supply (almost $400 \mathrm{~kW}$ ) to each gas space in the axial flow layout appears impractical with typical combustion/convecticn across tubes. This layout could be quite attractive using compact indirect heat transfer such as "heat pipes" into the engine, but this involves development risk unless the opposed-piston axial flow layout can be designed initially to use direct heating. Consequently, the axial design was modified to include heater tube "stalks" extending laterally from the engine central plane." With this extended surface and manifolding, direct combustion could be arranged on both sides of a vertical engine. However, the manifolded heater obviates most of the reasons for an opposedpiston layout having distant, inconvenient cranks. 


\subsubsection{Manifolded Single-Acting U-Design}

A single-acting design having parallel, adjacent cranks is mechanically convenient, including phase control, and with manifolds originating from the hot cylinder and the hot side of the regenerator for each gas volume, it is adaptable for all modes of heat supply. Such an engine design was prepared in some detail and is shown schematically in Figure 8. The primary advantage of the manifolded design is the possibility of separating the hottest section, heater and combustor from the engine, and having internally insulated, cooler cylinder, and regenerator housings. The primary disadvantage is the efficiency penalty associated with pressure loss and cyclic heat transfer in the manifolds. Whether previous manifold designs were poor or the analysis was inaccurate is obscure, but experience indicates that engines having large heater manifolds do not perform well ( $\underline{6})$.

\subsubsection{Concentric Module Design}

The general arrangement having heat exchangers concentric with the hot cylinder and an axisymmetric heater offers good flow distribution and minimum manifold or dead space, similar to that with an axial flow heat exchanger layout. Heater internal flow is folded in the fashion of multiple hairpins, with both ends of each hairpin attached near the same place on the common pressure dome for the cylinder and regenerator. This configuration forms a module that can be applied in several engine machine designs of single-acting, displacer, or double-acting type depending only on the cold-end duct or flow connections.

The significant advantages of the concentric module design are:

- Efficient internal and external flow distribution

- Simplicity of construction of the hot end 


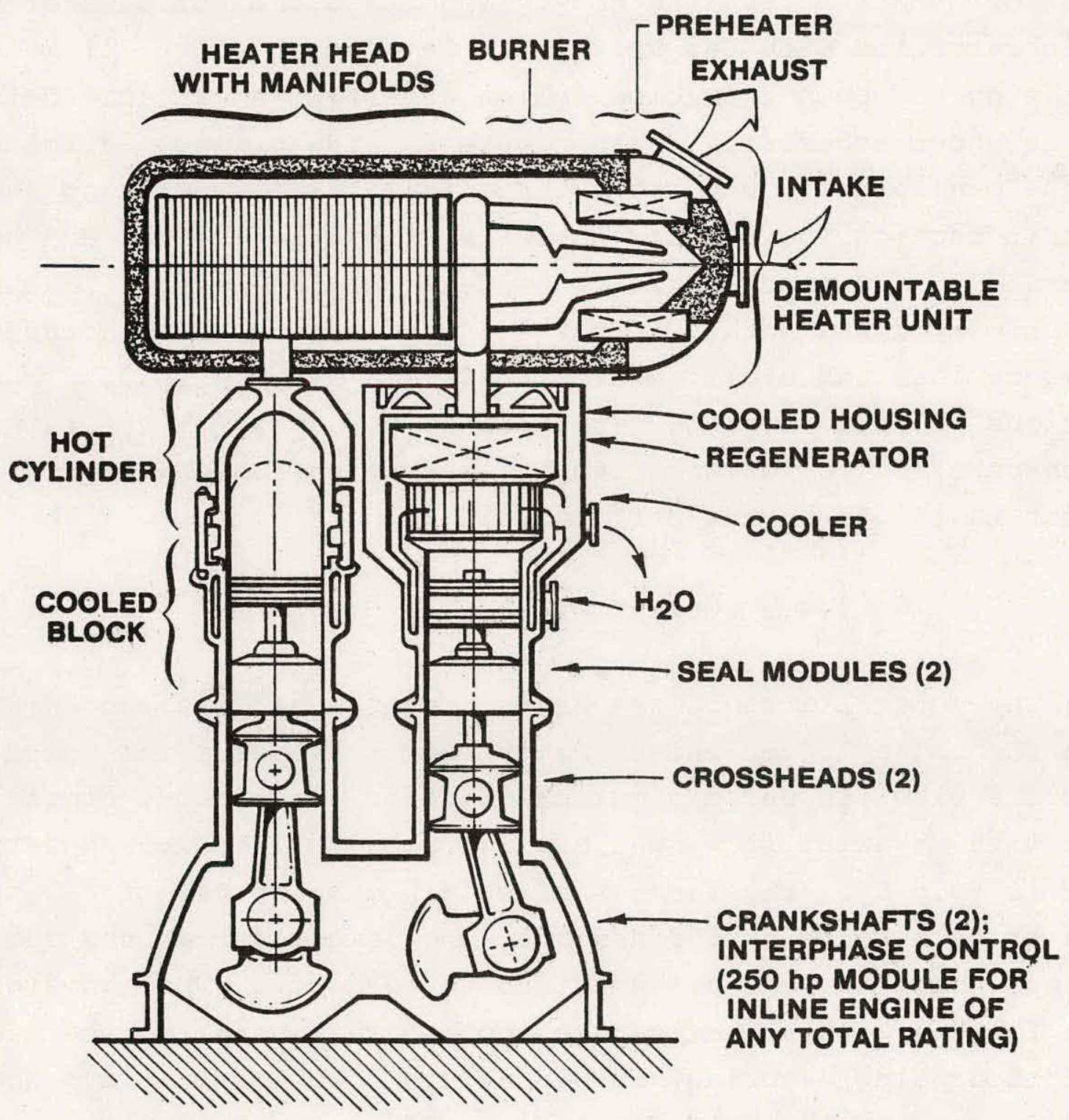

Figure 8. Single-Acting Manifolded Engine 
- Adaptability to direct or indirect heat exchange with various designs of heater element using wrought or cast alloys

- Modular assembly and maintenance

- Adaptability to various "lower end" designs.

The single disadvantage of the concentric design is the large diameter and bulk of the monolithic hot head.

\subsubsection{Alternate Machines with Modular Head Design}

It appears that the modular heat exchanger/cylinder head design can be used with a variety of machine lower ends, for both double-acting and displacer piston concepts. (It offers no advantage for single-acting machines.) The primary functional distinction between the designs contemplated is the method of power control each affords.

Displacer engines are of two types: displacer and piston in the same cylinder versus a separate cylinder for each. The separate cylinder type engines were designed and partially developed previously (2), but they were not pursued due to their low specific power that is partly due to the extra dead volume of this type. On the other hand, rod seals are accessible and phase control of the displacer is convenient because of its low load.

Some novel features might make this type worthy of development. For example, the displacer might be free (that is, bouncing on gas) and stroke controlled to oscillate and drift near to the hot end at part load, which would improve part load efficiency compared to phase control. The power and efficiency loss due to cxtra dead volume miylıl be cuuntered by the use of extended surface "isothermalizer" area in the cool compression space. 
Engines having the same cylinder for piston and displacer have reached a high state of development using the rhombic drive. This drive is complex, difficult to manufacture, does not afford phase or stroke control, and is difficult for rod seal arrangement. Another mechanical approach is shown schematically in Figure 9: a narrow V-engine using a single crank for the power pistons and separate linkage driving the displacers with rods parallel to, not concentric with the piston rods. The linkage shown offers no kinematic control of power, but since the loads are low there are many other possibilities for stroke and phase control using linkages similar to those that have long since been developed for cutoff control of steam engines.

A significant fact in favor of displacer engines for stationary application is that to date the greatest life achieved for ring seals has been with this type (for example, 4,000 hr for double-acting versus over $10,000 \mathrm{hr}$ for displacer). The reasons for greater life are not proven, but it is apparent that the displacer rings have practically no load, and the matching piston rings never contact hot gas, nor have a conductive path to hot metal.

Most of the multicylinder engines contemplated today are of the double-acting type because of its good power density and simplicity of parts inventory. For the present application, multiples of four or five cylinders are convenient to cover the nominal power range. Appropriate interconnecting ducts for cylinders can be easily provided in $\mathrm{V}, \mathrm{U}$, or barrel engine configurations. Obviously, a v-type design can be similar to the previous schematic in Figure 9, just leaving out the displacer mechanism and using double-acting pistons.

It appears that such an engine should have ring life equivalent to the displacer type if the piston is extended, an upper buffer ring is added that sees only the small heat exchanger 


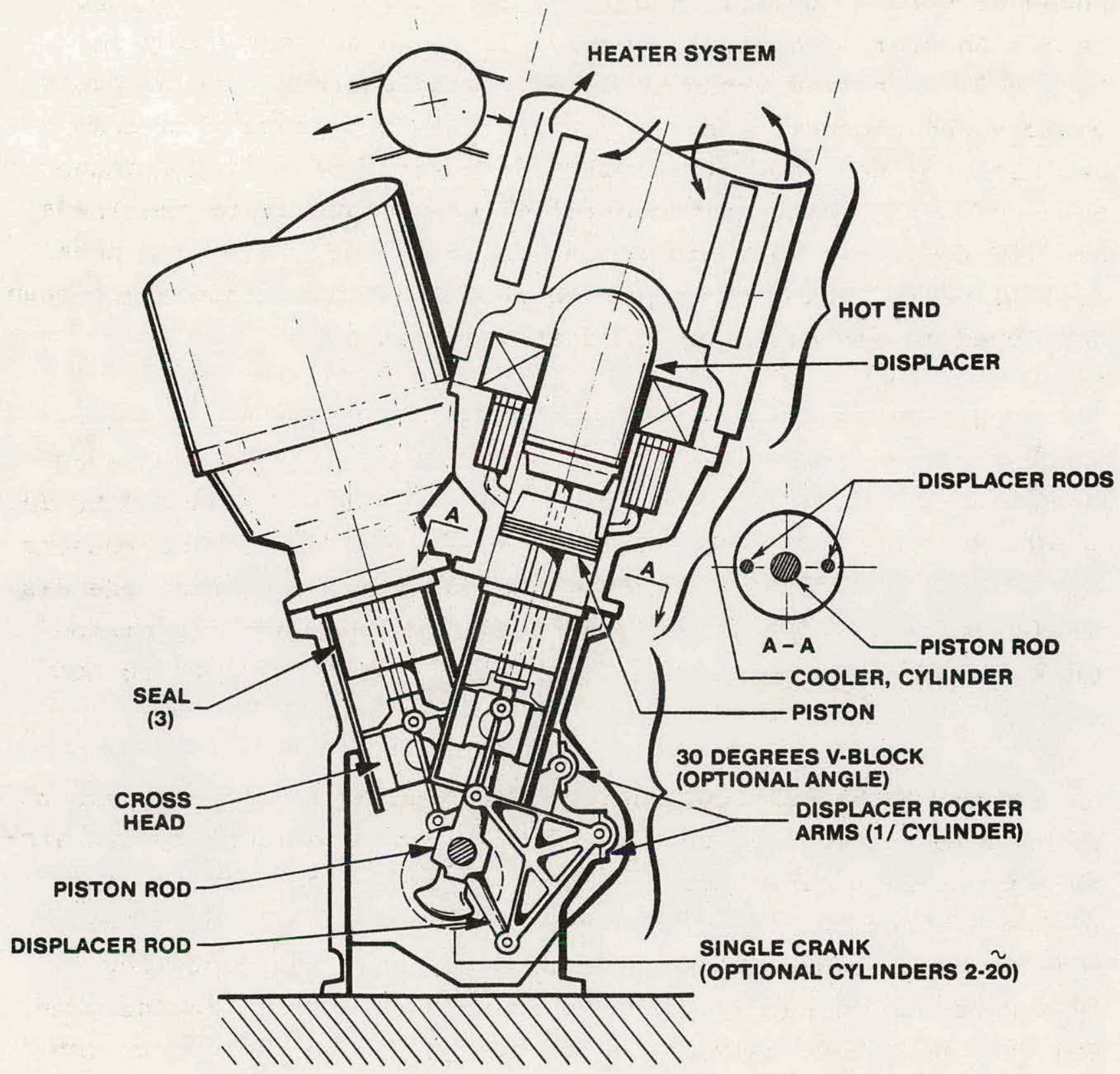

Figure 9. Single-Acting Displacer V-Engine With Pressure Control 
pressure differential, and cool gas is bled into the annular space between the buffer ring and the usual piston rings. The cylinder would have more length than in the usual double-acting engine, but less than with displacers.

Figure 10 shows schematically an engine having parallel closely spaced cylinders, or a so-called U-engine. Most U-engines have two cranks; this design is conceived to have either one crank or three, for the following reasons. As discussed in the parametric analysis, the desires for high power per cylinder, relatively high output speed, and low piston ring velocity all together press for large bore-stroke ratios. Large bore-stroke naturally results in rod-crank mechanisms that are relatively "beefy"; that is, the crossheads, rods, crank sections, and bearings are large compared to those of a typical diesel of similar stroke or power output. Lighter rods and cranks can be used with the mechanical advantage of rocker arms laterally connected to the piston crossheads of a U-engine. With a single crank, the outboard ends of the rocker arms are hung on simple swing links. This linkage can be directly modified to employ outboard cranksets instead of the swing links. In the three-crank configuration the outboard cranks have a stroke that is half or less that of the central crank, by which they are driven through phase control mechanisms such as torque control motors or differential splines. Thus, while the outboard, phased cranks carry a minor fraction of the total power, their phase shift results in stroke control of the pistons and Stirling cycle. (Variations of the twin crank stroke control mechanism are known from the art of steam engine valve gear.) In addition to the advantage of having one basic crank block either with or without stroke control, the layout offers several features:

Long crossheads provide excellent guidance of the piston rod, enhancing seal life 

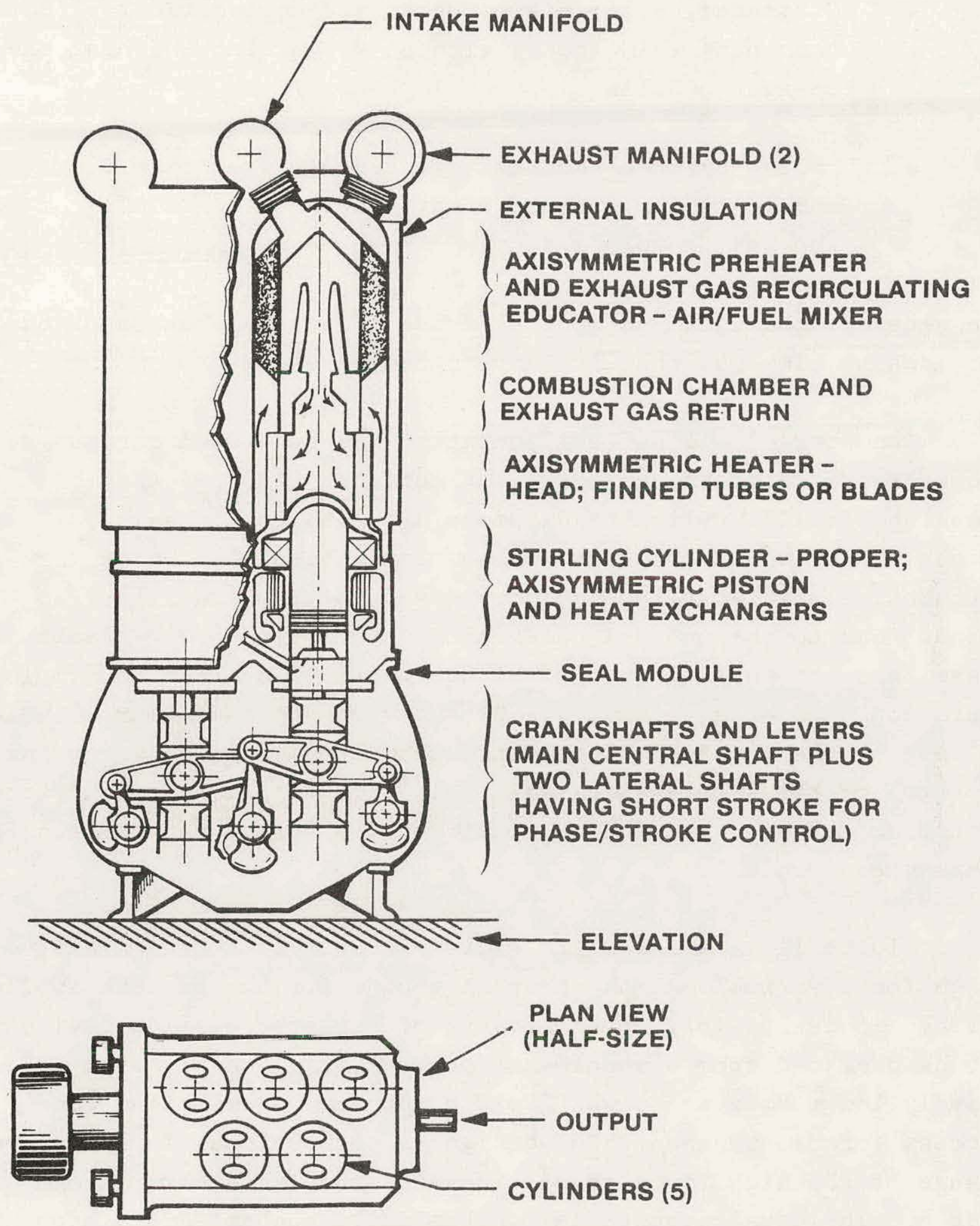

ACCESSORIES AND PHASE/STROKE GEAR

F'igure 10. Double-Acting Rhinia In-Line Engine 
- Crosshead, seal, piston units are accessible for "downthen-out" maintenance without disturbing the heat exchanger modules

- Engine cylinder modules are close-packed on a flat bed plate for ease of manufacturing and assembly of the heat supply system.

In general, the rocker-arm crank drive is unusual but requires no machine elements that are not in common use.

The "barrel engine" configuration has been used for pumps, compressors, diesels, and Stirling engines. (Barrel engine meaning parallel cylinders disposed around a common axis.) Swash plates and $z$-crank or wobble plates have been built for automotive size stirling engines. Swash plates are a poor approach due to the unusual pad-bearing requirements. z-cranks have been proven in prototype aircraft diesel engines and employ more common bearing elements. By superposing an eccentric angle sleeve on the z-crank, piston stroke control is affected by phase control of the sleeve-crank set. Either a direct hydraulic torque motor or transfer gearing to a differential drive can be used for this phase control.

Figure 11 is a schematic representation of a preliminary design for a variable stroke $\mathrm{z}$-crank engine for the present application. It is possibly novel because of transfer gearing devised to be operated from a stationary phase-control motor, with relatively low torque and power flow through the gearing and good access for maintenance. The design is proportionately heavy because of the high force requirements of the large bore-stroke ratio. The usual advantages of this drive mechanism are high mechanical efficiency, compactness, and inherent dynamic balance with variable stroke. In addition the configuration offers axisymmetric grouping of combustors for convenient exhaust gas recirculation and air preheating. In general it appears to be an 


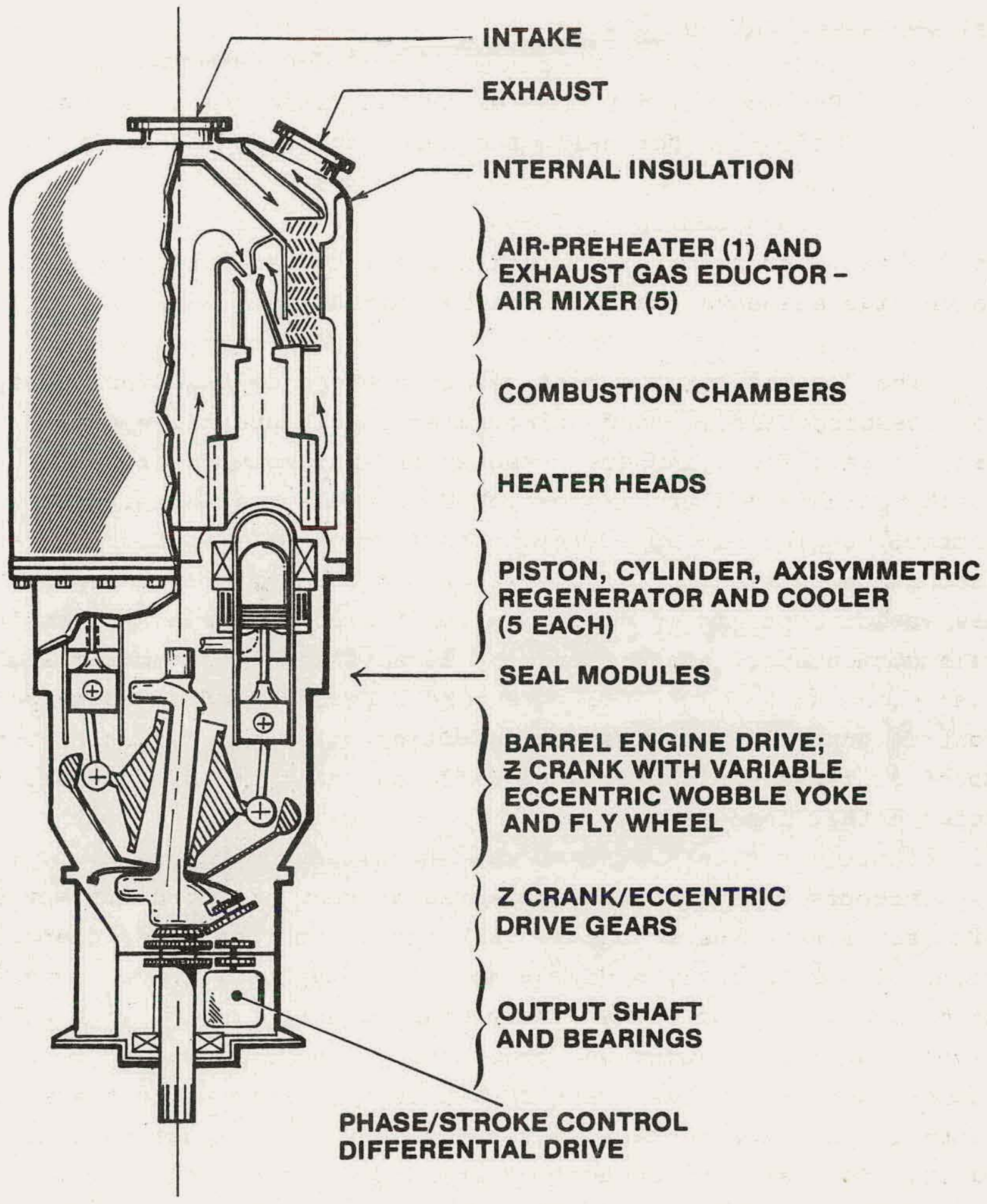

Flgure 11. Double-Acting Rhinia Barrel Engine With Variable Stroke Control 
excellent package engine, but is is not easily stretched for various power ratings and it is not in line (sic) with present diesel-generator machine practice.

\subsubsection{Engine Design Selection}

The various preliminary designs studied for the Stirling cycle engine proper are all suitable for use in the present range of stationary applications, 373 (500) to $2237 \mathrm{~kW}$ ( $3000 \mathrm{hp}$ ), and they are all adaptable to direct or indirect heat sources. Selection of the final engine design concept is based primarily on ease of development, manufacturing, and adaptability to various installations and fuel combustion systems. The initial design of this concept is described in section 6 , namely a narrow- $V$ engine having a conventional crank-set and doubleacting concentric stirling cylinder modules. A comparison of the various concept options is given in Table 3 , which lists the salient features, advantages, and disadvantages of each.

In general, our logic in selecting one concept (Table 3, No. 6) follows a process of elimination: all other concepts offer either less efficiency, more complexity with no better efficiency, or greater design risk requiring development. The two concepts offering possible performance or cost advantages but requiring development are relegated to the category of advanced system designs (Table 3 , No. 1 and No. 7). 
Table 3. Comparison of Engine Design Concepts

\begin{tabular}{|c|c|c|c|}
\hline Concept Description & Salient Feature & Advantages & Disadvantages \\
\hline $\begin{array}{l}\text { 1. Opposed pistons, } \\
\text { two cranks, axial } \\
\text { Ilow heat ex- } \\
\text { changer group }\end{array}$ & $\begin{array}{l}\text { Ideal internal } \\
\text { fluid dynamics }\end{array}$ & $\begin{array}{l}\text { - Possibly minimal hot } \\
\text { structure, dead volume, } \\
\text { and manifolding using in- } \\
\text { direct heat supply (for } \\
\text { example, heat pipe) }\end{array}$ & $\begin{array}{l}\text { Two widely separated } \\
\text { pistons (cranks) per } \\
\text { cylinders } \\
\text { - Not practical for direct } \\
\text { heat supply without } \\
\text { manifolds }\end{array}$ \\
\hline $\begin{array}{l}\text { 2. Single-acting } \\
\text { l-engine or } \\
\text { "folded" opposed } \\
\text { Fiston engine }\end{array}$ & $\begin{array}{l}\text { Independent gas } \\
\text { cycles allowing } \\
\text { phase control }\end{array}$ & $\begin{array}{l}\text { - High power per cycle } \\
\text { - Phase control } \\
\text { - Good mechanical separation } \\
\text { of heater section, cyl- } \\
\text { inders, and crankcase }\end{array}$ & $\begin{array}{l}\text { - Phase control poor at low } \\
\text { power } \\
\text { - Extensive hot manifolding } \\
\text { probably leading to poor } \\
\text { performance }\end{array}$ \\
\hline $\begin{array}{l}\text { 3. Concentric module } \\
\text { of heat ex- } \\
\text { changers and pis- } \\
\text { ton, for double- } \\
\text { azting or dis- } \\
\text { placer engines }\end{array}$ & $\begin{array}{l}\text { Compact module } \\
\text { without hot } \\
\text { mani iolding }\end{array}$ & $\begin{array}{l}\text { - Nearly ideal fluid } \\
\text { dynamics } \\
\text { Ease of fabrication for } \\
\text { hot end with widest } \\
\text { options for materials } \\
\text { Best pressure conțainment } \\
\text { structure }\end{array}$ & $\begin{array}{l}\text { - Large heat exchange unit } \\
\text { practical only for service } \\
\text { off-engine } \\
\text { - Large module diameter } \\
\text { leads to large crankcase }\end{array}$ \\
\hline $\begin{array}{l}\text { 4. Concentric module } \\
\text { displacer engine }\end{array}$ & $\begin{array}{l}\text { Possibly best } \\
\text { piston ring } \\
\text { life }\end{array}$ & $\begin{array}{l}\text { Low-force phase or stroke } \\
\text { control of displacer } \\
\text { - Independent modules for } \\
\text { ease of crank timing } \\
\text { - Possibility for free } \\
\text { (bounce) displacer engine } \\
\text { with gas-spring power } \\
\text { control }\end{array}$ & $\begin{array}{l}\text { - Low power per displacement } \\
\text { (that is, low Beale number) } \\
\text { - More complex per given } \\
\text { heat exchange module } \\
\text { - Possible free displacer } \\
\text { with power control requires } \\
\text { development }\end{array}$ \\
\hline
\end{tabular}


Table 3. Comparison of Engine Design Concepts (Continued)

\begin{tabular}{|c|c|c|c|}
\hline Concept Description & Salient Feature & Advantages & Disadvantages \\
\hline 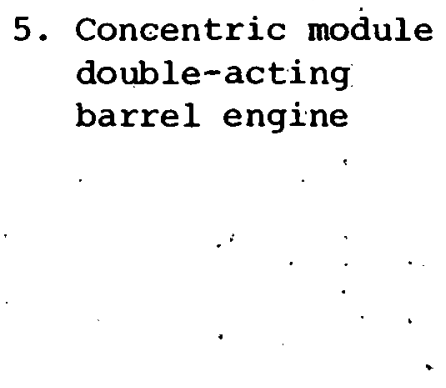 & 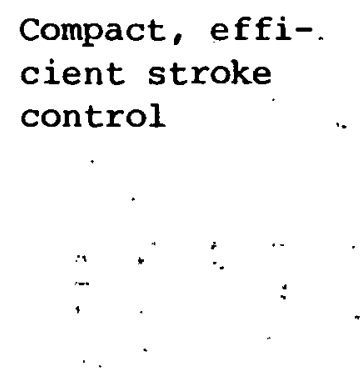 & $\begin{array}{l}\text { Excellent mechanical effi- } \\
\text { ciency and dynamic balance } \\
\text { and good thermal effi- } \\
\text { ciency at light load with } \\
\text { stroke control. } \\
\text { Excellent arrangement for } \\
\text { heat supply, direct or } \\
\text { indirect }\end{array}$ & $\begin{array}{l}\text { One } 500 \text { hp engine size : } \\
\text { higher power only by } \\
\text { grouping with gearing } \\
\text { - Requires development of } \\
\text { variable wobble crank and } \\
\text { manufacturing methods } \\
\text { Probably less convenient } \\
\text { for maintenance }\end{array}$ \\
\hline $\begin{array}{l}\text { 6: Concentric module } \\
\text { double-acting, } \\
\mathrm{v-crank} \\
\end{array}$ & $\begin{array}{l}\text { Simplest, most } \\
\text { common output } \\
\text { machinery }\end{array}$ & $\begin{array}{l}\text { - Low cost output end with } \\
\text { minimal development } \\
\text { - Single engine models to } \\
\text { cover } 373 \mathrm{~kW}-(500) \text { to } \\
2237 \mathrm{~kW}(3000 \mathrm{hp}) \\
\text { - Ease of maintenance } \\
\text { - Probable simplicity of } \\
\text { dead volume control }\end{array}$ & $\begin{array}{l}\text { - Full dynamic balance } \\
\text { requires counter shafts } \\
\begin{array}{llll} & & & \\
& & & \\
& & \end{array}\end{array}$ \\
\hline $\begin{array}{l}\text { 7. Low pressure } \\
\text { (less than 15 } \\
\text { atmospheres) } \\
\text { double-acting } \\
\text { in-line or } \\
\text { V-engine }\end{array}$ & $\begin{array}{l}\text { Large heater } \\
\text { tubes suittable } \\
\text { for direct heat } \\
\text { from combustion } \\
\text { of coal and } \\
\text { dirty fuels }\end{array}$ & $\begin{array}{l}\text { Design of static seals } \\
\text { and structure is less } \\
\text { critical } \\
\text { - Dynamic seals have low } \\
\text { pressure loading } \\
\text { - } 30 \mathrm{~Hz} \text { shaft speed } \\
\text { Less critical for opera- } \\
\text { tion and maintenance }\end{array}$ & $\begin{array}{l}\text { Requires development of: } \\
\text { high speed, low pressure } \\
\text { piston and rod seals; } \\
\text { integrated combustion } \\
\text { system (PC or FBC); and } \\
\text { unusual engine design } \\
\text { Engine proper is at least } \\
508 \text { larger in external } \\
\text { linear dimensions }\end{array}$ \\
\hline
\end{tabular}




\section{ENGINE THERMODYNAMIC PERFORMANCE EVALUATION}

Stirling engines, like other heat engines, convert heat to useful work. In this conversion process, there are various loss mechanisms due to the nonideal nature of the device which prevents one from obtaining desired high efficiency of ideal stirling cycle engines. : There are three groups of loss mechanisms that influence the stirling engine performance. The first group of losses occurs in the combustion system where fuel is burned to produce heat. Some of the fuel energy is wasted between heat source and engine. The second group of losses is called heat input loss. These losses occur because some of the heat delivered to the engine leaves the engine without producing useful power. The third group is called power loss because these losses occur after the heat input is converted to useful power. All loss mechanisms have to be carefully investigated and minimized in designing a stirling engine in order to obtain high performance. A list of the loss mechanisms is presented in Table 4. In order to evaluate the performance of a stiriing engine, one needs an analytical tool which can closely simulate the thermodynamic processes inside the engine with all the losses accounted for. FMA has developed a very fast and inexpensive second order* Stirling engine analysis which can predict steady-state performance with remarkable accuracy. FMA also has access to the SUNPOWER third order analysis which is one of the most sophisticated third order analyses presently available.

In the following subsections, the FMA and SUNPOWER analyses will be described qualitatively and engine performance predictions will be compared with actual experimental data. Also, results showing the sensitivities of various engine parameters on Stirling engine performance will be discussed.

\footnotetext{
"For definition of "order," refer to reference (7) (Martini).
} 
Table 4. Governing Factors Infiuencing Stirling Engine Thermodynamic Performance

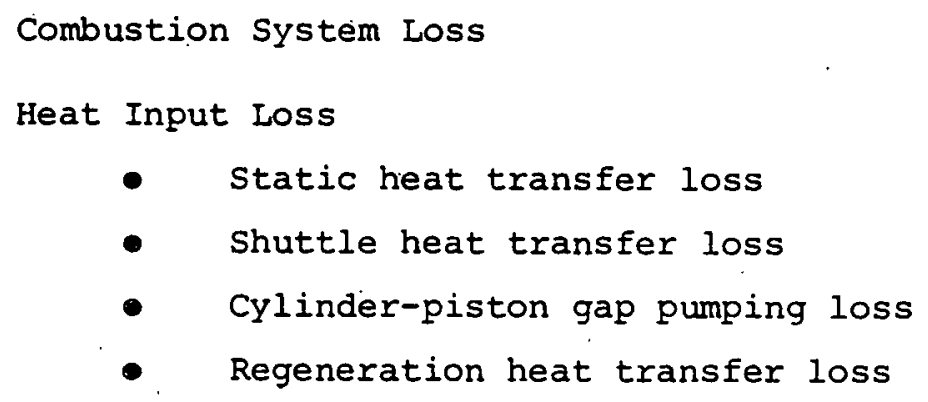

\subsection{Second Order Computer Analysis}

The basis for the FMA second order analysis is the pioneering work of Professor Joseph L. Smith, Jr. and Dr. Pedro A. Rios of MIT, which is reported in the latter's Ph.D. thesis.

The MIT analysis employs a two-step approach. The effect of pressure drop and heat transfer ineffectiveness of heat exchangers on the overall cycle performance is decoupled from the effect of dead space. As a first step, the MIT analysis calculates the performance of a basic model which does not include irreversibilities in the dead space. The assumptions are: 
- Cylinders are adiabatic; that is, there is no heat transfer between the gas and the walls inside the cylinders.

- All the heat exchangers are perfect; that is, no $\Delta T$ between the gas and heat exchanger walls, no $\Delta \mathrm{P}$ in the heat exchangers.

- Working gas is a perfect gas.

This means, for the basic model, the only irreversibility is due to the temperature difference when the working gas of the adiabatic region (cylinder spaces) mixes with the working gas of the isothermal region (heat exchange spaces).

Based on these assumptions, differential equations for engine pressure are derived and numerically integrated in order to obtain basic engine performance.

The next step is to correct the result of the above basic model taking into account the losses due to nonideal nature of the engine components such as pressure drop and finite heat transfer coefficient in heat exchangers, nonadiabatic cylinder processes, and various heat leaks from the engine to the environment as listed in Table 4. Further details of the MIT analysis are provided (8).

At FMA, the MIT analysis was revised and modified to include the loss mechanisms listed in Table 4. In the following subsections, the loss mechanisms included in the FMA analysis will be discussed. 


\subsubsection{Combustion System Loss}

In the present FMA analysis, the combustion system loss is represented by the overall combustion system efficiency which is defined as:

Combustion System Efficiency

$$
=\frac{\text { heat input to the engine heater }}{\text { heat input based on fuel flow: }}
$$

This loss is not explicitly simulated in the FMA analysis itself. Instead the value of the combustion system efficiency is calculated by a separate combustor analysis .

\subsubsection{Heat Input Loss}

The heat input loss adds to the ideal heat input due to heat leaks into the environment and the cooling water. The total heat input loss includes the following contributions:

- Static heat transfer loss

- Shuttle heat transfer loss

- Cylinder-piston gap pumping loss.

- Regenerator heat transfer loss.

Each of these heat transfer loss contributions is described briefly below.

\section{Static Heat Transfer Loss}

Static heat transfer loss includes the heat conduction from hot sections to cold sections along the cylinder wall, piston wall, regenerator wall, regenerator matrix, etc. Formulae to : 
estimate these losses are based on straightforward one-dimensional heat conduction, and similar to those listed ( 7 ).

Shuttle Heat Transfer Loss

The shuttle heat transfer is one of the many heat leak mechanisms from the hot part of the engine to the cold part of the engine. It is due to the shuttling motion of the piston or the displacer against the cylinder wall, both of which have a temperature gradient in the axial direction. The shuttling motion causes periodic changes in the temperature difference across the gap between the two sliding walls. When the piston is near the top dead center, heat is transported from the hot, upper part of the cylinder wall to the piston wall. Near the bottom dead center, the piston gives up the heat to the colder, lower part of the cylinder wall. The detailed analysis of this heat transport phenomenon is given ( 9 ).

Cyilinder - Piston Gap Pumping Loss

This loss is due to the heat transfer inside the gap between the piston and cylinder, the heat transfer causes the temperature difference between the gas which goes in and the gas which goes out of the cylinder piston gap. For example, in the expansion space, this phenomena causes a net enthalpy flux from the hot expansion space to the gap and then to the cold section of the engine. The net enthalpy flux by this enthalpy pumping action of the gap is estimated by a formula given (

\section{Regenerator Heat Transfer Loss}

Regenerator heat transfer loss is the combination of net enthalpy flux due to regenerator ineffectiveness and due to finite total heat capacity and finite thermal diffusivity of the 
material. Net enthalpy flux was estimated using the formula given ( 8 ) and losses due to matrix temperature swing were estimated by the formulas listed (7):

\section{Additional Heat Input Corrections}

The next heat input correction, pressure drop correction, comes from the engine pressure modification due to the pressure drop in the heat exchangers. There is a reduction of heat input to the heater approximately equal to heater pressure drop loss plus one half of the regenerator pressure drop loss, both of which are power loss mechanisms described later.

The final heat input correction, cyclic heat transfer correction, is the result of nonadiabatic cylinder processes. The transient heat transfer inside cylinder spaces causes steep temperature gradient inside the cylinder in the radial direction especially near the wall. This, in turn, causes the modification of engine pressure wave resulting in the heat input correction. The cyclic heat transfer will be further described later.

\subsubsection{Power Loss}

The net heat input to the working gas in the hot section of the stirling engine was reduced, from the total heat input to the combustion system based on the fuel flow rate and the heating value, by the amount equal to the combustion system loss and various heat input losses that escaped into the environment. Any losses that occur during or after the conversion of the net heat input to the hot working gas into the engine shaft power are called power losses. These losses are especially more critical than the heat input losses because they directly reduce the engine output power and the efficiency, and because, being relatively 
larger than heat input loss ratio of 3 to 1 , (see subsection 3.5, ) there is a potential of achieving much higher engine efficiency by reducing them significantly. The power loss includes the. following contributions:
- Adiabatic loss
- Pressure drop loss
- Heat exchanger $\Delta T$ loss
- Leakage loss
- Mechanical friction loss
- Cyclic heat transfer loss.

Each of these power loss mechanisms is described briefly below.

\section{Adiabatic Loss}

This is a hypothetical loss of power in a stirling engine when the cylinder processes are assumed to be adiabatic instead of isothermal as in the case of the ideal stirling cycle. In the FMA analysis, this loss mechanism is inherently. included in the basic cycle model calculation by assuming the cylinders are adiabatic. As shown in Figure 12, the adiabatic loss is the largest loss.

\section{Pressure Drop Loss}

This is one of the many corrections to the basic adiabatic model of the FMA second order analysis. Because of the pressure drop inside heater, cooler, regenerator, and connecting passages, the engine pressure is not uniform spatially at a given instant as assumed in the basic adiabatic cycle model. In stirling engines, most of the pressure drop loss occurs in the regenerator as shown in Table 5. Pressure drop is estimated using standard 


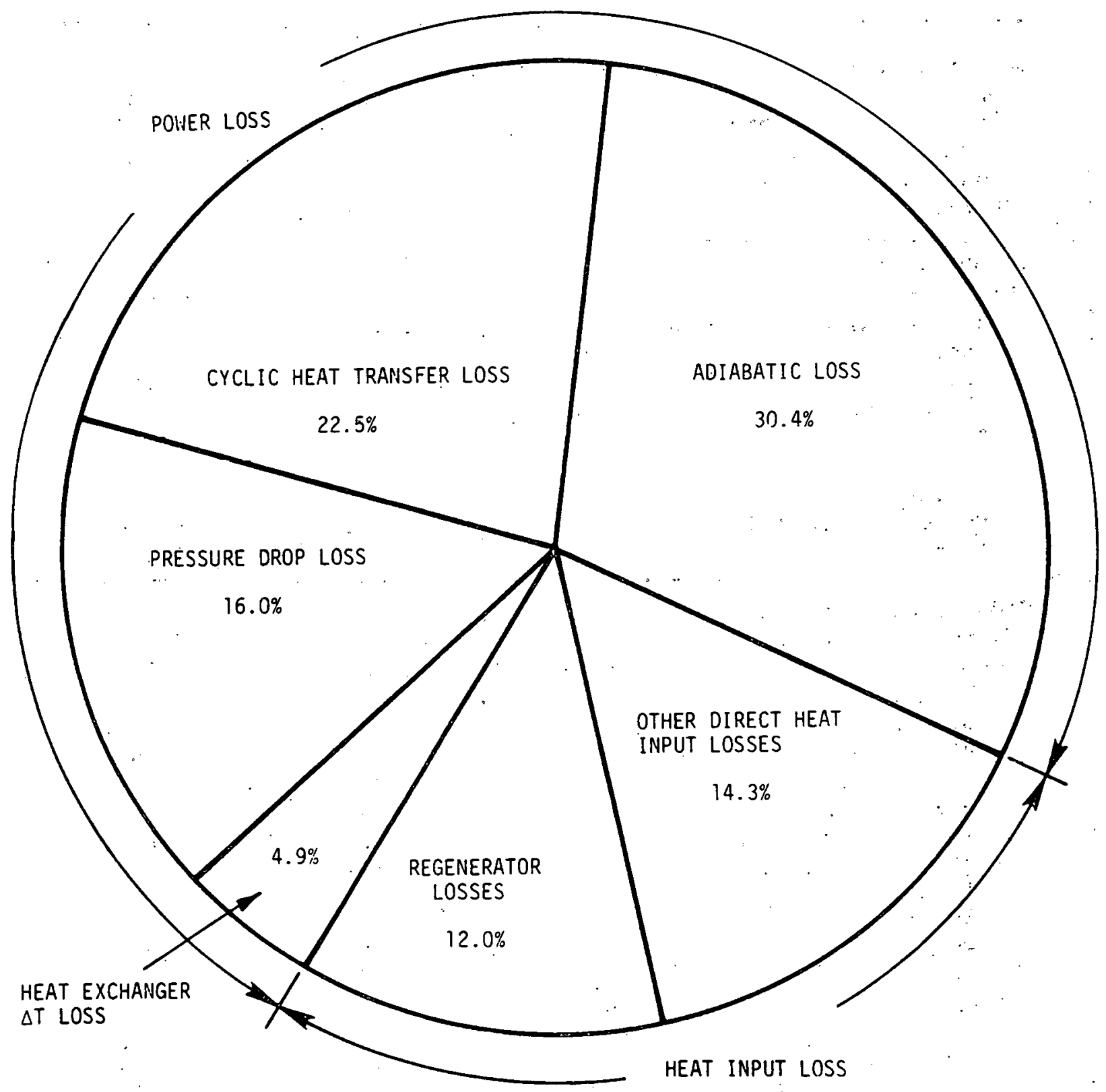

Figure 12. Relative Magnitudes of Various Power and Heat Input Losses in the Viking-1 Engine 
Table 5. Summary of the Performance Analysis for Viking-1 VS 4-D2 per Cylinder

\begin{tabular}{|c|c|c|}
\hline & $4-D 2$ & viking-1 \\
\hline $\begin{array}{l}\text { Operating conditions } \\
\text { Speed } \\
\text { Heat source. temperature } \\
\text { Heat sink temperature } \\
\text { Mean gas pressure } \\
\text { Working fluid }\end{array}$ & $\begin{aligned} 25 \mathrm{~Hz} \\
993 \mathrm{~K} \\
323 \mathrm{~K} \\
150 \text { Bar } \\
\text { Hydrogen }\end{aligned}$ & $\begin{array}{l}15 \mathrm{~Hz} \\
993 \mathrm{~K} \\
323 \mathrm{~K} \\
150 \mathrm{Bar} \\
\text { Helium }\end{array}$ \\
\hline $\begin{array}{l}\text { Power, watts } \\
\text { Basic power } \\
\text { Pressure drop loss, total } \\
\text { Heater } \\
\text { Cooler } \\
\text { Regenerator } \\
\text { Heat exchanger } \Delta T \text { loss, total } \\
\text { Cooler } \\
\text { Heater } \\
\text { Cyclic heat transfer } \\
\text { Net indicated power }\end{array}$ & $\begin{array}{r}22,188 \\
1,112 \\
128 \\
88 \\
897 \\
522 \\
130 \\
392 \\
1,650 \\
18,905\end{array}$ & $\begin{array}{r}98,625 \\
6,293 \\
959 \\
1,163 \\
4,171 \\
1,808 \\
381 \\
1,527 \\
8,836 \\
81,589\end{array}$ \\
\hline $\begin{array}{l}\text { Heat input, watts } \\
\text { Basic heat input } \\
\text { Static heat transfer loss, total } \\
\text { Gas conduction } \\
\text { Gas radiation } \quad \text { Piston wall } \\
\text { Cylinder wall } \\
\text { Regenerator wall } \\
\text { Regenerator matrix } \\
\text { Shuttle heat transfer loss } \\
\text { Cylinder-piston gap pumping loss } \\
\text { Regenerator heat transfer losses } \\
\text { Enthalpy flux } \\
\text { Matrix temperature swing loss } \\
\text { Matrix interior temperature } \\
\text { swing loss } \\
\text { Pressure drop connection } \\
\text { Cyclic heat transfer correction } \\
\text { Net heat input } \\
\text { Indicated thermal efficiency }\end{array}$ & $\begin{array}{r}35,562 \\
1,515 \\
12 \\
7 \\
265 \\
367 \\
536 \\
330 \\
394 \\
183 \\
2,158 \\
1,120 \\
1,032 \\
\\
6 \\
-556 \\
-1,093 \\
88,164 \\
0.495\end{array}$ & $\begin{array}{r}159,507 \\
3,956 \\
16 \\
37 \\
93 \\
1,662 \\
545 \\
1,603 \\
602 \\
1,061 \\
4,707 \\
3,063 \\
1,639 \\
5 \\
5 \\
-3,147 \\
-5,010 \\
160,676 \\
0.508\end{array}$ \\
\hline
\end{tabular}


steady flow correlations found in the literature (10). The effect of abrupt expansion and contraction in the flow paths, and the effect of the curvature on velocity distribution inside connecting tubes are also included in the pressure drop calculation (11).

Heat Exchanger $\triangle T$ LOSS

This loss is the result of finite NTU's, that is, less than perfect heat exchange process, which causes nonzero $\Delta T$ between the gas and the wall in the heater and the cooler. Gas temperatures entering the adjacent cylinders from the cooler or the heater are not the same as the wall temperatures of the respective heat exchangers, as was assumed in the basic adiabatic cycle model. In other words, the effective heat source temperature for the basic adiabatic cycle model has to be lowered by the appropriate amount dictated by the heater NTU in section 1. Similarly, the effective heat-sink temperature has to be raised by the appropriate amount dictated by the cooler NTU. The estimates for the above heat transfer losses were made using the formulae given (

Leakage and Mechanical Friction Losses

Leakage and mechanical friction losses are difficult to model analytically in general. Therefore, these losses are estimated using empirical relations based on past experiences with similar types of engines.

Cyclic Heat Transfer Loss

The cyclic heat transfer loss mechanism is the most salient feature of the FMA second order analysis. As of this writing, this loss has not been discussed or recognized, in the literature, as an important loss mechanism in stirling engines. The cyclic heat transfer loss is the result of periodic heating and cooling of the working gas near the gas-wall-interface inside the cylinders, manifold spaces, connecting tubes and reservoirs. 
This type of loss has long been observed in gas springs as they have often been called "gas spring hysteresis loss" (12).

An analysis was performed (13) based on the energy equation for the ideal gas undergoing one-dimensional compression and expansion cyclically. The boundary condition was that the temperature of the wall remained constant. A thermal diffusion boundary layer develops, the thickness of which is dependent on the gas properties, and the frequency of the compression cycle.

This thermal boundary layer acts as a capacitance as well as resistance to heat conduction between the outer region of the gas and the wall. Physically, the gas at the wall will undergo isothermal process and the gas outside the thermal boundary layer will undergo adiabatic process. Inside the boundary layer, polytropic processes will occur with the polytropic index, $n$, varying from $n=1$ at the wall to $n=\gamma$ at the edge of the boundary where $\gamma$ is the ratio of the gas specific heats.

Using the above one-dimensional compression/expansion model, the most conservative, baseline estimate of the rate of heat transfer inside the cylinder can be established.

In actual cylinder processes, the above mentioned thermal boundary layer will be disturbed by turbulent mixing, and the heat transfer will be enhanced compared to the ideal model of one-dimensional compression and expansion.

From dimensional analysis, the enhancement factor is dependent on cylinder space geometry usually bore-stroke ratio, relative clearance volume, properties of gas involved, and cycle frequency.

In order to determine the functional relationship between the enhancement factor and the dimensionless groups such as the 
Reyriolds No., Prandtl No., Bore-stroke ratio, and clearance volume, experiments had been performed using closed cylinder. reciprocating devices. Since there will be more turbulent mixing due to the mass flow into and out of the cylinder in Stirling engines, the enhancement factor obtained from the closed cylinder correlation would be expected to be an underestimated value.

The results of the closed cylinder tests had been reduced to the following functional form:

Enhancement Factor $F=$ function $\left(\operatorname{Re}, \operatorname{Pr}, \frac{B}{s}, \frac{\dot{V}_{c l}}{V_{d}}\right)$

where

$$
\begin{aligned}
\text { Re } & =\begin{array}{l}
\text { Reynolds number based on mean piston velocity and } \\
\text { cylinder bore } B
\end{array} \\
\text { Pr } & \text { Prandtl number based on mean gas property } \\
S & =\text { piston stroke } \\
v_{c l} & \text { clearance volume. } \\
v_{d} & \quad \text { piston displacement volume }
\end{aligned}
$$

The enhancement factor thus obtained gives an indication of how much heat transfer enhancement is caused by the turbulent mixing due to piston motion over the cycle basis compared to the basic one-dimensional compression/expansion model described earlier: 
This enhancement concept was utilized in the FMA second order andiysis in order to calculate the effect of cyclic heat transfer on stirling engine performance. For the purpose of analysis, a Stirling engine was divided into several control volumes as shown in Figure 13. It is of importance to consider only the spaces, which do not experience high heat transfer rates in the traditional sense, such as cylinder spaces, manifold spaces, and reservoirs.

Assume that for each of the above spaces, just as was assumed in the basic one-dimensional compression/expansion model, the core gas temperature follows adiabatic curve whereas inside the thermal boundary layer the gas temperature follows polytropic processes with the polytropic index $n$ varying from $n=1$ at the wall to $n=\gamma$ at the outer edge of the boundary layer. Then, from the conservation of mass for the entire engine, the engine pressure wave obtained from the basic adiabatic stirling engine model will have to be modified taking into account the fact that the temperature near the boundary layer was quite different from the temperature of the core region in each of the spaces of interest.

The enhancement factor at each ispace of interest acts as a weighting factor for the contribution of that individual space to the engine pressure modification.

The enhancement factor for each space is estimated using the characteristic speed, characteristic dimensions, and corresponding average fluid properties at the midpoint of each space.

Characteristic speed can be obtained from the basic adiabatic model of FMA second order analysis.

Employing the estimated enhancement factors, the FMA second order analysis calculates the loss of performance due to cyclic heat transfer inside the Stirling engines; a more detailed 


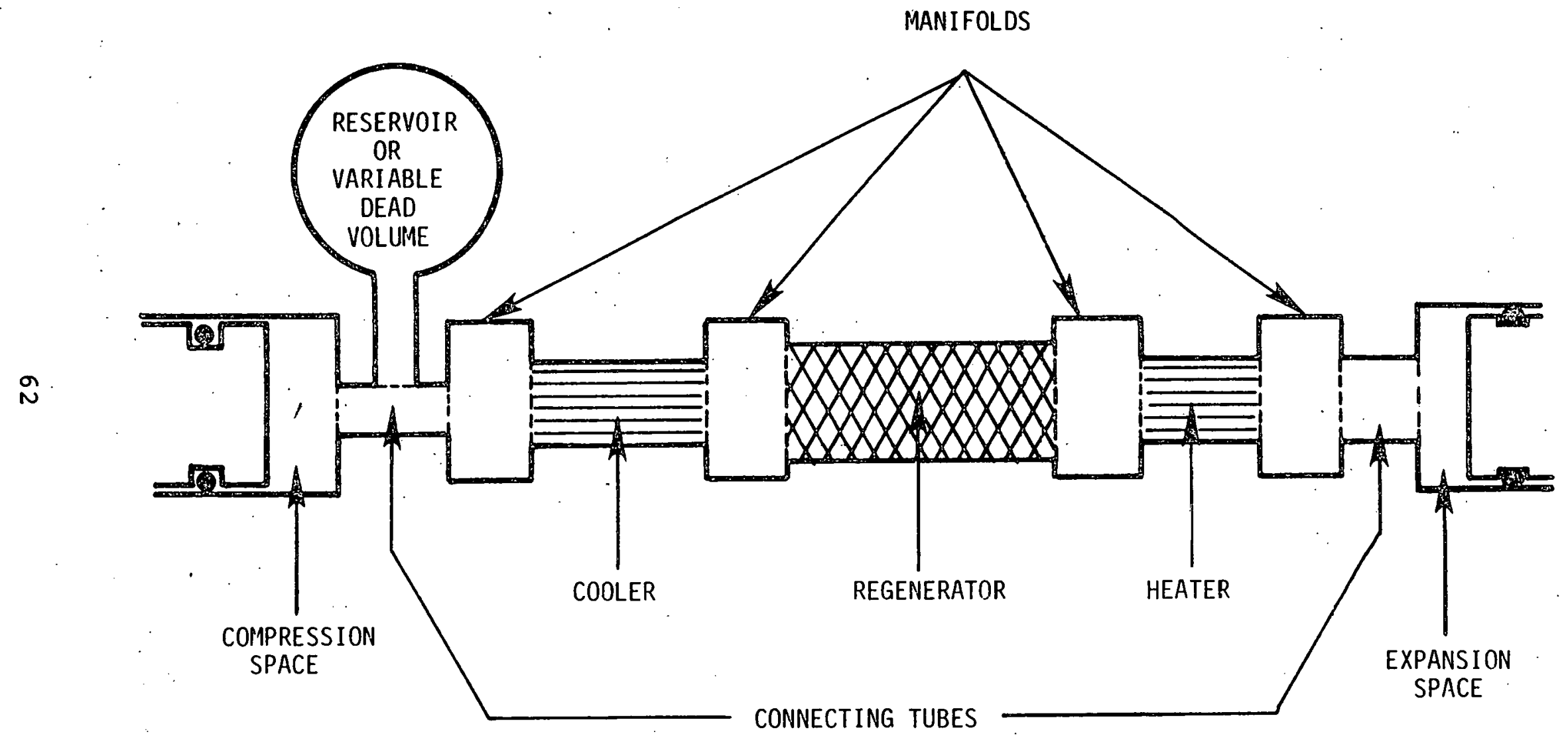

Figure 13. Control Volumes of a Stirling Engine for the Cyclic Heat Transfer Analysis 
discussion is provided (13). As mentioned earlier, the method employed for calculating the cyclic heat transfer loss results in conservative values. Still, the cyclic heat transfer loss is a significant power loss as shown in Figure 12 . It is revealed that the cyclic heat transfer loss is the second largest power loss mechanism in a stirling engine. For the stirling engine under investigation (FMA viking-1), the cyclic heat transfer loss was approximately 9 percent of the basic adiabatic power.

Illustrated in Figure 14 is an example showing how this loss mechanism can be detrimental to a stirling engine performance. The geometry of the manifold for one engine design was altered to increase the surface area. The results show that when surface to volume ratio was quadrupled for that particular manifold, which was between the cooler and the compression space, the engine power and efficiency dropped approximately 10 percent. This phenomena of performance degradation resulting from improper design or use of manifolds in stirling engines have been observed by other Stirling engine developers (14).

It is obvious that failure to include this important loss mechanism will result in inaccurate performance predictions regardless of the order of the stirling engine analysis, forcing one to use various empirical fudge factors in the analysis to match experimental data. The FMA second order analysis which includes this cyclic heat transfer mechanism as well as other well documented losses shown in Table 4 predicts the steady-state performance of stirling engines very accurately as will be shown in subsection 3.3 at a speed two orders of magnitude faster than a third order analysis.

\subsection{Third Order Computer Analysis}

Third order analysis or Nodal Analysis of Stirling engine models the engine thermodynamics by simultaneous differential 


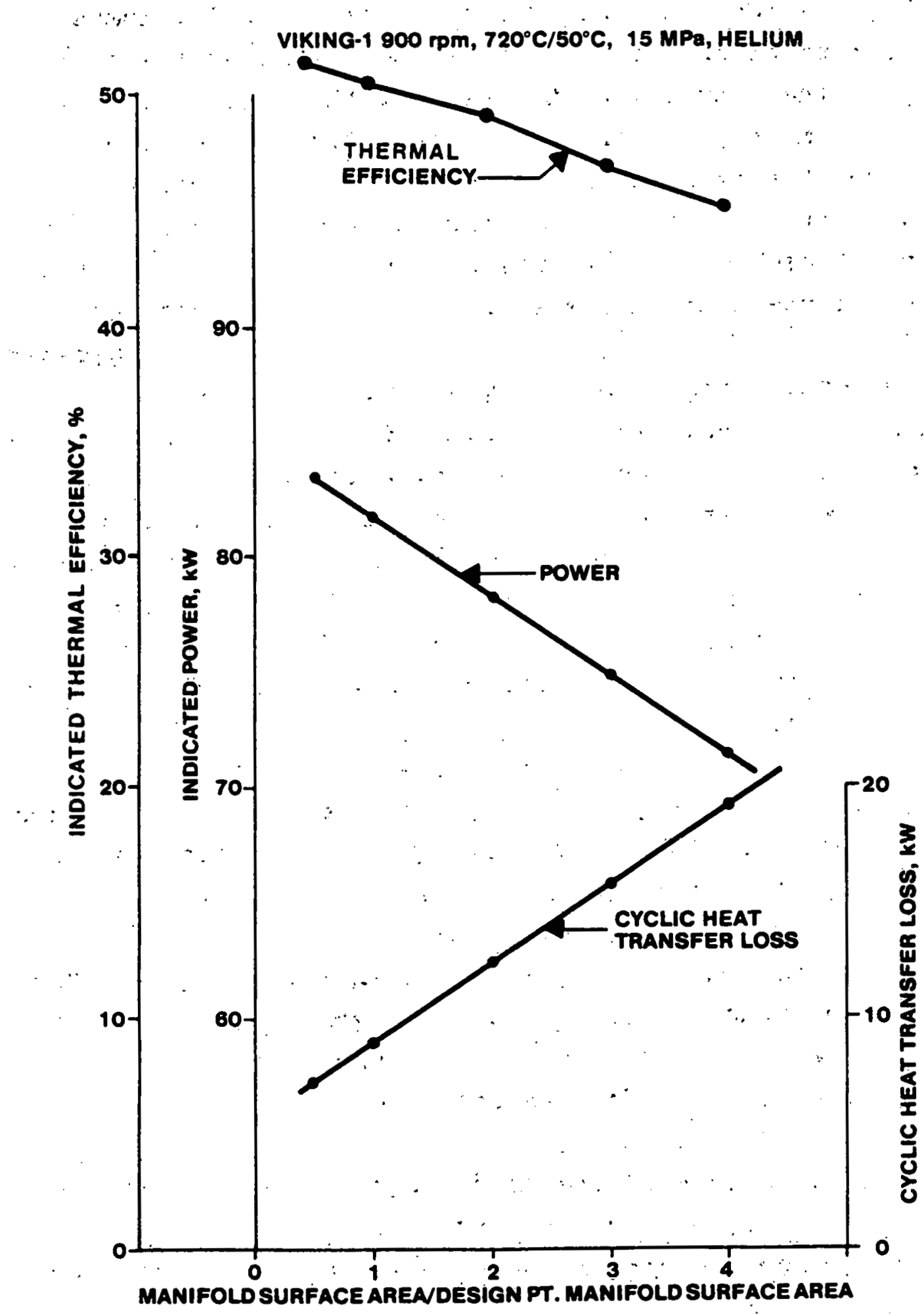

Figure 14. Effect of Manifold Geometry on Cyclic Heat Transfer and Stirling Engine Performance 
equations of energy, momentum and-continuity for the entire engine which is divided into several nodes or control volumes. Although this type of analysis stili has some limitations as to the validity of the results due to the fact that flows are modeled as one-dimensional, and that steady flow correlations are used in heat transfer and pressure drop calculation; they have the capability of "simulating", thermodynamic processes occurring inside each control volume of a stirling engine. They can be called state-of-the-art analyses for stirling engines.

of the several third order analyses known to exist, the SUNPOWER third order analysis is recognized in the stirling engine field as one of the most advanced, relatively fast and accurate. This was possible because SUNPOWER, Inc. initiated the stirling engine and code development early and accumulated the greatest body of practical engine development and operating experience outside Phillips and its licenses (15). The SUNPOWER, Inc. is the only commercial stirling engine manufacturer in the United States.

During the present large stirling engine development program, SUNPOWER third order analysis was extensively used to refine and validate the FMA second order analysis.

The items, compared and verified with the SUNPOWER and FMA analysis, include basic adiabatic cycle analysis, pressure drop calculation, the effect of finite NTU's in the heater and the cooler, and regenerator ineffectiveness, etc.

It was also used to predict the performance of candidate engine designs, and to perform sensitivity analysis of various engine parameters such as piston phase angle, engine speed, etc., described in subsection 3.4 . 
SUNPOWER third order analysis was an important factor in the refinement of the FMA second order analysis, which has become a very powerful tool in stirling engine design.

The following subsection gives the qualitative description of the SUNPOWER third order analysis taken from (16).

\section{SUNPOWER Third Order Stirling Engine Simulation}

The SUNPOWER third order analysis combines a one-dimensional control volume network for the analysis of the working gas with a two-dimensional control volume network to model the numerous heat flow paths down pressure vessel walls, cylinders, etc. The working gas control volume network solves both gas energy and momentum equations in time. Instantaneous rates of heat transfer and pressure drop are computed according to a subroutine which uses correlations taken from standard literature and component tests. Due account is taken of gas leaks past piston and displacer seals. The method of lines (17) is employed which effectively replaces the partial differential equations of working gas momentum, energy and continuity with a system of ordinary differential equations by using fixed differencing in the spatial dimension.

\section{Differential Equation Solver}

The numerical method chosen to solve the system of differential equations derived for the working gas is of great importance. Since gas momentum effects are modelled, the algorithm has the capacity to generate acoustical waves superimposed on the desired solution, a symptom of the problem known as stiffness in differential equation jargon (18). This phenomenon has dire consequences when the system is solved with 
an explicit linear multistep method in that instability arises if the integration time step grows beyond a limit which is on the order of the control volume transit time of an acoustic disturbance. This time step limit is about two orders of magnitude smaller than that required for accuracy of solution. Fortunately the problem can be circumvented by use of an implicit differential equation solver of the type designed for stiff systems. A version of Gear's stiffly stable algorithm revised by A. C. Hindmarah is used (19):

\section{Steady-State Acceleration}

Common to all simulations that attempt to arrive at a steadystate stirling cycle by way of a time evolving solution to a system of differential equations is the slow relaxation time of the regenerator matrix. For that matter any element of the system with a large heat capacity compared to the working gas may require several machine cycles before it reaches a satisfactory proximity to its equilibrium temperature. starting from typical initial estimates for regenerator matrix temperature on the order of 100 cycles might be required to establish equilibrium temperatures in a straightforward simulation. SUNPOWER, like all workers in this area, has developed a method to shorten the time required to establish equilibrium temperatures. Starting from a reasonable initial approximation to the steady-state conditions at the beginning of a cycle, the simulation is allowed to evolve for one machine cycle. At the end of the cycle the net energy flows to, and average temperatures of, all elements in the control volume network including the elements which represent the regenerator matrix are tabulated. A way was found to represent the net energy flows as an approximate function of the average temperatures of the network elements. The values of average temperatures are then estimated which would result in the desired equilibrium energy flows. With this information the current temperatures of the 
control volume network are incremented to form starting values. for the simulation of another machine cycle. The process repeats until a cycle is simulated that results in an energy balance .... within a prescribed. tolerance.

Using this method an energy balance is achieved for all. network control volumes which deviates from steady state by an amount no greater than 0.005 of the PV work output energy. The process requires about seven machine cycles for computation of the initial data point and thereafter in the course of the optimization about three machine cycles.

\section{Validations}

The SUNPOWER simulation code has evolved over the years in conjunction with ongoing hardware work with actual stirling engines. It has always been a problem to adequately debug experimental hardware and measuring instruments in order: to. meaningfully compare an actual machine with a simulation of itself. Furthermore, it is of intrinsic difficulty to measure more than a few of the quantities the simulation is capable of generating. Nonetheless, the hardware and the simulation have evolved together to the point that the optimization process: is a meaningful one. An agreement between simulation and engine within 10 percent in all measurable quantities can usually be *. obtained.

\subsection{Comparison of Predicted-Performance With Actual Performance}

As a means of validating and also demonstrating the prediction capability of FMA second order añalysis, GPU-3 engine data (20) were used. These data are the most thoroughly documented Stirling engine data ever published in the technical literature. 
Also, proprietary data from two modern stirling engines designated as 4-D1 and 4-D2 were obtained to be compared with FMA predictions.

Table 6 presents the predicted and actual brake power and efficiency of stirling engines, GPU-3, 4-D1, and 4-D2 in different operating conditions. FMA second order analysis predicts the. brake power with maximum 15 percent error and the brake efficiency with maximum 12 percent error. Considering the uncertainties in experimental data involved, the prediction errors are very reasonable. Figures 15 through 17 present predictions of both the FMA second order analysis and NASA LERC third order analysis and actual test data for GPU-3 and two modern engines designated by $4-D 1$ and $4-D 2$.

During the tests at NASA/Lewis (20), the regenerator matrix was discovered partially: clogged by wear particles and carbon deposits.- In an effort to match the engine performance data, NASA LERC analysis used a friction coefficient factor four times the steady flow value for the calculation of regenerator pressure drop.: Subsequent steady flow test of the regenerator indicated. an increase of 30 percent in frictional pressure drop as compared to steady flow correlation. FMA predictions shown in Figures 15 through 17 employ a multiplication factor of 2.5 in the regenerator pressure drop calculation.

The correction factor of FMA analysis is smaller than that of NASA LERC's mainly due to the fact that the FMA analysis includes the cyclic heat transfer power loss where as NASA LERC analysis does not.

Referring to Figure 15, the FMA second order analysis predicts slightly higher brakepower values than the NASA LERC's analysis. 
Table 6. Comparison of Predicted Performance with Actual: Performance

\begin{tabular}{|c|c|c|c|c|c|c|c|c|c|}
\hline \multirow[b]{2}{*}{$\begin{array}{l}\text { Engine } \\
\text { Name }\end{array}$} & \multicolumn{3}{|c|}{ Operating Condition } & \multicolumn{3}{|c|}{ Brake Power/Cylinder } & \multicolumn{3}{|c|}{ Brake Thermal Efficiency } \\
\hline & $\begin{array}{l}\text { Temperature } \\
\left({ }^{\circ} \mathrm{C}\right)\end{array}$ & $\begin{array}{c}\text { Mean } \\
\text { Pressure } \\
\text { (atmosphere) }\end{array}$ & $\begin{array}{l}\text { Speed } \\
\text { (rpm) }\end{array}$ & $\begin{array}{l}\text { Predicted } \\
(k W)\end{array}$ & $\begin{array}{l}\text { Actual } \\
(\mathrm{kW})\end{array}$ & $\begin{array}{c}\text { Error } \\
(\%)\end{array}$ & $\begin{array}{c}\text { Predicted } \\
(z)\end{array}$ & $\begin{array}{c}\text { Actual } \\
\text { (z) }\end{array}$ & $\begin{array}{l}\text { Error } \\
(8)\end{array}$ \\
\hline \multirow[t]{5}{*}{ GPU- -3} & $\begin{array}{l}\text { Heater: } 704 \\
\text { Cooler: } 15\end{array}$ & (400 $\begin{array}{l}27.2 \\
\left.1 \mathrm{~b} / \text { in. }^{2}\right)\end{array}$ & & & & & 25.5 & 24.4 & $4: 5$ \\
\hline & & & 1500 & 1.725 & 1.50 & 15.0 & 28.4 & 25.5 & 11.4 \\
\hline & & & 2000 & 2.25 & 1.98 & 13.6 & 29.3 & 27.1 & 8.1 \\
\hline & & & 2500 & 2.58 & 2.39 & 7.9 & 28.0 & 26.8 & 4.5 \\
\hline & & & 3000 & 2.75 & 2.61 & 5.4 & 25.9 & 25.5 & 1.6 \\
\hline 4-D1 & $\begin{array}{l}\text { Heater: } 650^{\circ} \\
\text { Cooler: } 75\end{array}$ & $\begin{array}{c}148 . \mathrm{l} \\
\left(2177 \mathrm{lb} / \mathrm{in} .{ }^{2}\right)\end{array}$ & 1.400 & 5.0 & 5.0 & 0.0 & 33.1 & 32.0 & 3.5 \\
\hline \multirow[t]{3}{*}{ 4-D2 } & $\begin{array}{l}\text { Heater: } 720 \\
\text { Cooler: } 50\end{array}$ & $\frac{148.1}{\left(2177 \mathrm{lb} / \text { in. }^{2}\right)}$ & & & & & & & \\
\hline & : & & 1250 & 11.95 & 11.0 & 9.0 & 35.4 & 36.0 & -1.7 \\
\hline & & & 1500 & 14.00 & 12.5 & 12.0 & 34.5 & 33.0 & 4.5 \\
\hline
\end{tabular}




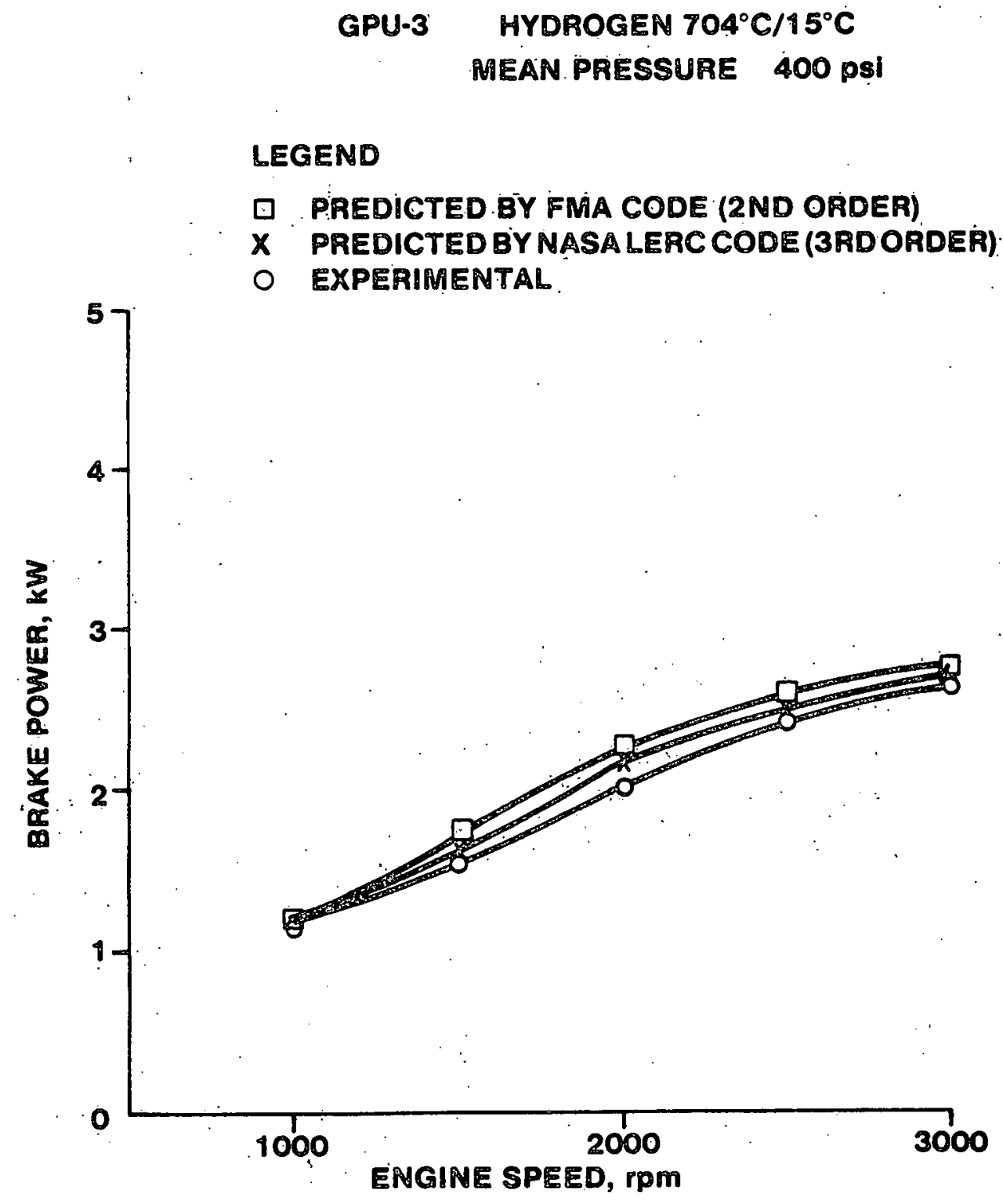

Flgure 1b: Comparison of Power Predictions
with Experimental Data for GPU-3 


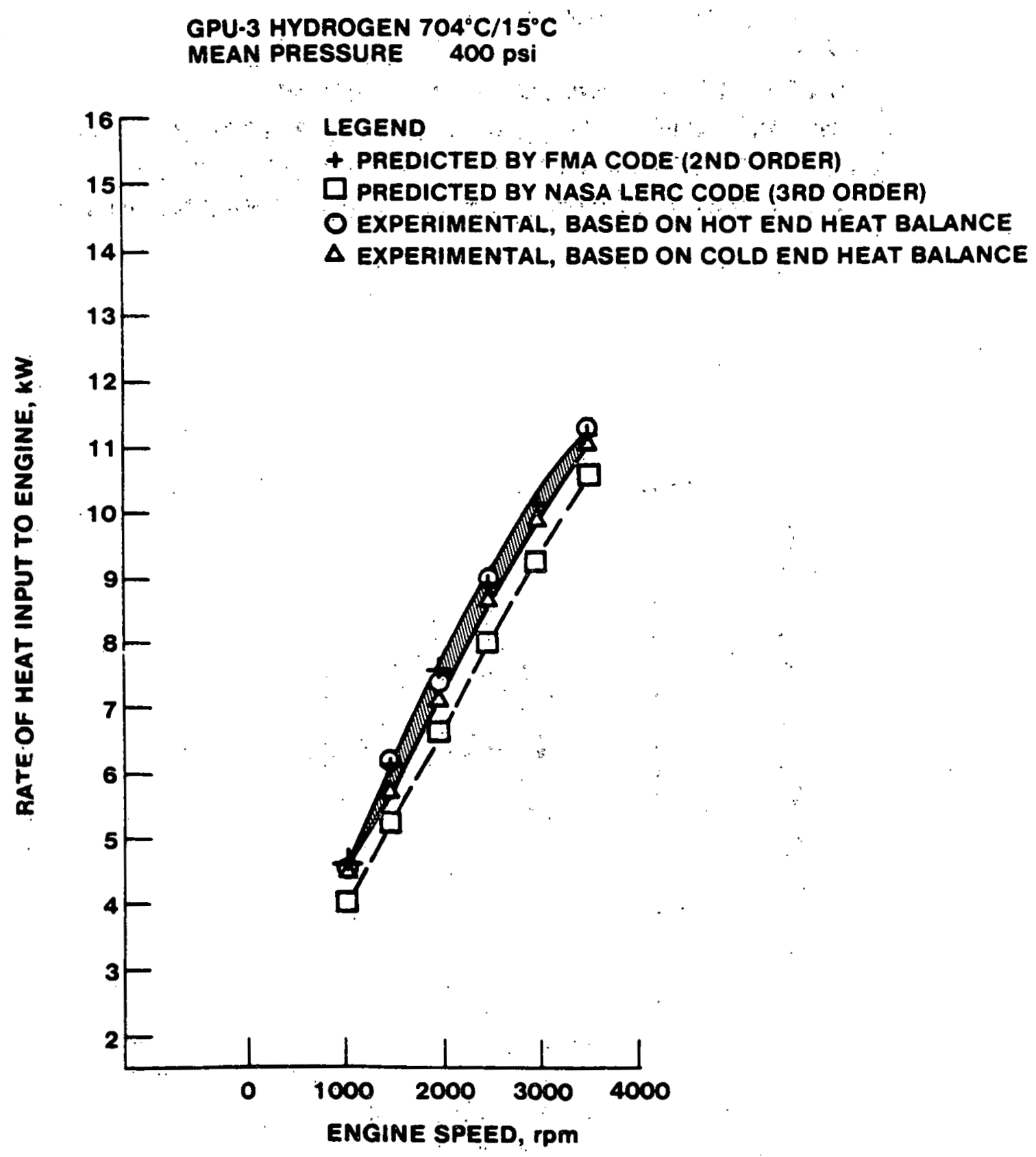

Figure 16. Comparisons of Heat Input Predictions with Experimental Data for GPU-3 
GPU-3 HYOROGEN $704^{\circ} \mathrm{C} / 15^{\circ} \mathrm{C}$

LEGEND

MEAN PRESSURE ,400 p8I

+ PREDICTED BY FMA CODE (2ND ORDER)

$\square$ PREDICTED BY NASA LERC CODE (3RD ORDER)

O EXPERIMENTAL, BASED ON HOT END HEAT BALANCE

$\triangle$ EXPERIMENTAL, BASED ON COLD END HEAT BALANCE

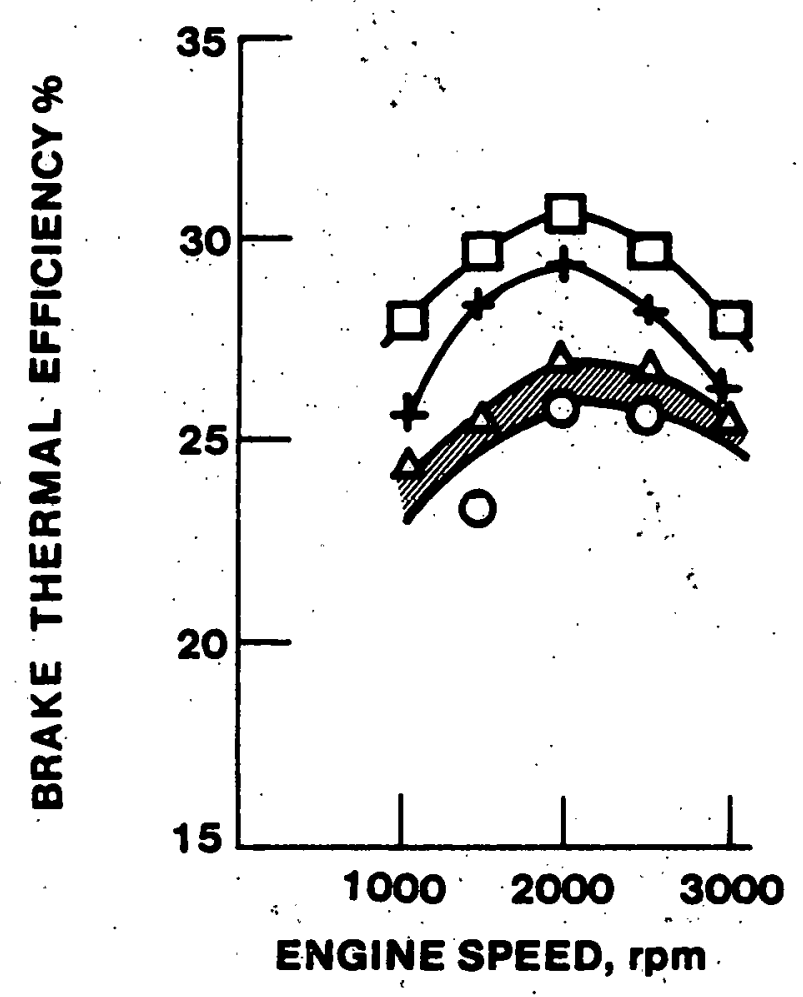

Fiyure 17. Comparison of Brake Efficiency Predictions with Experimental Data for GPU-3 
Figure 16 shows that heat input predictions of the FMA.; analysis is superior to NASA LERC analysis, and lie within the experimental data band.

Figure 17 shows that the brake efficiencies predicted by the FMA analysis were closer to the experimental data band than those predicted by the NASA LERC analysis. These comparisons shown in Figure 15, 16, and 17 demonstrate the fact that FMA has a relatively accurate and reliable stirling engine simulation program. The prediction accuracy of the FMA second order analysis is all

- the more remarkable considering the fact that it is at least two orders of magnitude faster than the simplest third order analysis.

Because of its accuracy and computational speed, the FMA analysis is a powerful tool for design and performance evaluation of Stirling engines.

\section{4 Sensitivity Analysis}

The purpose of the sensitivity analysis is to provide the Stirling engine designer with a range of values for the important thermodynamic parameters. With this portfolio of performance curves, the designer can perform a design tradeoff to arrive at various mechanical design configurations which satisfy the design objectives.

This method of engine thermodynamics analysis and design is instructive for the designer since it provides him with an intuitive understanding of the thermodynamic performance of stirling engines.

Both the SUNPOWER third order analysis and the FMA second order analysis were used to investigate the sensitivities of various engine parameters on stirling engine performance. 
This investigation includes the sensitivity analysis of piston phase angle, heater wall temperature, engine speed, various methods of power control, etc. Also included in the investigation were the sensitivity of heat exchange NTU's for both cooler and heater, on engine performance and the effect of changing heat capacity of regenerator material on engine performance. Some of the results of the sensitivity analysis will be presented in graphical forms below.

Figure 18 shows the effect of piston phase angle on Stirling engine efficiency and power: According to the results, the piston phase angle should be between 70 and 100 deg in order to achieve high efficiency and high power density. For double acting engines, the five-cylinder arrangement with 72 deg piston phase angle is slightly preferred to the usual four-cylinder arrangement from the thermodynamic considerations.

Figure 19 shows the rapid increase in efficiency and power as the heater wall temperature increases. The hot end temperature is limited by materials limit for the burner or heater tubes, especially more so due to uneven distribution of combustion gas causing local hot spots in the heater tubes.

In order to obtain the highest thermodynamic performance under the present materials limit on heater wall temperature, one can attempt to eliminate the local hot spots by employing indirect heat transfer method such as heat pipe or high pressure inert gas circulation loop. As a short term approach to this objective of reaching higher heater wall temperature, FMA Viking-l design has a cast alloy, monolithic heater head shown in Section 5. This design reduces the strain in the heater tube wall due to the differential thermal expansion at the tube joints by having the heater tubes attached to the monolithic heater head. 
VIKING-1

He $900 \mathrm{rpm}$

150 BAR

$7200 / 500^{\circ} \mathrm{C}$

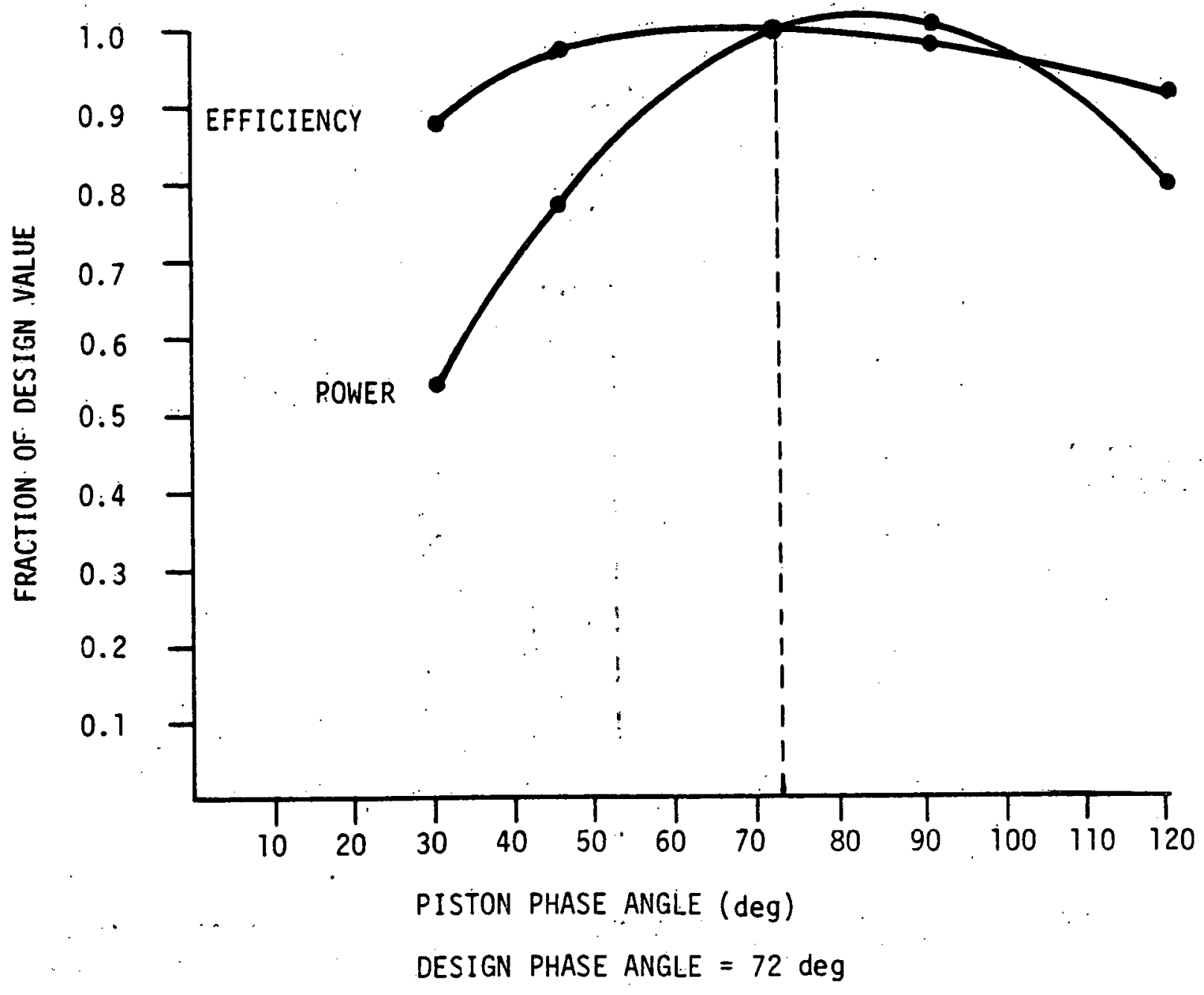

Figure 18. Effect of Piston Phase Angle Variation, on Stirling Engine Performance 
VIKING- 1

He $900 \mathrm{rpm}$

150 BAR

FRACTION OF

DESIGN VALUE

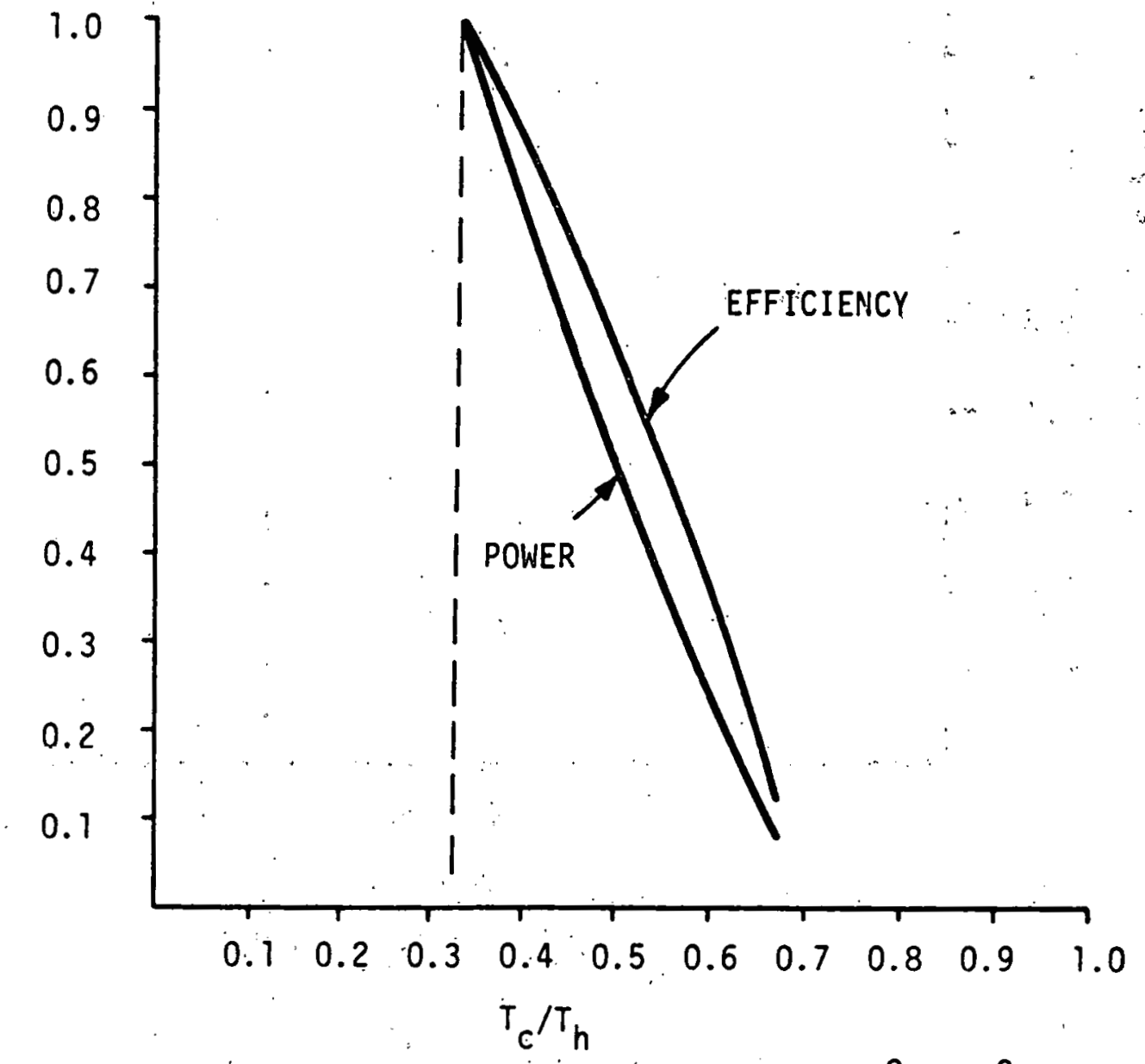

$T_{c} \cdot=$ COOLER WALL. TEMPERATURE $323^{\circ} \mathrm{K}\left(50^{\circ} \mathrm{C}\right)$

$T_{h}=$ HEATER HALL TEMPERATURE

$T_{c} / T_{h}=0.32$ AT DESIGN

Figure 19. Effect of Hot Temperature Variation On Stirling Engine Performance 
In order to choose the best speed for the FMA designed stationary engine Viking-1, the FMA second order analysis was used to predict the viking-1 performance over a speed range. Figure 20 shows both indicated and brake thermal efficiency and power versus speed evaluated at five different speeds. $(600,700$, $900,1200,1800$ ) which are compatible with alternator arrangements. The power losses associated with seal leakages, the mechanical frictions, and auxiliary power demand were extrapolated based on the data from several modern. Stirling engines. From this analysis, the speed for the FMA Viking-1 was chosen to be $900 \mathrm{rpm}$, at which speed the brake thermal efficiency is 42.5 percent.

Figure 21 shows the changes in efficiency and power of Stirling engines when the heat exchange effectiveness (measured in NTU's) in the heater changes. For a stirling engine with fixed operating conditions such as pressure, temperature, speed, etc., higher NTU's means larger heat exchange surface. Figure 21 indicates that there is little to be gained in engine performance by increasing heater NTU beyond 1.0. On the other hand, too small an NTU, that is, values below 0.8 will cause noticeable decrease in efficiency and power. The present Viking-2 design has an NTU value of 0.88 .

A similar observation is made for the cooler in Figure 22. Here an NTU value of 1.2 to 1.3 seems to be a reasonable design (design point 1.3). Beyond 1.3, practically no benefit will be gained by increasing cooler NTU for the given engine design under investigation.

Figure 23 shows the effect the specific heat of regenerator matrix material has on Stirling engine power and efficiency. The specific heat is represented by a dimensionless time, $\sigma$, defined by: 


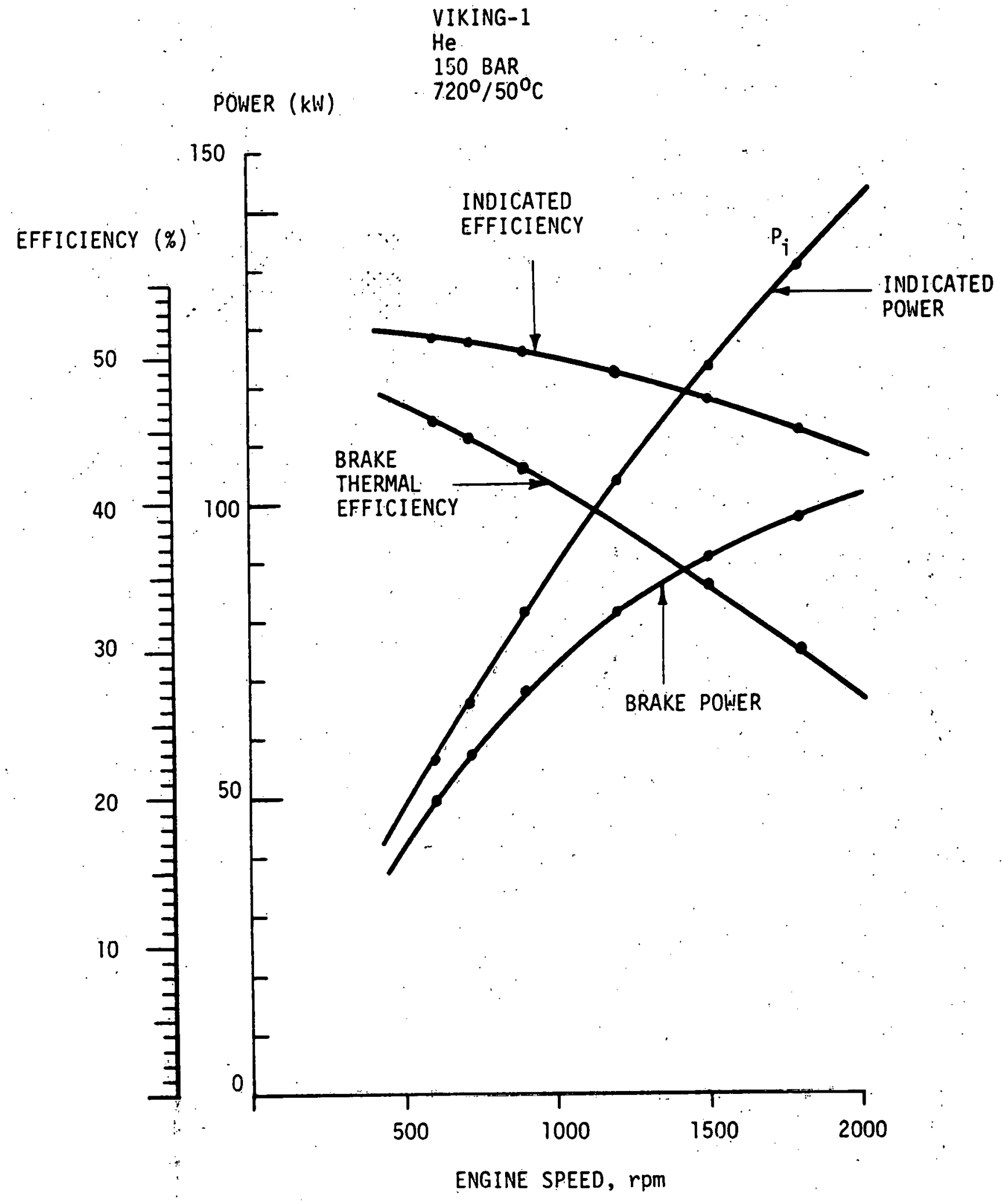

Figure 20. FMA Viking-1 Performance Versus Engine Speed 


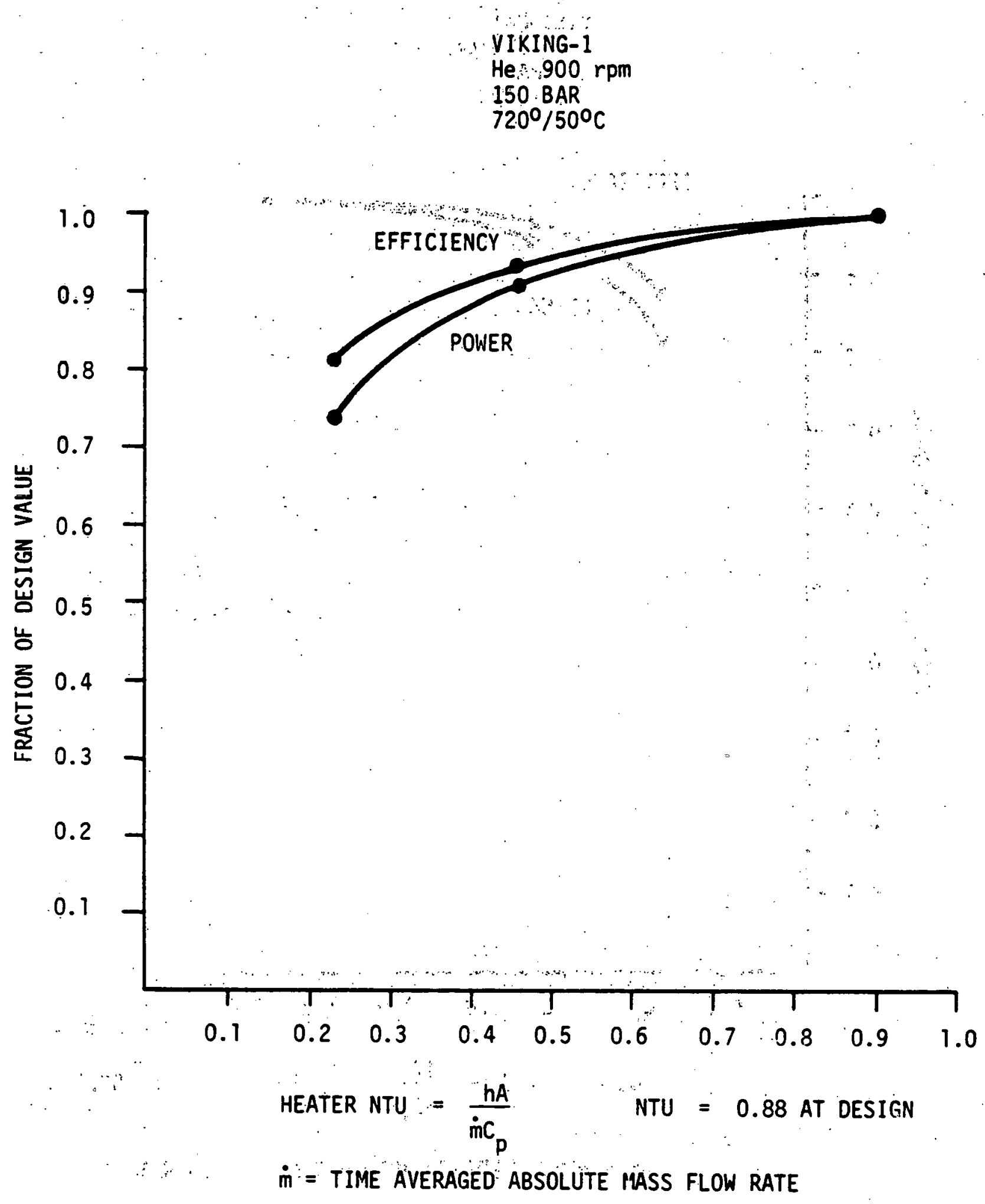

Figure 21." Effect of Heater NTU Variation on Stirling Engine Performance 


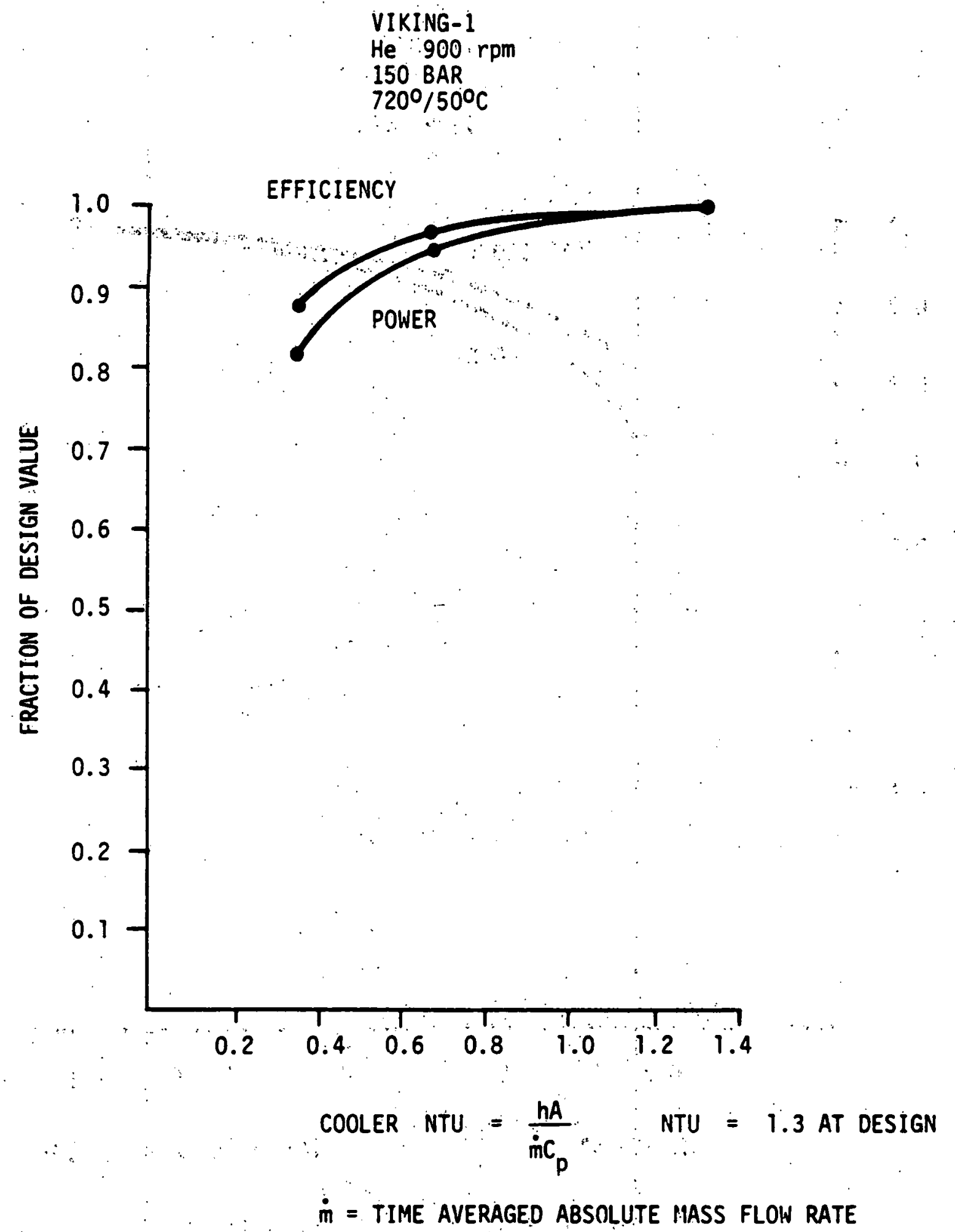

Figure 22. iffeot of cooler NTU Variation on Stirling Engine Performance. 
VIKING-1

He 900 rpin

150 BAR.

$720^{\circ} \mathrm{C} / 50^{\circ} \mathrm{C}$

DIMENSIONLESS TIME

$\sigma=\frac{C_{P} P S D^{2}}{R T m C}$

LEGEND

$\mathrm{m}=$ MATRIX MASS

$C=$ MATRIX SPECIFIC HEAT

$T=$ MEAN GAS TEMPERATURE IN

$\mathrm{R}=$ GAS CONSTANT

$C_{p}=$ GAS SPECIFIC HEAT

$P=$ CHANGE IN PRESSURE

$S=$ STROKE.

$D=$ PISTON DIAMATER

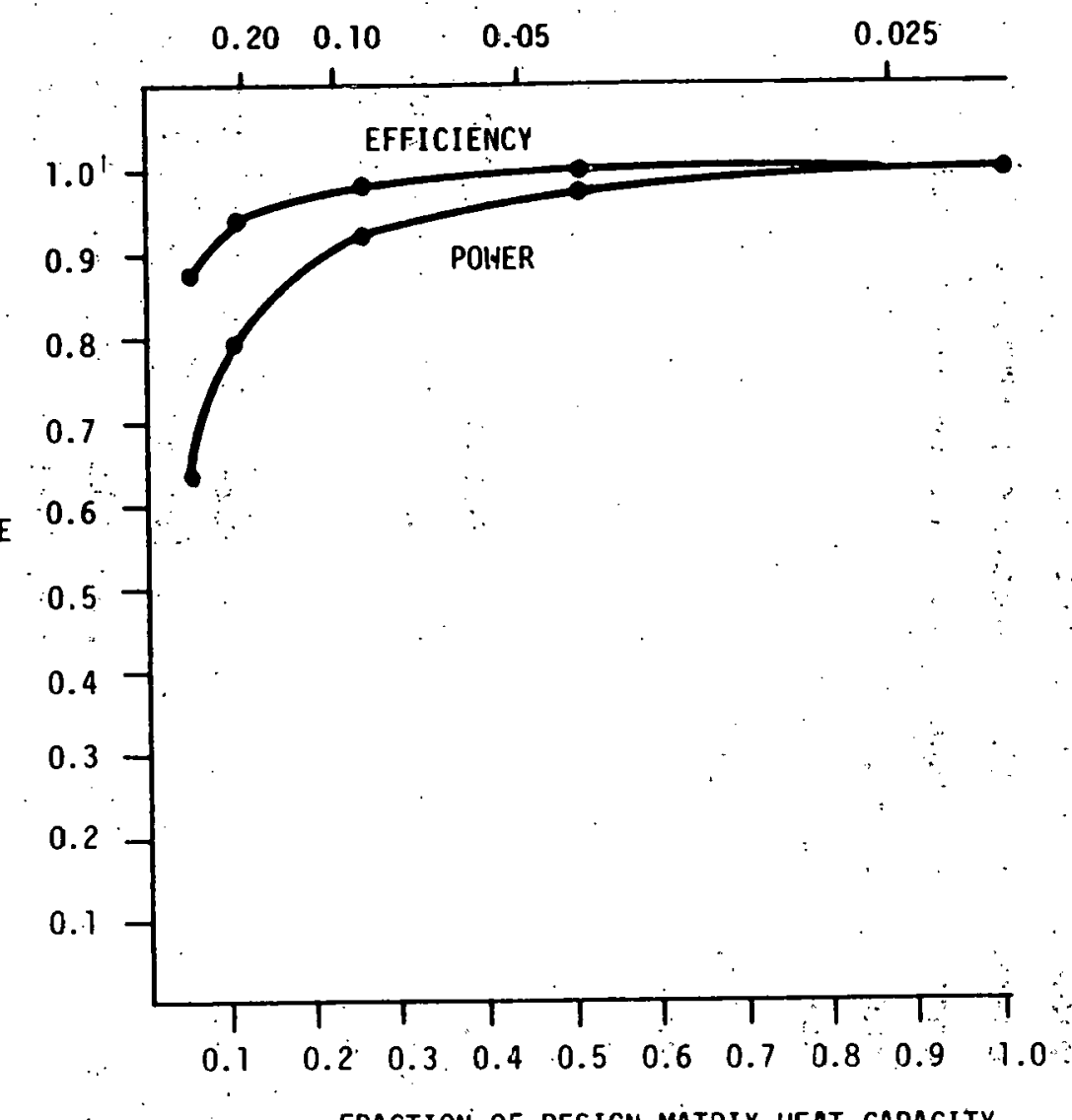

FRACTION OF DESIGN MATRIX HEAT CAPACITY

$\left(\mathrm{mC}=7.1 \mathrm{E} 3 \mathrm{~d} /{ }^{\circ} \mathrm{K}\right.$ AT DESIGN)

Figure 23. Effect of Regenerator Matrix Specific Heat Variation on Stirling Engine Performance. 


$$
\sigma=\frac{C_{p} P S D^{2}}{R T M C}
$$

where

$$
\begin{aligned}
M & =\text { mass of matrix material } \\
C & =\text { specific heat of matrix material } \\
T & =\text { mean gas temperature in regenerators } \\
\mathrm{R} & =\text { gas constant } \\
\mathrm{C}_{\mathrm{p}} & =\text { gas specific heat } \\
\mathrm{P} & =\text { chäge pressure } \\
\mathrm{S} & =\text { stroke } \\
\mathrm{D} & =\text { piston diameter }
\end{aligned}
$$

$\sigma$ is defined as the ratio of entrained gas to matrix heat capacity multiplied by the ratio of cycle period to mean fluid transit time in the regenerator.

The information shown in Figure 23 will be a major factor in choosing the proper material for regenerator matrix, along with other factors such as materials cost and manufacturability. It was noted that some matrix material has a desirable tendency of having increased specific heat at higher temperatures.

The relative merits of five different methods of power modulation are shown in Figure 24." of the five control methods investigated, heater temperature control is immediately. eliminated due to the rapid drop in efficiency at partial power which is a thermodynamically obvious consequence of having lower temperature heat source.

The phase control seems to be reasonable as long as the power modulation is as low as 80 percent of design power; beyond that other control methods are clearly more advantageous. 
VIKING- 1

$\mathrm{He} 900 \mathrm{rpm}$

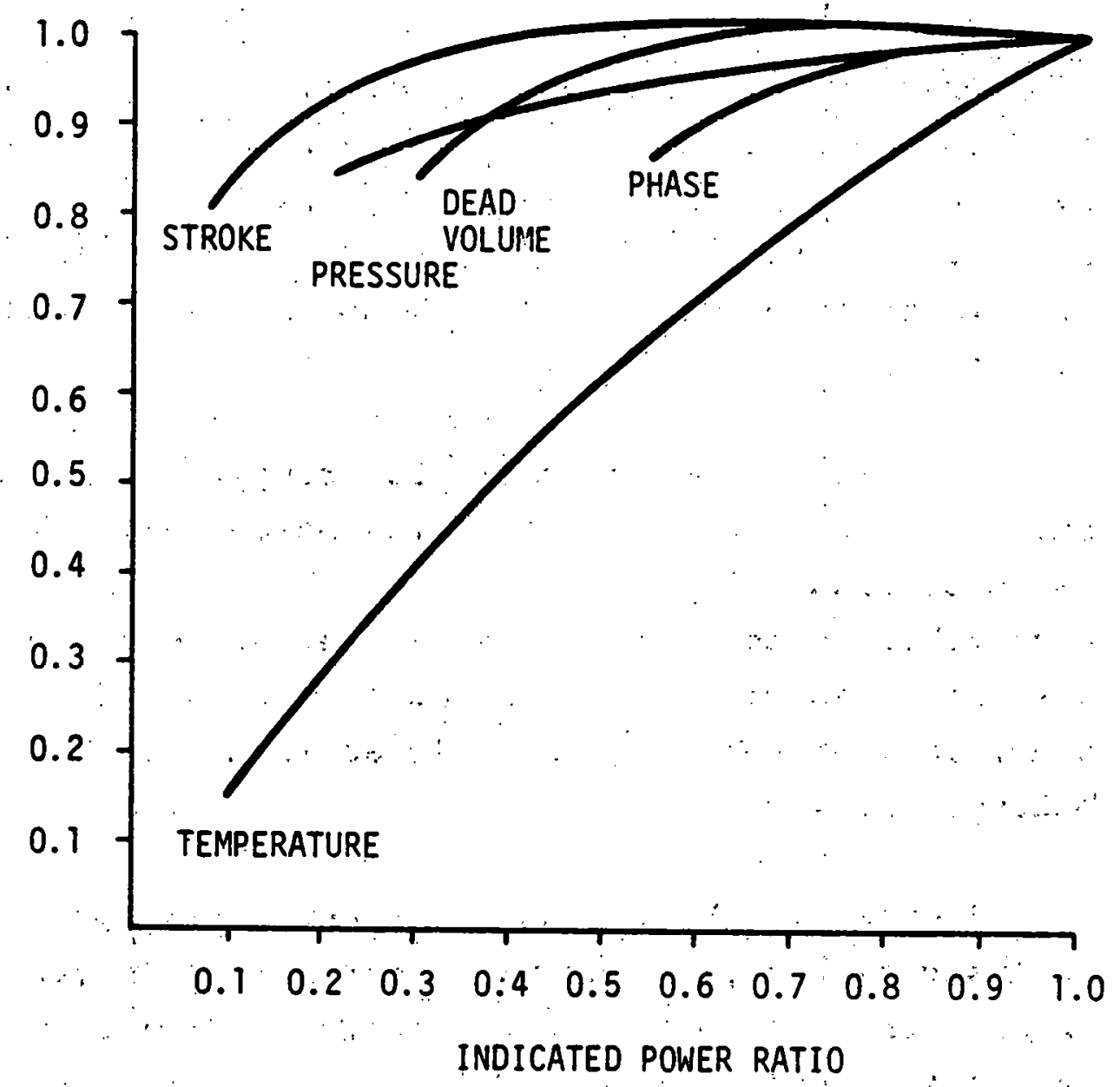

Figure 24. Comparison of Power Control Methods For a Stirling Engine 
From the thermodynamic point-of-view, stroke control is the best method to control the power of stirling engine for a wide range of power modulation; that is, virtually no loss in indicated efficiency occurs down to 40 percent of design power. However, the means to achieve stroke variation such as variable angle swashplate configuration, or the present FMA design shown in section 6 has yet to be proven reliable.

Dead volume control seems to give reasonable efficiencies down to 50 percent of design power. However, this method requires extra reservoirs at high pressure and all the connecting lines and valve arrangements.

Pressure control is less efficient in part power than both dead volume control and stroke control. The pressure control requires high pressure reservoirs, connecting passages, valves, and a compressor. One advantage of pressure control would be the fact that it has been already used in several automotive Stirling engines.

In case the power modulation range is limited to, for example, 70 to 80 percent of design power; all four control methods (stroke, dead valves, pressure, and phase control) seem to be acceptable although there are slight differences in performance. The final decision on power modulation methods will depend on other factors such as difficulties in mechanical design, reliability, cost, etc.

Figures 18 through 24 represent a part of the sensitivity analysis performed which was instrumental in arriving at the present FMA Viking-l stirling engine design for statiọary power generation applications. 


\subsection{Thermodynamic Performance Prediction of FMA Engine Design}

Using FMA second order analysis which had been proved to be quite accurate in its predictions, the thermodynamic performance was predicted for the FMA's basic engine design (Viking-l) shown in section 6." Since the same basic engine design is used in all of FMA's recommended candidate engine layouts, the following thermodynamic performance analysis applies to all the candidates, although slight differences in performance may result due to the different mechanical design at the bottom end of the engines.

Table 5 presents the detailed breakdown of the basic power and heat input along with an itemized list of various power and heat input losses discussed previously in subsection 3.1. The results for FMA designed Viking-l engines are shown alongside the result for a modern reference engine designated as 4-D2 from which FMA Viking-1 was initially scaled up. Note the fact that Viking-1, using Helium as the working gas has better efficiency than the reference engine even though the reference engine uses hydrogen as the working gas.

Figure 25 is the energy flow diagram of the viking-1 engine. It shows that 6.4 percent heat input, was diverted away from the power conversion process by leaking into environment and cooling water. Isothermal heat rejection to cooler ( 30.4 percent) was from the net heat input (93.6 percent) multiplied by ( 1 -Carnot efficiency), which is dictated by the Second Law of Thermodynamics in the case of isothermal ideal Stirling cycle. Adiabatic power loss is the largest loss ( 7.4 percent) and is the result of the assumption that cylinder processes are adiabatic instead of isothermal. Then there is a significant power loss called cyclic heat transfer loss ( 5.5 percent) due to the fact that in actuality the cylinder processes are not truly adiabatic but nonadiabatic with cyclic heat transfer. 


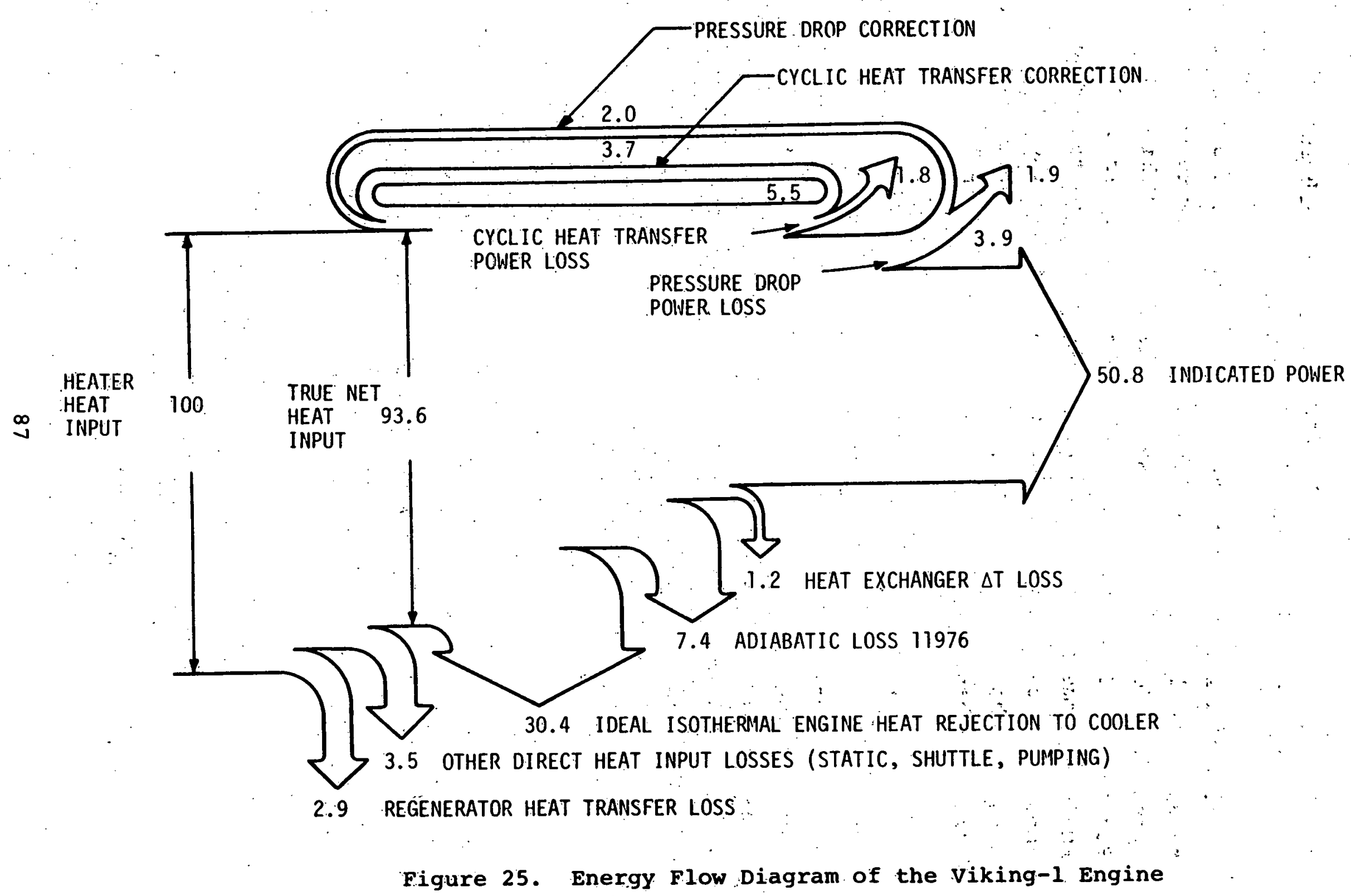


As previously shown in Figures 21 and 22 , the NTU's of the heater and the cooler were designed near the point of diminishing return. The small heat exchanger $\Delta \mathrm{T}$ loss of 1.2 percent, which is the result of finite NTU's of the heater and the cooler, demonstrate this. The pressure drop loss of 3.9 percent, which is the result of pressure drop through: the heat exchangers and passages, is almost the best one could achieve given the design requirements. The feedback loops of cyclic heat transfer power loss and $\Delta \mathrm{P}$ power loss are artificial ones, generated by the particular method of the FMA analysis, and should not be misunderstood as actual losses.

In order to demonstrate the relative magnitudes of losses more clearly, only the power and heat input losses are shown in. the pie chart (Figure 12) in proportion to their relative importance.

It shows that heat input loss is only approximately onequarter of all the losses, and the remainder three-quarters is the power loss. The salient point is that the power loss has a higher weighting factor than the heat input loss because the power loss occurs after the power conversion from heat input occurs at a much lower efficiency than the carnot efficiency. Therefore, it can be shown that the power loss is approximately six times as important as the heat input loss, assuming 50 percent power conversion efficiency.

Looking at this important power loss, two larger losses, that is, adiabatic loss and cyclic heat transfer loss constituting approximately three-quarters of total power loss, can be theoretically eliminated, thereby increasing the efficiency and power substantially, by making the cylinder processes isothermal. Therefore, for the long-term, isothermalization of cylinder spaces has to be attempted in order to achieve a quantum jump in stirling engine efficiency. 
It would be worthwhile to show, on the same graph, the resulting performance of the FMA Viking-l engine for large stationary power generation applications and the performance of the smaller, automotive modern stirling engines, one of which. Viking-l was scaled up from. Figure 26 shows that the FMA designed Viking-1. which has an output of $80 \mathrm{~kW} / \mathrm{cylinder}$ and uses helium: as working gas achieved a higher efficiency than smaller (less than $20 \mathrm{~kW} /$ cylinder) Stirling engines using hydrogen as working gas.

\subsection{Conclusions and Recommendations}

FMA has a second order stirling engine analysis which is very fast, reliable, and accurate. This analysis was validated against the highly refined. SUNPOWER third order analysis in detail. The FMA second order analysis predicts the thermodynamic performance of three existing stirling engines with maximum 15 percent error.

FMA second order analysis has a unique loss mechanism called cyclic heat transfer loss. which has not been recognized as an important loss mechanism by other stirling engine investigators so far. This is a major power loss mechanism in stirling engines, and has to be considered in designing the engine internal geometry.

FMA second order analysis, being. extremely fast and accurate in its predictions, is suitable for both performance analysis and design optimization. It has become a very effective design tọol. For detailed thermodynamic investigation and design, FMA has access: to the powerful SUNPOWER third order analysis. Based on thermodynamic analysis alone, the stroke control is the best power modulation method. Dead volume control and mean pressure control follow next: Engine optimized for helium can have efficiencies as high as or higher than the engine optimized for hydrogen. 


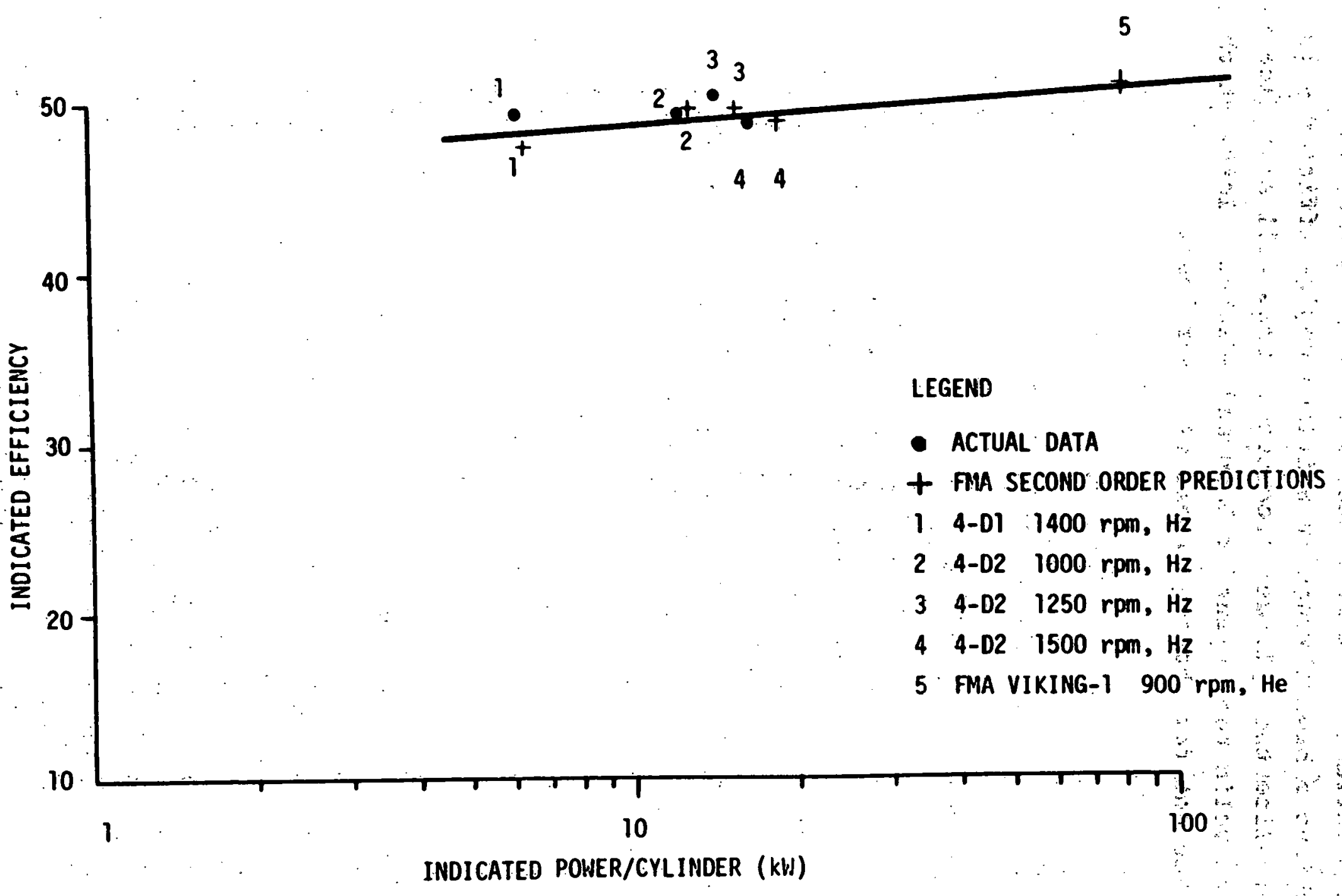

Figure 26. Effect of Scaling-Up on Stirling Engine Performance 
Under the materials limit in heater wall temperature, the only way to achieve a breakthrough in stirling engine efficiency is to isothermalize the cylinder processes. This will significantly reduce the cyclic heat transfer loss and adiabatic loss, which combined account for three-quarters of power loss.

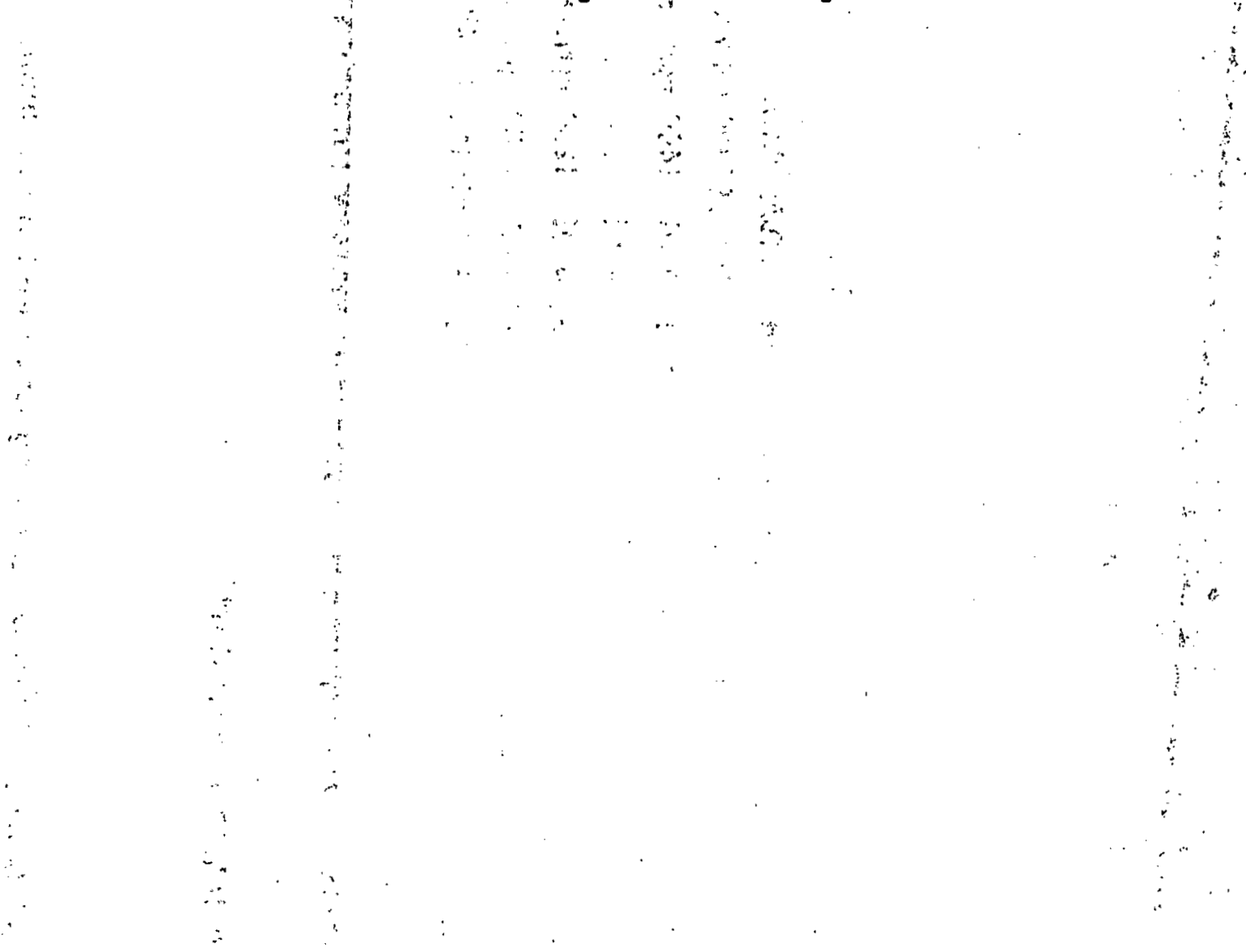


4. COMBUSTION SYSTEMS ANALYSIS AND DESIGN

All combustion engine types place specific constraints on. specific fuel qualities or conversely a specific fuel implies a limited range of practical hardware concepts. For example the diesel and spark ignition engines have different constraints on ignition characteristics; the diesel desires a low ignition temperature fuel (high Cetane No.) while the spark ignition engine desires a high ignition temperature fuel (high octane No.). These properties unfortunately are only practical in a very narrow range of liquid and gaseous fuels.

As a general class the continuous combustion engines such as gas turbines, steam and stirling engines are particularly insensitive to the fundamental combustion properties of the fuel. Their fuel quality requirements are generally only constrained by corrosion and ash characteristics of the combustion products. In continuous combustion engines with heat addition through a heat exchanger it is technically and usually practically feasible to use nearly any "fuel." A notable example is the bituminous coal fired central steam power plant. One of the attractions of the stirling engine is the potential for low quality fuel use in the high efficiency cycle.

Stirling engine heating. systems are perhaps the most highly interactive system in the power field. None of the components can be designed in isolation as the specific performance of each part directly affects the performance of all others.

Based on current engine developments, there appear to be no major obstacles to burning conventional liquid and gaseous fuels. Improvements should be pursued in emissions, durabilitý, velocity, and temperature profiles as well as for wider cut and higher ash 
content fuels. A clean fuel combustion system which burns either natural gas or oil is described in the following subsection.

Because the stirling engine is an external combustion engine, fuels which produce high levels of abrasive particulates and relatively large amounts of corrosive by-products can be used without adversely affecting the engines operating parts. The atmospheric fluidized bed combustion system for the burning of coals is selected as the suitable coal combustion system candidate for the large Stirling cycle engine and is presented in subsection 4.2.

\subsection{Clean Fuel Combustion System}

This subsection describes the analysis and design of a clean fuel combustion system for a large stirling cycle engine. This combustion system is designed for direct coupling to the heater head of the engine and is restricted to the use of clean fuels. clean fuels are defined as those which do not have solid particulates in the combustion products at concentrations that will coat heat exchanger" surfaces at a high rate with soot or ash; and also do not contain high levels of sulfur or vanadium which may cause rapid corrosion of engine components. Natural gas and other gaseous fuels qualify as clean fuels. Also, because of the unique method of fuel preparation used in the proposed burner and other FMA-designed burners, any fuel oil "cut" up to and including No. 2. fuel oil may be considered as a clean fuel.

In FMA burners liquid fuel is vaporized by atomization into a carrier stream of hot gases, either exhaust gas recirculation (EGR); or combustion gas recirculation (CGR) mixed with air. Vaporized fuel and air mixtures then burn with a sootless, quiet, blue flame. Figure 27 shows how fuel vaporization has been applied to the proposed combustion system. This principle has been applied successfully many times at FMA for gasoline and No. 2 fuel oil, for burners ranging in size from $586 \mathrm{~kW}(2 \mathrm{M} \mathrm{Btu} / \mathrm{hr})$ to 


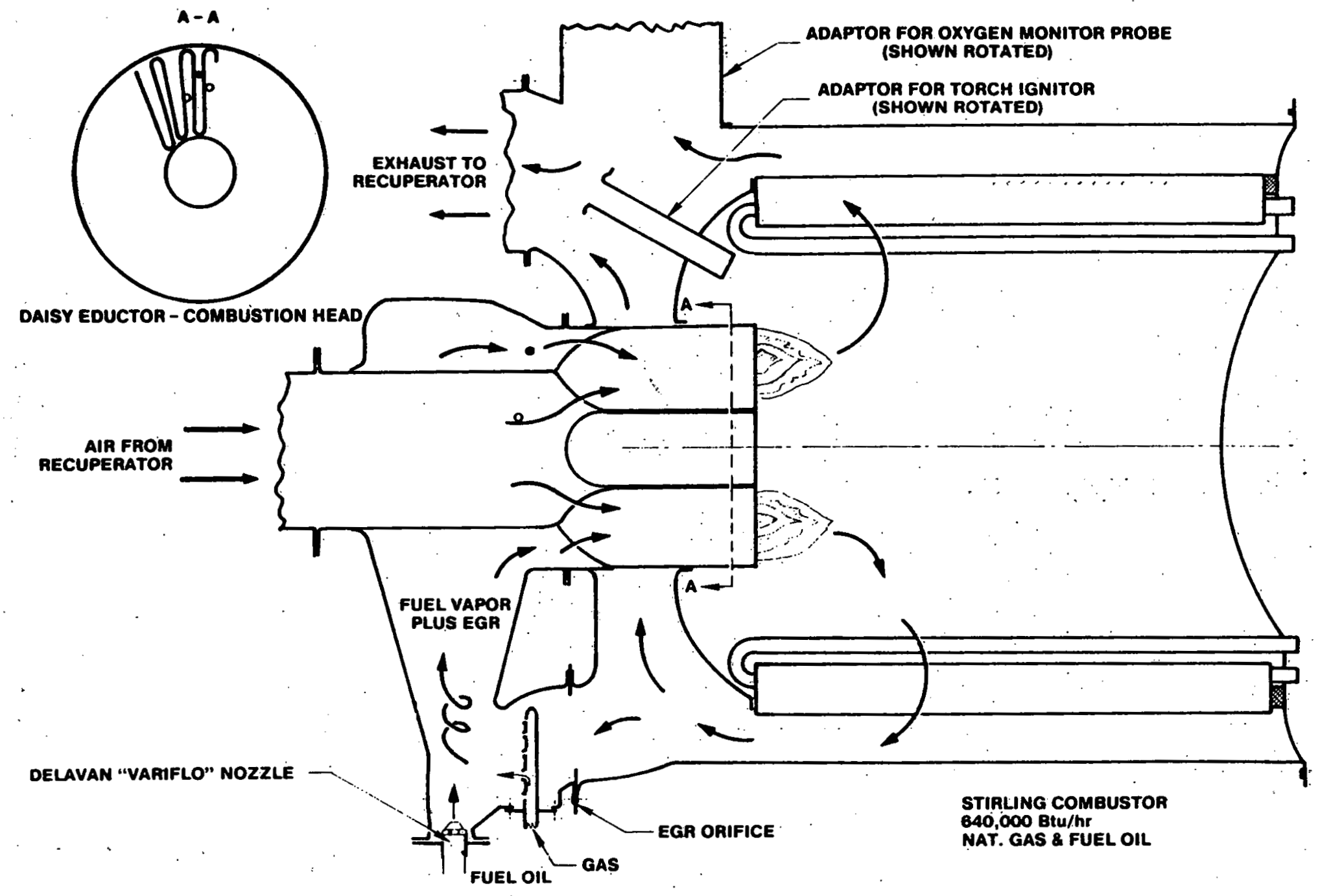

Figure 27. Clean Multifuel Burner for Stirling Engine 
$2.9 \mathrm{~kW}(0.01 \mathrm{M} \mathrm{Btu} / \mathrm{hr})$, and for a 20 to 1 turndown variable firing rate burner (No. 2 diesel fuel) with a response time of 2 sec (21-23). Table 6 illustrates the depth of FMA's experience in conventional fuel combustion.

The design goals for the proposed clean fuel combustion system are presented in Table 8. To meet these design goals requires several critical compromises. For example; low excess air. (XSA) and low EGR enhance efficiency, but the resulting high flame. temperature would cause high levels of $\mathrm{NO}_{x}$ pollution. High preheat of the combustion air results in higher efficiency, but also subjects the recuperator and burner materials to high temperatures. High recuperator effectiveness is desirable; but is achieved at the cost of recuperator size. For example, increasing recuperator effectiveness from 0.90 to 0.95 more than doubles the volume of: the recuperator.

A practical set of compromises was arrived at after a mathematical model of the combustion system was analyzed for the effects of various parameters on temperatures throughout the system. Specifications for the resulting combustion system are presented in Table 9. The EGR and XSA ratios have been carefully chosen to control both the flame temperature and burner temperature.

4.1.1 Proposed Clean Fuel Combustion System Analysis and Design

There are several options for the clean fuel combustion system:

- Conventional direct fired system

- Split flow recuperator direct fired system

- Remotely fired system with a heat transfer loop between the burner and engine heater heäd. 
Table 7. Typical FMA Experience in Conventional Fuel combustion

\begin{tabular}{|c|c|c|c|c|c|c|c|c|c|c|c|}
\hline : Title & $\begin{array}{l}\text { VPR Gas } \\
\text { Burner }\end{array}$ & $\begin{array}{c}\text { FMA } \\
\text { VFR Oil - Burnex }\end{array}$ & $\begin{array}{c}\text { Mining } \\
\text { Steam } \\
\text { Engine }\end{array}$ & $\begin{array}{l}\text { Home Heat } \\
\text { Boiler }\end{array}$ & $\begin{array}{l}\text { Commercial } \\
\text { Hot. Water }\end{array}$ & $\begin{array}{l}\text { Steam Car } \\
\text { (5 Models) }\end{array}$ & $\begin{array}{l}\text { Heat Pump } \\
\text { Boiler }\end{array}$ & $\begin{array}{l}\text { Test Engine } \\
\text { Boiler }\end{array}$ & $\begin{array}{l}\text { Cali fornia } \\
\text { Steam Car }\end{array}$ & $\begin{array}{l}2 \mathrm{In} . \\
\text { Olameter } \\
\text { Test Rig }\end{array}$ & $\begin{array}{c}\vdots \\
\text { High Density } \\
\text { Bụrner }\end{array}$ \\
\hline 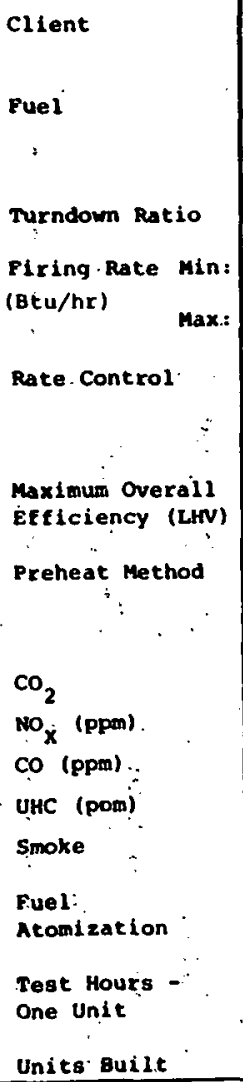 & 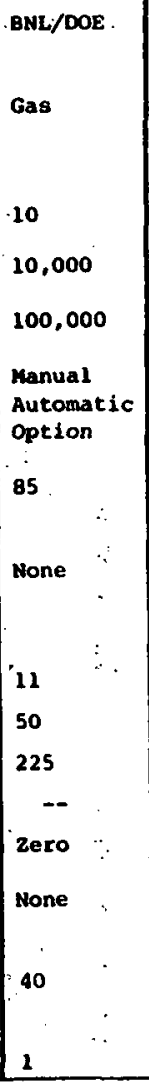 & 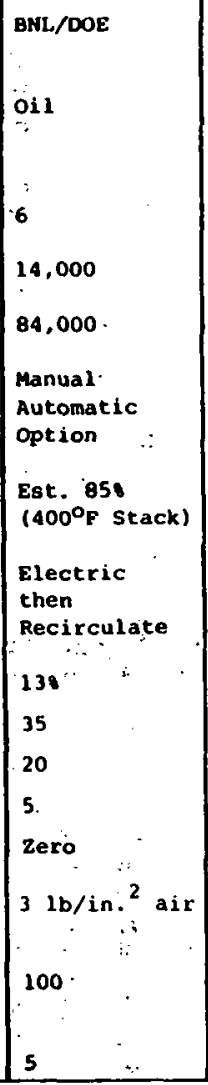 & $\begin{array}{l}\text { USBM } \\
\text { Oil } \\
20 \\
72,500 \\
1,450,000 \\
\text { Automatic } \\
948+ \\
\left(270^{\circ} \text { s Stack }\right) \\
\text { Oil rorch } \\
\text { then } \\
\text { Recirculate } \\
120 \\
20-40 \\
10-90 \\
5 \\
\text { zero } \\
31 \mathrm{~b} / \text { in }{ }^{2} \text { air } \\
100 \% \\
2 \\
\end{array}$ & $\begin{array}{l}\text {-Self- } \\
\text { Gas } \\
3 \\
45.000 \\
150,000 \\
\text { Manual } \\
\text { Change. } \\
\text { Orifice } \\
\text { o58 } \\
\text { None } \\
\ddots \\
118 \\
50 \\
225 \\
\text { 2ero } \\
\text { None } \\
\vdots \\
2 \cdot \text { years } \\
\text { in Home } \\
6 \\
\end{array}$ & 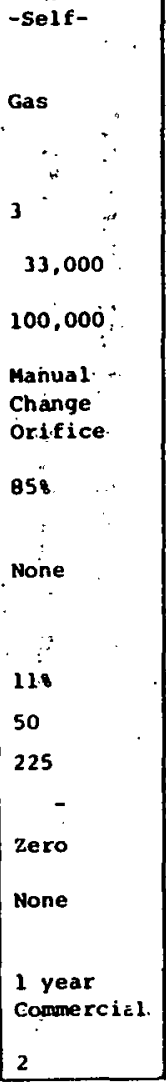 & $\begin{array}{c}\text { EPA/ERDA } \\
\text { Gasoline } \\
\vdots \\
20 \\
100,000 \\
2,000,000 \\
\vdots \\
\text { Automatic } \\
\\
961 \\
\text { Recircu- } \\
1 \text { ate } \\
10 \text { - } 148 \\
10-30 \\
15-500 \\
5 \\
\text { zero } \\
31 \mathrm{~b} / \mathrm{in} . \\
\text { air } \\
400 . \\
6 \\
\end{array}$ & $\begin{array}{l}\text { CNG } \\
\text { +ERDA } \\
\text { Gas } \\
10: \\
30 ; 000 \\
300,000 \\
\vdots \\
\text { Automatic } \\
\vdots \\
892 \\
\text { Airr-to-Air } \\
\text { Regenerate } \\
11.52 \\
50 \\
225 \\
\text { zero } \\
\text { None. } \\
\\
\text { Bo test } \\
\text { now in use } \\
1 \\
\end{array}$ & 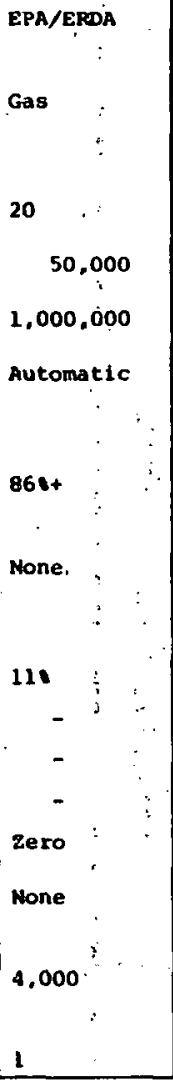 & 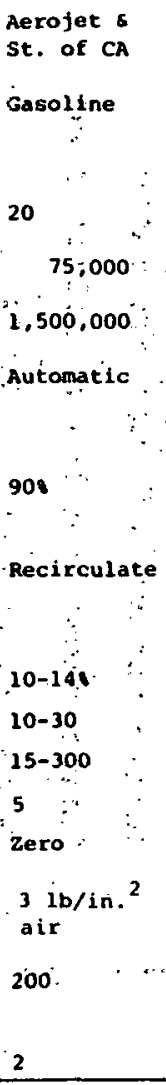 & 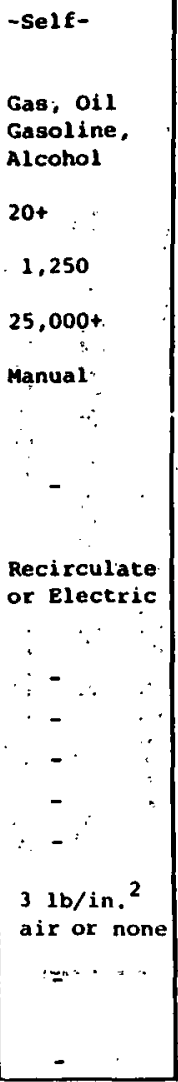 & 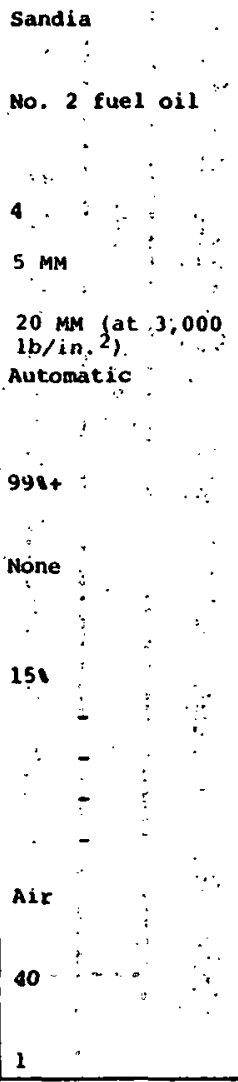 \\
\hline
\end{tabular}


Tabie 8. Clean Combustion System Design Goals

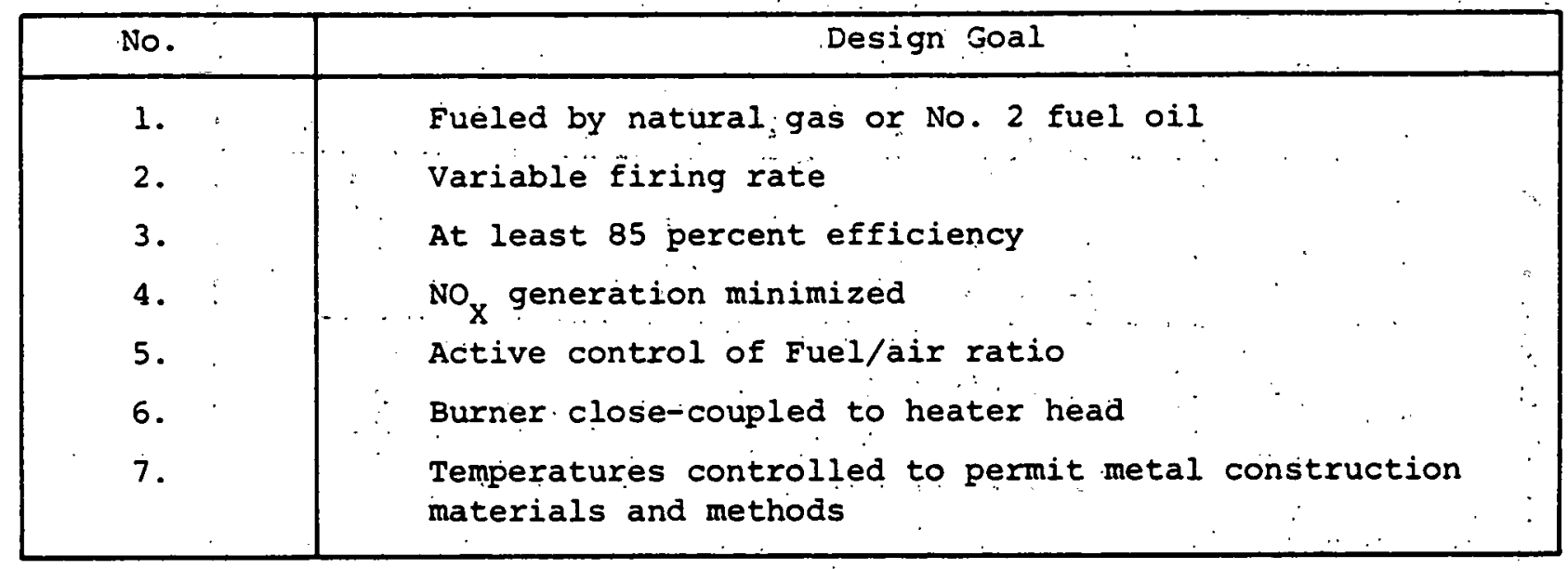

\section{Table 9. Burner Specifications}

\begin{tabular}{|c|c|}
\hline Parameter & Specification. \\
\hline Firing rate & 5 burners, $186 \mathrm{kw}(636,000 \mathrm{Btu} / \mathrm{hr})$ \\
\hline Turn-down. & 7 to 1 \\
\hline Fuels & Natural gas, propane, fuel oils up to 8 in. No. 2 \\
\hline F/H control & $\begin{array}{l}\text { fuel flow coupled to exhaust } \mathrm{O}_{2} \text {, zirconium oxide } \\
\text { sensor }\end{array}$ \\
\hline Firing rate control & $\begin{array}{l}\text { Blower speed or damper controls air flow, commanded } \\
\text { by engine system contrọl }\end{array}$ \\
\hline Excess air ratio & $\{0.65\}$ or $\{0.1\}$ \\
\hline EGR ratio & $(0.65) \quad(1.39)$ \\
\hline $\begin{array}{l}\text { Recuperator } \\
\text { effectiveness }\end{array}$ & 0.9 \\
\hline $\begin{array}{l}\text { Heater head } \\
\text { effectivenuss }\end{array}$ & 0.9 \\
\hline Flame temperature & $1538^{\circ} \mathrm{C}\left(2800^{\circ} \mathrm{F}\right)$ \\
\hline Exhaust temperature & $98^{\circ} \mathrm{C}\left(208^{\circ} \mathrm{F}\right)$ \\
\hline Exhaust dew point & $41^{\circ} \mathrm{C}\left(106^{\circ} \mathrm{F}\right)$ dry combustion air \\
\hline Combustor efficiency & 91 percent \\
\hline $\begin{array}{l}\text { Pre-combustion } \\
\text { temperature }\end{array}$ & $841^{\circ} \mathrm{C}\left(1545^{\circ} \mathrm{F}\right)$ \\
\hline EGR temperature & $787^{\circ} \mathrm{C}\left(1448^{\circ} \mathrm{F}\right)$ \\
\hline $\begin{array}{l}\text { Recuperator air output } \\
\text { temperature }\end{array}$ & $882^{\circ} \mathrm{C}\left(1619^{\circ} \mathrm{F}\right)$ \\
\hline
\end{tabular}


The last option can use either the conventional or split flow combustion system. Figures 28, 29, and 30 describe the three combustion system options.

A heater head with high heat transfer effectiveness has been designed for this engine, eliminating any need for the intermediate heat transfer loop shown in Figure 30.

A desirable feature of our combustion system is the vaporization of fuel oil by atomization into an inert or nearly inert, stream of exhaust gas, with final mixing with combustion air occurring at the burner head. This method of fuel vaporization eliminates the possibility of explosion or burning behind the burner head and also eliminates the necessity of controlling the temperature in the relatively narrow range between fuel vapor dew point and the ignition point, as is the case when vaporizing in a hot air stream. These considerations eliminate the split flow recuperator option of Figure 29.

The combustion system proposed is an adaptation of the first option (conventional direct fired, Figure 28) with the recuperator outside the EGR loop, and is presented in Figure 31.

This placement of the recuperator has several important advantages. Other parameters remaining constant, changing the placement of the recuperator from inside the EGR loop to outside results in calculated temperature increases of less than $38^{\circ} \mathrm{C}$ $\left(100^{\circ} \mathrm{F}\right)$. However, placement outside the EGR loop greatly reduces the mass flow in the recuperator (both streams) permitting a proportional decrease in size for equivalent thermal transfer effectiveness. This placement of the recuperator also eliminates the EGR duct from the exhaust end of the recuperator to the blower, and provides a hot EGR stream for vaporization of fuel. 


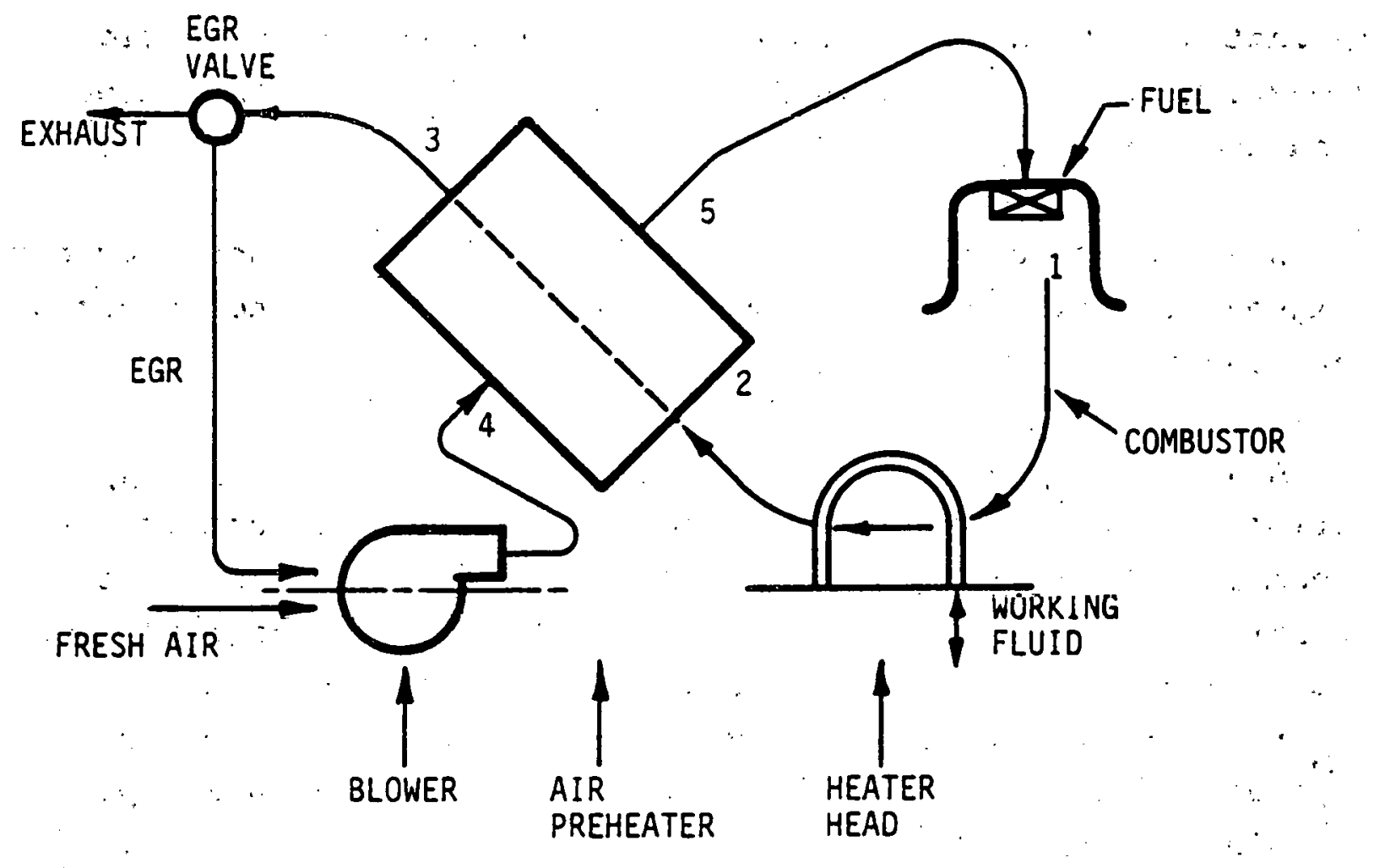

Figure 28. Conventional Direct Fired Heating System

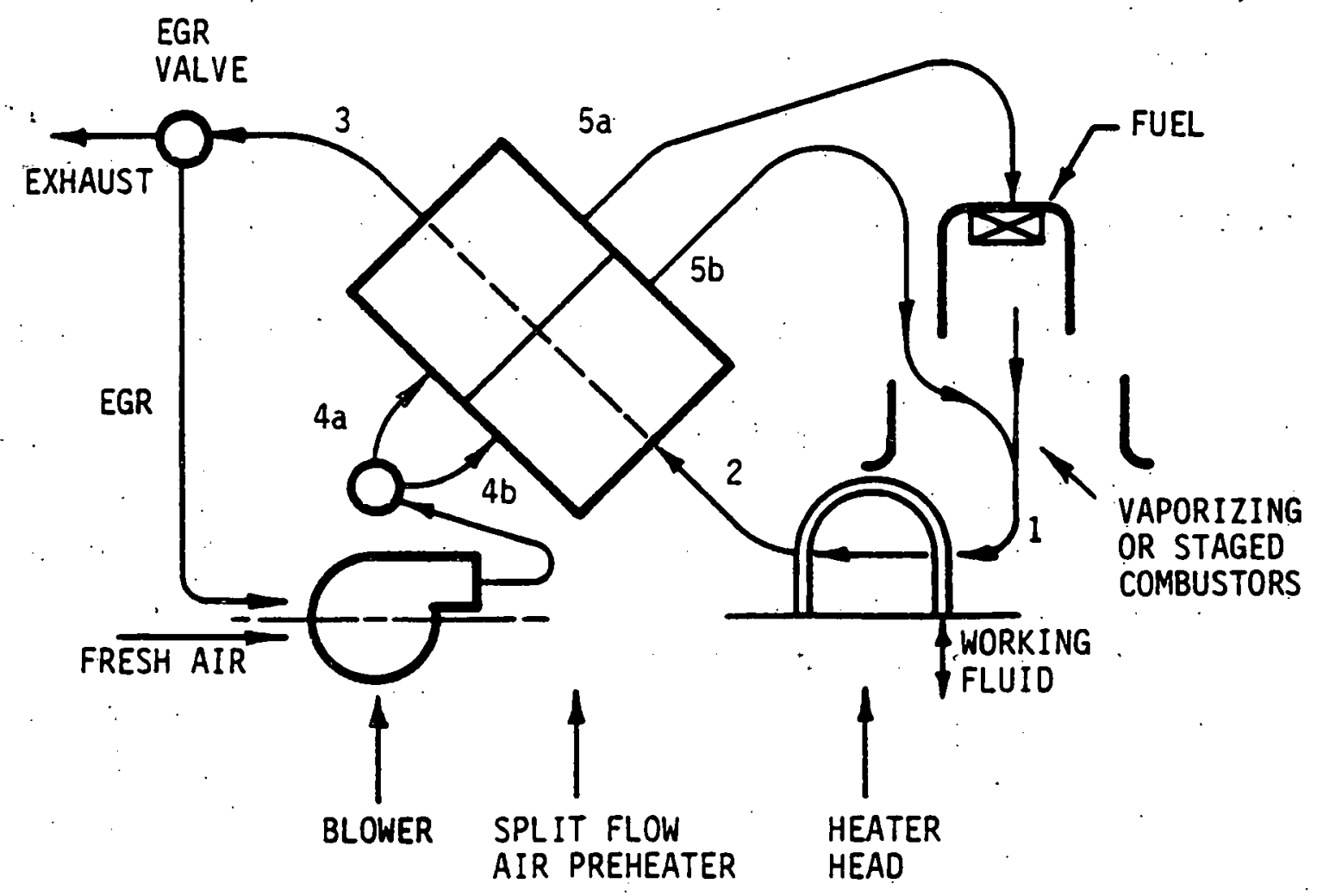

Figure 29. Split Flow Air Preheater, Direct Fired Heating System. Provides Cooler Air For Vaporizing or Staged Combustion 


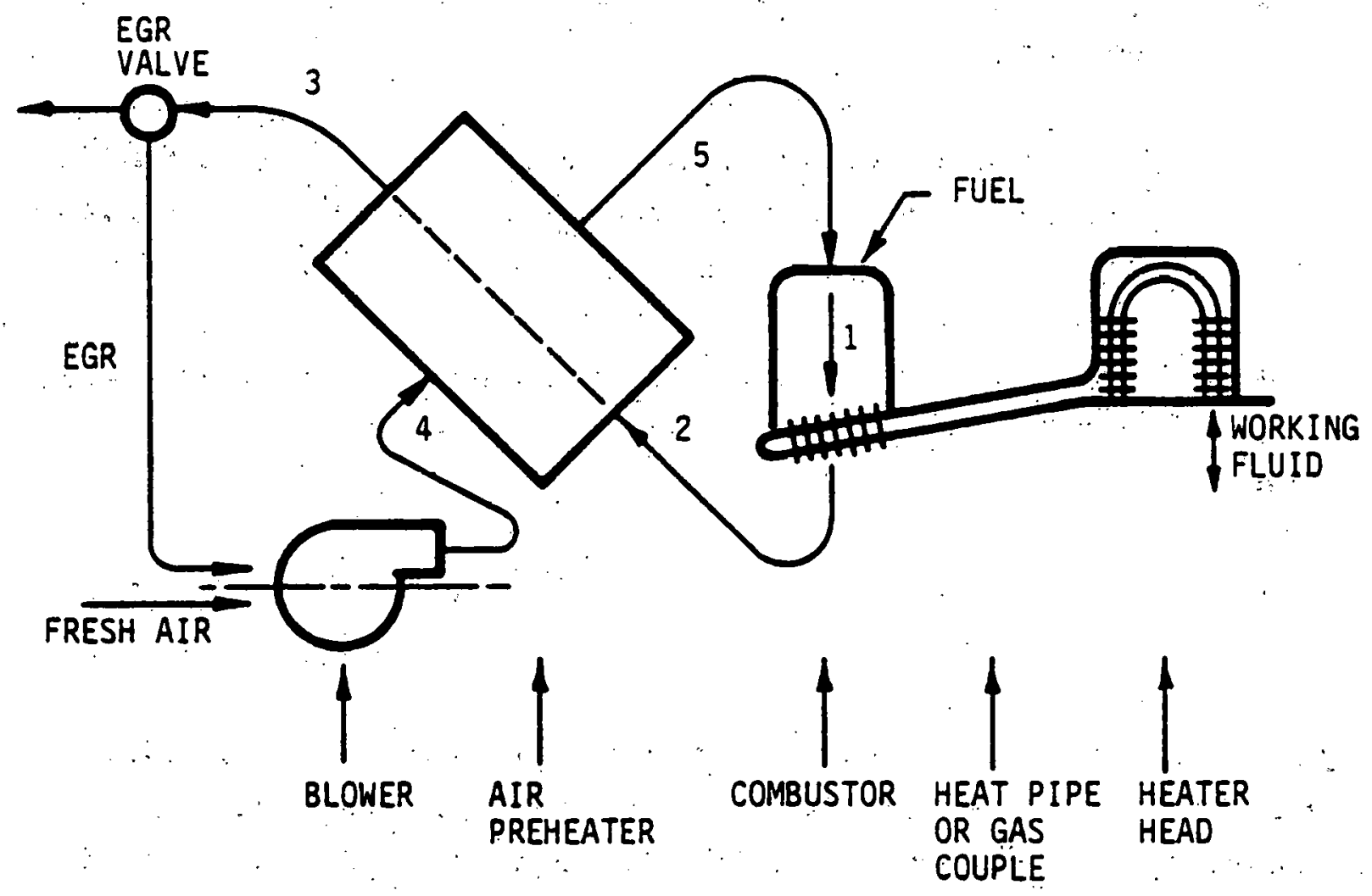

Figure 30. Remotely Fired Heating System with Heat Pipe or Gas Couple. EGR and split Flow Air Preheater Are Options 
Calculation of temperature at important points in the combustion system is necessary to establish burner operating parameters and specifications. The following temperature points were selected:

- $\mathrm{T}_{2}$ - recuperator output temperature (heated air into the burner)

- $\mathbf{T}_{3}$ - precombustion temperature (burner air and EGR mixture, indicative of the burner operating tempera-

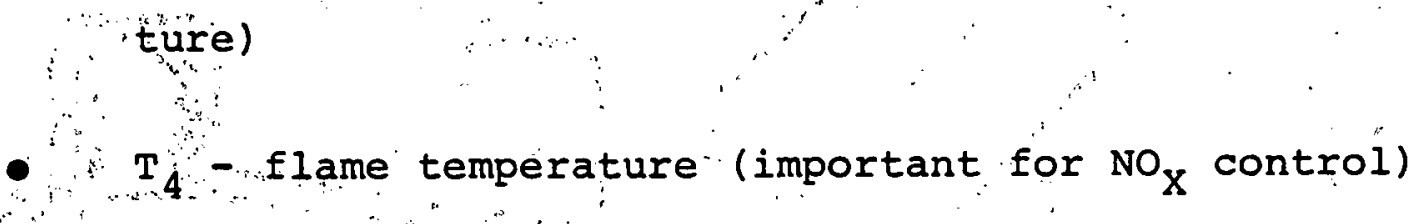

$\because \quad T_{5}-E G R$ temperạture

- $T_{6}$ - exhaust temperature (for calculation of combustion system efficiency).

Figure 31 illustrates the location of these temperature points in the combustion system and also lists the system equations and explanatory notes. The specific heats used can be derived from temperature - enthalpy data for air and combustion products (24). These equations are solved by an iterative process wherein specific heats and specific heat ratios are first assumed and temperatures calculated. From these temperatures more accurate specific heats are derived from the temperature - enthalpy data and the solution is repeated. Temperatures calculated for various values of the design parameters are shown in Table 10; this table includes the temperatures for the proposed system in the last two columns. The proposed parameters represent a practical compromise of overall size, burner and recuperator temperatures, and flame temperature. 


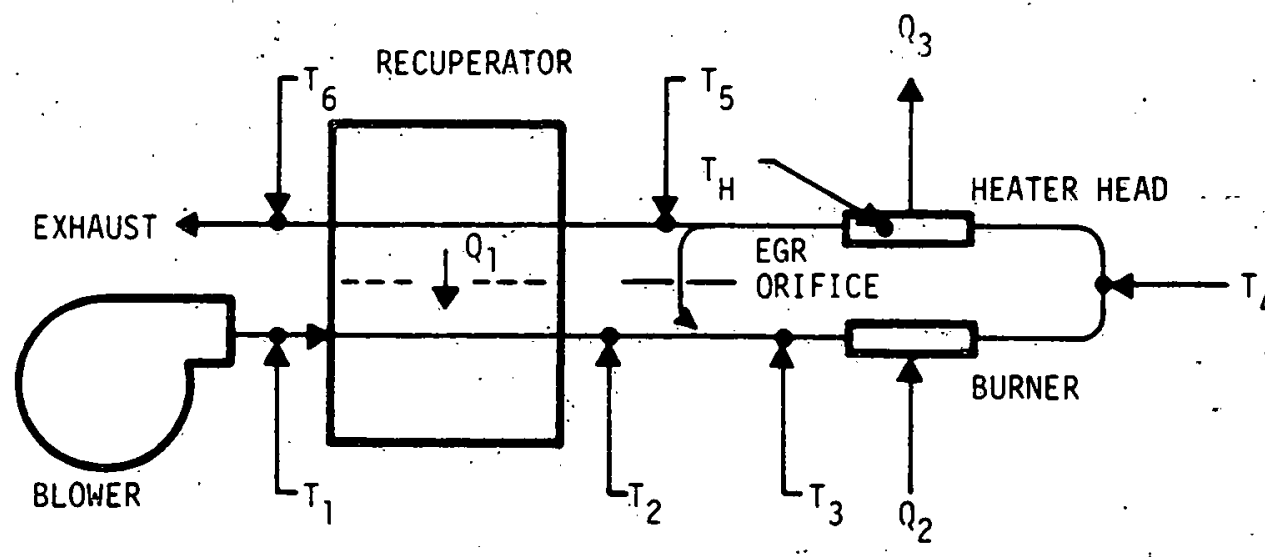

$$
\begin{aligned}
\left(T_{5}-T_{6}\right) C_{56}(1 / F+1+E) & =\left(T_{2}-T_{1}\right) C_{21}(1+E) \\
T_{5}-T_{6} & =\varepsilon_{p}\left(T_{5}-T_{1}\right) \\
T_{4}-T_{5} & =\varepsilon_{h}\left(T_{4}-T_{H}\right) \\
T_{4}-T_{3} & =\frac{9}{F C_{43}[1 / F+(1+E)(1+\eta)]} \\
\left(T_{5}-T_{3}\right) C_{53} R(1+E) & =\left(T_{3}-T_{2}\right) C_{23}(1+E)
\end{aligned}
$$

\section{LEGEND}

$$
\begin{aligned}
& E=\text { EXCESS AIR RATIO } \\
& R=\text { EGR RATIO } \\
& \varepsilon_{p}=\text { RECUPERATOR (PREHEATER) EFFECTIVENESS } \\
& \varepsilon_{h}^{\cdot}=\text { HEATER HEAD EFFECTIVENESS } \\
& g=\text { FUEL HEAT VALUE } \\
& F=\text { STOICHIOMETRIC AIR/FUEL RATIO } \\
& T_{H}=\text { HEATER HEAD TEMPERATURE. } \\
& C_{21}=\text { AIR SPECIFIC HEAT, } T_{1} \text { to } T_{2} \\
& C_{23}=\text { AIR SPECIFIC HEAT, } T_{2} \text { to } T_{3} \\
& C_{43}=\text { COMBUSTION PRODUCTS SPECIFIC HEAT, } T_{3} \text { to } T_{4} \\
& C_{53}=\text { COMIBUSTION PRODUCTS SPECIFIC HEAT; } T_{3} \text { to } T_{5} \\
& C_{56}=\text { COMBUSTION PRODUCTS SPECIFIC HEAT, } T_{5} \text { to } T_{6}
\end{aligned}
$$

Figure 3i.. Clean Fuel Combustion System, Final Design Schematic and Equations 
Table 10. Calculated Combustion System Temperatures for No. 2 Fuel oil

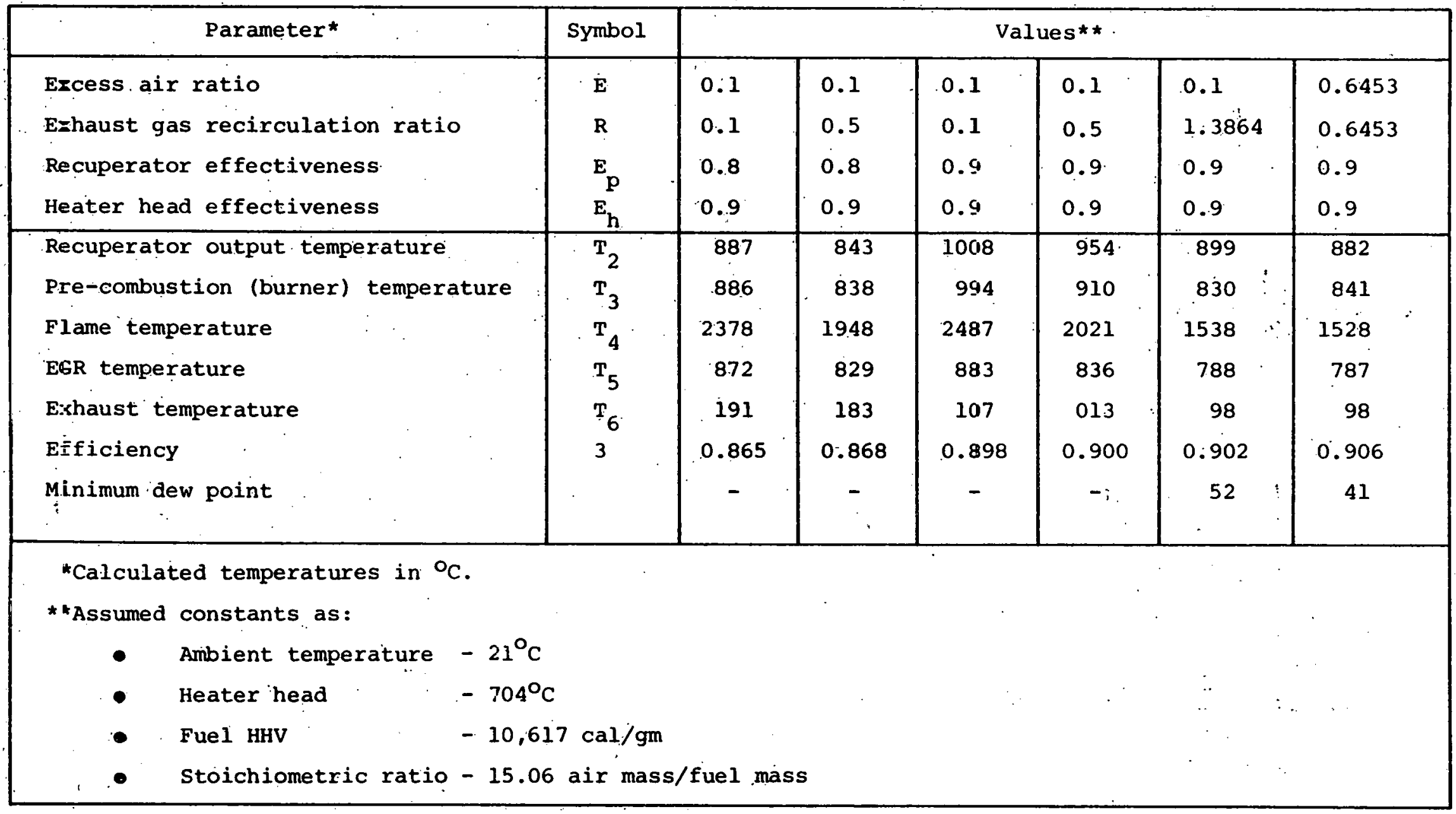




\subsubsection{Efficiency}

Combustion system efficiency results primarily from the high heat exchanger effectiveness of the recuperator:and engine heater head. High recuperator effectiveness ( 90 percent) can be achieved with a unit of $0.232 \mathrm{~m}^{3}\left(8.2 \mathrm{ft}^{3}\right)$ in volume for each engine head or burner. It is shown in subsection 5.1 that it is practical to achieve 90 percent heater head effectiveness with a fin-and-tube design. Designing for 90 percent heater head effectiveness allows for some degradation in performance without overheating the burner.

The calculated combustion system efficiency is slightly over 90 percent with a $98^{\circ} \mathrm{C}\left(208^{\circ} \mathrm{F}\right)$ exhaust temperature and a $41^{\circ} \mathrm{C}$ $\left(106^{\circ} \mathrm{F}\right)$ minimum dew point. Additional stages of recuperation. made of plastic materials can be added to reduce the exhaust temperature below the dew point and thereby extract the latent. heat of condensation of the water vapor in the combustion products. An advantage of counterflow heat exchangers is the option of installing additional stages of recuperation, made of cheaper. materials, to the original recuperator.

\subsection{3 $\mathrm{NO}_{\mathrm{X}}$ Minimization}

The generation of thermal $\mathrm{NO}_{X^{\prime}}$ as opposed to $\mathrm{NO}_{X}$ generated. from fuel nitrogen, can be minimized by using a combination of three approaches:

- Reducing flame temperature with EGR and XSA

- Providing for good mixing of fuel and air

- Minimizing the residence time of combustion products at high temperature. 
The ${ }^{N O} X$ reaction rate is very sensitive to flame temperature $(\underline{25})$, and should be less than $20 \mathrm{ppm} / \mathrm{sec}$ at $1538^{\circ} \mathrm{C}\left(2800^{\circ} \mathrm{F}\right)$, the specified flame temperature. There are two combinations of EGR and XSA which reduce the flame temperature to $1538^{\circ} \mathrm{C}\left(2800^{\circ} \mathrm{F}\right)$ : they are:

$$
\begin{aligned}
& \text { - } \quad E G R=1.3864 \text { and } X S A=0.10 \\
& \text { - } . \mathrm{EGR}=\mathrm{XSA}=0.6453 \text {. }
\end{aligned}
$$

The second combination is preferable, as far as burner head design is concerned, because the EGR and air mass flows are in a better balance for the eduction function of the burner head, which generates the pressure differential that drives the EGR loop. The first combination is preferable, as far as fuel vaporization is concerned, because the EGR gases are nearly inert, obviating the possibility of explosion or burning behind the flame holder. There is only a 3 percent difference in heater head mass flow. between these two combinations of EGR and XSA, permitting the use of either combination (or intermediate combinations) without adversely affecting heater head effectiveness. During combustion system testing, ${ }^{N O}{ }_{X}$ concentration, and its response to changes in EGR and XSA ratios will be measured and an experimental determination will be made of the EGR and XSA ratios that yield low ${ }^{N O}{ }_{X}$ levels concurrent with reliable burner operation over the entire firing rate range.

Good mixing of fuel and air during or prior to combustion eliminates local areas of rich F/A ratio which will generate hotter than the average flame temperature and therefore generate $\mathrm{NO}_{X}$ at a high rate. In the proposed combustion system, mixing is accelerated at the burner head by dividing the air and fuel streams into thin alternating layers. Mixing should be complete at a distance from the burner head which is approximately five to ten times the width of the streams. 
Residence time is minimized by providing each engine heater. head with its own burner, closely coupled to the heat exchanger: The average residence time in the volume between the burner head and the heater head exchanger surface is $0.02 \mathrm{sec}$ at the high firing; and 0.16 sec at a 7 to 1 turndown.

The ' $\mathrm{NO}_{\mathrm{X}}$ concentration can not be predicted accurately, Every reasonable effort has been made, in the design and specification of the proposed combustion system, which will contribute to low No $\mathbf{x}$ production.

\subsubsection{Burner Description}

Figure 27 shows the burner installed on the heater head. The burner head has been placed a short distance from the heat exchanger, and is specially designed to promotemixing and eduction. The "daisy" shaped end of the burner head breaks up the fuel and air flows into small alternating streams for rapid mixing... The exchange of momentum between the air streams and the fuel streams makes the burner head an eductor which forces the flow in the EGR loop. The EGR ratio is determined by an orifice in the loop. Fuel oil or gas is introduced into the EGR loop, where the fuel oil vaporizes $(\underline{26}, \underline{27})$ before entering the burner head. Premixing of fuel and air, as practiced with other. FMA burners, is not possible with this burner because the mixture temperature:would be above the ignition point. It was decided to simulate the FMA premix burners as closely as possible, however, by dividing the fuel and air into small interlaced streams which will provide the same rapid, uniform combustion as the premix burner.

Figure 27 also shows a tube which contains either a torch igniter or retractable ignition electrodes. Standard ignition electrodes would not survive: in the combustion chamber. Another. such tube will be used for an ultraviolet flame sensor. A sick 
port is shown in the exhaust manifold for the insertion of an oxygen:sensor.

A: cylindrical exhaust gas collection shell surrounds the heater head. This shell can be used to insure the uniform flow of combustion gases through the heater head matrix. The downward momentum of the flame tends to concentrate the flow through the bottom of the heater head. By restricting the annular flow area," that is; by adjusting the exhaust shell. diameter, flow. through the upper part of the heater head is encouraged at the expense of the flow through the lower part. The proper shell diameter will be determined experimentally by mapping exhaust temperature on the outside of the heater head fin matrix for different diameter exhaust shells.

Above the burner-heater head assembly is the recuperator, connected by. vertical ducts, shown in the figure, with exhaust: gases ascending and heated air descending.: A recuperator with $0.32 \mathrm{~cm}(1 / 8 \mathrm{in.})$ passages and volume of $0.232 \mathrm{~m}^{3}\left(8.2 \mathrm{ft} \mathrm{t}^{3}\right)$ would have a 90 percent temperature effectiveness for the maximum. mass flow of the burner $183 \mathrm{~g} / \mathrm{sec}(1450 \mathrm{lb} / \mathrm{hr}),(28)$. A recuperator is required for each burner.

\subsubsection{Controls}

A schematic of fuel and air flows with control components is shown: in Figure 32. In this control: scheme the burner air; and " hence firing rate, is controlled by a command from, the engine control, varying either blower speed. or the position of an air damper. Fuel flow is controlled to match the combustion air via the signal from the exhaust oxygen analyzer. A zirconium oxide oxygen sensor is placed in the exhaust of each cylinder; the sensors are used to balance the fuel/air ratio for each burner, after which only one of them is used. for fuel control. The zirconium oxide oxygen 


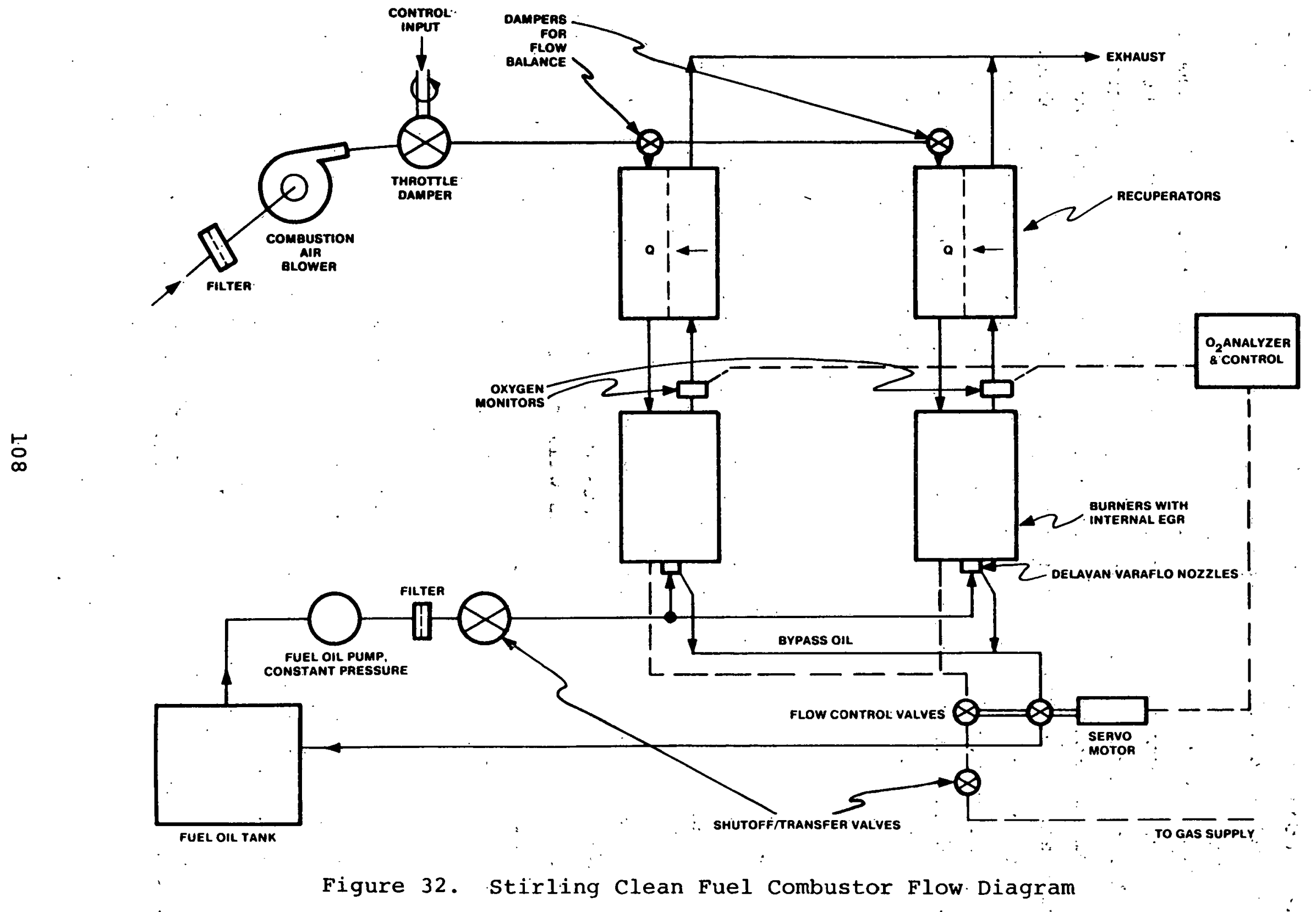


sensor does not require pumping exhaust gas samples and is, therefore, reliable and responds quickly.

Air. flow to the burners is balanced by a one-time adjustment of manual dampers at the recuperator inlets. Fuel flow can be similarly, balanced with manual valves on the fuel lines. Iiquid fuels are: injected with Delavan "vara-flo" nozzles, which are high.pressure nozzles with a fuel bypass from the swirl chamber; and have a 7 to 1 turndown ratio. Standard high pressure fuel pumps are proposed to feed the nozzles. Gaseous fuels can be ". supplied through standard regulators and shut-off valves, the only unique, component being the servo-operated metering valve.

\subsubsection{Safety Controls}

Standard ultraviolet flame sensors are proposed at each burner head. These can be programmed to attempt a relight after a flame-out, after which fuel flow is shut off if relight fails.

Temperature on the output. side. of the heater head will be measured (thermocouples or resistance element) and shut-down will occur on over-temperature. This will protect the engine and burner from high temperatures in case of engine stall or degradation of heater head performance. Safety controls are listed in Table 11.

Table 11. Combustor safety Controls

\begin{tabular}{|c|c|}
\hline Sensor & \multicolumn{1}{|c|}{ Function } \\
\hline Ultraviolet flame sensor & $\begin{array}{l}\text { Atempts relight on flame-out, then } \\
\text { shuts fuel off and signals status } \\
\text { alarm } \\
\text { EGR temperature }\end{array}$ \\
\hline
\end{tabular}




\subsubsection{Start-Up}

Operation on liquid fuel is possible only after the burner has been warmed up to approximately $316^{\circ} \mathrm{C}\left(600^{\circ} \mathrm{F}\right)$. This can be accomplished by starting the system on a gaseous fuel and then switching to fuel oil. For a smooth transition, the gas metering valve and the fuel oil bypass valve will have their flow characteristics (firing rate versus stem position) matched to each other. and be linked together on a single servo motor. start-up on gas is straightforward.

\subsubsection{Design Summary}

A design has been presented for a clean fuel combustion system which will be directly coupled to the engine head ( $a$. complementary heater head design is presented in subsection 5.1). By the use of FMA's proven combustion techniques, the range of useable clean fuels has been extended beyond the usual gaseous fuels to incluaje light distillate fuel oils. The same proven techniques, combined with EGR and XSA, are used to minimize $\mathrm{NO}_{\mathbf{x}}$ pollution. A combustion system efficiency of slightly over 90 percent is expected, achieved by the use of recuperation and good heater head design. The combustion head of the burner is the only unique component in the system; all other components and fabrication techniques are standard. A careful analysis of system temperature was used to arrive at operating specifications which will result in meeting all the design goals, including reliability, without depending on very sophisticated materials and components.

\subsection{Onsite Coal Utilization Systems}

It is amply evident, in the light of the national energy situation, that the role of coal as a contributor to the country's future energy needs will be prime and based on the results of the assessment performed by ANL. The ultimate success of the large 
Stirling Cycle stationary engine program, therefore, hinges on the utilization of coal as fuel. Accordingly, it is very appropriate to consider all possible ways of using coal, as Stirling engine fuel, economically, efficiently both in the near future and distant future.

In Section 2, various fuel/combustion options were discussed, in which synthetic fuels: such as low or medium Btu gas and coal liquids were assumed to be produced at a central plant and distributed. In this subsection the direct use or onsite conversion and use of coal, leading up to our selection of the system considered most suitable for applications in the near future will be discussed. Figure 33 shows the onsite coal utilization options.

Stirling engines, in the 373 to $2237 \mathrm{~kW}$ (500 to $3000 \mathrm{hp}$ ). range and having a 40 percent efficiency; require a maximum of $6 \mathrm{~mW}(t)$ heat input. This has a significant bearing on the economics and feasibility of the alternative methods of using coal onsite, as will be seen from the discussions below. It should be noted that only the mode of heat transport from the heat source to the engine will affect the engine or engine head design and not the origin of the fuel. For example, the engine design for synthetic gaseous and liquid fuels remains the same as natural gas or fossil liquid fuels. Revisions in burner design and downstream processing to meet environmental requirements may be necessary. As such, only the economic feasibility and process availability are discussed in this subsection and the effect on engine head design is alluded to in section 5 .

\subsubsection{Coal Gasification}

Coal can be gasified by one of the better known methods such as HYGAS or BI-GAS and burned before or after gas cleanup to provide heat. Alternatively, hot combustive products can be generated for the heat needs using the Coal Hot Gas Generator (COHOGG) process. 


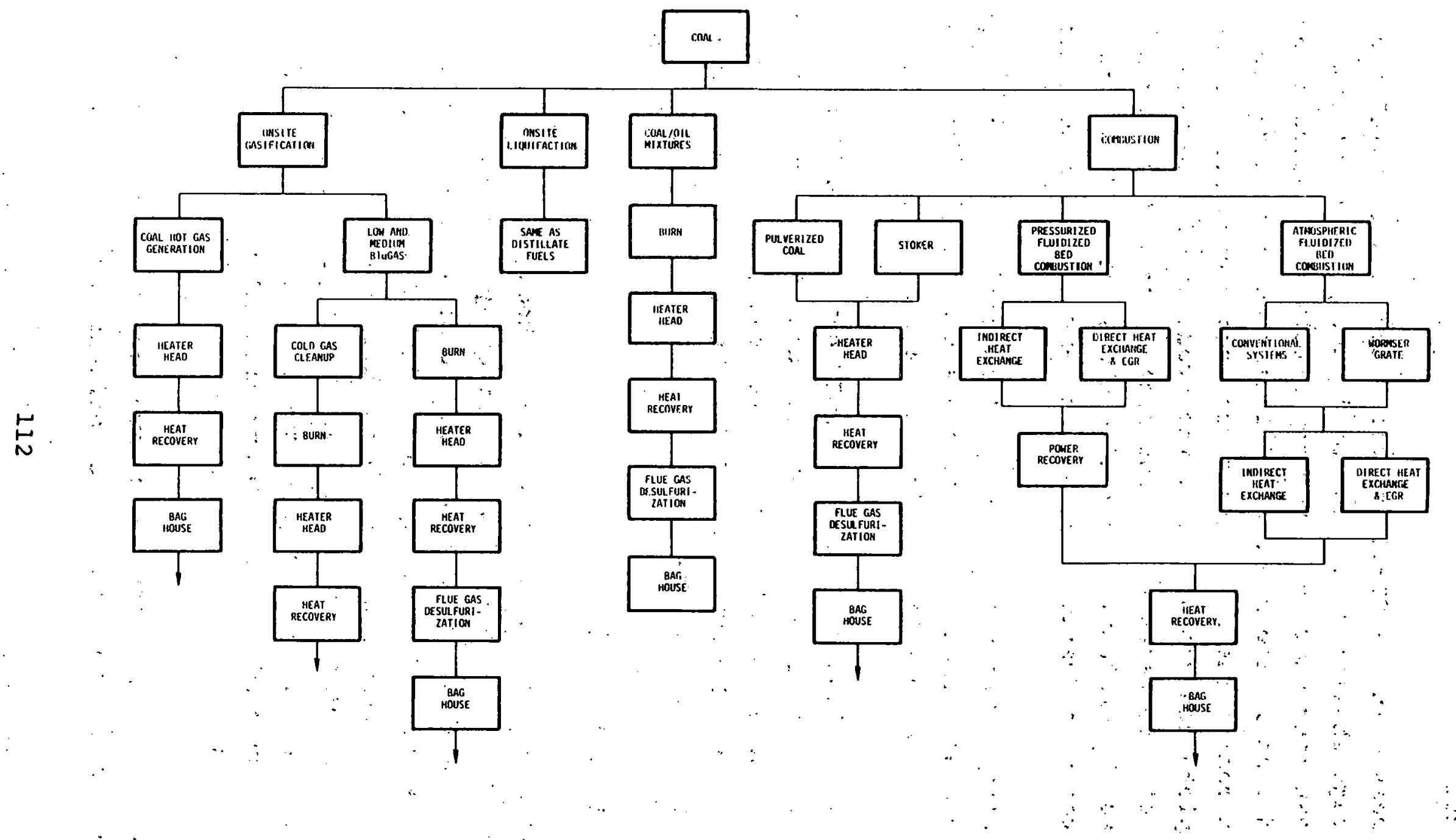

Figure 33. Fuel/Combustion System Configuration Decision Tree: Onsite Coal Utilization 


\section{2 .1 .1 COHOGG}

The Process - In the COHOGG process, the coal is pyrolyzed in a first stage ebullated bed reactor in the presence of limestone; the resulting char is burned separately in a second stage fluidized bed also in the presence of limestone which fixes the sulfur in the coal. "The first and second stage products are then mixed to complete the combustion of the products of pyrolysis generating a high temperature gaseous heat source. The process thus minimizes $\mathrm{SO}_{\mathrm{x}}$ production by fixing the sulfur and $\mathrm{NO}_{\mathrm{x}}$ production by staged combustion with obvious environmental benefits.

Availability - The process is still in -the development stage. However, good operational capabilities are claimed for the process, even in small sizes to suit stirling engine applications (29).

Feasibility - Cost figures for coHoGg have not yet been fully evaluated. For this reason and because of the developmental status of the process, COHOGG has not been considered in the system design options. However, COHOGG must be reviewed in the future as a posible alternative.

\subsubsection{Low and Medium Btu Gas}

The Processes - There are several well known fixed bed; fluidized bed and entrained bed gasification systems proven at the pilot plant scale. It is beyond the scope of this program to describe them all. Reliability and efficiency of the components for these processes have not been fully resolved as yet. Low- and medium-Btu gases are produced. These:gases can be burned directly requiring emissions control devices downstream or be subjected to cold gas cleanup and eliminating the need for downstream controls.

Availability - These processes have been operated at pilot plant and PDU levels and some are now offered commercially. 
Feasibility - In a recent report (30), it was concluded that, because of environmental considerations, an economically viable gasification plant will have to generate $3000 \mathrm{MW}(t)$ equivalent gas or 500 times the size required for the Stirling engines addressed in this study. Thus, onsite production of low and medium gas for Stirling engines is not viable.

\section{2 .2 Coal Liquefaction}

SRC II and Exxon Donor Solvent processes convert coal to liquid products that can be used like petroleum derived fuels with minimal system changes.

The Process - A slurry of residual liquids from the process itself and coal is reacted with hydrogen causing the coal to liquify. Again, several reports describe these processes in detail.

Availability - The liquifaction processes have been tested at the pilot plant scale. Sufficient confidence has been generated to lead to the design and start of construction of demonstration plants.

Feasibility - Current estimates (31) call for plants 10 times the size required for the stirling engine as a minimum. pilot plant. This excludes onsite coal liquefaction from consideration in this program.

\subsubsection{Coal/Oil Mixtures (COM)}

By burning a slurry of pulverized coal in oil the dependency on fossil liquid fuels can be, at most, reduced. In the long run, when coal liquids become available, com can be a viable fuel. 
Avaizabizity - Long, trouble-free, tests with CoM at utility boilers have been performed, and the process may be considered as a technology available today.

Feasibizity - The current status of the technology dictates the minimum economic plant capacity, to allow for the necessary grinding and pollution control equipment costs, to be $100 \mathrm{MW}$ (e) (32), far above the stirling engine requirement.

\subsubsection{Coal Combustion}

Coal can be directly burned and the product gases then cleaned to remove particulate and gaseous emissions or it can be cleaned and then directly burned which requires particulate removal only. Several projects are underway to prove coal cleaning as well as burning coal in a manner that would reduce No $\mathbf{x}$ by staged combustion. Physical coal cleaning only reduces pyritic sulfur in the coal. Chemical coal cleaning is expected to produce compliance coal. Although, superior to physical coal cleaning, the chemical process triples the price of coal to between 60 and $\$ 80 /$ ton (33). Solvent Refining of Coal (SRC) is the first step in a coal liquefaction mentioned in subsection 4.2.2. To be economical SRC plants have to be large, centralized and preferably close to a mine. When these conditions are met, the solvent refined coal price is still estimated at $\$ 45 /$ ton compared to 20 and $\$ 30 /$ ton for raw coal. Onsite coal cleaning is, therefore, not considered an economic alternative for the foreseeable future.

Raw coal combustion can be achieved in several ways: entrained pulverized coal burning ( $P C B$, stoker burning (SB), fluidized bed combustion (FBC), cyclone burning, etc. The developers of the last technology no longer offer commercial plants because of several unresolved problems. 
The Processes - In pulverized coal combustion, finely ground coal (usually 70 percent through 200 mesh) is entrained in the combustion air, injected through a nozzle and burned. "Dry" ... burning, in which the flame temperature is kept low enough to. prevent the resulting ash from softening and agglomerating, is preferred.

Stoker burning involves the spreading of randomly sized. coal above a grate through which the combustion air flows upward. The finer coal is entrained and burned while the coarser particles fall on to the grate and burn in a fixed bed manner.

FBC is similar to stoker combustion except that:

- The coal used is of medium size usually less than $1 / 4$ in.

The velocity of the combustion air up through the grate (distribution plate) is just sufficient to suspend the coarser particles and yet not entrain them.

The coal is usually injected into the bed.

Advantages and Disadvantages - Pulverized coal burning has been in practice for a long time and as such is a well developed hardware. The flame temperatures are kept very high to ensure reasonably high heat transfer under radiant conditions. This results in high oxides of nitrogen (NO ${ }_{x}$ ) formation. Several projects are currently underway to study the mechanisms of $\mathrm{NO}_{\mathbf{x}}$ formation and control to meet present and future emissions standards. Slow burning; staged combustion, flue gas recirculation. to limit flame temperature, etc.", are several methods that appear promising. Most of the sulfur in the coal is also oxidized contributing to the emissions. Only flue gas desulfurization (FGD) has beẹn developed to a stage of acceptable 
performance in the control of sulfur oxides $\left(\mathrm{SO}_{\mathrm{x}}\right)$. FGD produces a sludge which creates disposal problems.. Since, coal combustion is a,complex function of the coal characteristics, it is necessary to control the coal size closely. for entrained burning. Hence, the grinding and classification costs are very: high. The efficiency of pulverized coal combustion is very high... However, significant quantities of liquid fossil fuel are required for start up and reliable modulation of the flame;

Coal grinding costs are much. lower for stoker burner, as it accepts randomly. sized coal below an upper limit. The $\mathrm{SO}_{\mathrm{x}}$ and No $x$ problems for the stoker burner are the same as for pulverized coal burning.. Combustion efficiency in stoker burner also is very high.

Fluidized bed coal combustion is the youngest of the three technologies. However, with intense programs the FBC has been rapidily developed to a stage where small units are now commercially available. Fluidized beds offer several critical advantages over PCB or SB.: This process permits the maintenance of uniform temperature throughout the fluidized bed and hence control over temperature related side effects, and affords introduction of heat transfer surfaces. within the bed to control the bed temperature over a wide range. Also the solid residues of combustion in the bed can be substituted with other inert materials to control gaseous emissions.

The minimization of temperature excursions makes confident choice of heat exchanger materials possible. The concurrent presence of pockets of reducing and oxidizing atmosphere within the bed, however, limits this confidence. Means to overcome this problem, based on established mechanisms for bed tube erosion and corrosion, are already: underway as explained below. 
High heat transfer rates in a fluidized bed minimize heat exchanger surface requirements, and reduce the overall equipment size. The bed operating temperature can be closely controlled using bed hẹat exchangers. This flexibility can be taken advantage of in controlling $\mathrm{NO}_{\mathrm{x}}$ formation. Additional No $x$ control by staged combustion is also possible as described below. FBC inherently emits less $\mathrm{NO}_{x}$ and at present shows most promise for further reductions to meet future regulations.

By maintaining a bed of sorbents (limestone or dolomite) and burning coal in this inert medium most of the $\mathrm{so}_{x}$ formed during combustion can be fixed in the sorbent by chemical reactions. The spent sorbent must either be regenerated or disposed of. Sorbent disposal is considered less problematic than FGD sludge from $\mathrm{PCB}$ or $\mathrm{SB}$. Sulfur retention is a strong function of temperature and the degree of control over the temperature alluded to above will permit optimum sulfur fixation.

Finer particles. in the coal feed are entrained and do not always burn completely. Recycle of fly ash or a separate stage carbon burn up cell is required to achieve high combustion efficiency. Very high temperatures that increase stirling engine efficiencies are not possible in a conventional FBC because of the deterioration in sulfur retention beyond $810^{\circ} \mathrm{C}$. Some addițional development work is necessary in materials handing and distribution.

Feasibility - It has been shown that combustion of raw coal by all three methods is possible and that each method has certain advantages over others. However, costwise, even first-of-a-kind atmospheric fluidized bed shows significant advantages over the other two, for small scale operations. With modifications to the operating mode and production in quantity, FBC's are expected to show better economics and environmental acceptability. Figure 34 shows the cost comparison of $\mathrm{FBC}$ and $\mathrm{PCB} / \mathrm{SB}$ for 


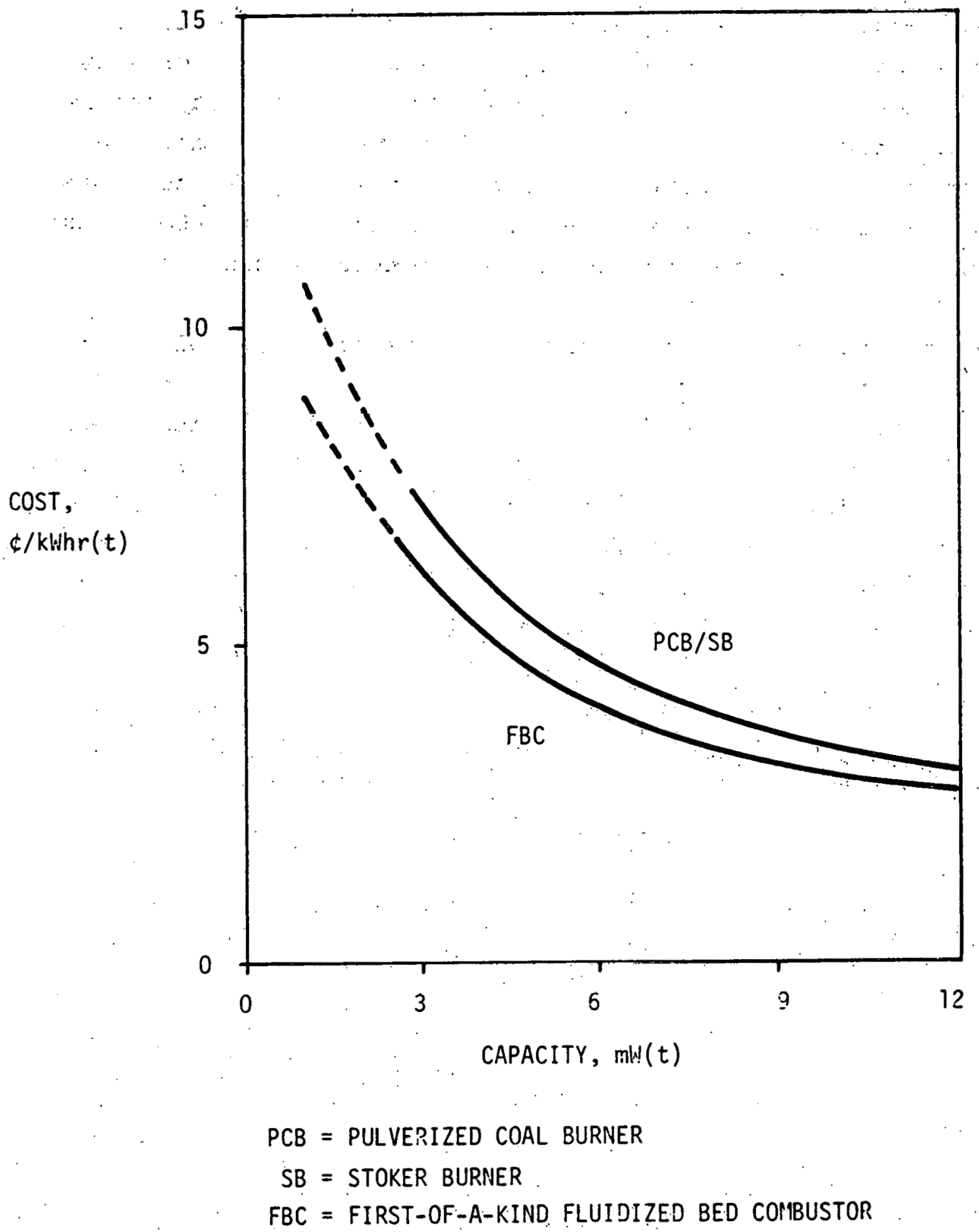

Figure 34. Effect of Capacity on Cost of Heat (34) for Coal Combustion Systems 
small-scale boilers. The costs allow for pollution control and waste disposal as well as added cost of anticipated development required for FBC (34). The effect of capacity on the economics, mentioned. in the introduction to this subsection 4.2 , can be clearly seen from the comparison. At high capacities, 60. MW( $t)$ and above, $\mathrm{PCB} / \mathrm{SB}$ show economic advantages over first-of-a-kind FBC. In the Stirling engine capacity range 1 to $6 \mathrm{MW}(t)$ FBC shows clear cost superiority over $\mathrm{PCB} / \mathrm{SB}$.

Accordingly, even with developmental work now going on pollution control to ease the penalties on $\mathrm{PCB} / \mathrm{SB}$, fluidized bed combustion has been chosen as the more feasible, adaptable, near term heat source for stirling engines.

\subsubsection{Pressurized versus Atmospheric Fluidized Bed Combustions}

In pressurized fluidized bed combustion (PFBC) the whole bed is maintained under pressure, thus reducing the volume of gas flow at a given temperature and hence reducing equipment size at a given fluidizing velocity. Pressurized operation produces a better quality of fluidization and superior sulfur fixation using approximately one half the sorbents (35) compared to atmospheric fluidized bed combustion ( $A F B C$ ). Equipment cost reduction is partly offset by the requirement for high pressure/high temperature system design. The pressurized gas effluent from the PFBC permits power recovery using gas turbines, a part of which power is used to compress the combustion air. However, some problems with particulate and alkali removal from PFBC effiluents, has cast a doubt on the possibility of direct gas turbine use (36). The coal also needs to be transferred from atmospheric storage to a pressurized combustor. All of these unresolved questions are being addressed in a number of on-going developmental programs. 
Other than the advantages and disadvantages mentioned above, $\mathrm{PFBC}$ and $\mathrm{AFBC}$ have the same benefits and shortcomings discussed in detail above (subsection 4.2.4). FMA considers PFBC's as a longer term ( 5 to 10 years behind AFBC's in development) viable stirling engine heat source. As such for the near-term application, only AFBC's have'been considered.

\subsubsection{Conventional Atmospheric Fluidized Beds versus Two Stage Beds}

In a conventional fluidized bed combustor the bed material used is the sorbent for sulfur retention and the elutriated coal fines are burned in a carbon burn up cell (37) or in the main bed using char/fly ash recirculation ( 38$)$. As can be seen from Figure 35 the efficiency of sulfur retention is a function of temperature showing a peak between $810^{\circ}$ to $850^{\circ} \mathrm{C} \mathrm{(39)}$. So for optimum So $_{x}$ control the bed operating temperature is restricted to this narrow temperature band and in turn limits the stirling cycle efficiency. Since almost all of the combustion is carried out in the main bed with full air flow, the bed atmosphere is oxidizing in some spots and reducing at other spots. This phenomenon imposes severe limitations (Figure 36) on the bed heat exchanger material selection and design (40-45). Internal pressures of the heat transfer fluids (such as helium, hydrogen or molten salt) in the heat exchanger tubes for stirling. applications can be extremely high causing further worries to designers. NO $\mathrm{N}_{\mathbf{x}}$ emissions, even under the controlled temperature conditions of a conventional fluidized bed combustor, are higher than for staged combustors $(\underline{46})$. In addition, high turndown ratios can only be achieved with multicell construction, which for small scale applications cause complications and severe cost penalties. All the above reasons point to the beneficial use of a two stage atmospheric fluidized bed combustor described in subsection 4.2.4.3, for stirling engine applications. 


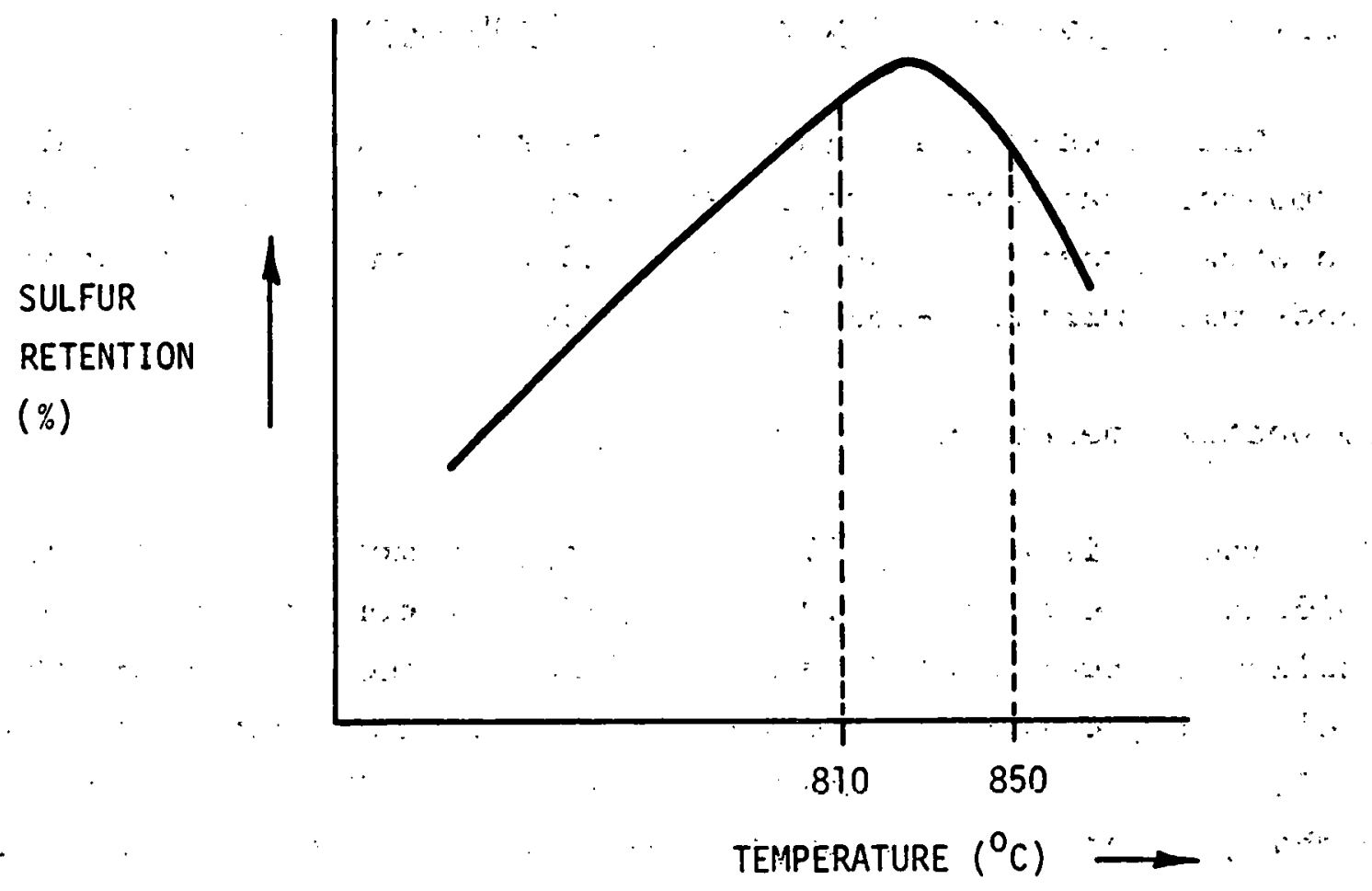

Figure 35. Effect of Bed Temperature on Sulfur Retention

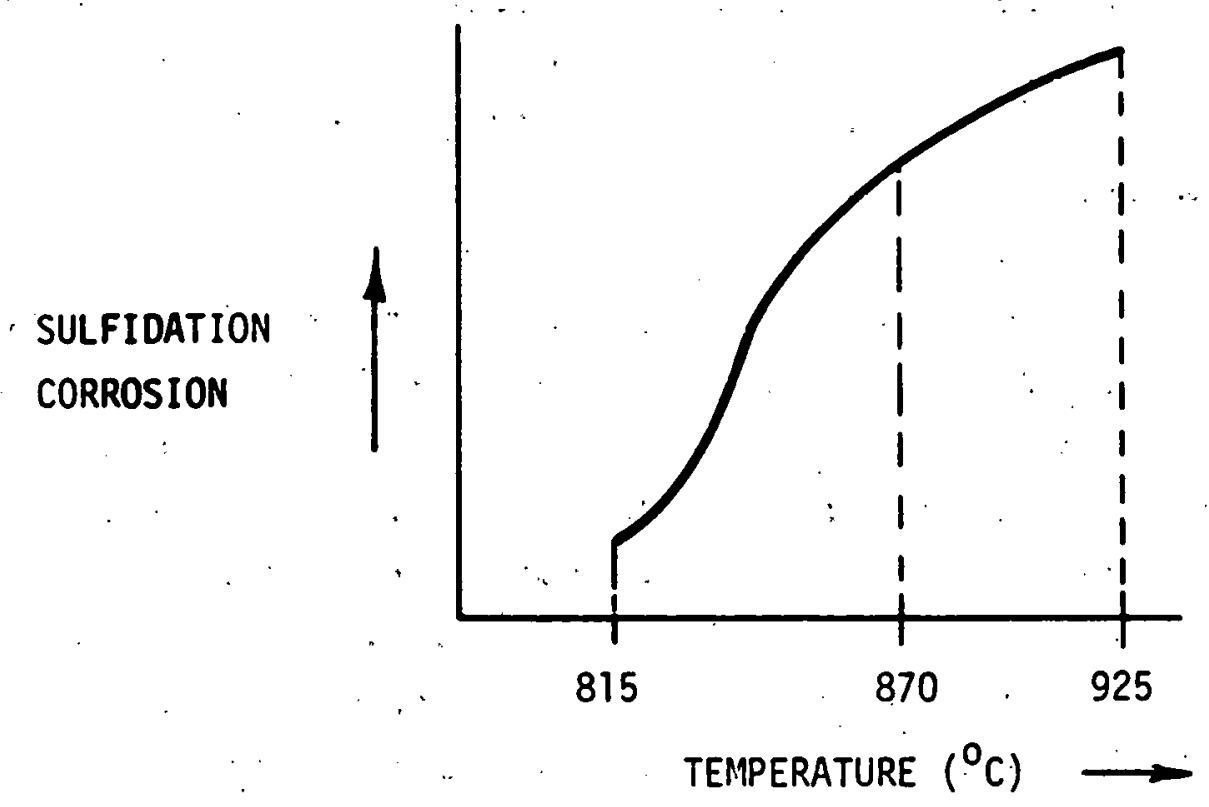

Figure 36. : Effect of Bed Temperature on Sulfidation Corrosion 


\subsubsection{A Two-Stage Fluidized Bed Combustor}

The Wormser Grate (WG) (47) is a two stage fluidized bed combustor that specifically addresses small scale applications and shows great promise for easy adaptation to stirling engine needs with minimal additional development.

Combustor Operation

The WG is essentially a two-stage combustor with a third holding stage as shown in Figure 37 . It consists of a fairly shallow combustion bed made up of inert sand into which the coal is injected. Only a part of the stoichiometric air (up to 90 percent) is supplied to this stage. The indirect heat exchanger can be introduced into this stage to maintain the bed temperature at any level independent of the sulfur retention needs. This fuel rich stage is, therefore, essentially at reducing conditions easing the materials selection problem for the heat exchanger. The possibility of operating the bed at temperatures above that for sulfur fixation will permit the improvement of the Stirling engine efficiency. The higher temperature also increases the heat flux, reducing the heat exchanger surface.

The upper bed contains the sorbent for sulfur removal. The operating temperature of the bed can be adjusted to the optimum with in bed heat exchangers or interstage recuperators (used in heat recovery). More efficient use of sorbent is also claimed $(48)$. The remainder of the stoichiometric combustion air and the excess air are introduced either just below or just above the upper stage distributor thus making the upper bed atmosphere essentially oxidizing in nature, again easing materials selection. The upper stage also helps burn all the entrained fine coal eliminating the need for carbon burn up cell or fly ash recirculation, to improve combustion efficiency. 


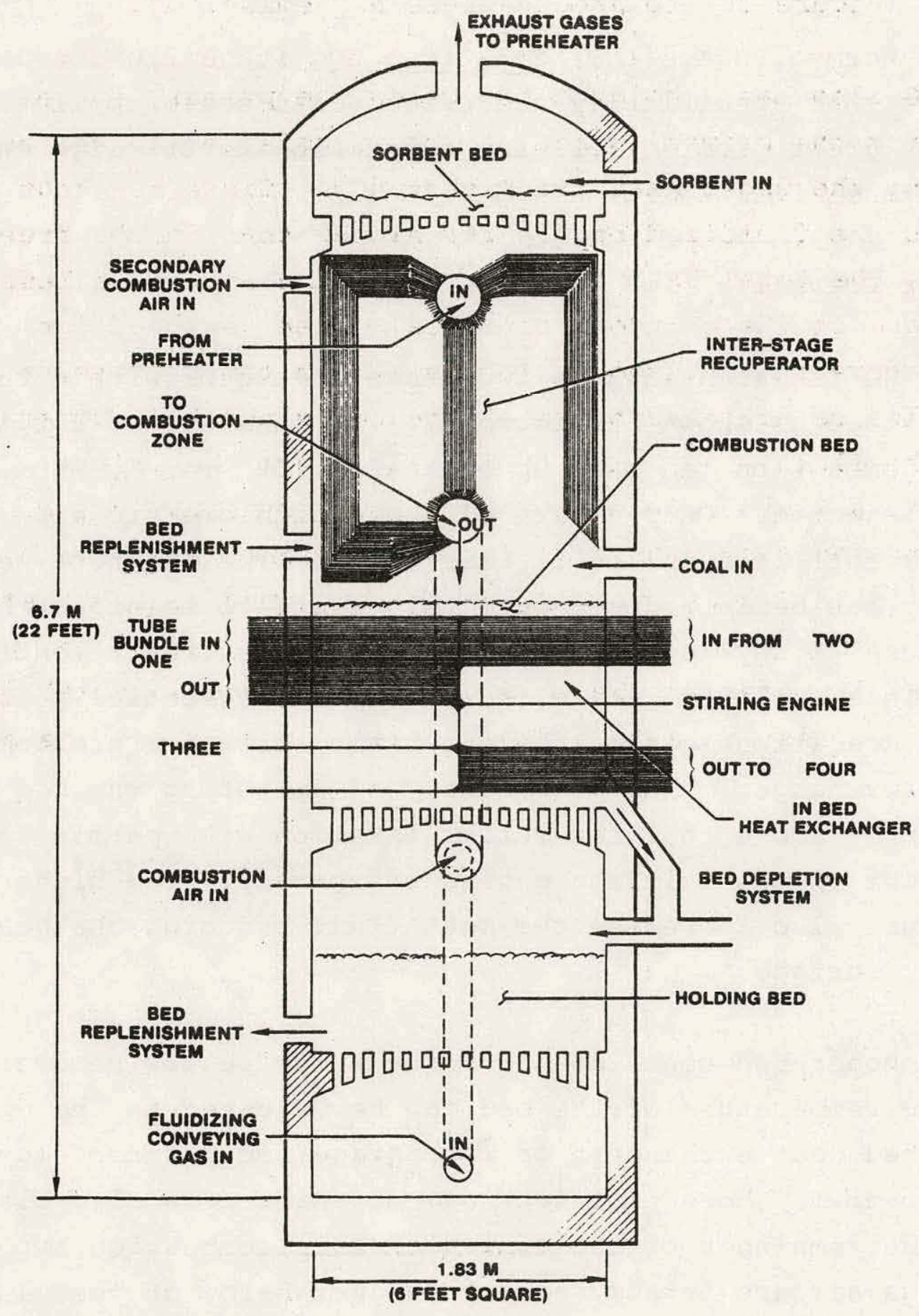

Figure 37. Atmospheric Fluidized Bed Coal Combustor for Stirling Engine Applications:

Preliminary Schematic 
This type of approach to two stage combustion has already been shown (Figure 38 ) to produce less $\mathrm{NO}_{\mathrm{x}}$ emissions.

The WG also has a holding bed below the primary stage. Bed material from the primary stage can be transferred to the holding bed exposing the upper heat transfer tubes.: Since the heat transfer in the fluidized bed is far higher than in the freeboard zone above, the total heat transferred to the engine is less, affording one of the turndown controls. When designed for operation above the optimum sulfur retention temperature, turndown can also be achieved by merely reducing the bed temperature. Reducing the fiuidizing velocity in (slumping) the primary combustor is a third mode of turndown; by providing less combustion air and reducing heat transfer coefficient, as shown by Figure 39 (48). Typical valves for the bed tube heat transfer coefficient range from 35 to $45 \mathrm{Btu} / \mathrm{hr}-\mathrm{ft} \mathrm{t}^{2}-\mathrm{F} \%$ During the primary bed material transfer to the holding bed, the bed material particle size can also be altered to increase or decrease the bed

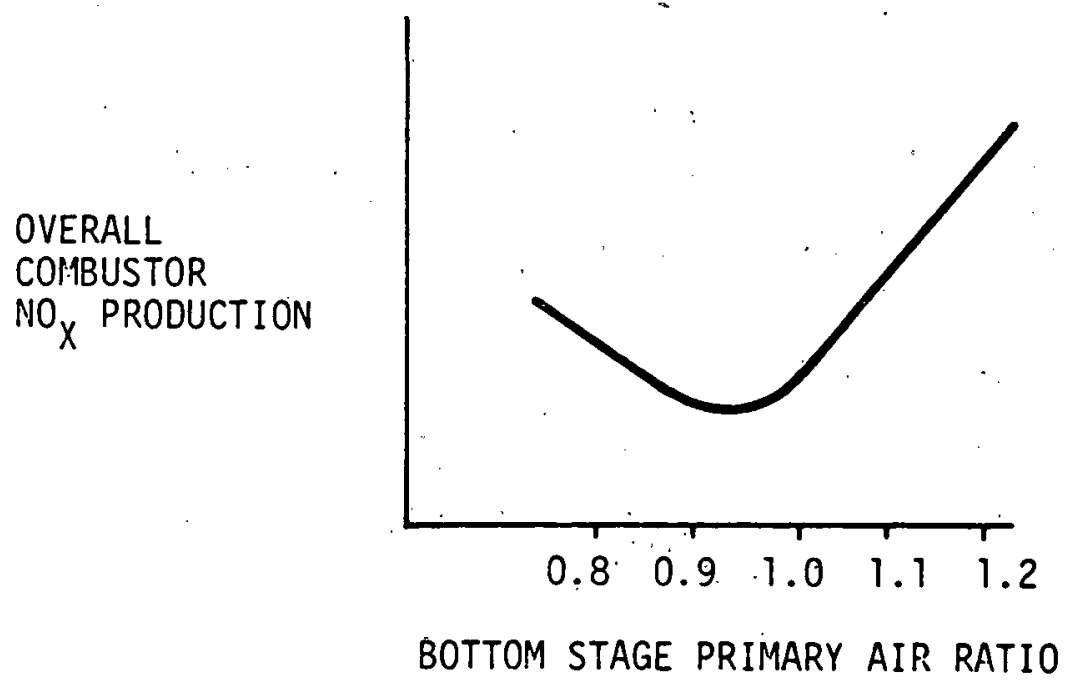

Figure 38. Effect of Staging Fluidized Bed Combustion (43) 


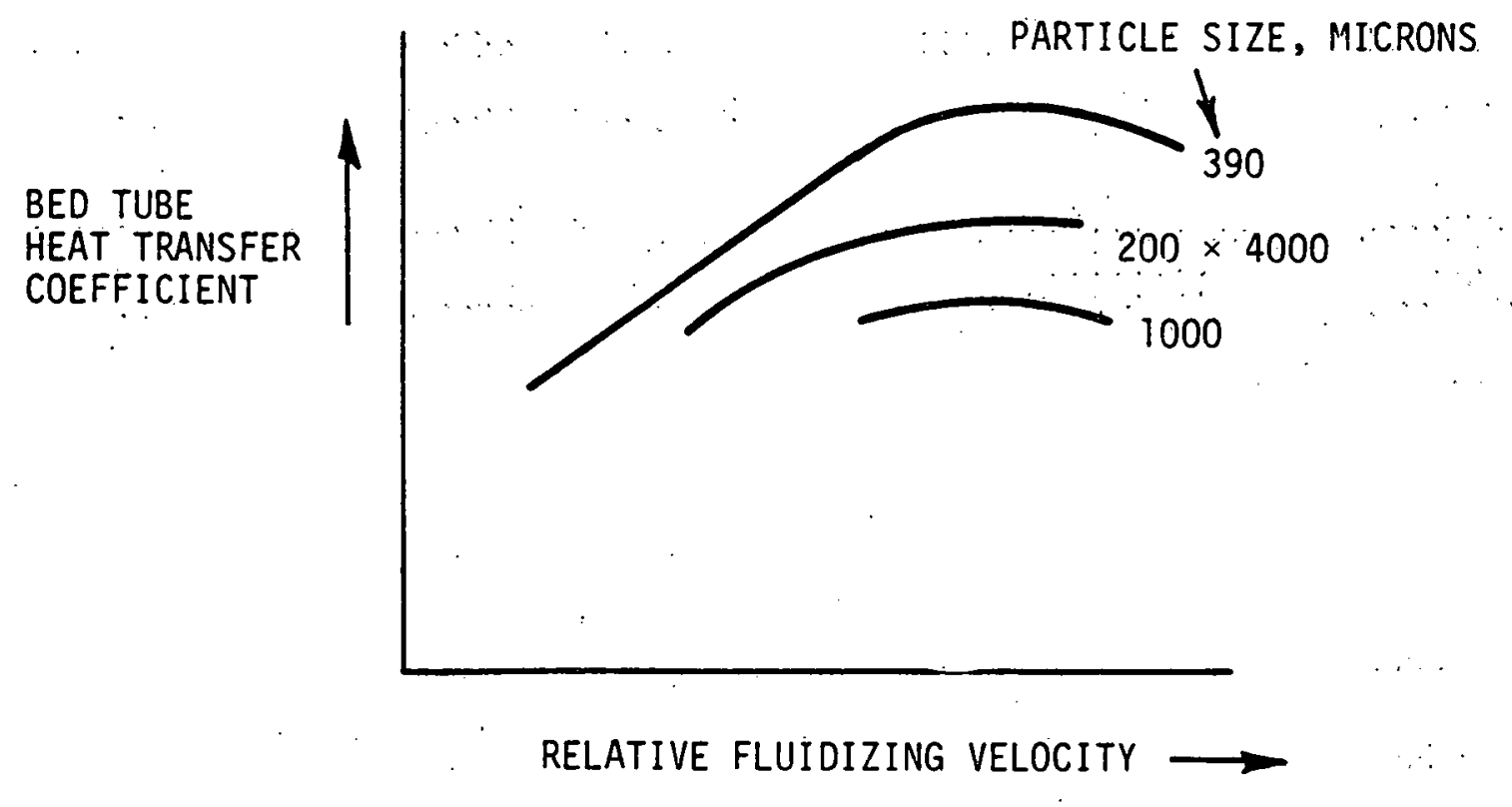

Figure 39. Effect of Fluidizing Velocity and Particle Size on Bed Tube Heat Transfer Coefficient

heat transfer coefficient, resulting in yet a fourth method for turndown. Turndown ratios, using only the slumping mode, are predicted to be at 6 to 1. Ratios of 30 to 1 are expected to be possible using all the alternatives.

Transfer of material to the holding bed is carried out using bed overflow and gravity transport method. The holding bed remains hot over long periods of time. The material in the holding can be fluidized and pneumatically returned to the main bed for replenishment of the bed and peak, operation.

Since the WG can be started up in the depleted, slumped mode, far less liquid fossil fuel is required to start it up than conventional FBC. 
Combustor Désign Considerations

Several highly interacting parameters affect the design of a two-stage fluidized bed combustor for efficient, environmentally acceptable performance. In our preliminary design we have taken into account the following factors:

\section{Combustor}

\begin{tabular}{|c|c|}
\hline- & $\begin{array}{l}\text { Maximum heat requirements } \\
\text { Coal properties }\end{array}$ \\
\hline - & Bed material composition \\
\hline- & Combustion efficiency \\
\hline- & Bed heat transfer \\
\hline- & In bed surface requirements \\
\hline- & Turndown requirements \\
\hline- & Primary, secondary air requirements \\
\hline - & ${ }^{\text {NO }} x$ control, \\
\hline- & so $_{x}$ control sorbent characteristics \\
\hline- & Bed slumping, start up, hold up and replenishment \\
\hline- & Inter-stage heat recovery \\
\hline- & Bed depth and combustor height minimization \\
\hline- & Coal feeding and ash removal \\
\hline & d heat exchanger \\
\hline- & Engine heat requirements \\
\hline- & Heat transfer characteristics \\
\hline - & Fluidizing velocity and particle size \\
\hline- & Total tube area required \\
\hline - & Tube size \\
\hline - & Tube configuration \\
\hline- & Tube skin temperature \\
\hline - & Tube stress and vibration \\
\hline- & Sulfidation and alkali corrosion, erosion \\
\hline- & Position of tubes in the bed \\
\hline
\end{tabular}


- Emissions control

- Staged combustion and $\mathrm{NO}_{x}$ control

- Upper bed temperature and $\mathrm{SO}_{\mathrm{x}}$ control:

- Sorbent characteristics

- Inter-stage heat recuperation

- Exhaust gas cooling/combustion air preheat

- Particulate removal

- Instrumentation and controls .

A preliminary design of the two-stage combustor is shown in Figure 37 and a preliminary schematic of the system is shown in Section 7 .

Preliminary Two-Stage Fluidized Bed Combustor Design

In the previous subsection, the factors affecting the design of the FMA selected two-stage fluidized bed combustor were discussed. The following is a summary of the preliminary conceptual design of a two-stage combustor for stationary stirling :* engines addressed in this program:

- Combustion efficiency of 80 percent

- Mode of operation - recirculated helium/indirect heat exchange

- Capacity - 5.86 MW $(t)$ heat delivered

- Fluidized bed combustor

- Length - $1.83 \mathrm{~m}$ (internal dimensions)

- Width.- $1.83 \mathrm{~m}$ (internal dimensions)

- Overall height - $6.7 \mathrm{~m}$ (internal dimensions) 
- Sorbent bed

$$
\begin{aligned}
& \text { - Bed height }-15 \mathrm{~cm} \text { (expanded) } \\
& \text { - Bed temperature }-843^{\circ} \mathrm{C} \therefore \therefore
\end{aligned}
$$

- Combùstion bed

- Bed temperature $-1010^{\circ} \mathrm{C}$

In-bed heat exchanger

- Tube zie - $2.54 \mathrm{~cm}$ OD

- Number of tubes. 800

- Tube area - $112 \mathrm{~m}^{2}$

- Horizontal pitch $-4.6 \mathrm{~cm}$

- Vertical pitch - $5.71 \mathrm{~cm}$.

- Outer skin temperature $-811^{\circ} \mathrm{C}$

- Interstage recuperator

- Tube size $-2.54 \mathrm{~cm} O D$
- Number of tubes -400
- Horizontal pitch $-9.1 \mathrm{~cm}$
- Transverse pitch $-9.1 \mathrm{~cm}$

- Holding her

- Bèd height - $61^{-} \mathrm{cm}$

- Preheater

- Gas temperature, inlet $-843^{\circ} \mathrm{C}$ (outlet $-302^{\circ} \mathrm{C}$ )
- Air temperature, inlet $-2.1^{\circ} \mathrm{C}$ (outlet $-739^{\circ} \mathrm{C}$ )

- It is anticipated that further reduction in outlet gas temperature may be necessary upstream of the Bag house. 


\section{HEATER SYSTEM ANALYSIS AND DESIGN}

For an externally heated engine such as a stirling cycle engine; a heat transport system is required to transfer the heat from the energy source to the engine working fluid. The heat transfer may either be accomplished directly or indirectly. Presently all stirling cycle engines employ direct heating. "For the heater head assembly it is desirable to minimize the inter:nal heater tube volume and surface area in order to obtain better engine performance. However, for the case of coal and heavy oil combustion products which have high particulate concentrations, fouling occurs on the external surfaces of the tubes and since the combustion side heat transfer coefficient dictates the overall heat transfer coefficient, there is a desire to increase the tube heat transfer surface area or to provide blower power for forced convection. There is a tradeoff of heat trainsfer surface area and blower power to reduce heater tube volume.

Because of the presence of the heavy fouling for solid fuels, residual oils and other heavy fouling fuels, it is desirable to employ indirect heating techniques. Three heat transport systems were studied for indirectly transporting heat from the combustion system to the heater tubes: liquid metal heat pipes, liquid metal circulation loop, and gas circulation loop.

For the burning of clean fuels, a direct-fired stirling cycle engine heater head design is presented. The proposed conceptual design consists of 48 tube hairpins with external fins. The projected heat exchanger effectiveness of the heater head is 0.90 . 
For the burning of coal and other nonclean fuels, designs for both a liquid metal heat pipe system and a gas circulation loop to accommodate indirect heat transfer are presented. The proposed liquid metal heat pipe design concept consists of two separate heat pipe systems thermally communicating with each other via liquid metal joints which connect to a single manifold. The small primary heat pipes are located in the fluidized bed coal combustor and the secondary heat pipes are attached, to the hot ends of the stirling engine cylinders. The heat transfer working fluid is sodium, vapor and liquid.

Ti'he gas circulation loop consists of 800 tubes embedded in the atmospheric fluidized bed combustion system and connected by a manifold to the engine head heat exchangers. A blower is used to circulate the heat transfer working gas of either hydrogen or helium.

Because of the installation and maintenance difficulties associated with a liquid metal circulation loop, this method of indirect heat transfer is considered unsuitable for the stirling cycle engine for stationary power generation.

\subsection{Direct Heat Transfer}

The simplest engine configuration is one in which the heat from the combustion products of a burner is coupled directly to. the heater head. There are two major restrictions in applying this method of engine heating:

- The engine side volume of the heater head exchanger is Iimited

- The temperature effectiveness of the heater head exchanger must be relatively high because the heater head 
is an integral part of the total combustion system and its performance critically affects the EGR and burner temperatures as was shown in section 4.

These restrictions dictate several features of the proposed direct heat transfer system. First, the heater head exchanger must be both small and efficient, necessitating a compact heat. exchanger design, that is, one in which the combustion side area is extended by the use of fins or other such matrix of small flow passages. Secondly, the small flow passages in the heater. head, in turn, require a very clean combustion system which will not foul the heater head. The burner proposed for this application is especially designed for clean combustion and employs prevaporization of liquid fuel and thorough mixing of fuel and air.

The proposed heater head is small, efficient, and complements the proposed combustion system. It has been designed for long service life and ease of cleaning. Materials and fabrication techniques are compatible with current state-of-the-art technology.

\subsubsection{Heater Head Design Goals and Specifications}

The design goals for the proposed heater head are listed as follows:

- Creep rate of 1 percent in $10^{5} \mathrm{hr}$ with internal temperature and pressure of $2.07 \times 10^{7} \mathrm{~Pa}\left(3000 \mathrm{lb} / \mathrm{in}^{2}{ }^{2}\right)$ and $700^{\circ} \mathrm{C}\left(1292^{\circ} \mathrm{F}\right)$, respectively

- Withstand combustion side temperature of $1538^{\circ} \mathrm{C}$ $\left(2800^{\circ} \mathrm{F}\right)$

90 percent heat exchanger effectiveness for a thermal mass flow of $259 \mathrm{~W} /{ }^{\circ} \mathrm{C}\left(492 \mathrm{Btu} / \mathrm{H}^{\circ} \mathrm{F}\right)$ on the combustion side 


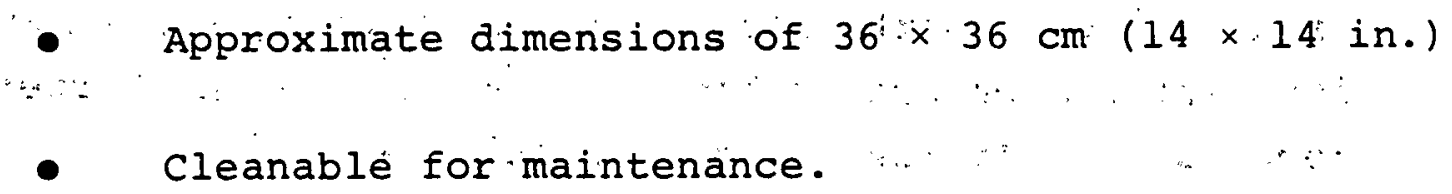

These goals support system features of small size, high efficiency, long service life, and ease of maintenance. Satisfying these design goals requires several compromises.: Creep rate is controlled by employing thick-walled tubing of relatively expensive stainless steel. Efficiericy is attained by increasing the combustion-side surface area to $7.1 \mathrm{~m}^{2}\left(76 \mathrm{ft}^{2}\right)$ by the use of fins. With the increase in fin density; the material cost is increased and the cross-sectional flow area is reduced. The smali passages make cleän combustion an essential feature of the combustion system if maintenance downtime is to be kept at a minimum. Table 12 presents the specifications for the proposed direct-fired heater head for the Stirling cycle engine.

Table 12. Direct-Fired Heater Head Specifications

\begin{tabular}{|c|c|}
\hline Parameter & Specifications \\
\hline $\begin{array}{l}\text { Tube material: } \\
\text { Fin material: } \\
\text { Brazing alloy: } \\
\text { Brazing flux or atmosphere: } \\
\text { Fin density: } \\
\text { Minimum cross-sectional flow area: } \\
\text { Combustion side heat exchanger area: }\end{array}$ & $\begin{array}{l}800 \mathrm{H}, 9.53 \mathrm{~mm}(3 / 8 \mathrm{in.}) \mathrm{OD}, \\
6.35 \mathrm{~mm}(1 / 4 \mathrm{in.}) \mathrm{ID} \\
\text { Carpenter } 20 \mathrm{cb}-30.76 \mathrm{~mm} \\
(0.030 \mathrm{in.} \text { thick } \\
\text { H\&H premabraze } 130 \\
\text { H\&H Boron modified high tem- } \\
\text { perature flux or Argon } \\
\text { atmosphere } \\
10 \text { fins/in. } \\
0.11 \mathrm{~m}^{2}\left(1.2 \mathrm{ft}^{2}\right) \\
48 \mathrm{tube}^{2} \text { hairpins } \\
7.1 \mathrm{~m}^{2}\left(76 \mathrm{ft}^{2}\right)\end{array}$ \\
\hline
\end{tabular}




\section{1 .2 Heater Head Theory and Design}

Since the thermal mass flow on the engine side of the heat exchanger is many times greater than the thermal mass flow of the combustion products, the heat exchanger effectiveness and surface area are determined by the following equations:

$$
\begin{aligned}
& \varepsilon=1-e^{-N_{T U}} \\
& N_{T U}=\frac{h A}{W C_{p}}
\end{aligned}
$$

where

$$
\begin{aligned}
\varepsilon & =\text { heat exchanger effectiveness } \\
\mathrm{h} & =\text { combustion side heat transfer coefficient } \\
\mathrm{A} & =\text { heat exchanger surface area } \\
\mathrm{C}_{\mathrm{p}} & =\text { specific heat capacity } \\
\mathbf{W} & =\text { mass flow rate }
\end{aligned}
$$

For $\varepsilon=0.90, \mathrm{~N}_{\mathrm{TU}}$ is required to be 2.30 . For flow between parallel plates, $\mathrm{h}$ is equal to $2.9 \mathrm{~W} / \mathrm{O}^{\mathrm{C}}\left(18 \mathrm{Btu} / \mathrm{hr}-\mathrm{O}_{\mathrm{F}}\right.$ ) (28), which dictates an effective heat exchanger surface of at. least $5.11 \mathrm{~m}^{2}\left(55 \mathrm{ft}^{2}\right)$. A fin effectiveness of 0.75 is expected for the proposed design, resulting in an actual heat exchanger surface area requirement of $6.8 .1 \mathrm{~m}^{2}$ (73.3 $\mathrm{ft}^{2}$ ). The proposed heater head has more heat exchange surface area than the calculated value and, in addition, there is a row of bar tubes in front of the finned tubes. This extra heat exchanger surface area ensures an effectiveness of at least 0.90 . 
Figure 40 presents the geometry of the tubes and fins in the proposed heater head. There are 48 tube hairpins with external fins; the fin density is 10 fins/in. The minimum flow cross section for the combustion gases i.s $0.11 \mathrm{~m}^{2}\left(1.2 \mathrm{ft}^{2}\right)$, resulting in a calculated pressure drop of $8.14 \mathrm{~Pa}:(0.03$ in. water column).

\subsubsection{Materials and Construction}

The material proposed for the heater head tubes is $800 \mathrm{H}$ stainless steel. This steel was chosen for its excellent creep resislance at the rated temperature. 'The tubes are y.b3 mm $(3 / 8 \mathrm{in.})$ oD and $6.35 \mathrm{~mm}(1.4 \mathrm{in.})$ ID. At $2.07 \times 10^{7} \mathrm{~Pa}$ $\left(3000 \mathrm{lb} / \mathrm{in}^{2}{ }^{2}\right)$ the tube wall stress is $4.48 \times 10^{7} \mathrm{~Pa}$ $\left(6500 \mathrm{lb} / \mathrm{in} .{ }^{2}\right)$, resulting in a second-stage creep rate which is significantly less than 1 percent in $10^{5} \mathrm{hr}$ and a creep-rupture life (extrapolated) of $300,000 \mathrm{hr}$ at a temperature of $700^{\circ} \mathrm{C}$ $\left(1292^{\circ} \mathrm{F}\right)$.

Carpenter $20 \mathrm{Cb}-3$ is the alloy proposed for the fin material. It was chosen for its resistance to sulfur corrosion, and is recommended for heat exchangers, flow scrubbers, and acidhandling equipment.

Vanadium corrosion is a more difficult problem. Vanadium pentoxide acts like a flux, removing passivating layers of oxide and exposing the underlying metal for corrosive attack. Fuel additives containing magnesium oxide and calcium oxide inhibit the corrosive action of vanadium, and such additives, which are commercially available, are successful in retarding this form of corrosion. Minimizing flame temperature, as has already been done for the purpose of $\mathrm{NO}_{\mathrm{x}}$ reduction, also reduces corrosion rates. For the long term, the vanadium content of the fuel (or the 


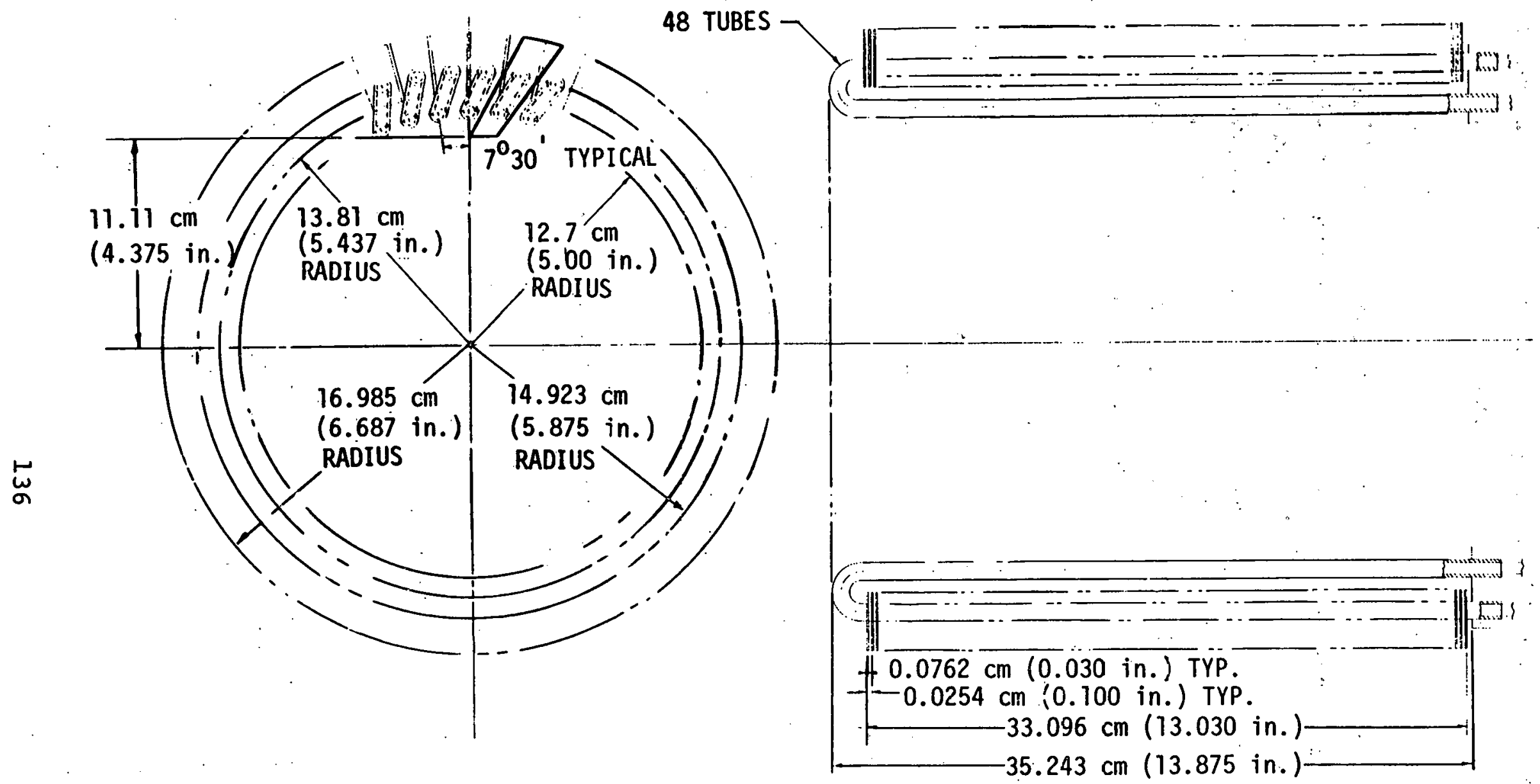

STIRLING HEATLE HLAL 
effectiveness of fuel additives) may prohibit the use of heavier fuel oils, such as No. 4 and No. 6, from direct firing into the heater head.

Fabrication techniques are straightforward. The fins will be made as annular rings with 48 holes in each ring to admit the hairpin tubes. After installation of the fins (and spacing fixtures) on the tubes, the assembly will be oven brazed. The last step will be to cut 48 slits through the fin matrix, as shown in Figure 40. These slits will eliminate stress and warping of the fin matrix as it is heated and cooled.

\section{$5: 1.4$ Design Summary}

Any direct-fired stirling cycle engine heater head must be designed as an integral part of the combustion system. The heater head proposed here is a small, efficient heat exchanger. The efficient heat exchanger contributes to the combustion system efficiency and helps reduce the operating temperature of the combustion system components. In turn, the heater head requires from the burner a clean, smokeless flame, a feature designed into the combustion system.

The design, materials, and joining techniques are all stateof-the-art technology, thus meeting the design goals with a dependable, long life component.

\subsection{Indirect Heat Transfer}

In large coal-fired stirling engines for stationary power generation applications, it is advantageous to transfer heat by means of indirect heat transfer for the following reasons: 
- An extremely corrosive and fouling environment is present inside the fluidized coal combustion system to employ direct heat transfer heater tubes.

Relatively low heat transfer coefficient is present inside the fluidized bed. This requires too large a heat transfer area for the stirling engine to accommodate, geometrically.

- There are practical difficulties of directly combining a large fluidized bed with a stirling engine.

The low external heat transfer of the heater tube poses a severe restraint for the Stirling engine design, since the designer has to deal with two sets of design requirements, one from the stirling engine thermodynamic standpoint, and the other from the combustion system standpoint.

One of the advantages of indirect heat transfer is that the two sets of design requirements are separated by physical boundaries, and can be dealt with on an individual basis. Now, the designer can have as much heat transfer area in the combustion side without affecting the internal thermodynamics of the Stirling engine proper.

The second advantage is that there will not be any local. hot spots which occur for the case of direct heat transfer due to uneven distribution of heat. In other words, the average heater tube temperature can be increased significantly using the same tube material without damaging the heater tubes, which will result in higher engine efficiencies. 
The third advantage is that since the heater tube external head transfer is much higher than before, the entire heater can be designed to be more compact. This can be useful in achieving near isothermal processes inside the expansion space by extending the heater directly into the expansion space as shown in the advanced engine design presented in section 6 .

Three indirect heat transfer schemes, the liquid metal heat pipes, the liquid metal circulation loop, and the gas circulation loop were investigated for the present application. They will be briefly described in the following subsections.

\subsubsection{Liquid Metal Heat Pipes}

A heat pipe is the most effective way of transmitting heat over a considerable distance with extremely small temperature differences and with zerro or very small external pumping power. In its conventional configuration, the heat pipe is a closed tube, circular, fluted, or other shape. Its inner surface is lined with porous material which acts as capiliary tubes and flow paths for the heat pipe liquid between one end of the tube which acts as the condenser and the other end of the tube which acts as the evaporator.

When external heat is supplied to the evaporator section, the liquid evaporates into vapor. Due to vapor pressure difference the vapor travels to the other end of the tube where the vapor is condensed to liquid, and the latent heat of vaporization is taken out by external heat transfer. The condensed iqquid is absorbed into the porous wick material and is pulled to the evaporator section by the capillary force developed inside the wick. In summary, the heat pipe has a vapor source at the 
evaporator and a vapor sink at the condenser which creates vapor flow from the evaporator to the condenser, and for the returning liquid flow, the heat pipe has the wick passages which accommodate the capillary action.

The amount of the heat transported by the latent heat of: vaporization in the heat pipe is an order of magnitude higher than the amount that can be transported by the sensible heat $\therefore$. in a conventional convective heat transport system.

In addition to the capability of transporting large amount of heat for its size, the heat pipe has an additional advantage of the small temperature decrease from the heat source temperature. This temperature decrease consists of the usually small temperature decrease in the evaporator and condenser across the pipe walls and wick material, and the temperature decrease caused by the vapor pressure drops due to vapor flow which can also be made. very small by a proper heat pipe design.

For the case of the stationary Stirling engine using a fluidized coal combustion system, the heat pipe is a natural candidate to transport the large amount of heat from the fluidized bed coal combustor to the engine heater with a small temperature decreàse.

For a given heat pipe design, there are four limitations on the amount of heat that can be transported: capillary, sonic, boiling, and entrainment limitations.

Capillary limitation is due to the fact that there is a maximum capillary pressure for a specific choice of liquid-wick pair. This capillary pressure is what drives the liquid flow from the condenser side to the evaporator side, continuously replenishing the liquid being evaporated at the evaporator.' For 
a steady operation of the heat pipe, this liquid mass flow rate has :to be equal to the vapor mass flow rate which in turn dictates the amount of heat transported.

Sonic limitation is the result of the fact that the vapor flow inside a.constant area heat pipe resembles a flow. in a. conver:gent-divergent. nozzle due to gradual evaporation and.condensation along the length of the heat pipe. When the vapor flow velocity is such that the choked flow occurs, increasing the condenser side heat removal rate may result in excessive lowering of condenser temperature.. Usually, the heat pipe is designed to be well below (Mach No. 0.2) the choked flow limit (Mach: No. 1.0). in order to ensure that the temperature drop is small.

Boiling limitations are due to vapor bubbles formed in the evaporator wick layer as the radial heat flux at the evaporator section increases to a point where the saturation vapor pressure at the wick-pipe interface temperature exceeds the liquid pressure at that point. The formation of bubbles causes hot spots and obstructs the proper circulation of the liquid to be vaporized.

Entrainment limitation is due to the fact that when the vapor velocity is high the liquid flowing in the opposite direction can be entrained in the vapor flow disrupting the entire balance of the heat pipe operation.

These four limitations will have to be taken into account in designing a heat pipe for large stationary stirling engines.

As for the working fluid for the present application, sodium was chosen; which has a normal boiling point temperature of $882^{\circ} \mathrm{C}$, suitable for the fluidized bed with maximum bed temperature of approximately $1000^{\circ} \mathrm{C}$, and which also has high heat transport characteristics. 
There are several problem areas which have to be dealt with before the sodium heat pipe can be used in conjunction with the fluidized bed coal combustion system.

The permeation of hydrogen into the heat pipe is a crucial. problem because the hydrogen gas decreases the active portion of. the heat pipe. Inside the fluidized bed coal combustor, the problem becomes worse since the heat pipe will experience in-. creased rate of hydrogen permeation due to the presence of water vapor, unburnt hydrocarbon', and nascent hydrogen, with the heat. pipe wall metal acting as a catalyst.

Another obvious problem is the extremely corrosive environment in the fluidized bed. The heat pipe will also have to. ensure the vibration and impacts caused by the coal feed process.

Thermacore, Inc., which FMA relied on for its expertise heat pipe technology, developed a patented metal treatment process that makes stainless steel tubes almost impermeable to hydrogen. According to tests performed by Argonne National Laboratory, the hydrogen permeation rate of this treated material displayed only one-one-hundredth of the best untreated stainless steel: At Thermacore, a sodium heat pipe employing this treatment underwent a fluidized bed test at $800^{\circ} \mathrm{C}$ for several weeks without any evidence of hydrogen permeation (49).

The criteria used for the heat pipe design are simplicity, reliability, redundancy, maintainability, manufacturability. cost, and high heat transport capability with a small temperature difference.

The following assumptions and initial design decisions were made for the heat pipe design. 
Heat pipes inside the fluidized bed will be $2.54 \mathrm{~cm}$ ( 1 in.) OD and approximately $1.83 \mathrm{~m}$ ( $6 \mathrm{ft}$ ) long. These dimensions are based on the work performed previously by Holcomb ( $\underline{50})$.

The heat transport system will consist of two separate heat pipe systems thermally communicating with each other via liquid metal joints.

As shown in Figure 41, for the entire Stirling engines producing up to $2237 \mathrm{~kW}(3000 \mathrm{hp})$, there will be a single manifold at the side of the fluidized bed which houses the above mentioned liquid metal joints.

One side of the manifold has heat pipe liquid joint wells which receive the condenser section of the small primary heat pipes coming out of the fluidized bed. The liquid joint design will facilitate the removal and servicing of malfunctioning primary heat pipes in the fluidized bed without disrupting Stirling engines.

The other side of the manifold acts as the evaporator section of a single secondary heat pipe system which supplies the heat required by the entire Stirling engine. This secondary heat pipe has a fairly long, insulated transport tube. The end of the transport tube is connected to the engine side manifold that branches out to each of the condenser enclosures surrounding the heater tubes on top of the hot cylinders.

The outer surfaces of the heater tubes of the Stirling engine acts as condensing surfaces for the secondary heat pipe. This concept was already tested successfully by Philips (51). 


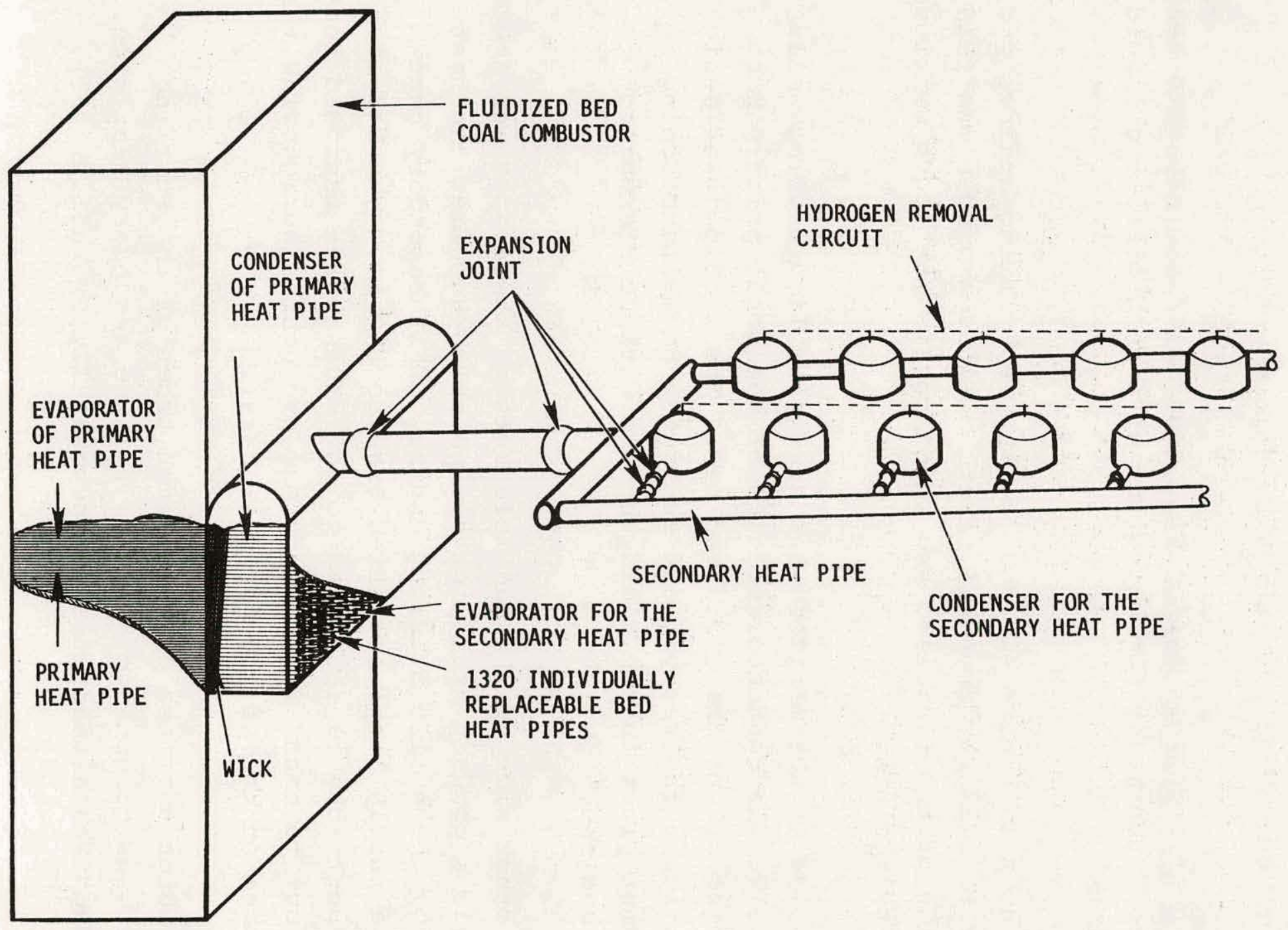

Figure 41. Schematic of Heat Pipe System for a Large Stationary Stirling Engine/Fluidized Coal Combustion 
In order to guarantee that the evaporator wick for the secondary heat pipe does not become dry, the liquid return paths are inclined downward, toward the evaporator section, thus utilizing gravitational force to assist the capillary force.

The 1320 small primary heat pipes in the fluidized bed will be overdesigned to accommodate the required heat load even when some of the heat pipes malfunction. This arrangement will ensure that the operation of the stirling engines will not be interrupted due to a relatively minor malfunction of the heat pipes inside the fluidized bed. It is expected that the fluidized bed environment is harsh enough to cause some problems for the primary heat pipes during a long-term operation.

Based on the above assumptions, the heat pipe system was designed. The design process is an iterative one. For each design variation, the heat pipe performance was evaluated to have adequate heat transport rate with a reasonable temperature decrease. The rate of heat transport was kept well below the capillary, sonic, boiling, and entrainment limits to ensure the safety factor in the design.

The following presents a summary of the heat pipe system design for a large stationary stirling engine for power generation utilizing fluidized bed coal combustion.

Number of heat pipe systems Working fluid

Pipe wall material

Heat load

\section{2}

Sodium

Stainless steel with hydrogen impermeability treatment $5600 \mathrm{~kW}$ for $2237 \mathrm{~kW}$ (3000 hp) engine 
Temperatures

Primary heat pipe (fluidized

bed side)

Evaporator outersurface

(bed tube skin temperature)

$815^{\circ} \mathrm{C}$

Secondary heat pipe (Stirling

engine side)

Condenser outer surface

(heater inner wall

temperature)

$730^{\circ} \mathrm{C}$

Dimensions and Specifications

Primary Heat Pipe system

Number of heat pipes

1320

Lengths

Evaporator

$180 \mathrm{~cm}$

Adiabatic

$60 \mathrm{~cm}$

Condenser

$60 \mathrm{~cm}$

Diameters

Tube OD

$2.54 \mathrm{~cm}$

Tube ID

$2.16 \mathrm{~cm}$

Vapor core

$1.80 \mathrm{~cm}$

Wick thickness

$0.18 \mathrm{~cm}$

Material

Stainless steel wire screen Mesh No. 100

(0.01143 cm OD wire)

Liquid Metal Joints

Liquid metal used

Tin - silver alloy

Well depth

$60 \mathrm{~cm}$

ID

$2.69 \mathrm{~cm}$

OD

$2.95 \mathrm{~cm}$

1320

Number of wells

\section{0}

Manifold Housing for Liquid Metal Joints

Location

Overall dimension

Height

Width

Depth
Attached to the side of the fluidized bed

$130 \mathrm{~cm}$

$180 \mathrm{~cm}$

$70 \mathrm{~cm}$ 
Secondary Heat Pipe System

Number of heat pipes

Evaporator

Length

Shape

Wick material

Wick thickness

at the base of fingers

around the fingers

Adiabatic Transport Tube

Length

Shape

ID

OD

Wick

Condenser

Design I

Shape

Design II

Shape

ID

Depth

Number
1

$60 \mathrm{~cm}$

Outer surfaces of the 1320

liquid metal joint wells that protrude like array of fingers into the manifold housing for liquid metal joints

100 mesh stainless steel wire screen

$1.25 \mathrm{~cm} \sim 2.0 \mathrm{~cm}$

$0.18 \mathrm{~cm}$

$300 \mathrm{~cm}$

Circular tube

$38 \mathrm{~cm}$

$40 \mathrm{~cm}$

100 mesh stainless steel wire screen that covers the bottom half of the transport tube

(Viking-1 heater head) Outer surfaces of conventional Stirling engine heater tubes with blade fins - see Section 6

(Advanced Design)

Matrix of horizontal tubular cavities which form one side of the compact, integrated heater for Advanced Design - See Figure 42

$1.52 \mathrm{~cm}$

$10 \mathrm{~cm}$

1320 
Two kinds of Stirling heater configurations are used. One uses the tubular heater with blade fins as shown in section 6 which is identical to the heater arrangement with conventional direct combustion. The other heater configuration is totally different as shown in Figure 42 , and is suitable for a high power density, compact design.

These proposed designs do not represent optimum designs for given requirements. They are presented to demonstrate the capability of the heat pipe to transport the large amount of heat from the fluidized bed to the large stationary engine.

\subsubsection{Liquid Metal Circulation Loop}

Liquid metal circulation for indirect heat transfer has been developed for the nuclear industry. Aside from features peculiar to nuclear applications, the typical liquid circulation loop containing sodium-potassium mixture (NaK) has the advantages of:

- Melting temperatures below room temperature

- Low vapor pressure at high temperatures

- High density and specific heat, resulting in low power required for circulation.

There is little question that a NaK circulation loop could be engineered to deliver heat from a fluidized bed to a stirling cycle engine with very low loss of temperature or power. However, NaK systems have the disadvantages of:

- Massive inventory of highly dangerous liquid

- Requirements for effectively hermetic seals at all flanges, joints, or through-hull shafts 


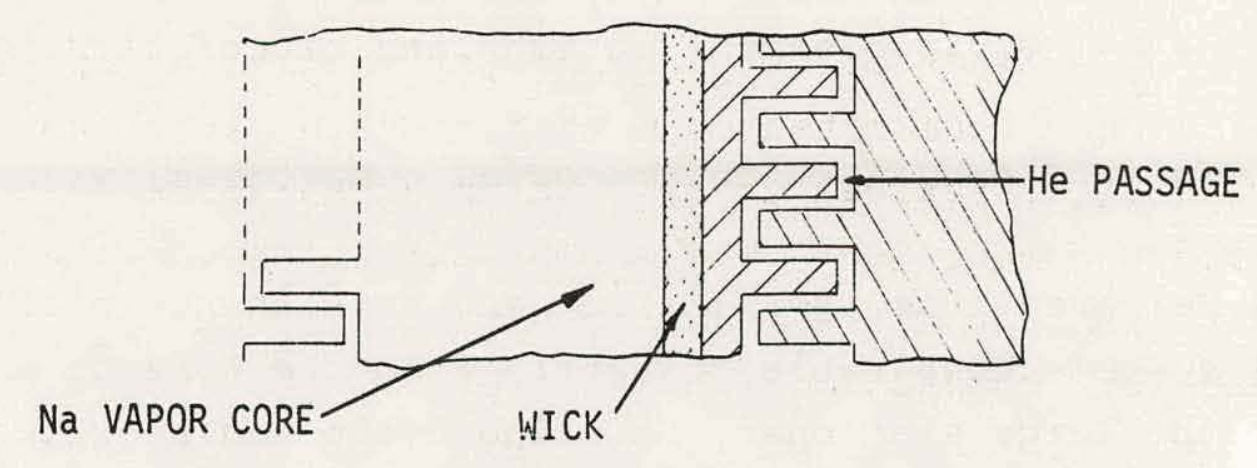

SECTION A-A
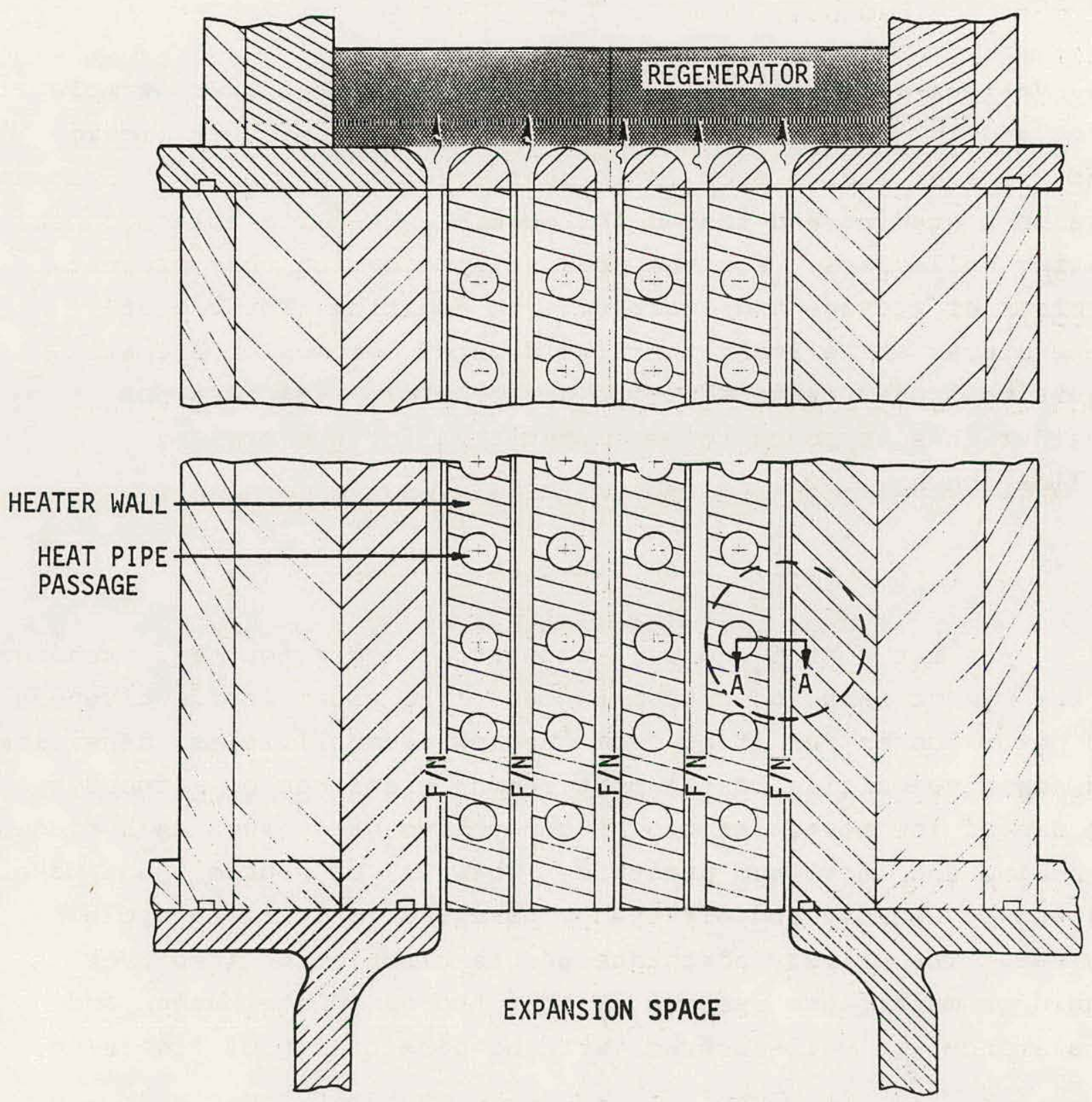

Figure 42. Cross-sectional View of the Compact, Integrated Heater Design for an Advanced Engine - Schematic 
- Required expansion tank and circulation pump

- Limitations for material compatibility.

FMA believes that installation and maintenance difficulties make NaK systems unsuitable for entry into the type of market intended for the large stationary stirling cycle engine which is to be competitive with diesel generators or small steam and gas turbine plants.

Various mixtures referred to as "draw salts" (for example $\mathrm{NaNO}_{3}$ and $\mathrm{KNO}_{3}$ ) are commonly used for high temperature liquid heat transfer medium such as in heat treating of metals. Systems have been studied and tested for possible use with solar concentrating collectors. For the present application they present problems of storage and start-up. In addition, for use at temperatures above $900 \mathrm{~K}$, the liquid metal becomes problematic, requiring pressurization or off-gas control. FMA does not consider this approach to be competitive for the present application.

\subsubsection{Gas Circulation Loop}

Gases are common and well-understood media for heat exchange in the widest range of circumstances. The usual ineffectiveness and power losses resulting from the low conductivities, densities, and sonic velocities of the most common gases can be reduced by the use of low molecular weight conductive gases such as hydrogen or helium and increased pressure. This is, of course, what makes high-power density and efficiency possible in Stirling cycle engines. The primary advantage of gas circulation loop over liquid or multiphase systems is that the gas distribution and consistency are well-assured, with no possibility of freeze-up, 
voiding "bubbles," fluid degradation, or significant contamination. The obvious basic disadvantage is the required pressure containment.

Several other factors are significant when considering gas circulation for the large stirling cycle engine for stationary power generation. First, the pressure of this gas reduces the pressure differential across the engine heater head and heater tubes. This can be a significant help in satisfying the conflicting demands of cycle temperature, service life, and material cost. Secondly, if hydrogen is used for the gas circulation as well as the engine cycle, then the ultimate performance is achieved in both; engine gas permeation is reduced, and gas availability is not a problem. Helium can be used interchangeably, with some derating, at least until questions of hydrogen safety and metal embrittlement are resolved. Thirdly, a gas circulation loop can be constructed with internal insulation for transfer ducts and large manifolds, so that "super-alloy" materials are required only for the heat exchange surfaces and immediate connections: (Other fluid media present problems of condensation or contamination that make internal insulation impractical.) Lastly, gas circulation appears to offer excellent adaptability to various installation and heat exchanger designs.

Initial design estimates were made for a gas circulation loop connecting a multicylinder stirling engine to a fluidized bed combustor. Nominally, each engine cylinder heater head is designed for a capacity of $100 \mathrm{~kW}$ and the fluidized bed is designed for $6000 \mathrm{~kW}$. The in-bed tubes are typical of the designs discussed in subsection 4.2.4.3: 800 tubes, $2.54 \mathrm{~cm}$ OD by $180 \mathrm{~cm}$ heated length. Gas pressures to 70 atmospheres of hydrogen or helium are considered.. With mass flows of 6,500 or $19,500 \mathrm{~kg} / \mathrm{sec}$ for the gases, respectively, the temperature 
differential in the gas circulation loop is approximately $56^{\circ} \mathrm{C}$ $\left(100^{\circ} \mathrm{F}\right)$. This is a small temperature difference or penalty to pay for the indirect heat transfer system.

With circulating gas that is noncorrosive or erosive, and is well-mixed and limited in temperature, the engine head heat exchangers can be optimized with respect to alloy selection, extended surface, and flow pressure loss. For example, closespaced copper fins can be brazed on wrought super alloy tubes with minimum difficulty due to thermal gradients. Engineering calculations indicate that the transfer effectiveness can be quite high without significant pressure loss, employing additional fins on a heater tube array that is suitable also for direct combustion (see subsection 6.1)

Heat exchange between the gas circulation loop and the fluidized bed is difficult at this time, but the gas side at least seems amenable to straightforward design once the bed parameters are better defined. In order to design the in-tube gas flow, bed dimensions of area, depth, temperature, and effective bed heat transfer coefficient must be prescribed: Bed parameters must satisfy combustion and pollution requirements dependent on bed size constraints and temperature, among other things. As discussed in section 4, FMA believes there are at least two viable bed options, the single or usual atmospheric fluidized bed and the double bed or Wormser Grate, with quite different constraints on bed parameters. FMA also believes that with either case the bed heat transfer should be better determined than it is at present, because it is the controlling resistance in the gas circulation loop.

The initial design for the in-tube gas transfer is predicted on a compact double bed having a high combustion temperature in 
the lower bed. This offers the lesser quantity of tubing, but presents the greater difficulty with respect to pressure loss in gas circulation. A single (limestone) bed at lower temperature offers more sectional area for in-tube gas flow. Estimates indicate that even wịth the compact bed the pressure loss can be quite small including manifold losses approximately equal to tube losses. Using hydrogen at 60 to 70 atmospheres, the blower power for gas circulation could be approximately 2 percent of engine rated power. With helium the power requirement would be seven times as much ( 14 percent) unless the bed tube bank were redesigned or a lower mass flow and higher bed-to-engine temperature differential were acceptable. As said before, tubes for a single lower temperature bed could be arranged for less pressure loss.

The principal practical problems for a gas circulation loop involve the manifolding and penetrations for the bed. The design should provide for thermal expansion, single tube replacement or plug-off, and demountable, elastic connections to the ducting and engine: A high temperature gas-circulating blower is required, but the duty is well within the range of gas-turbine alloy materials for the rotor, and shaft seal isolation would be used for the drive system. Whether variable speed drive is required for circulation depends on the method of turn-down of the fluidized bed combustor. 


\section{RECOMMENDED CONCEPTUAL SYSTEM DESIGNS}

Previous sections of this report have dealt with the various conceptual options and design methods for components of a stationary stirling engine system. Here a recommended design approach for the development of a basic engine with optional fuel systems using technology that is near the state of the art is presented. In addition, opportunities for possible development of advanced designs that may improve fuel performance or reduce cost are discussed.

Because Stirling engines have not been proven in commercial application it is appropriate to contemplate the meaning of "state of the art" versus "advanced development." For purposes of this study it was important to adhere to the following definitions:

- State-of-the-art systems are composed of components that can be designed and developed using current materials, fabrication, and design methods with little risk of major changes or delays.

Advanced systems are those systems that require, extensive design, development, and testing of certain components or subsystems before the overall system design can be fixed and planned in development. In short, it is a question of whether one is developing a design, or, first, proving a technique before true design is possible.

\subsection{Initial Design and Development}

In general, the recommended conceptual system is modular; having a basic stirling engine cylinder that is easily adaptable 
to any type of heat input or machine output, nominal power determined by a number of cylinders and design conditions, and several options for fuel combustion.

\subsubsection{Stirling Engine Design}

Stirling Engine Cylinder Module

As introduced in section 2, the cylinder module is axisymmetric around the piston with a single hot head and hairpin-like heater flow passages: A layout to scale of the initial design is shown in Figure 43. The cylinder module is arranged in a double-acting, narrow $V$.engine configuration shown in Figure 44 . The engine cylinder module is the viking-l engine cylinder module presented in section 3 .

Flow is distributed evenly between cylinder and heater tubes by a nonstructural, meridionally-slotted metal fabrication that also serves as the hot cylinder wall and regenerator liner. No significant pressure differential occurs across this flow director; it is loosely sealed with a metal split-ring to limit blowby while allowing differential thermal growth.

The heater tube passages penetrate the pressure dome as axial holes symmetrically spaced around the perimeter of the internal flow director. They provide excellent flow distribution to and from the regenerator. Conically reamed passages can be used to minimize flow entrance-exit effects. Heater tubes are brazed in countersunk holes on the outside of the dome. E-beam welding is a possibility with cast blades.

The pressure-dome is monolithic, about $67 \mathrm{~cm}$ largest diameter. but it is not necessarily of a single material. A choice is possible between a single casting of iron or nickel-based super alloy, or a lower cost iron-base material for the skirt with a super alloy central dome welded in place. Material choice is critically dependent on both nominal engine gas temperature as 
well as the decision either to expose or to.isolate the dome from direct heating. These decisions should not be made without a detailed analysis considering cost, life, and fuel economy as functions of alloy selection and heat transfer to and from the pressure dome. Because this application requires design limits similar to the boiler code, it is estimated that the practical temperature limit will be near $700^{\circ} \mathrm{C}$ for the central dome. The skirt is at significantly lower temperature and the flange area is water-cooled, making the use of polymeric gas seals possible.

Thermal isolation of the skirt of the pressure dome is enhanced by the use of a metal liner that also serves as the outer housing of the annular regenerator. "Dead" gas at mean pressure serves as insulation between the skirt and the iiner. The liner sees only cyclic pressure variation and need not be designed for hot creep resistance.

The regenerator is of typical design, consisting of metal fibers compacted and diffusion welded to resist fatigue and migration due to cyclic gas flow. Variations are possible between dense woven mesh and highly porous knitted mesh. The latter appears far superior with respect to cost and flow performance, but further analysis and test data are desirable. The regenerator size used in the conceptual design is relatively larger (using scaling parameters) than is typical for small engines having high power density. This is to obtain maximum thermal efficiency, as previously discussed.

The fabrication that contains the regenerator also contains the cooler directly juxtaposed. The cooler consists of a fairly typical annular array of axial tubes having gas flowing internally and water externally in cross flow. A particular feature of the cooler design is the two-pass radial in-out water flow 


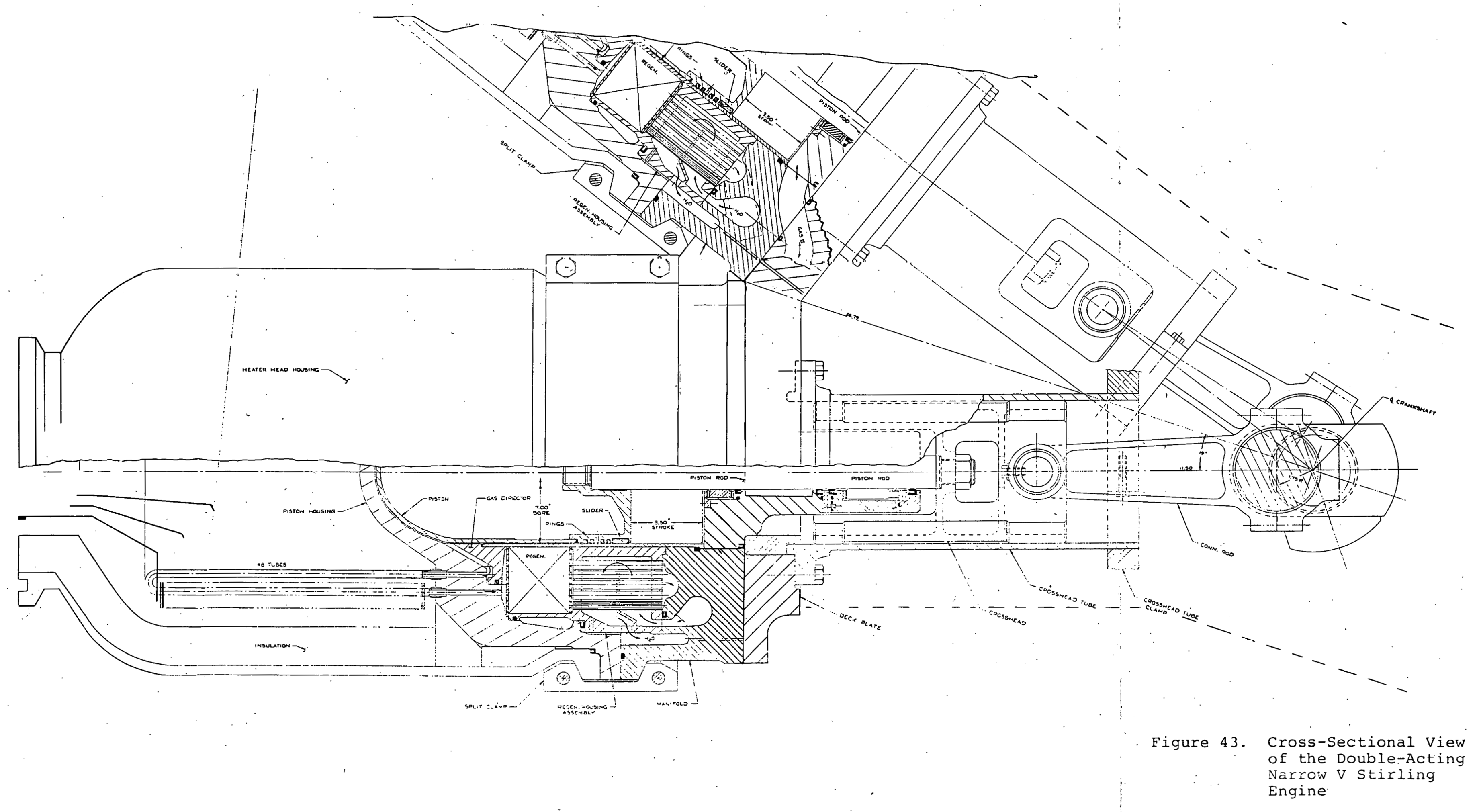


THIS PAGE

\section{WAS INTENTIONALLY LEFT BLANK}


that provides excellent thermal symmetry and low hydraulic losses. Another feature is the use of internal extended surface $\therefore$ (for example, corrugated strip copper swaged and brazed) inside the tubes. This greatly reduces the required number of tubes and the difficulty of fabrication.

Water flow through the cooler also cools the cylinder liner over the active stroke of the piston rings.: Water and gas flows to and from the cylinder module are directed by the manifold block, which also is the structural mounting block for the entire module.

The heater head dome and the heater head housing for pressurized gas circulation, if the latter is used; are attached to the manifold block using a split-ring flange. This type of connection is preferred for compactness and good stress distribution. Note that it is intended primarily for assembly while the module is off the engine, although some combustion-heat-transfer systems and engine layouts may permit removal of individual heater heads from an installed module.

The module is bolted to the engine deck plate by way of the manifold block. Temporary attachment of the rod seal assembly to the cylinder module through the manifold allows installation of a complete module from above, with subsequent attachment of the piston rod to the crosshead from below. The deck plate forms a simple parting plane, with spot-recessed face seals. All manifold service connections are made from below, where there is ample room because the crosshead is much smaller in diameter than the cylinder module.

\section{Piston Seals}

Piston seals require comment because they appear to be the critical component that limits the time between overhaul. Current 
practice prescribes a particular filled polymer and piston speed of approximately $2 \mathrm{~m} / \mathrm{sec}$ for life of, say over $4000 \mathrm{hr}$ in doubleacting engines and over $10,000 \mathrm{hr}$ in displacer engines $(52,53)$. This is not attactive for the present application in terms of piston speed or life.

Design practice and experience with piston rings for unlubricated gas compressors indicate that higher piston speed is allowable and more rings of pressure-balance design are recommended $(\underline{54}, 55)$.

Until better piston ring design and performance are developed it seems necessary to plan for at least yearly maintenance.

$\underline{\text { Rod Seals }}$

The rod seal assembly and system conceived for this application is one having very low friction and very long life, although both remain to be proven. The seal system is an active one in which engine on-off controls activate valves and a positively pumped circuit maintains oil presence. Operation of the rod seals is described referring to Figure 43 .

The lowest, outermost seal is a common static seal having C-cross section of filled polymer with a metal expander spring. This seal maintains oil in the seal block only when the engine is not rotating. While the engine turns, a bleed is opened upstream of the static seal.

While this bleed is open, oil leakage is limited by the choke ring or close-clearance bushing at the outboard end of the seal block. This ring is of rigid material and is not pressureloaded against the rod; but it is elastically or loosely mounted so that it is free to folzow any lateral excursions of the piston rod. Thus the clearance of the bushing can be much less than the clearance of the piston and crosshead without incurring large bushing forces, friction or wear. 
oil supply to the upstream or gas pressure side of the bushing is maintained by a system including an engine-driven pump, a gas-oil pressure-balanced accumulator and suitable controls. Estimates of oil leakage indicate that oil pumping power will be very low (a fraction of l percent of the total engine power).

Inboard of the bushing, a barrier is required between oil and gas. This barrier experiences a very low pressure differential, dependent only on the sensitivity of the oil bleed control system, not the gas pressure in the buffer space. The barrier shown is a set of commercial wipers; although segmented circumferential seals, wedge-film pumping rings, or flexible diaphragms can be considered.

Inboard of the oil-to-gas barrier, or wiper, there is the usual gas buffer space, which is maintained constantly at minimum cycle pressure by appropriate check-bleeds and iṇtercylinder gas lines. These bleed connections also maintain all cycle gas spaces, or cylinders, at the same mean pressure, and hence, equal power.

Various sealing methods can be used between each buffer space and the immediate working gas space. Current practice uses a polymeric sphincter (cap seal) and elastomeric back-up ring. Segmented circumferential seals or, ultimately, a close-clearance floating bushing will offer the required long. life. Note that some leakage is required in this seal, or elsewhere, to equalize the cylinders.

\section{Engine Output Configuration}

After considering the merits and cost or risk of unusual designs offering stroke control versus usual crank designs requiring some other. form of power control, it.is recommended that initial development be of the simplest, most common 
configuration currently manufactured for large stationary diesel engines. This is the single crank, narrow $-V$, multicylinder approach in which any number of cylinders, in groups of four, provides the desired power rating up to the limit of crankshaft torque. For example, single engine ratings from $373 \mathrm{~kW}$ (500 hp) using four cylinders, up to $2237 \mathrm{~kW}$ ( $3000 \mathrm{hp}$ ) using 24 cylinders, are practical.

The initial design of the narrow- $V$ engine (Viking-l) is illustrated in Figure 43 and 44 , showing the features sufficiently detailed in section and the overall dimensions of the basic engine.

The most important feature of the design is that complete servicing of the piston, cylinder liner, seal assembly, and all lubricated machine parts can be accomplished from below, crankside, without disturbing any parts on the upper side (after cooldown and depressurization, of course).

The engine uses one crank throw per cylinder, so that the $V$-angle and the cycle phase angle $(90$ or 108 deg for four or five cylinder groups, respectively) are optional, requiring only proper specification of crank angles. This configuration can be partially balanced using counterweights integral with the crankshaft, which is probably sufficient for many low-speed installations. For sensitive installations and high speed operation complete balancing:can be achieved using counterweights at the four lateral corners of the engine, with parallel shafts geared to the crankshaft. This is a little added complication because the shafts can also serve for accessory drives.

\section{Stirling Cycle Power Control}

With constant-displacement engines, dead-volume control offers the highest efficiency at high power fractions and mean-pressure control is more attractive at low power fractions 


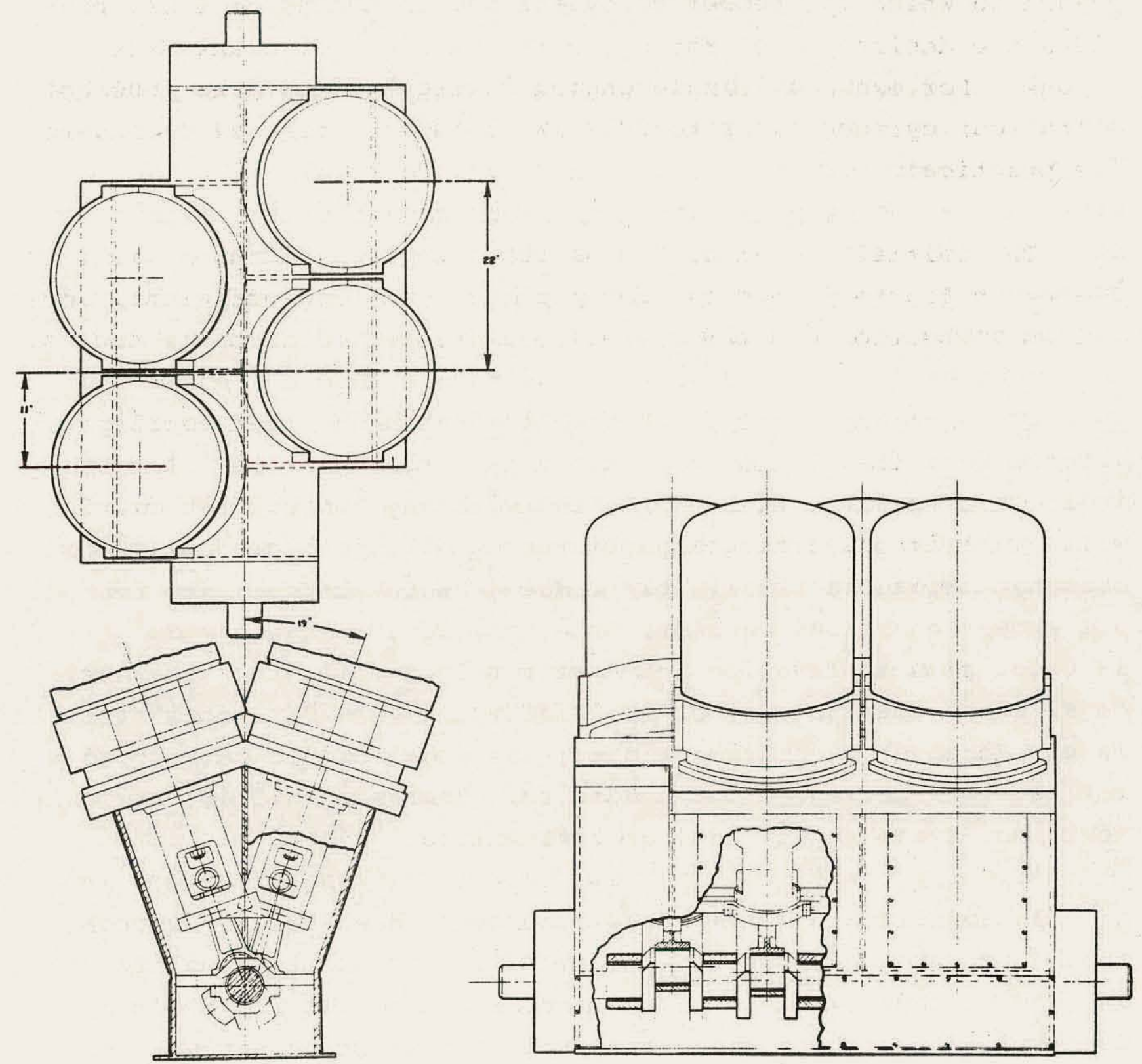

Figure 44. Configuration Layout of the $373 \mathrm{~kW}$ (500 hp) Double-Acting, Narrow $V$ Stirling Engine (4 Cylinders) 
(see Section 4). Dead-volume control is also favorable for following frequent, rapid power fluctuations with minimum power loss for practical systems for bleed and repumping.

The engine should be developed initially with mean-pressure control using methods previously developed but perhaps with "tiered" gas reservoirs at several pressure levels in order to minimize repumping power and compressor capacity (the engine itself can be used to pump across its own pressure ratio using appropriate bleed-check control plumbing). Along with this, or any control method, inter-cylinder dump-valve connections probably must be provided to protect the engine from overspeed due to circuit-break of the electrical load at high power setting. (Stored heat capacity of the system is large, particularly with indirect combustion systems.) Also with any control method, it will probably be advantageous, in terms of life-cycle costs, to operate the engine at slightly reduced heater temperature for all except peak load demands. That is, if the engine model is used in an application intended for load-following, it should be sized to operate most of the time below peak rating; if it is base-loaded or continuous duty, the model should be derated for the application. (The tradeoffs, discussed earlier, are fuel cost, hot-system cost, and hot-system life.)

In addition to mean-pressure control, dead-volume control should be developed for rapid load following and to simplify the gas storage system. An attractive method for implementing dead-volume control for the proposed double-acting narrow-V engine is to attach an air-oil accumulator to each cylinder gastransfer duct. The accumulator can be a commercial bladder type providing total exclusion of oil from the working gas with negligible pressure differential across the bladder. (Note that this bladder cycles slower and less frequently, by about two orders of magnitude, than piston rod diaphragms.). To increase or decrease engine power, oil is pumped into, or bled from the 
accumulators. It appears that only one pump and bleed is required for all the cylinders; if the accumulators are connected together, in parallel, with a suitable hydraulic network for pressure-equalization, then the accumulators will stabilize at equal volumes, consistent with equal mean pressure and power of the gas spaces or cylinders. This system is theoretically stable, but its efficiency remains to be proven. One possible drawback to wide dead-volume control is the added surface area in the gas space, which may result in significant losses due to cyclic heat transfer, a somewhat moot point at this time.

Dead-volume control at constant gas charge mass, as well as mean-pressure control reduce the gas pressure in the cylinder when power is reduced. This extends the creep-limited life of a given engine, which is an advantage compared to stroke-control for part-power operation.

\section{Rated Speed}

The basic engine design is suitable for speeds up to about $30 \mathrm{~Hz}$ without severe penalties in thermal efficiency or machine life except for piston rings, as discussed. Given specific engine hardware, it probably will be sensible to rate electrically base-loaded engines at 15 or $20 \mathrm{~Hz}$, and load-following engines at 20 or $30 \mathrm{~Hz}$. For least-expensive generators in the smaller sizes, $30 \mathrm{~Hz}$ is most attractive.

\subsubsection{Direct Combustion Systems}

The recommended combustion and control system for multitype clean fuels is described in subsection 4.1 , including initial design-matching of the heater head and the air preheater, offering uniform combustion, low emission, and low exhaust temperature by the use of massive internal exhaust gas recirculation. 
A schematic of the proposed $373 \mathrm{~kW}(500 \mathrm{hp})$ Stirling engine/generator set with clean fuel combustion system is shown in Figure 45. The combustion and control system is suitable for any fuels that can be pumped through nozzles so long as fouling, erosion, or corrosion do not result. The prevaporized, premixed combustion method is expected to yield very low carbonaceous soot, but it remains to be determined what sulfur, ash, and metal salt levels can be tolerated in various residual- or coal-converted fuels. To this end, the most expensive alloys may be used for the heater tubes, which are not massive, and a separate air preheater, common for all cylinders, will offer more design freedom.

For burning of quite clean fuels, compact preheaters for individual cylinders are probably more cost-effective, because then the air and exhaust manifolds are at moderate temperatures.

Direct combustion systems will include an engine-driven blower for combustion air. Control of this air is a primary variable in the load-following system. The control is accomplished best with inlet throttling guide vanes that prerotate the air, thus reducing blower load at part-power. Preliminary estimates of the air preheater, which is the major pressure loss, combustor, heater head, and system ducting indicate that the power loss to the combustion blower needs not exceed approximately 2 percent of engine power. (Automotive Stirling engines suffer much more than this because of compact flow systems.)

\subsubsection{Indirect Combustion Systems}

In subsection 4.2 it was concluded that fluidized-bed combustion (FBC), is the only method within the near-term horizon of development for utilizing coal on-site in a way that is both environmentally acceptable and possibly economical for the low range of power in this application. Only atmospheric FBC systems are currently available, and an indirect heat transfer 


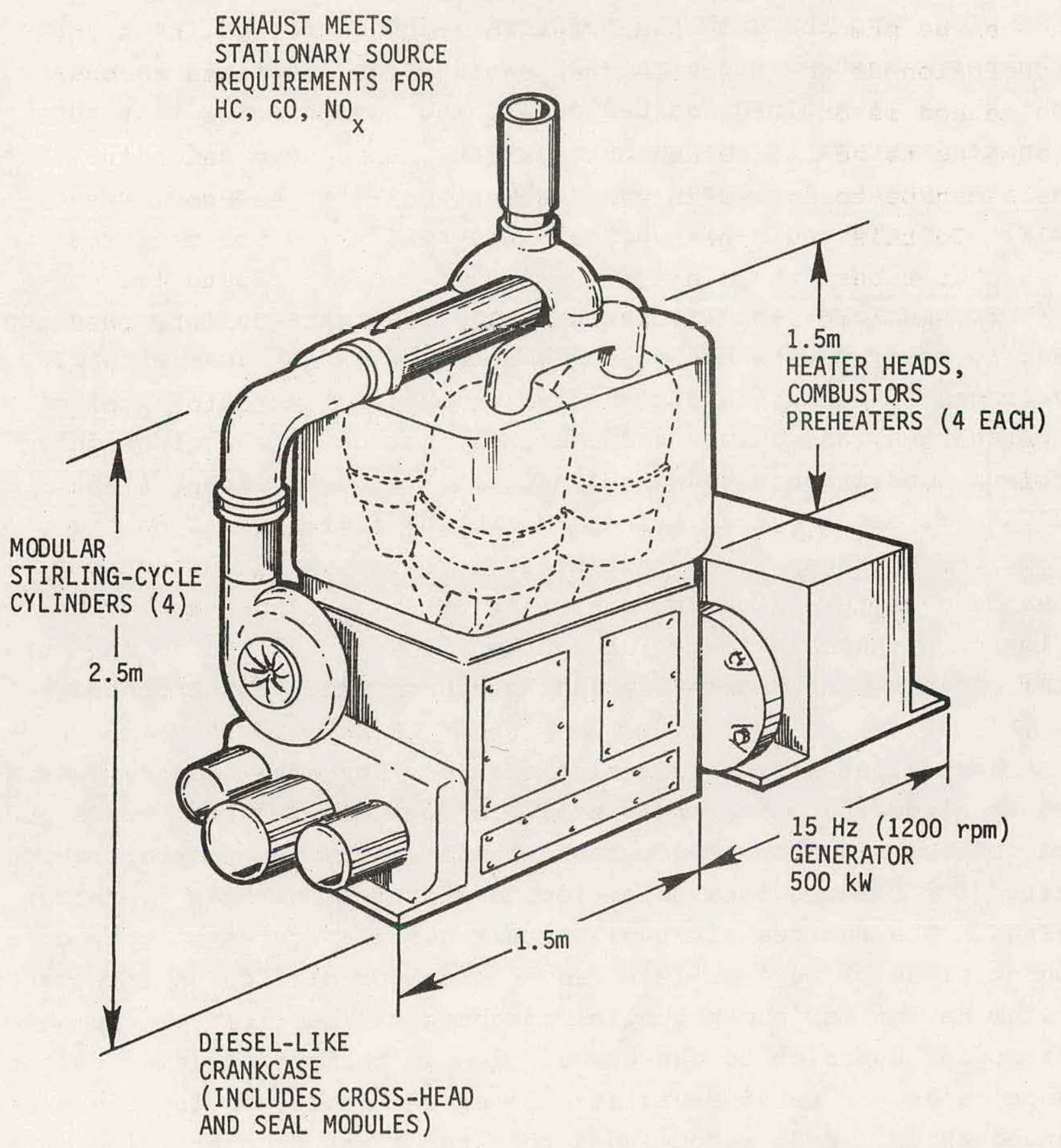

Figure 45. $373 \mathrm{~kW}(500 \mathrm{hp})$ Stirling Cycle Engine with Clean Fuel Combustion System 
loop is required in order to mate the usual configuration of an FBC to a typical Stirling engine. Also, it was judged in subsection 5.2 that a pressurized-gas circulation loop and liquid metal heat pipes are the only two practical methods for indirect heat transfer. A schematic of a $2237 \mathrm{~kW}$ (3000 hp) Stirling engine/generator set with fluidized bed coal combustion and indirect heat transfer systems is shown in Figure 46. A process flow diagram of the atmospheric fluidized bed combustion system coupled to the Stirling cycle engine is shown in Figure 47.

Pressurized-gas circulation loops for transfer of combustion heat to power cycles has been demonstrated in the past with closedcycle gas turbines and alternative combustors including fuel oil, supercharged, and pulverized coal, dry bottom or slagging ( $\underline{56})$. Various constituents and gas conditions to 58 atmospheres and $923^{\circ} \mathrm{K}$ were accommodated. These operating limits resulted from practical considerations, not necessity, particularly the cost advantage of low-alloy or "stainless" steels, rather than superalloy or nickel-base materials. Low alloy steel ducting and turbine casings were internally insulated and sheet-metal lined.

Heat pipes having very high flux density have been demonstrated in sizes up to the order of $10 \mathrm{~cm}$ diam and several meters long, and for several thousand hours. However, a system of the size required for the proposed conditions of interest has not ever been tested. The choices are two: either build a system of many component pipes of more-or-less proven size, or develop an integrated system having maximum potential advantage. The first choice does not appear superior to gas circulation in terms of thermal performance, cost, or serviceability; the second choice definitely does. Consequently, it is recommended that the first demonstration of a FBC-Stirling engine be planned for pressurized-gas circulation and that an advanced heat pipe system be developed independently.

Previous gas loops for power generation encountered generally higher combustion temperature, but lower specific heat flux 


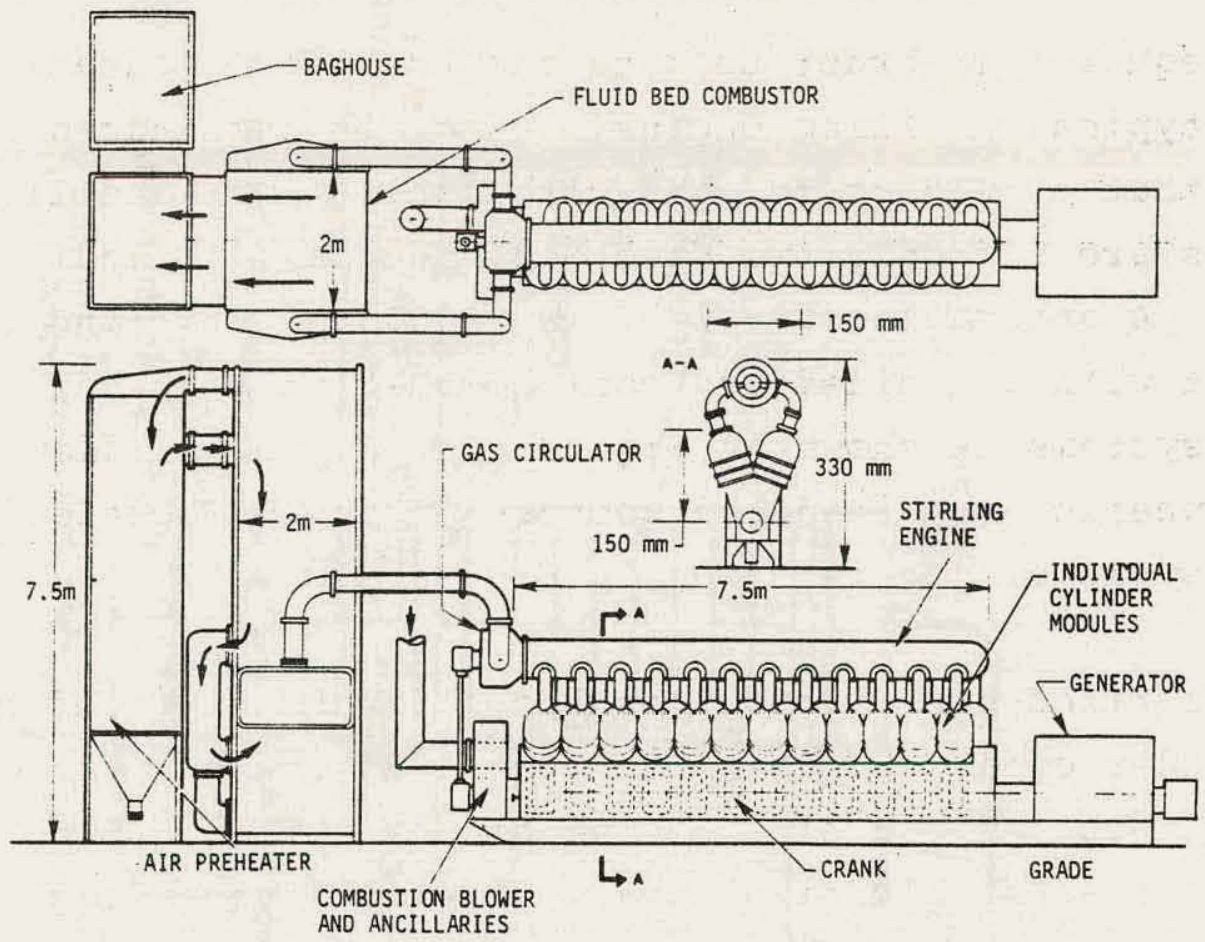

a) TOP AND SIDE VIEWS OF THE, STIRLING CYCLE ENGINE SYSTEM

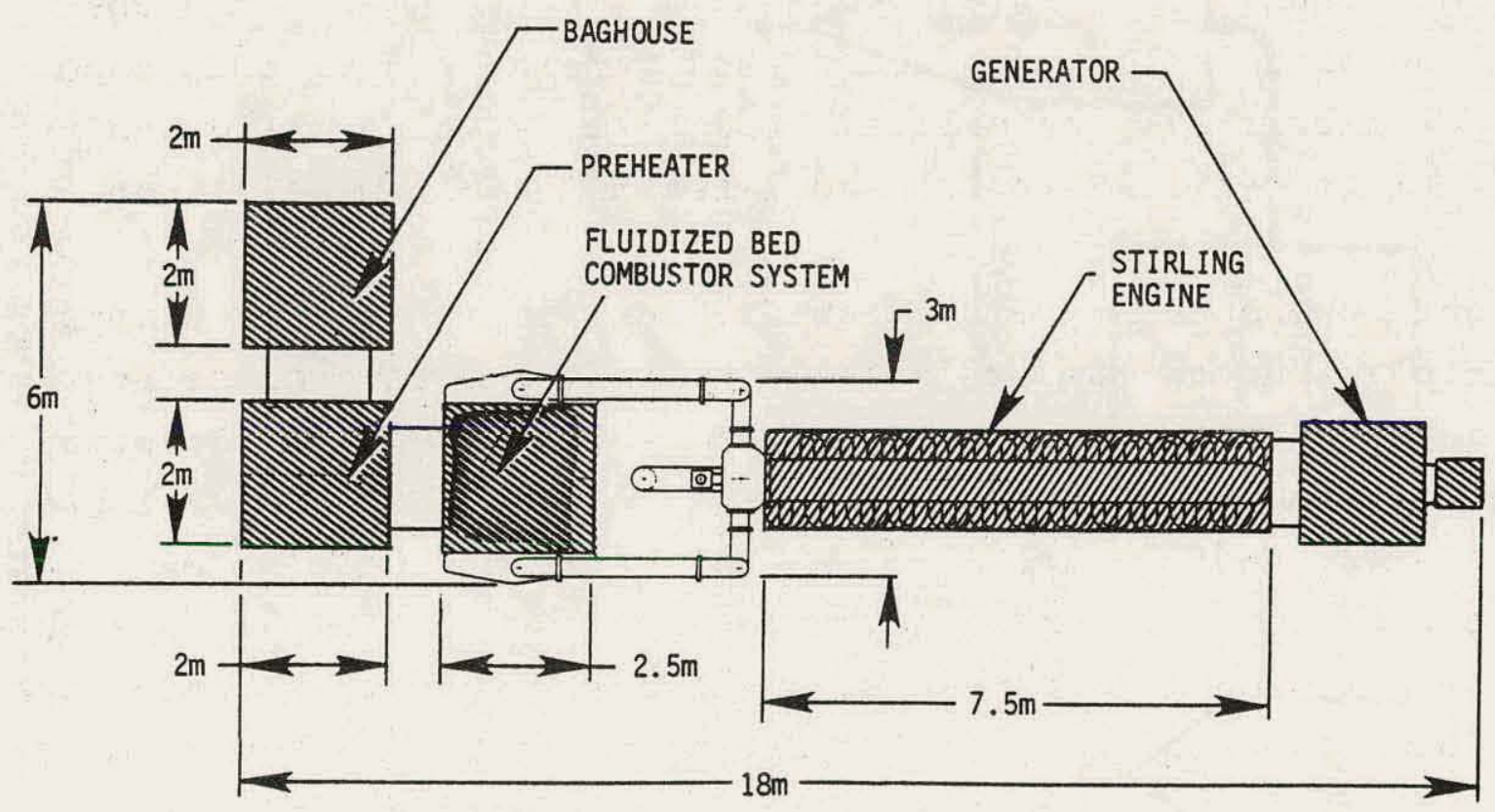

b) LAYOUT OF THE STIRLING CYCLE ENGINE SYSTEM

Figure 46. $2237 \mathrm{~kW}$ ( $3000 \mathrm{hp}$ ) Stirling Cycle Engine with a Two-Stage Atmospheric Fluidized Bed Combustion System and a Gas Circulation Loop 


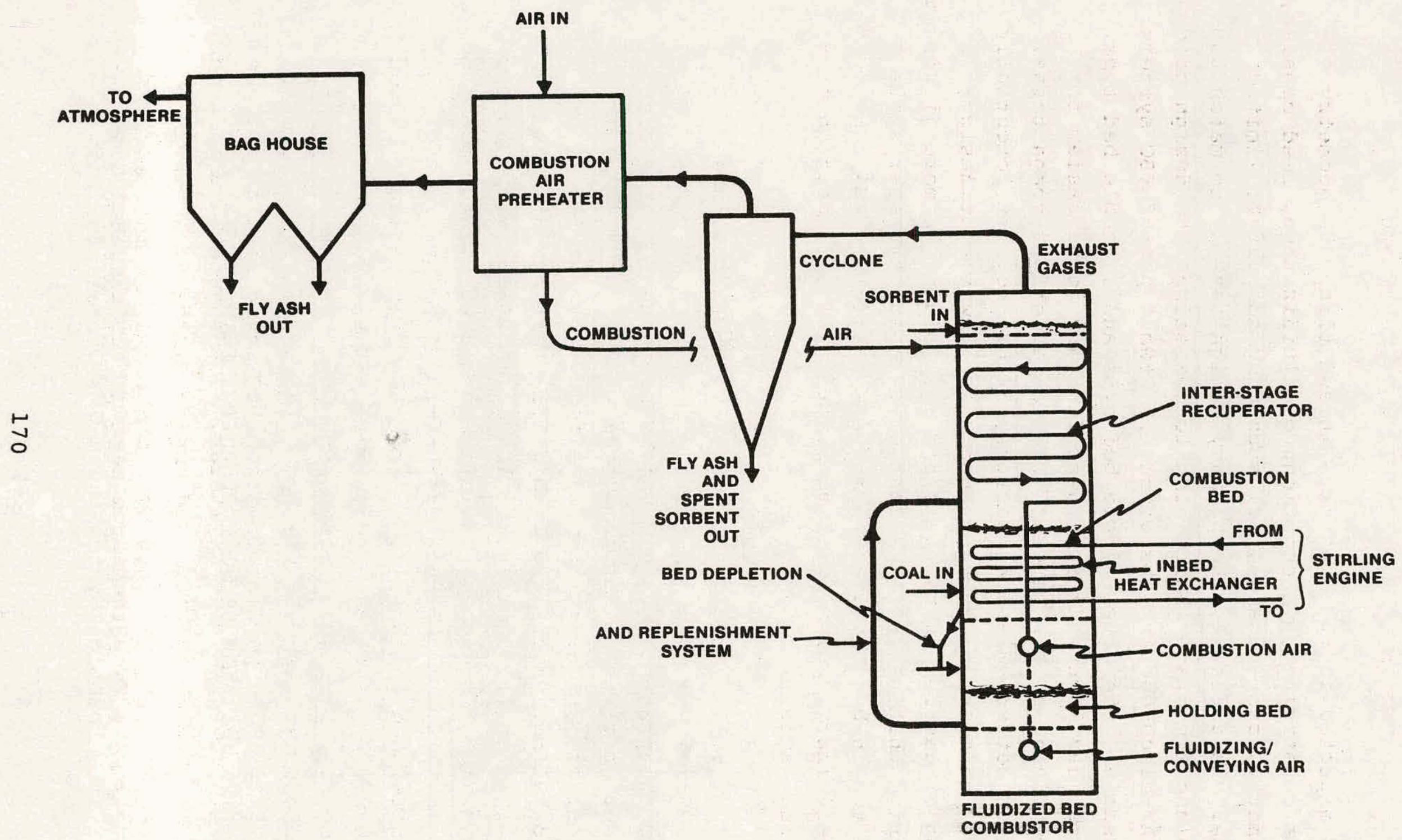

Figure 47. Process Flow Diagram of the Atmospheric Fluidized Bed Combustion System Coupled to the Stirling Cycle Engine 
than is expected in FBC systems. In addition, the geometry of a FBC is constrained by conditions of fluidization, feed consist, stoiciometry, and emission, all according to current limited practice. As a result, the primary design task is to match tube bundles and immediate manifolding to "existing" FBC design practice. As discussed in subsection 4.2 , two types of FBC systems are possible: the usual single bed type and a double bed type. The former has lower specific heat flux and so is easier for design-matching a tube bundle. The latter offers compactness, as well as better emission characteristics, so that potentially the size and cost of the tube bundle are lower, but designin matching of gas-loop parameters and manifolding is more difficult. Considering that the primary cost of the heat transfer system will be the in-bed tubes and immediate manifolds, FMA recommends that preliminary design and demonstration of a compact doublebed be initiated.

\subsubsection{Predicted Engine System Performance}

All the proposed engine systems are based on the "core" engine design illustrated in Figures 43 and 44 . The basic dimensions of the design shown are for a bore of $180 \mathrm{~mm}$ and stroke of $90 \mathrm{~mm}$, which is suitable for shaft output power levels up to about $100 \mathrm{~kW}$ per cylinder at $20 \mathrm{~Hz}$, with 150 bar mean pressure of hydrogen, exclusive of power for the combustion system and indirect heat transfer. This power level would be reduced to about $65 \mathrm{~kW}$ at $15 \mathrm{~Hz}$ with helium. Obviously the number of cylinders selected for a given engine rating will depend on many secondary factors once the production of one basic.module has been established. Any groupings of four or five cylinders can be accommodated with insignificant difference in efficiency or power per cylinder. The predicted efficiency of several options for proposed engine system is given in Table 13. In shurt, the hydrogen engine with clean fuel and evaporative cooling is the best that can be expected for small 
$\because$ Table 13. Stirling Engine system Predicted

Design Point Efficiency

\begin{tabular}{|c|c|c|}
\hline 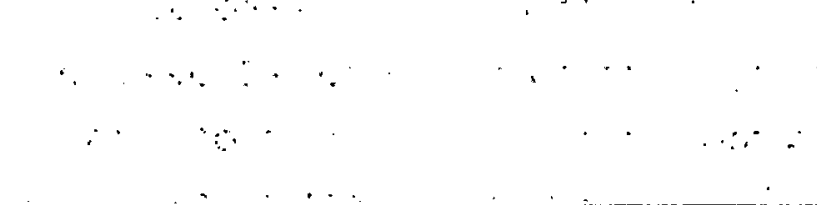 & $\begin{array}{l}\text { Hydrogen } \\
\text { Evaporative } \\
\text { Cooling } \\
(50 \circ \mathrm{C})\end{array}$ & $\begin{array}{c}\text { Helium } \\
\text { Cogeneration } \\
\left(80^{\circ} \mathrm{C}\right)\end{array}$ \\
\hline $\begin{array}{l}\text { Stirling engine* } \\
\text { Indicated thermal efficiency } \\
\text { Internal friction (piston rings) } \\
\text { External friction (crankcase) } \\
\text { Gross brake thermal efficiency } \\
\text { Auxiliary power fraction: } \\
\text { Clean fueis - direct combustion } \\
\text { Coal - fluidized bed combustion: } \\
\text { - Gas circulation } \\
\text { - Heat pipe } \\
\text { Combustor/preheater efficiency: } \\
\text { Clean fuels - direct combustion } \\
\text { Coal - fluidized bed combustion } \\
\text { Net system brake thermal efficiency: } \\
\text { clean fueis - direct combustion } \\
\text { Coal - fluidized bed combustion: } \\
\text { - Gas circulation } \\
\text { - Heat pipe } \\
\text { overall fuel to electrical energy } \\
\text { conversion efficiency: } \\
\text { clean fuels - direct combustion } \\
\text { Coal - fluidized bed combustion: } \\
\text { - Gas circulation } \\
\text { - Heat pipe }\end{array}$ & $\begin{array}{l}0.48 \\
0.06 \\
0.07 \\
0.42 \\
\cdots \\
0.02 \\
0.02 \\
0 \\
\\
0.90 \\
0.80 \\
\\
0.37 \\
0.32 \\
0.33\end{array}$ & $\begin{array}{ll}\because & \\
\ddots & 0.44 \\
& 0.06 \\
& 0.07 \\
& 0.39 \\
& \\
\ddots & \\
& 0.02 \\
& \\
& 0.09 \\
& 0\end{array}$ \\
\hline
\end{tabular}

*Design point conditions: $1200 \mathrm{rpm}$, heater tube temperature of $720^{\circ} \mathrm{C}$. 
systems, and the helium engine with coal and cogeneration is the poorest to be expected for large systems, within the present state of the art. We cannot predict a dramatic increase in the efficiency of Stirling engine systems with advanced design and development, considering the practical constraints of cost and life in utility application: There is no substantive... basis for expecting much higher temperature capabilities from metal alloys, and methods for designing and joining ceramic elements for combustion - heater systems remain to be demon-: strated. Some of the advanced design approaches to be discussed may be expected to improve system efficiency on the order of 10 percent. No single; variable in stirling engine design appears to be particulariy vulnerable for great. improvement.

\subsection{Advanced. Systems Designs}

Indirect heat transfer using heat pipes from a fluidized bed to a large stirling cycle engine, the initial design discussed in subsection 5.2 , is considered to be very attractive for an advanced system. Assuming that the illustrated simple arrangement is developed to perform satisfactorily, it offers minimum cost (mass) of alloy material, no pumping requirements, ease of in-bed tube replacement, and complete safety in failure. This system is immediately applicable for use with the proposed state-of-the-art engine design and any FBC system; it is also attractive for advanced engines or other combustion methods.

As discussed in subsection 2.3, pertaining to engine heat exchanger configuration, and subsection 5.2, describing heatpipe-to-heater-head interfacing, the type of design that is most attractive thermodynamically is one having purely axial fluw through the serles of heat exchangers with essentially no 
manifolding and a heater having high flux density. This offers possibly improved efficiency due to reduced adiabatic cycle loss, cyclic heat transfer loss, and flow friction. loss, as well as increased volumetric specific power. Possible compact blocklike hot sections also offer reduced engine cost. It is recommended that preliminary design of an engine using this concept be continued, using more detailed analyses and test information on internal thermodynamics as they become available:

In Section 2 the parametric scaling and design of a lowpressure engine were mentioned but not described further. $\because$ Preliminary sizing and computer simulation of performance indicate that at approximately 10 atmospheres charge pressure a $100 \mathrm{~kW}$ output stirling cycle cylinder design could have a $50 \mathrm{~cm}$ bore, $15 \mathrm{~cm}$ stroke, and most importantly, heater tubes over $150 \mathrm{~cm}$ long and over $3 \mathrm{~cm}$ ID. The significance of long, large diameter. lightly stressed heater tubes is that they may be compatible with direct combustion and heat transfer with dirty fuels, including FBC and coal. The resulting system, although large on the engine side might be the most cost-effective and maintainable.

The initial analytical designs showed that the low pressure engine has as high thermal efficiency as the proposed high pressure design, and parametric analysis indicates that the mechanical design is not necessarily more massive and expensive. One scaling rule that is violated in low-pressure designs for 20 or $30 \mathrm{~Hz}$ is the recommended design practice for piston ring velocity. However, at low pressure (pressure differential loading) this highpressure velocity limit probably is not valid, and in fact different piston seal designs, including clearance seals, may offer life far-exceeding that of current high-pressure practice.

With the large heater tubes of a low-pressure engine, direct combustion of "dirty" fuels may not be limited to FBC alone. A possibility to consider is a single large combustor or furnace 
in proximity to the engine with massive hot exhaust gas recirculation for control of $\mathrm{NO}_{\mathrm{X}}$ emissions, a fluidized hed of sulfur absorbent downstream of the heater head where the temperature is nearly ideal, and a suitable air preheater. This system, along with site-delivery of specific prepared fuel, such as partiallycleaned pulverized coal; could be both the most cost-effective and least capital - intensive for the range of stationary applications presently considered. It is recommended that further. systems-design effort be devoted to this possibility. 
7. MANUFACTURING ASSESSMENT/PRODUCTION .COST ESTIMATES

A manufacturing assessment and production cost esțimates of the proposed Stirling cycle engine systems described in Section 6 were performed: The total systems were divided into subsystems and a preliminary cost analysis was performed for. each of the following subsystems:

\footnotetext{
- Stirling cycle engine. .

- 'Conventional direct combustion system

- Tworstage fluidized bed combustion system

- $\quad$ Indirect heat transfer systems.
}

For a clean fuels combustion the proposed $2237 \mathrm{~kW}$ (3000 hp) system production cost is $\$ 478,242$ or $\$ 214 / \mathrm{kW}(\$ 159 / \mathrm{hp})$ for production rate of 1000 units per year. For solid coal combustion the proposed $2237 \mathrm{~kW}(3000 \mathrm{hp})$ system production cost is approxi-. mately $\$ 2,246,242$ which corresponds to $\$ 1004 / \mathrm{kW}$ ( $\$ 749 / \mathrm{hp})$.

\section{7:1 Engine Manufacturing Assessment}

TCM conducted the manufacturing assessment of the stirling cycle engine conceptual designs prepared by FMA. The protocol employed by TCM consisted of the following steps: ·

- Review conceptual design layouts and specifications

- Determine manufacturing.-technology levels.

- Identify components in preparation for production cost estimates. 
The purpose of the review of design layout drawing and specifications was to ensure good engine design practice which included preliminary stress analysis, seals, mechanical fasteners, utilization of diesel engine technology where appropriate, and reliability. Also materials selection, manufacturing processes, and maintainability requirements such as accessibility of maintenance items, special tools and equipment, and human factors were investigated.

The manufacturing technology was identified in terms of current state-of-the-art manufacturing technology, manufacturing technology development, and projected manufacturing technology. The current state-of-the-art manufacturing technology is defined as manufacturing technology available today and which is readily available for the mass production of engine components. Mänufacturing development technology is defined as manufacturing technology available for the production of prototypes, but development of the manufacturing processes is required for eventual commercial manufacturing: And projected manufacturing. technology is defined as new materials/manufacturing technology which has never been used for stirling cycle engines.

The last step in the manufacturing assessment is the identification of engine components so that production cost estimates can be determined.

TCM evaluated three design layout configurations of a fourcylinder double acting stirling cycle engine. Primary criteria considered in the analysis included:

- Minimization of dead volume between cylinders

- Avoidance of unbalanced inertia forces 
- Minimization of weight and volume

- Utilization of diesel engine technology where appropriate

- Minimization of production costs.

The first configuration reviewed was a double-acting in-line engine. Salient disadvantages regarding this configuration are:

\section{Different dead volumes exist between cylinders}

The distance between main bearing is dictated by the cylinder spacing. As a result a very poor crankshaft configuration with high bending stresses exists due to the long distances between bearings.

The second configuration reviewed was a double-acting $V$ engine. This configuration has equal dead volumes between all cylinders and is the smallest of the three configurations. examined by TCM.: A disadvantage of this configuration is that it eliminates the possibility of stroke control.

The third configuration reviewed was a double-acting, vertical staggered engine and offers similar advantages as the double-acting $V$ engine such as zero resultant inertia forces, equal dead volumes between cylinders; and small volume. However, a disadvantage is that the power train may either be two crankshafts geared at the. flywheel end of the engine, or a single crankshaft and beams. Both arrangements increase the size of the engine and cost.

At the conclusion of the manufacturing assessment and preliminary cost assessment, TCM recommended the double acting $\mathrm{V}$ engine for further consideration. 


\subsection{Engine Production Cost Estimates}

Preliminary production cost estimates were prepared for the double-acting $\mathrm{V}$ configuration Stirling cycle engine. $\therefore$ As part of the cost estimate methodology, the engine was broken down to the component level. Weight and cost estimates were prepared for each component. The estimated weight of a $373 \mathrm{~kW}(500 \mathrm{hp})$ engine module, excluding the burner assembly, blower, air preheater, radiator, fan, fan drive, oil cooler, fuel pump/fuel system, and pressure control system is $2700 \mathrm{kgr}(5947 \mathrm{lb})$ which reduces to a weight to power capacity ratio of $7.24 \mathrm{kgr} / \mathrm{kW}(11.89 \mathrm{lb} / \mathrm{hp})$. A detailed weight analysis of a 4 cylinder $373 \mathrm{~kW}(500 \mathrm{hp})$ stirling engine module is presented in Table 14. The weight to power capacity ratio for comparable stationary diesel engines varies from 3.5 to $6.5 \mathrm{kgr} / \mathrm{kW}$. The average value for current production diesel engines is $4.5 \mathrm{kgr} / \mathrm{kW}$, excluding radiator and fan.

In Table 15 a comparison of the weight to power capacity ratio for other stirling cycle engines is presented. Of course, many of the previous engines were designed for automotive applications which requires compact design for fuel efficiency and low initial costs. The proposed double-acting $\mathrm{V}$ configuration Stirling cycle engine has a larger ratio of weight to power capacity as compared to existing diesel engines and stirling cycle engines. The weight can be further reduced during Phase II - Preliminary Design by redesigning the deck plates, manifolds, piston housing, heater head housing, and cylinder hold down clamps.

A detailed production cost estimate for the manufacture of the double-acting $\mathrm{V}$ configuration $373 \mathrm{~kW}\left(500^{\circ} \mathrm{hp}\right)$ Stirling cycle engine for quantity of 1000 units per year is presented in Table 16. The dominant cost element is the piston housing which represents approximately 37 percent of the total estimated cost. A summary of the production cost estimates for the 
Table'14. Estimated Weight of a Four Cylinder $373 \mathrm{~kW}(500 \mathrm{hp})$ Stirling Engine Module

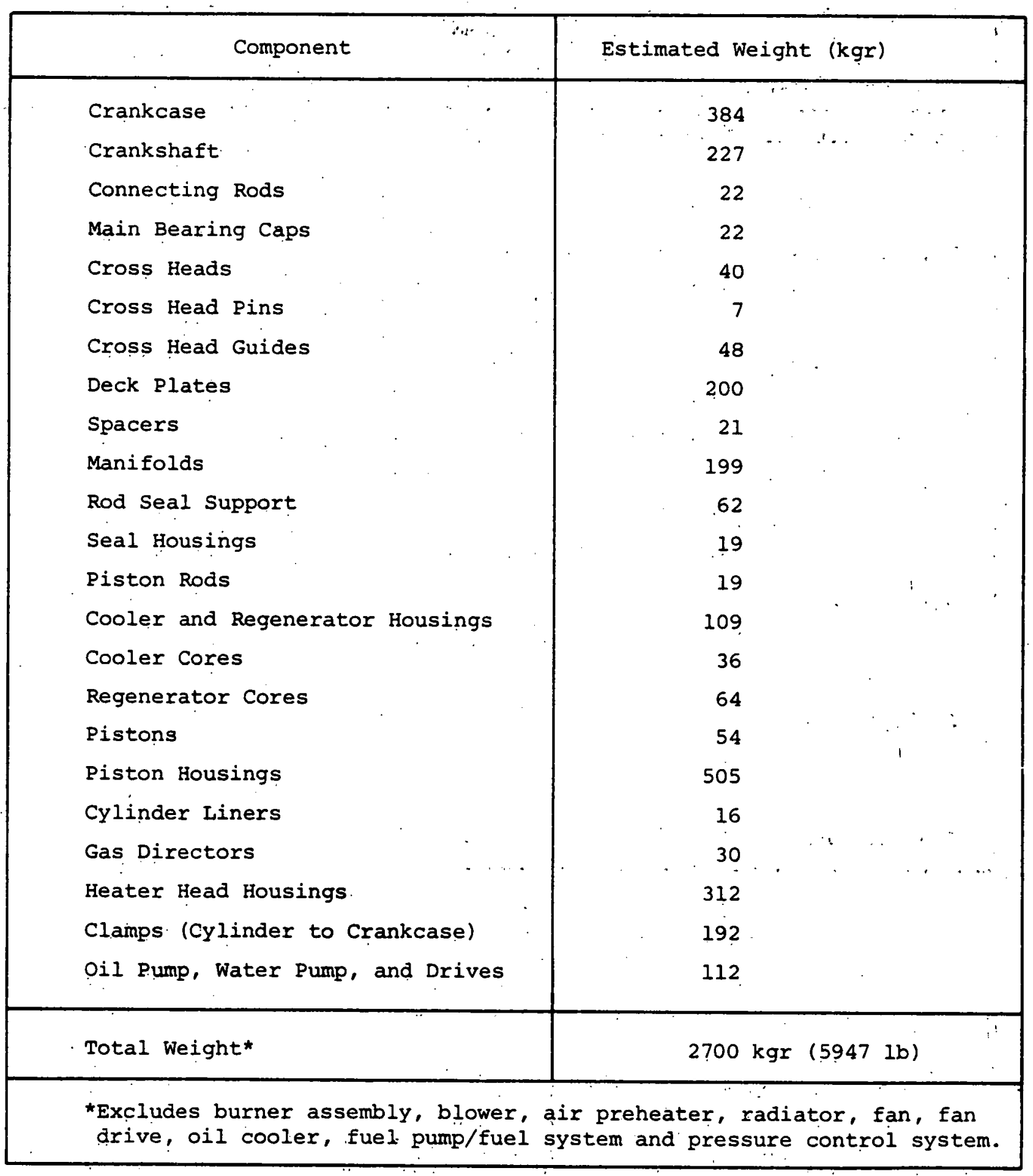


Table 15: Comparison of Weight to Power Capacity Ratios for Stirling Cycle Engines

\begin{tabular}{|c|c|c|c|c|}
\hline Description & $\begin{array}{l}\text { Power } \\
\text { Capacity } \\
\text { (kw) }\end{array}$ & $\begin{array}{c}\text { Weight } \\
(\mathrm{kgr})\end{array}$ & $\begin{array}{c}\text { Weight/Power } \\
\text { Capacity } \\
(\mathrm{kgr} / \mathrm{kW})\end{array}$ & \\
\hline United Stirling of Sweden, P40 & 40 & 180 & 4.5 & \\
\hline United Stirling of Sweden, P75 & 75 & 350 & 4.67 & \\
\hline United Stirling of Sweden, P150 & 150 & 650 & 4.33 & \\
\hline Philips, 4-98 & 62.6 & 169 & 2.70 & \\
\hline Philips, 4-215 & 127 & 340 & 2.54 & \\
\hline Philips, 4-235 & 150 & 758 & 5.05 & 1 \\
\hline General Motors, GPU-3 & 5.2 & 75 & 14.4 & \\
\hline
\end{tabular}


Table 16. Detailed.Production Cost Estimates for the Manufacture of the Double-Acting $V$ Configuration $37.3 \mathrm{~kW}$ (500 hp) Stirling Cycle Engine for Quantity of 1.000 Units/Year

\begin{tabular}{|c|c|c|c|}
\hline Component & Quantity & Laborhours & Material Costs \\
\hline Crankcase & 1 & 15.2 & $\$ 1,500$ \\
\hline Crankshaft & 1 & 14.7 & 1,000 \\
\hline Connecting Rods & 4 & 5.6 & 176 \\
\hline Main Bearing Caps & 5 & 3.5 & 130 \\
\hline Cross Heads & 4 & 4.0 & 144 \\
\hline Cross Head Pins & 4 & 0.8 & 60 \\
\hline Cross Heàd Guides & 4 & 16.1 & 176 \\
\hline Deck Plates & 4 & 14.0 & 116 \\
\hline Spacers & 4 & 10.0 & 900 \\
\hline Manifolds & 4 & 10.0 & 224 \\
\hline Rod Seal Supports & 4 & 6.0 & 68 \\
\hline Seal Housings & 4 & 4.0 & 204 \\
\hline Piston Rods & 4 & 6.0 & 204 \\
\hline $\begin{array}{l}\text { Cooler and Regenerator } \\
\text { Housings }\end{array}$ & 4 & 65.2 & 1,500 \\
\hline Cooler Cores & - & & 400 \\
\hline Regenerator Cores & - & & 400 \\
\hline Pistons & 4 & 24.0 & 1,440 \\
\hline Piston Housing & 4 & 72.0 & 16,146 \\
\hline Cylinder Liners & 4 & 10.0 & 516 \\
\hline Gas Directors & 4 & 64.0 & 1,320 \\
\hline Heater Head Housings & 4 & 12.0 & $1,7,00$ \\
\hline Clamps & 4 & 12.00 & 1,100 \\
\hline Seals & 4 & & 1,000 \\
\hline Other Parts & - & & 3,930 \\
\hline Assembly & - & 16.6 & - \\
\hline Total Material Cost & & & $\$ 35,350$ \\
\hline Total Labor Cost 385 & $x \$ 45 / \mathrm{hr}$ & & $\$ 17,357$ \\
\hline Total Production Cost & & & $\$ 52,707$ \\
\hline
\end{tabular}


manufacture of the proposed double-acting $\mathrm{V}$ configuration $373 \mathrm{~kW}(500 \mathrm{hp})$. engine excluding the clean fuel combustion system for quantities of 10 and 1000 units/year is shown in Table 17. The expected annual production quantities are too small tọ justify high speed, high volume production methods: Hence, the manufacturing costs for annual quantities of 100 and $1000373 \mathrm{~kW}(500 \mathrm{hp})$ modular units will be approximately the same:

\section{7..3 Conventional Direct Combustion System Production Cost Estimates}

The production cost estimates for a clean fuel direct combustion system which includes combustor, engine blower and damper, evaporator cooler, and air preheater were prepared for a four cylinder $373 \mathrm{~kW}(500 \mathrm{hp})$ engine module. For quantities of 10 and 1000 units/year the estimated production costs are $\$ 29,000$ and $\$ 27,000$; respectively.

Table 17: Summary of Production Cost Estimates for the Manufacture of the DoubleActing $V$ configuration stirling Cycle $373 \mathrm{~kW}(500 \mathrm{hp})$. Engine

\begin{tabular}{|l|c|c|}
\hline Description & 10 Units/year & 1000 Units/year \\
\hline Labor & $\$ 26,037$ & $\$ 17,357$ \\
Material & 47,100 & 35,350 \\
\hline Total & $\$ 73,137$ & $\$ 52,707$ \\
\hline
\end{tabular}


7.4 Production Cost and operating Cost Estimates for : : a Two-stage Fluidized Bed Combustion system

A preliminary production cost and operating cost estimates were prepared for a two-stage fluidized bed combustion system for $5.86 \mathrm{MW}(+)$ heat delivered. This capacity is compatible with a $2237 \mathrm{~kW}(3000 \mathrm{hp})$ stirling cycle engine. The following assumptions were made for the economic analysis for the first system:

- First-of-a-kind fluidized bed combustion system so costs include development costs to advance the technology to the levels required by the design criteria (56) stated in section 4

- Cost estimates include the total cost combustion system from coal receiving to gas exhaust and waste disposal. Ash handing system includes the cyclone and baghouse

- Cost estimates are in 1979 dollars

- Proposed combustion system employs limestone and has a combustion efficiency equal to that of a conventional atmospheric fluidized bed combustion system

- Projected cost estimates are subject to significant reductions for subsequent unit and large quantity. production.

A summary of the estimated production costs and operating costs for the first two-stage fluidized bed combustion system is presented in Table 18. The initial capital cost is $\$ 4.24$ million which represents $\$ 724 / \mathrm{kW}(+)$ and the annual operating cost is approximately $\$ 1.712$ million. It is obvious that both the 
Table 18. Estimated Manufacturing and operating Costs for a (Demonstration) First Two-stage Atmospheric

Fluidized Bed Combustion System (56)

\begin{tabular}{|c|c|c|}
\hline$\therefore \quad$ subsystem & $\begin{array}{l}\text { Initial Capital } \\
\text { Cost }(\$ 1000)\end{array}$ & $\begin{array}{l}\text { Operating cost } \\
(\$ 1000)\end{array}$ \\
\hline $\begin{array}{l}\text { Coal Receiving } \\
\text { Coal Preparation } \\
\text { Storage } \\
\text { Limestone Receiving and Storage } \\
\text { Combustor } \\
\text { Ash Handling } \\
\text { Othcr Operating Espunses } \\
\text { Insurance and Taxes } \\
\text { Capital Charges }\end{array}$ & $\begin{array}{r}530 \\
570 \\
840 \\
420 \\
1,690 \\
190\end{array}$ & $\begin{array}{r}23 \\
27 \\
5 \\
39 \\
579 \\
28 \\
\\
\\
188 \\
823 \\
\end{array}$ \\
\hline Total Capital Cost & $\$ 4.240$ & \\
\hline Total, Annual Operating Cost & & $\$ 1,712$ \\
\hline $\begin{array}{l}\text { Fluidized-bed pricing reflects } \\
\text { However, the inherent advantage } \\
\text { volume production and package } \\
\text { result in decreased capital cos } \\
\text { few years. } \\
\text { 2.perating Costs are direct cost } \\
\text { Operator Labor } \\
\text { Raw Materials \& Fuels } \\
\text { Coal } \\
\text { Oil : } \\
\text { Gas } \\
\text { Limestone } \\
\text { Electricity } \\
\text { Water } \\
\text { Ash Disposal. } \\
\text { Repair and Maintenance Costs ar } \\
\text { of equipment costs. } \\
\text { General Overhead is included as } \\
\text { other than raw materials and fu }\end{array}$ & $\begin{array}{l}\text { "first-of-a-kind" } \\
\text { of the FBC boile } \\
\text { standardized des } \\
\text { ts for FBC units w } \\
\text { s and include, whe } \\
11.00 / \mathrm{hr} \\
31.00 / \text { ton } \\
17.64 / \mathrm{bbl} \\
2.25 / 1000 \mathrm{ft}^{3} \\
12.00 / \text { ton } \\
0.04 / \mathrm{kWhr} \\
0.30 / 1000 \text { gal } \\
5.00 / \text { ton } \\
10 \text { percent of all } \\
\text { included general } \\
\text { iel }\end{array}$ & $\begin{array}{l}\text { technology. } \\
\text { r should promote } \\
\text { ign. This would } \\
\text { ithin the next } \\
\text { re applicable: }\end{array}$ \\
\hline
\end{tabular}


capital and operating costs of the proposed atmospheric fluidized bed combustion system significantly exceed the respective costs for the large Stirling cycle engine.

The projected production and operating costs for the twostage fluidized bed combustion system produced in quantities of 10 or more are presented in Table 19. The following assumptions were made:

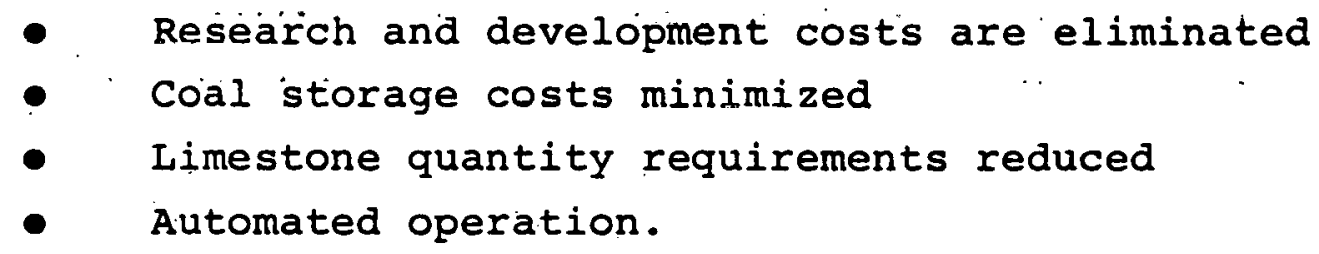

\subsection{Indirect Heat Transfer Systems Production Cost Estimates}

As was explained in Sections 5 and 6 in order to employ an. atmospheric fluidized bed system an indirect heat transfer system is required. Production cost estimates were prepared for a heat pipe loop and a gas circulation loop for a $2237 \mathrm{~kW}(30,00 \mathrm{hp})$ stirling cycle engine system. The costs are summarized as follows:

Indirect Heat Transfer System

Liquid metal heat pipe loop

Gas circulation loop
Cost (\$)

120,000

110,000

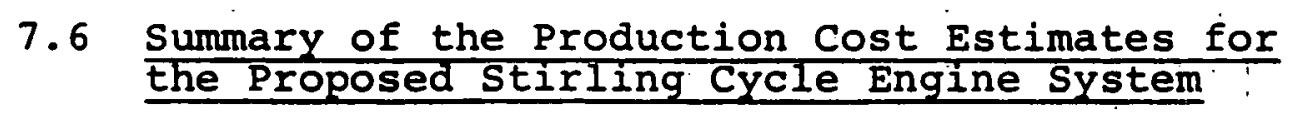

Production cost estimates for quantities of 1000 units/year were prepared for the four proposed stirling cycle engine systems:

- $373 \mathrm{~kW}(500 \mathrm{hp})$ stirling cycle engine with clean fuel direct combustion system 
Table 19. Estimated Production and Operating Costs for Developed. Two-stage Atmospheric Fluidized

Bed Combustion System

\begin{tabular}{|c|c|c|}
\hline Item & $(\$ 1000)$ & $(\$ 1000)$ \\
\hline $\begin{array}{l}\text { Total capital cost } \\
\text { Operating cost } \\
\text { Other operating expense } \\
\text { Insurance and taxes } \\
\text { Capital charges }\end{array}$ & 1,810 & $\begin{array}{r}410 \\
85 \\
371\end{array}$ \\
\hline Total annual operating cost & & 866 \\
\hline
\end{tabular}

- $2237 \mathrm{~kW}(3000 \mathrm{hp})$ Stirling cycle engine with clean fuel direct combustion system

- $\quad 2237 \mathrm{kw}(3000 \mathrm{hn})$ Stirling cycle engine with a twostage atmospheric fluidized bed combustion system and a heat pipe

$2237 \mathrm{~kW}$ ( $3000 \mathrm{hp})$ stirling cycle engine with a twostage atmospheric fluidized bed combustion system and a gas circulation loop.

A summary of the production cost estimates is presented in Table 20. Costs include only production costs and not installation costs. For clean fuels combustion the proposed $2237 \mathrm{~kW}$ ( $3000 \mathrm{hp}$ ) system (does not include generator) production cost is $\$ 478,242$ or $\$ 214 / \mathrm{kW}(\$ 159 / \mathrm{hp})$. A comparable size diesel engine cost is between approximately $\$ 40 / \mathrm{kW}(\$ 30 / \mathrm{hp})$ for a cost ratio of Stirling to Diesel ranging from 2.9 to 5.4 . It is apparent that stirling engines employing clean fossil fuels and appropriate coal derived fuels cannot compete with diesel engines. 
Table 20. Summary of Production Cost Estimates for the Proposed Stirling Cycle-Engine Systems

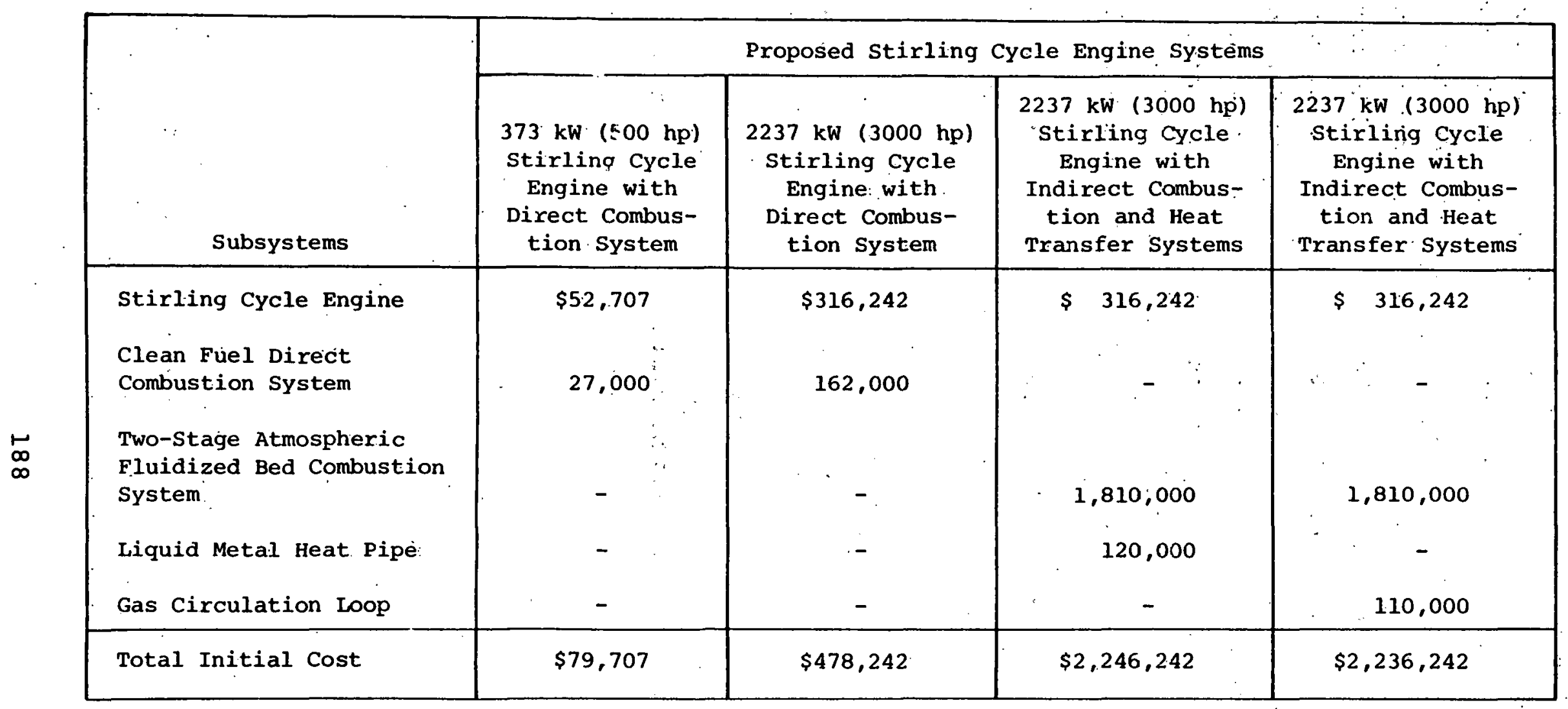


For solid coal combustion the proposed $2237 \mathrm{~kW}$ (3000 hp) system production cost is approximately $\$ 2,246,242$ which corresponds to a cost to power capacity ratio of $\$ 1004 / \mathrm{kW}(\$ 749 / \mathrm{hp})$. It is obvious that the dominant cost contribution for the proposed system is the two-stage atmospheric fluidized bed combustion system which represents 81 percent of the total cost; the engine represents only 14 percent of the total cost. However, depending on the future price differential between coal and oil, a short payback period of the proposed stirling cycle engine/FBC system will justify the initial cost. For example, if the present price differentials are employed and assuming the following:

- Capital cost of $2237 \mathrm{kw}$ (3000 hp). Stirling engine with two-stage atmospheric fluidized bed combustion system $=\$ 2,246,242$

- Capital cost of $2237 \mathrm{~kW}$ (300 hp) diesel engine = $\$ 100,000 ;$ initial capital cost premium $=\$ 2,146,242$

- Overall fuel to electrical energy conversion efficiency for the stirling engine with two-stage atmospheric fluidized bed combustion system is approximately equal to a diesel engine with a clean fuel combustion system

- No. 2 fuel oil cost is $\$ 1.00 / \mathrm{gal}$. So, for $8000 \mathrm{hr} /$ year of operation and $145,790 \mathrm{Btu} / \mathrm{gal}$, the annual fuel cost is $\$ 1,124,000$

- Coal cost is $\$ 80 \%$ ton. So, for $28 \times 10^{6} \mathrm{Btu} / \mathrm{ton}$, the annual fuel cost is $\$ 468,000$; annual energy cost differential $=\$ 656,000$.

The payback period is approximately 3.3 years and the recurring annual energy cost savings is approximately $\$ 656,000$. This payback period can be further reduced as the price spread between coal and oil is increased. 


\section{SUMMARY}

The first phase of the design and development of Stirling engines for stationary power generation applications in the $373 \mathrm{~kW}$ $(500 \mathrm{hp})$ to $2237 \mathrm{~kW}(3000 \mathrm{hp})$ range was completed. The tasks in Phase I include:

- Conceptual designs of large Stirling cycle stationary engines

- Program plan for implementing Phases. II through V.

The conclusions of the first phase are presented below.

Design studies were conducted to evaluate the different engine configurations. Four different heater head designs and five different machine designs were prepared in sufficient detail to select a design recommended for development in the near future. In addition, a concentric module design which can be applied to several machine designs was prepared. The significant advantages of the concentric module design are:

- Efficient internal and external flow distribution

- Simplicity of construction of the hot end

- Adaptability to direct or indirect heat exchange

- Modular assembly and maintenance

- Adaptable to various engine lower end designs.

FMA developed a second order analysis for examining the various loss mechanisms in the Stirling engine and for predicting the thermodynamic performance of stirling engines. Included in the analysis is the cyclic heat transfer loss mechanism which has been shown analytically that it can be significant and in some cases as high as 9 percent of the basic adiabatic power. The 
second order analysis predicts the brake power of the GPU-3 within a 15 percent maximum error and the brake efficiency within a 12 percent maximum error. Considering the uncertainties in the experimental data involved, the prediction errors are very reasonable, particularly since the second order model is based solely on the fundamental principles and require no empirical calibration with Stirling engine data.

The basic engine design thermodynamic performance was predicted with both the FMA second order analysis and the SUNPOWER third order analysis computer programs. The predicted thermal brake efficiency excluding combustion efficiency is approximately 42 percent which exceeds the design objective of 40 percent.

The combustion. system designs were prepared for both a clean fuel combustion system and a two-stage atmospheric fluidized bed combustion system: The proposed clean fuel combustion system employs vaporization of iiquid fuel via exhaust gas recirculation or combustion gas recirculation. The calculated clean fuel combustion system efficiency is approximately 90 percent.

A two-stage atmospheric fluidized bed combustion system was designed for the stirling cycle engine system. The proposed. external combustion system design is an extension of the Wormser Grate; a two-stage fluidized bed combustion system; which is suitable for small scale applications and is readily adaptable to the stirling cycle engine. The advantages of the Wormser Grate FBC system are:

- Combustion bed temperature is independent of sorbent bed temperature

- Combustion temperature only limited by materials of construction 
- Sorbent bed can be operated at the optimum temperature band of 810 to $850^{\circ} \mathrm{C}$ for maximum sulfur retention

- Lower $\mathrm{NO}_{\mathrm{X}}$ emissions and less sulfidation corrosion than that for conventional atmospheric fluidized bed combustion systems

- Turndown ratios of 30 to 1 are possible

- Less liquid fossil fuel is required to start the proposed combustion system as compared to a conventional atmospheric fluidized bed combustion system

- Combustion efficiency of 80 percent is achievable.

For an externally heated engine such as a stirling cycle engine a heat transport system is required to transfer the heat from the energy source to the engine working fluid. The heat transfer may either be accomplished directly or indirectly. For the burning of clean fuels, a direct-fired stirling cycle engine heater head design was prepared. The heater head is a small, efficient heat exchanger with a projected heat exchanger effectiveness of 0.90 .

For the burning of coal and other nonclean fuels, designs for both a liquid metal heat pipe system, and a gas circulation loop to accommodate indirect heat transfer were prepared. The proposed liquid metal heat pipe design concept consists of two separate heat pipe systems thermally communicating with each other via liquid metal joints which connect to a single manifold. The 1320 small primary heat pipes are located in the fluidized bed coal combustor and the secondary heat pipes are attached to the hot ends of the stirling engine cylinders. The heat transfer working fluid is liquid sodium. 
The proposed gas circulation loop consists of 800 tubes embedded in the atmospheric fluidized bed combustion system and connected by a manifold to the stirling engine head heat exchangers. A blower is used to circulate the heat transfer working gaș of either hydrogen or helium.

The recommended conceptual system is modular, consisting of a basic stirling engine cylinder that is easily adaptable to any type of heat input or machine output. The nominal power is determined by the number of cylinders and design conditions and the cylinder has been designed to accommodate the several options for fuel combustion. The cylinder module is axisymmetric around the piston with a single hot head and hairpin arranged, heater flow passages.

The engine output configuration selected is the single crank, narrow $V$, multicylinder arrangement in which any number of cylinders, in groups of four or five, provide the desired power rating. This is the simplest and most common configuration currently manufactured for large stationary Diesel engines.

For clean fuel combustion the prevaporized, premixed, EGR combustion method is employed. For coal combustion, a Wormser Grate two-stage atmospheric fluidized bed combustion system with a high pressure gas circulation loop system is recommended because of compactness, low NOX emissions, and potential low cost.

For clean fuels combustion the proposed $2237 \mathrm{~kW}$ (3000 hp) system production cost is $\$ 478,242$ or $\$ 214 / \mathrm{kW}(\$ 159 / \mathrm{hp})$. A comparable size Diesel engine cost is between approximately $\$ 40 / \mathrm{kW}(\$ 30 / \mathrm{hp})$ and $\$ 100 / \mathrm{kW}(\$ 75 / \mathrm{hp})$ for cost ratios of stiriing to Diesel of 2.9 to 5.4 . It is apparent that stirling engines employing clean fossil fuels and appropriate coal-derived fuels cannot compete with Diesel engines. 
For solid coal combustion the proposed $2237 \mathrm{~kW}$ (300 hp) system production cost is approximately $\$ 2,246,242$ which corresponds to a cost to power capacity ratio of $\$ 1004 / \mathrm{kW}(\$ 749 \% \mathrm{hp})$. The dominant cost contribution for this proposed system is the two-stage atmospheric fluidized bed combustion system which represents 81 percent of the total cost; the engine represents only 14 percent of the total cost.

Depending on the future price differential between coal and conventional clean fuels, a short payback period of the proposed Stirling cycle engine/FBC system may justify the initial cost. For example, if the present price differentials are employed,.. the payback period is approximately 3.3 years and the recurring annual energy savings is approximately $\$ 656,000$ : 


\section{REFERENCES}

1. Marciniak, T.J., J.C. Bratio, A. David, and C. Lee, "An

Assessment of Stirling Engine Potential in Total and Integrated Energy Systems," Argonne National Laboratory, Argonne, IL, ANI/ES-6, February 1979.

2. Hoagland, I.C.", and W.H. Percival, "A Technology Evaluation of the Stirling Engine for Stationary Power Generation in the 500 to 2000 Horsepower Range," Amtech, Inc., ORO/5392-01, September 1978 .

3. Kays, W.M., and A.L. London, Compact Heat Exchangers, McGraw-Hill Book Co., New York, 1964.

4. Mätini, W.R., "Etirling Englne Design Manual," University of Washington, DOE/NASA/3152-78/1, April 1978.

5. Walker, G., "Stirling Engines," University of Calgary, September 1978 .

6. Personal communication with Professor Joseph.I. Smith, Jr. and Mr. Stig Carlquist.

7. Martini, W.R., "Stirling Engine Design Manual,". DOE/NASA/ 3152-78/1, April 1978 .

8. Rios, P.A., "An Analytical and Experimental Investigation of the Stirling Cycle," Sc.D. Thesis, Massachusetts Institute of Technology, Cambridge, MA, September 1969.

9. Rios, P.A., "An Approximate Solution to the Shuttle HeatTransfer Losses in a Reciprocating Machine," Trans. A.S.M.E., Journal of Engineering for Power, April 1971.

10: Kays, W.M.., and A.L. London, Compact Heat-Exchangers, McGraw-Hill, New York, 1964.

11. Rohsenow, W.M., and H.Y. Choi, Heat Mass and Momentum Transfer, Prentice-Hall, Englewood Cliffs, NJ, 1961.

12. Breckenridge, R.W., Jr., et al., "Rotary-Reciprocating Cryogenic Refrigeration System Studies, Part I," Technical Report AFFDL-TR-71-115; ADL, Inc., September i971.

13. Lee, K., and J.I. Smith, Jr., "Performance Loss Due to Transient Heat Transfer in the Cylinders of Stirling Engines," Proc. of the 15th IECEC Conference to be held at Seattle, WA in August 1980.

14. Carlqvist, S.G., stirling Engine Consultant, Malmö, Sweden, Private Communication, 1980. 
15. Walker, G., Stirling Engines, Vol. I, University of Calgary, Canada, September 1978.

16. Gedeon, D.R., "The Optimization of Stirling Cycle Machines," Proc. of the 13th IECEC Conference, San Diego, CA, 1978.

17. Berchowitz, C.J., et al., "A New Mathematical Model for Stirling Cycle Machines," Proc. of the 12 th IECEC Conference, Washington, DC, 1977.

18. Lambert, J.D., Computational Methods in Ordinary Differential Equations, Wiley, 1973.

19. Hindmarsh, A.C., "GEAR: Ordinary Differential Equation System Solver," Lawrence Livermore Laboratory, UCID 30001, Rev. 3, 19.74 .

20. Tew, R.C., Jr., et al., "Initial Comparison of single Cylinder Stirling Engine Computer Modei Predictions with Test Results," DOE/NASA/1040-78/30, NASA/LeRC, 1979.

21. "Demonstration of a Steam-Powered Face Haulage Vehicle," Final Report by Foster-Miller Associates for the U.S. Department of Energy, July 1979.

22. "Variable Firing Rate Power. Burner for High Efficiency Gas Furnaces," Final Report by Foster-Miller Associates for the U.S. Department of Energy, February 1980.

23. "Development of Low Input, Variable Firing Rate, Oil Fired Heating Equipment," by Foster-Miller Associates for the U.S. Department of Energy, Final Report To Be Published.

24. Pearson, J.D., and R.C. Felilinger, "Thermodynamic properties of Combustion Gasses," Iowa State University Press, 1965.

25. Bell, A.W., et al., "Nitric oxide Reduction by Controlled Combustion Processes," Western States Section/Combustion Institute, Spring Meeting, WSCI-70-5, 1970.

26. Spadaccini, L.J., "Autoignition Characteristics of Hydrocarbon Fuels at Élevator Temperatures and Pressures," ASME Paper 76-GT-3.

27. Zabetakis, M.G., "Flammability Characteristics of Combustible Gasses and Vapors," Bulletin 627, USBM.

28. Kays, W.M., and A.L: London, Compact Heat Exchangers, McGraw-Hili Book Company, New York, 1964.

29. Dawson, W.H., and A. Wormser, Paper Presented at the 6 th International Conference on Fluidized Bed Combustion, Atlanta, GA; April 198.0 . 
30. Musgrove, R.S., "Consideration in Sizing Coal Gasification Plants," C.F. Braun, Alhambra, CA, 1978 .

31. Comments at the Conference on DOE Plants for Commercialization of Industrial AFBC, Boston, MA, April 1979.

32. Foo; O.K., Conference on Coal-Oil Mixtures, Danvers, MA, December 1979.

33. EPA Conference on Coal Cleaning, Hollywood, FL, September 1978 .

34. Cost Comparison Study, Industrial Size Boilers, Davy McKee Corp., Under DOE Contract EX-77-C-01-2418, October 1979.

35. A Development Program for PFBC, Chemical Engineering Division, Argonne National Laboratories, Monthly Report, June through necember 1076.

36. Pope, Evans and Robbins, "Multicell Fluidized Bed Boiler Design," Construction and Test Programs, Reports 1978 to 1979 .

37. "Industrial Application of Fluidized Bed Combustion - Process Airheater, Fluidyne Engineering Reports, April 1978.

38. "Industrial Application of Fluidized Bed Combustion"- Steam Generation," Georgetown University, December 1979.

39. "Hot Corrosion in Direct Fired Coal Turbine," CPC, Inc., Menlo Park, CA, September 1976.

40. Stringer, J., International Fluidized Bed Combustion Symposium, Cambridge, MA, April 1979.

41: Stringer, J., Proceedings, Corrosion/Erosion of Coal Conversion Systems Materials Conference, Berkley, CA, January 1979 .

42. Stringer, J., Third Annual Conference on Materials for Coal Conversion and Utilization, Gaithersberg, MD, October 1978.

43. Probert, P.B., Corrosion in Reducing Atmospheres - A Designer's Approach, International Symposium on Corrosion and Deposits, Henniker, NH, July 1977.

44. Dapkunas, S.J., Performance of Heat Exchanger Materials in AFBC, 86 th Annual Meeting of the AICHE, Houston, TX, April 1979 .

45. Cohen, S., Materials for Air Cooled Heat Exchangers, 86 th Annual Meeting of the AICHE, Houston, Tx, April 1979. 
46. Tomita, M., et al., 6th International Conference on Fluidized Bed Combustion, Atlanta, GA, April 1980.

47. Wormser, A., "Wormser Grate: A Second Generation Fluidized Bed Combustor for Industrial Heat," Wormser Engineering, Inc., Middleton, MA, 1979.

48. "Industrial Application of Fluidized Bed Combustion - Category III, Indirect Fired Heaters," Exxon Reports, September, 1977 to March, 1978.

49. "Liquid Metal Heat Pipe Technology Applicable to stirling Engines," Thermacore, Inc., Leola, PA, Prepared for Foster-Miller Associates, Inc., Waltham, MA, April 1979.

50. Holcomb, R.S.; "Development Progress on the Atmospheric Fluidized Bed Coal Combustor for Cogeneration Gas Turbine System for Industrial Cogeneration Plants," Transactions of the ASME, Paper No: 79-GT-104, March 1979.

51. Meijer, R.J., "The Philips Stirling Engine as a Propulsion Engine," Proc. 5th IECEC, Iras Vegas, NV, September 1970.

52. Personal communication with S. Carlquist.

53. Theeuwes, G.J.A., N.V. Philips Research Laboratory, 1979.

54. Personal communication with Koppers Corp.

55. "Koppers Handbook on Rings."

56. Keller, C., and Escher Wyss, "AK Closed-Cycle Turbine," Tran. ASME, November, 1946.

57. Cost Comparison Study, Industrial Size Boilers, Davey McKee Corp., October, 1979 under DOE Contract EX-77-C-01-2418. 